\title{
Final Report for the Cryogenic Retrieval Demonstration
}

\author{
D. J. Valentich \\ E. L. Yokuda
}

Published September 1992
Idaho National Engineering Laboratory EG\&G Idaho, Inc.
Idaho Falls, Idaho 83415


Final Report for the Cryogenic Retrieval Demonstration

EGG-WTD-10397

Approved by:
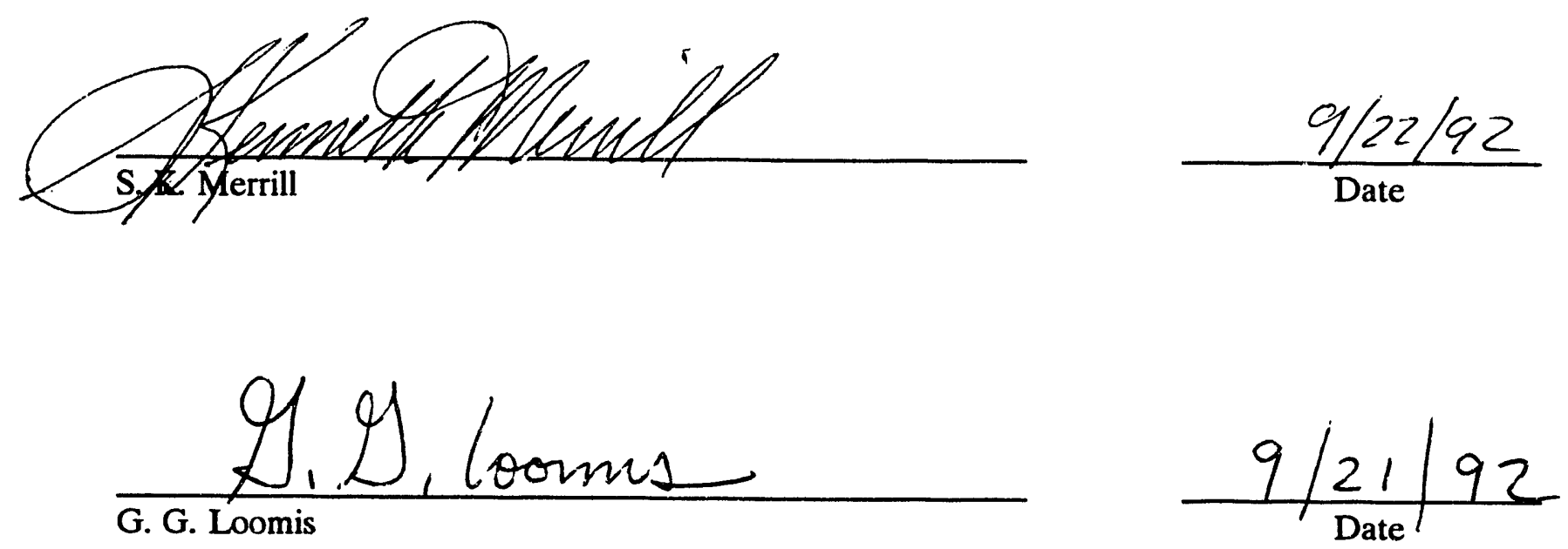

Prepared by:

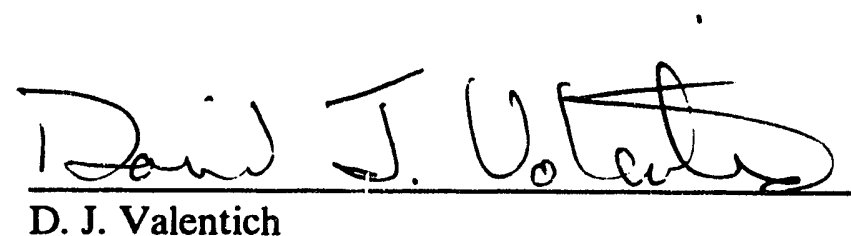

D. J. Valentich

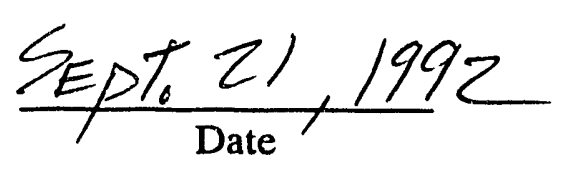

E. leer Z yolanda

$\frac{\text { sept 21,1992 }}{\text { Date }}$ 


\begin{abstract}
This report documents a demonstration of a proposed buried transuranic waste retrieval concept that uses cryogenic ground freezing and remote excavation. At the Idaho National Engineering Laboratory (INEL), there are over 8 million $\mathrm{ft}^{3}$ of intermingled soil and transuranic (TRU) wastes in shallow land burial, and retrieval of the material is one of the options being considered by the Buried Waste Integrated Demonstration for the Environmental Restoration program. Cryogenically freezing contaminated soil and buried waste has been proposed as a way to greatly reduce or eliminate the threat of contamination spread during retrieval activities. In support of this idea, a demonstration of an innovative ground freezing and retrieval technology was performed at the INEL. This initial demonstration was held near the Radioactive Waste Management Complex at a "cold test pit" that was built in 1988 as a test bed for the demonstration of retrieval and contamination control technologies. This pit is not contaminated with any radioactive or hazardous wastes. Barrels and boxes filled with metals, plastics, tools, paper, cloth, etc. configured in the same manner as expected in contaminated pits and trenches are buried at the cold test pit.
\end{abstract}

A contract was awarded to Sonsub Services, Inc. of Houston, Texas, to perform the design, engineering, procurement, fabrication, and field demonstration of a system used for ground freezing and remote retrieval of buried waste from the cold test pit. After design, fabrication, and shop testing, Sonsub mobilized to the field in early July 1992 to perform the field demonstration. It was planned to freeze and extract four pits, each $9 \times 9 \times 10 \mathrm{ft}$. Each pit represented a different configuration of buried waste (stacked boxes, stacked barrels, random dumped barrels and boxes, and random dumped barrels). Sonsub's proposed technology consisted of driving a series of freeze pipes into the soil and waste, using liquid nitrogen to freeze the mass, and extracting the soil and debris using a series of remote operated, bridge crane mounted tools. In conjunction with the freezing and removal activities, temperature and moisture measurements, and air monitoring was performed.

This report describes how the technology was deployed to the field, effectiveness of the ground freezing (temperature monitoring), how well the remote operated tools removed soil and simulated waste, air monitoring and moisture detection results, and includes an estimate for applying this technology to retrieval of buried TRU waste. 


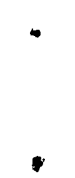




\section{SUMMARY}

There is a need to remediate radioactive and hazardous buried waste sites throughout the U.S. Department of Energy (DOE) complex. The DOE, Office of Technology Development (OTD) has initiated a comprehensive program to develop and demonstrate advanced remediation technologies that support DOE's environmental restoration objectives. Proven technologies do not exist for the in situ treatment, removal, and treatment after exhumation. To address these issues and to identify other technological deficiencies, OTD has initiated the Buried Waste Integrated Demonstration (BWID) at the Idaho National Engineering Laboratory (INEL). BWID is coordinated for the DOE by EG\&G Idaho, Inc., at the INEL, however, the program involves engineers and other professionals with scientific expertise from throughout the DOE complex, universities, and the private sector to advance the understanding of potential technologies for remediation of buried wastes.

BWID will address the complex problems associated with buried waste by initially focusing on buried waste located at the INEL. This waste stream is generally representative of most buried waste throughout the DOE complex. Technologies that are successfully developed within the BWID will result in transfer of scientifically sound, demonstrated technologies that can be deployed in various Environmental Restoration Programs throughout the DOE complex.

One of the technologies demonstrated through the BWID is cryogenic retrieval. This proposed technology for the retrieval of buried waste combines relatively common ground freezing technology and the use of remote operated tools to break out and extract frozen soil and debris in a contained area. The primary advantages of this method is that by freezing the soil and waste, the dispersal of airborne contaminants is greatly limited and using remote tools to remove the waste reduces human contact.

In the late summer of 1991, a Request for Proposal detailing the technical requirements and field conditions for performing a cryogenic retrieval demonstration at a cold test pit (simulated nonhazardous and nonradioactive waste) near the Radioactive Waste Management Complex (RWMC) was issued. Two firms responded and Sonsub Services, Inc. of Houston, Texas, was selected to design, procure, fabricate, and demonstrate a hardware system for cryogenic retrieval.

The technology consists of driving a series of freeze pipes into a quantity of waste and soil. The pipes are placed with a standard vibratory drill. Once the pipes are in place liquid nitrogen is flowed into the pipes to promote freezing of the soil and waste mass. In addition to the freeze pipes, a series of temperature and moisture probes are also installed to indicate when the mass is frozen and the quantity or movement of moisture in the soil. Once the mass is frozen an access pit is excavated in clean soil just to the side of the waste to be extracted. A gantry equipped with remote operated tools, such as a breakout tool which develops 360 tons of force; shears rated at 1200 tors of cutting force; grapple; and 60 horsepower jackhammer, is moved over the area to be excavated. These tools are operated from a remote control console located in a trailer a short distance from the gantry. These tools were actuated by a combination of hydraulic and electrical controls. The breakout tool is used to pry the freeze pipes out, hopefully developing an ice column or "popsicle" around the freeze pipe. The jackhammer loosens soil and debris not readily removed by the breakout tool. The shears are intended to cut large metal, concrete, wood, or other objects, and the grapple picks debris and soil from the bottom of the pit and places the same in storage boxes. The gantry is covered with

a weather proof shield to allow round the clock work and provide for a protected and enclosed work 
area. Inside of the gantry, a series of cameras and lights are mounted to provide visual reference to orient and operate the tools.

The field demonstration was held at the RWMC cold test pit. This facility was developed in 1988 and consists of five cells, each representing a different configuration of waste. There are random dumped barrels, random dumped boxes and barrels, stacked barrels, stacked boxes, and large object cells. Each cell (except for the large objects) is laced with a rare earth tracer (dysprosium, ytterbium, terbium, and neodymium). The rare earth tracers were incorporated into the cold test pit to grossly simulate the presence of radionuclides. A total of four $9 \times 9 \times 10$-ft cells were planned to be frozen and excavated. Air monitoring equipment was installed and operated during the retrieval phase of the testing to detect the emission of any rare earth tracers. The frozen material was removed, placed in $4 \times 4 \times 8$-ft storage boxes, and placed at the north end of the cold test pit to form a new test cell.

A contract was awarded to Sonsub on February 7, 1992. Engineering, procurement, and fabrication activities commenced immediately. A shop test of the hardware was held in late June and early July in Houston. The purpose of the shop test was to ensure that the hardware and instrumentation systems designed for field application would perform to stated requirements. Significant troubleshooting, repair, and adjustment of the equipment was required during the shop testing phase (because of the short time frame allowed for engineering and hardware procurement). The gantry was erected and the tools installed. The tools were each put through a full range of motion and functional testing. The instrumentation and data logging system was tested by creating simulated input, storing, and manipulating data. The shop assembly, testing, and troubleshooting lasted about 2 weeks.

After completion of the shop testing, the hardware was disassembled and transported to the cold test pit at the INEL. Sonsub mobilized to the site on July 7. Mobilization of a variety of equipment including a generator, crane, forklift, vehicles, control trailer, liquid nitrogen $\left(\mathrm{LN}_{2}\right)$ storage and distribution piping, and other items was accomplished in the first 10 days.

Placing of freeze pipes into the test cells was the first key task associated with the demonstration. In the first cell, the random dumped barrels, placement of abrut 65 pipes, 40 collars, and about a half dozen temperature and moisture probes was accomplished in under 4 days. There were technical problems with the drilling equipment that contributed to the relatively slow placement. However, as these difficulties were worked out and equipment reliability irnproved, the average time to place a pipe or probe to the required 11 to $12 \mathrm{ft}$ depth was just under a minute. After the freeze pipes were in place, $\mathrm{LN}_{2}$ was flowed through the piping to promote freezing of the soil and waste mass. During the entire test, about 85,500 gal of $\mathrm{LN}_{2}$ were used to freeze approximately $1500 \mathrm{ft}^{3}$ of soil and debris. Only about $810 \mathrm{ft}^{3}$ of frozen soil and debris were slated for excav rtion. The remainder was additional soil that was frozen around the perimeter of the waste and the access pits. The front half of the pit was left dry (no water added), and about 1800 gal of water were added to the back half of the pit to promote cohesion and to determine if saturating the soil would help to reduce the spread of contamination. As water was added to the pit the percentage of moisture detected by the time domain reflectometry (TDR) probes also increased. This indicated that water had migrated completely through the test area and was in contact with the TDR probe. Originally it was planned that when the pit temperature was near $-4^{\circ} \mathrm{F}$, the water would be added, freeze upon contact with the soil and waste, and be contained within the boundary of the test cell. Later during 
excavation, it was confirmed that a large portion of the water added had leaked out because there was almost no saturated soil.

An access pit was dug adjacent to the area to be remo"red. The gantry and remote operated tools were positioned over the pit and excavation began. The breakout tool was tried first. It was positioned over a pipe collar and pried the upper 2 to $3 \mathrm{ft}$ of the pipe and surrounding soil loose before bending the pipe. Other collars and pipes were tried in this fashion with the same result. It was apparent that the ice columns or "popsicles" that were hoped would form around the freeze pipes were not developing. Since the first portion of the pit had no water added, this was not to surprising. The jackhammer was then used to loosen the soil and debris, and the shears were used to cut and size the freeze pipes as they fell into the access pit. The remote operated grapple picked up soil and waste and placed it in a $4 \times 4 \times 8$-ft plywood storage box. After the first half of the pit was excavated in this manner, the breakout tool was again tried on the second (wet half) of the pit. Basically the same results were observed. There was slightly better formation of the columns, but nothing appreciable. About half of this section of the pit was then removed with the other tools. A total of 10 boxes of debris and soil were excavated from this test pit in about 6 days. At the conclusion of the excavation, the gantry was moved to the next pit and the area backfilled with clean soil.

Air monitoring results indicated that dysprosium had been detected in fairly high concentrations (116 versus $29 \mathrm{ppm}$ background) when excavating the dry side of the pit and about $44 \mathrm{ppm}$ for the wet side. The highest concentrations were detected near sensors by the storage box loading area where a considerable amount of soil and debris had been spilled during the loading process. Reduced quantities of the tracer were detected nearer the area where breakout had occurred. During breakout there was almost no visual indication of airborne dust, even though the soil was very dry and crumbly in both the dry and wet sides of the pit. It was during the actual dumping of the soil into the storage box (a 4 to 6-ft fall) that dust was present. Even so, this dust usually dispersed in a matter of seconds.

The second test pit consisted of random dumped barrels and boxes. As with the first pit the freeze pipes and probes were placed and the area frozen. About the same number of probes and pipes were placed as in the first pit and required just under 2 days to complete. A total of 76,700 gal of $\mathrm{LN}_{2}$ were used during the freezing process. In the front half of this pit, water was poured around the freeze pipes from the surface to see if better formation of ice columns could be achieved. About 130 gal of water were poured around 14 freeze pipes on the front half of the pit over a 4 day period. When excavation commenced, the breakout tool was again used to pry the freeze pipes. With the addition of water at the surface, the concept worked a little better but again nothing significant. In general the column was about 2 to $3 \mathrm{ft}$ long and appeared to be more cohesive (not as crumbly) than soils from the previous pit. Again the jackhammer and shears were used to excavate and size material from the front half of this pit. Water was injected into the second half of the pit during the initial freezing process. In this instance about 1,700 gal were added in just under 2 hours. The water was cbserved to leak into the access pit that had been excavated adjacent to the area to be exhumed. The water had obviously found a pathway through the soil and debris. The concept of freezing the water upon injection was not working as planned.

Excavation of the second half of the pit was initiated with the breakout tool, with similar results to the other attempts. After trying the first full row, the jackhammer and shears were then used as the primary tools to remove the remaining soil and debris. The coidition of the soil was somewhat 
better than other areas, indicating that more moisture had been retained. Some large pieces of frozen soil were excavated. A total of 10 storage boxes were filled with freeze pipes and dirt and paper, pipes, cardboara, cloth, wood, and sludge found in this pit. As with the first pit very little visible dust was generated during the breakout of this pit. No rare earth tracer (ytterbium) above background levels was detected by the air monitoring system during the excavation and subsequent loading operating, indicating that possibly enough moisture was present in the soil to suppress the generation of significant airborne dust.

The third area selected for demonstration was the stacked boxes pit. The freeze pipes were placed in about a day and a half. There was difficulty in placing the moisture probes and three of the four were lost during the driving process. After the pipes were in place, freezing the area began. A total of 72,600 gal of $\mathrm{LN}_{2}$ were used during the chilling process for this pit. In this pit a different concept for the addition of water was tried. A specially designed floor freeze pipe was used to first freeze the bottom of the back half of the pit before adding water (the front half was left dry, except for small quantities of water added at the surface). Only the bottom 2 feet of these freeze pipes had $\mathrm{LN}_{2}$ been added. The theory was that the natural moisture in the ground would be frozen at the bottom of the pit, forming a barrier, and when water was injected it would not migrate past this frozen area. After the freezing was completed, water was injected (about $20^{n} \mathrm{n}$ gal), but the moisture probe indicated water was moving beyond the bottom of the pit and a pathway had been found through the soil and waste. An additional 500 gal of water were added at the surface to again determine if this method would promote the formation of ice columns.

When excavation started the breakout tool was used, and the results were the same as with previous efforts. Only the top 2 to 3 -ft of soil around the freeze pipes was removed with the aid of the breakout tool. The jackhammer and shears were used to remove the remainder of soil from this pit. The condition of the soil varied. Near the surface where water had been added, there were some medium sized pieces of frozen soil removed. Portions of the pit were dry and crumbly, and a saturated portion was not encountered again indicating the injected water had found a pathway beyond the boundary of the pit. No waste was encountered during the excavation of this pit although it was expected that large quantities of metal and concrete would be found in the stacked boxes. Later, it was determined the boxes had been compressed and were actually below the lowest elevation excavated during digging activities. This meant there was about 8 to 9 - $\mathrm{ft}$ of cover over the boxes. No rare earth tracers above background level were detected during the excavation, which correlates with the fact that no waste was encountered. At the conclusion of the digging, the gantry was moved and the pit backfilled with clean soil.

It was planned to freeze and excavate a fourth area, the stacked barrels pit. However, because of budget and schedule limitations, this was not possible.

Summary conclusions and observations about the demonstration include

- Cold testing of retrieval technologies is necessary to demonstrate viability in a safe working environment and reveal potential problem areas.

- The remote operated tools were quite effective. The concept of forming ice columns is not feasible, however, using a mining technique to remove the soil and debris is workable. 
- Freezing the soil and debris to promote contamination control has good promise. A better method of dispersing moisture through the soil mass must be developed.

- $\quad$ Based on preliminary findings from this field demonstration, the cost of retrieval of buried waste in a large scale project is estimated at about $\$ 1250 / \mathrm{yd}^{2}$.

- The moisture probes (TDR's) are a viable new instrument developed especially for this project to measure moisture content and migration of fluid. This technology has other promising applications for buried waste retrieval and private industry.

- There were reliability problems with the hardware, primarily the jackhammer and to a lesser extent the shears. As the field demonstration progressed, so did the reliability of the equipment. Additional time for shop testing of the hardware would have improved the initial reliability. Working at a remote site ( 60 miles from Idaho Falls) often compounded simple hardware failures.

- $\quad \mathrm{LN}_{2}$ conservation could be greatly improved by ardding insulation and improving design by a more thorough analysis of the delivery and freezing system.

- An air-tight (negative pressure) gantry enclosure would have been helpful in preventing dust infiltration. The cover over the gantry was weatherproof, but with the constant wind, dust and grit was a problem.

- A 4 psi limitation was observed for equipment and personnel while working directly over the cold test pit to minimize the danger from subsidence. There were no subsidence related problems.

- Analysis of air samples obtained during the testing resulted in the development and validation of chemical analysis methods for the determination of rare earth element tracers by Inductively Coupled Plasma Mass Spectrometry (ICP-MS).

- A side experiment that was conducted to determine if dust could be suppressed during drilling and placement of probes by drilling through a slurry mixture at the surface was successful. No rare earth tracers were dispersed while drilling through the slurry.

Other items to note are that the demonstration was conducted under a high pressure schedule and difficult field working conditions with no injuries or damaged equipment. Sonsub designed, built, fabricated, tested, and mobilized the demonstration hardware to the field in 5 inonths.

Outstanding issues raised during this cold demonstration that require further study before the initiation of a hot demonstration include:

1. Applicability of the technology to large buried objects.

2. Crmparison of dust collected during this cold test to a baseline dust case during onventional retrieval. 
3. How to determine the bottom of the waste seam.

4. Can the technology be scaled up to meet production quotas required for actual buried waste retrieval?

5. Reduction of the amount of pipe used during the placement and freezing process thereby reducing the amount of debris generated during the retrieval action.

It has been recommended to the BWID program that work on cryogenic retrieval continue during the coming fiscal year (FY-93). Ultimately, it is hoped that once the suggested refinements are incorporated and further cold and hot testing conducted, this technology can be used to help remediate buried waste sites throughout the DOE complex. 


\section{CONTENTS}

ABSTRACT $\ldots \ldots \ldots \ldots \ldots \ldots \ldots \ldots \ldots \ldots \ldots \ldots \ldots \ldots \ldots \ldots \ldots \ldots \ldots \ldots \ldots$

SUMMARY $\ldots \ldots \ldots \ldots \ldots \ldots \ldots \ldots \ldots \ldots \ldots \ldots \ldots \ldots \ldots \ldots \ldots \ldots \ldots$

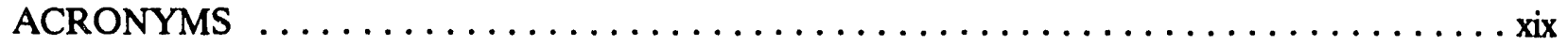

1. BACKGROUND AND PURPOSE $\ldots \ldots \ldots \ldots \ldots \ldots \ldots \ldots \ldots \ldots \ldots \ldots$

1.1 Brief History of Buried Waste and the Subsurface Disposal Area $\ldots \ldots \ldots \ldots \ldots$

1.2 Need for Restoration of the SDA $\ldots \ldots \ldots \ldots \ldots \ldots \ldots \ldots \ldots \ldots \ldots$

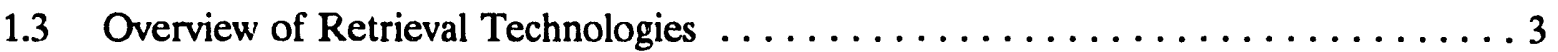

1.4 Development of the Cryogenic Retrieval Concept $\ldots \ldots \ldots \ldots \ldots \ldots \ldots \ldots$

2. PROPOSED TECHNOLOGY $\ldots \ldots \ldots \ldots \ldots \ldots \ldots \ldots \ldots \ldots \ldots \ldots \ldots$

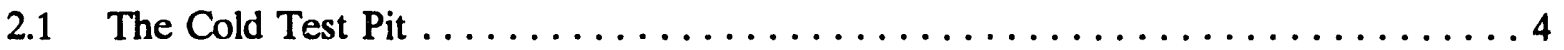

2.2 Testing of the Cryogenic Retrieval Technology

at the Cold Test Pit ............................. 12

2.3 Selecting a Demonstration Contractor $\ldots \ldots \ldots \ldots \ldots \ldots \ldots \ldots \ldots \ldots$

2.4 Objectives and Requirements of the Field Demonstration $\ldots \ldots \ldots \ldots \ldots \ldots$

2.5 Detailed Explanation of the Planned Technology Demonstration $\ldots \ldots \ldots \ldots$. . . 15

$2.5 .1 \quad$ Overview . . . . . . . . . . . . . 15

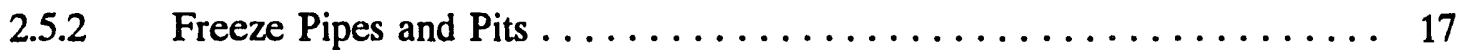

2.5.3 Freeze Pipe Arrangement for the Random Dumped

Barrels and Random Dumped Barrels and Boxes Pits . . . . . . . . 17

2.5.4 Freeze Pipe Arrangement for Stacked Barrels and Stacked Boxes Pits . . 24

2.5.5 Gantry and Remote Operated Tools ................. 30

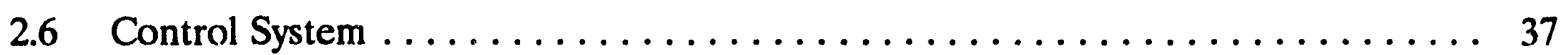

3. TESTING AND MONITORING $\ldots \ldots \ldots \ldots \ldots \ldots \ldots \ldots \ldots \ldots \ldots \ldots$

$3.1 \quad$ Air Monitoring $\ldots \ldots \ldots \ldots \ldots \ldots \ldots \ldots \ldots \ldots \ldots \ldots \ldots \ldots \ldots \ldots$

3.2 Establishing Baseline Data for Air Monitoring $\ldots \ldots \ldots \ldots \ldots \ldots \ldots$

3.3 Air Monitoring During the Demonstration $\ldots \ldots \ldots \ldots \ldots \ldots \ldots \ldots \ldots$ 
3.4 Data Quality Objective for Moisture Monitoring .............. 45

3.5 Description of the Time Domain Reflectometry Used for Moisture Monitoring $\ldots \ldots \ldots \ldots \ldots \ldots \ldots \ldots \ldots \ldots \ldots \ldots$

3.6 Temperature Monitoring $\ldots \ldots \ldots \ldots \ldots \ldots \ldots \ldots \ldots \ldots \ldots \ldots \ldots$

4. TECHNOLOGY DEVELOPMENT $\ldots \ldots \ldots \ldots \ldots \ldots \ldots \ldots \ldots \ldots \ldots \ldots$

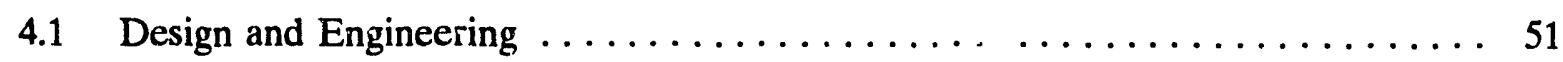

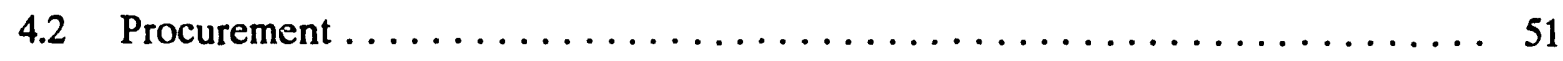

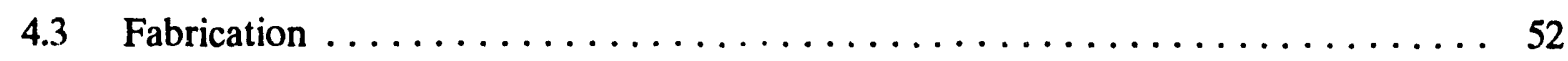

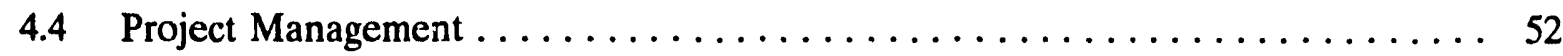

5. SHOP DEMONSTRATION AND READINESS REVIEW $\ldots \ldots \ldots \ldots \ldots \ldots \ldots$

5.1 Shop Demonstration $\ldots \ldots \ldots \ldots \ldots \ldots \ldots \ldots \ldots \ldots \ldots \ldots \ldots \ldots$

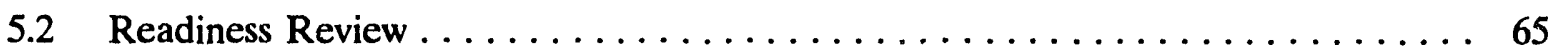

6. FIELD DEMONSTRATION $\ldots \ldots \ldots \ldots \ldots \ldots \ldots \ldots \ldots \ldots \ldots \ldots \ldots \ldots \ldots \ldots$

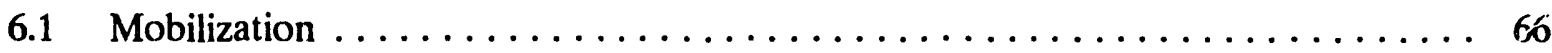

6.2 Random Dumped Barrels $\ldots \ldots \ldots \ldots \ldots \ldots \ldots \ldots \ldots \ldots \ldots \ldots \ldots \ldots$

6.3 Random Dumped Boxes and Barrels $\ldots \ldots \ldots \ldots \ldots \ldots \ldots \ldots \ldots \ldots$

6.4 Stacked Barrels $\ldots \ldots \ldots \ldots \ldots \ldots \ldots \ldots \ldots \ldots \ldots \ldots \ldots \ldots \ldots \ldots$

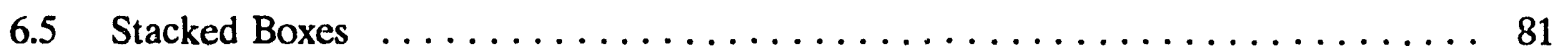

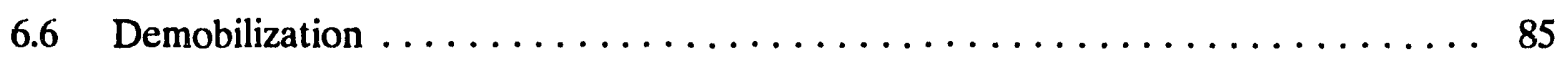

7. RESULTS AND INTERPRETATIONS $\ldots \ldots \ldots \ldots \ldots \ldots \ldots \ldots \ldots$

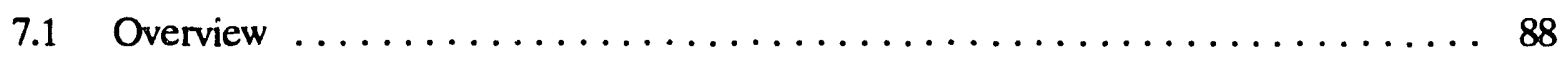

7.2 Results from Random Dumped Barrels . . . . . . . . . . . . . . . 90

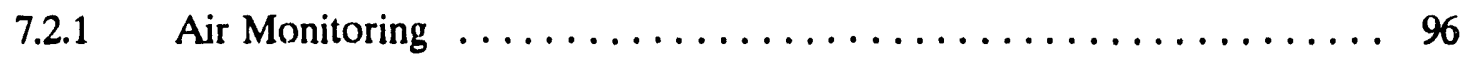

7.3 Results from the Random Dumped Barrels and Boxes $\ldots \ldots \ldots \ldots \ldots \ldots$ 
7.3.1 Air Monitoring $\ldots \ldots \ldots \ldots \ldots \ldots \ldots \ldots \ldots \ldots \ldots \ldots \ldots \ldots \ldots \ldots \ldots \ldots$

7.4 Results from Stacked Barrels $\ldots \ldots \ldots \ldots \ldots \ldots \ldots \ldots \ldots \ldots \ldots \ldots \ldots$

7.5 Results from the Stacked Boxes $\ldots \ldots \ldots \ldots \ldots \ldots \ldots \ldots \ldots \ldots \ldots \ldots \ldots$

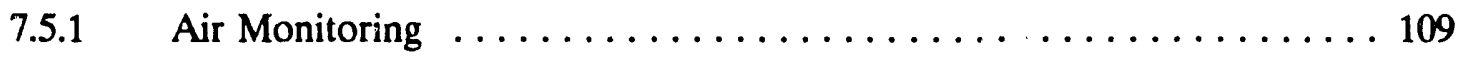

7.6 Comparison of Results with Pre-established Criteria $\ldots \ldots \ldots \ldots \ldots \ldots \ldots . \ldots 111$

8. CONCLUSIONS AND RECOMMENDATIONS $\ldots \ldots \ldots \ldots \ldots \ldots \ldots \ldots \ldots \ldots \ldots$

8.1 Overall Conciusions Drawn from the Demonstration $\ldots \ldots \ldots \ldots \ldots \ldots \ldots$

8.1.1 Environriental, Safety, and Health $\ldots \ldots \ldots \ldots \ldots \ldots \ldots \ldots \ldots \ldots$

8.1.2 Technical ..................................... 116

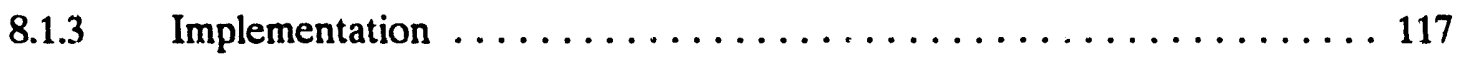

8.2 Recommendations and Justification for Follow on Work ............. 118

9. COST ESTIMATE FOR FIELD APPLICATION $\ldots \ldots \ldots \ldots \ldots \ldots \ldots \ldots \ldots \ldots$

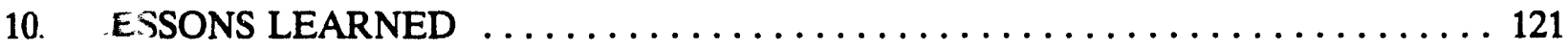

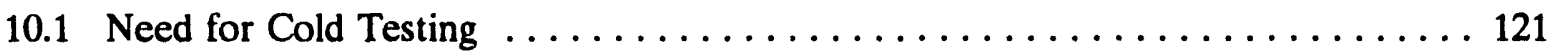

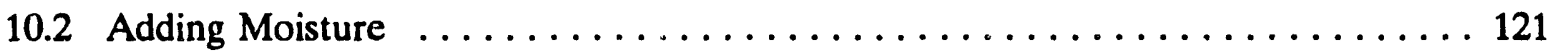

10.3 Drilling and Placement of Freeze Pipes $\ldots \ldots \ldots \ldots \ldots \ldots \ldots \ldots \ldots \ldots \ldots \ldots \ldots$

10.4 Conservation of Liquid Nitrogen $\ldots \ldots \ldots \ldots \ldots \ldots \ldots \ldots \ldots \ldots \ldots \ldots \ldots \ldots \ldots \ldots, 22$

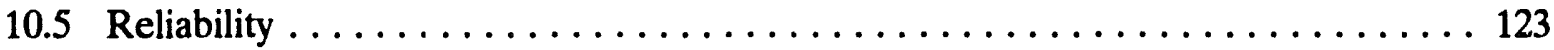

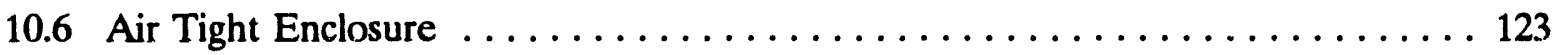

10.7 Continuous Power Source for Instrumentation $\ldots \ldots \ldots \ldots \ldots \ldots \ldots \ldots \ldots \ldots$

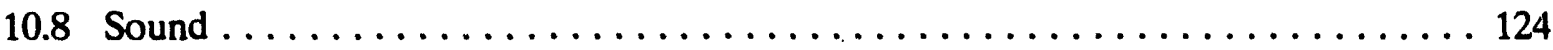

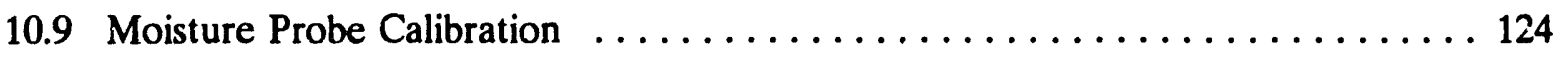

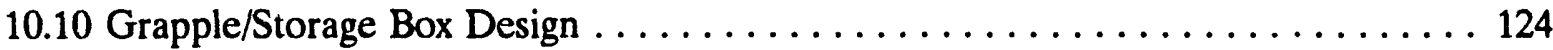

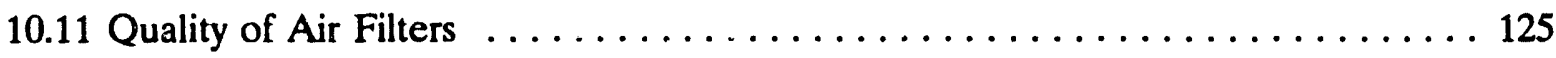

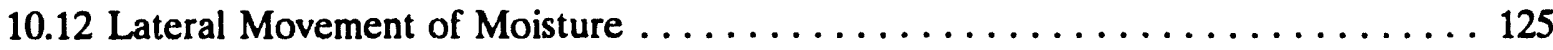




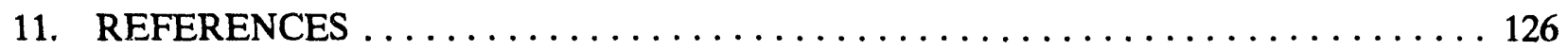

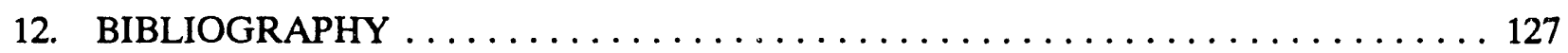

Appendix A-Summary of Statistics for Background Measurements $\ldots \ldots \ldots \ldots \ldots \ldots$ A-1

Appendix B-Test Plan for the Cryogenic Retrieval Demonstration $\ldots \ldots \ldots \ldots \ldots \ldots$ B-1

Appendix C-Preliminary Tests Performed on In Situ TDR Probes $\ldots \ldots \ldots \ldots \ldots \ldots$ C-1

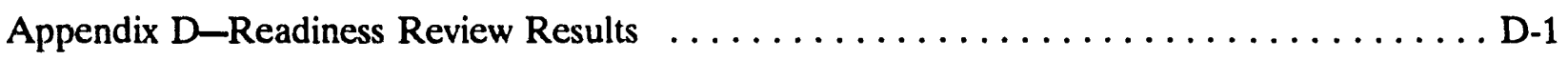

Appendix E-Results of Smears Taken During Freeze Pipe Placement $\ldots \ldots \ldots \ldots \ldots \ldots$ E-1

Appendix $\mathrm{F}-\mathrm{Cost}$ Estimate $\ldots \ldots \ldots \ldots \ldots \ldots \ldots \ldots \ldots \ldots \ldots \ldots \ldots \ldots \ldots \ldots \ldots \ldots$

\section{FIGURES}

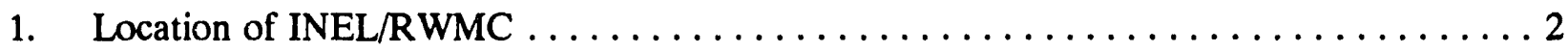

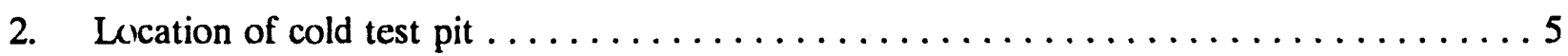

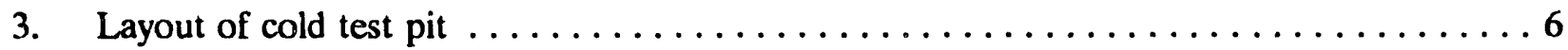

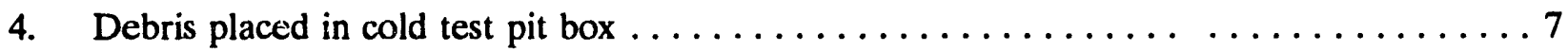

5. Debris placed in cold test pit barrel $\ldots \ldots \ldots \ldots \ldots \ldots \ldots \ldots \ldots \ldots \ldots \ldots \ldots$

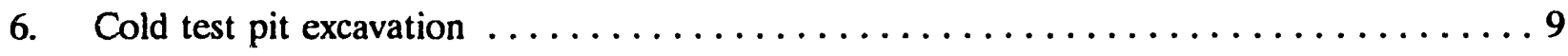

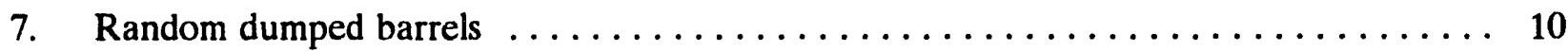

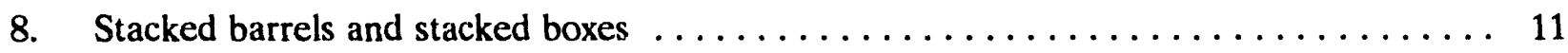

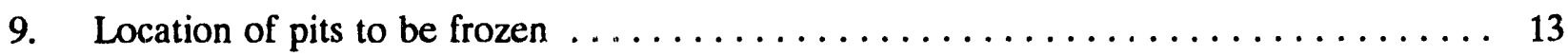

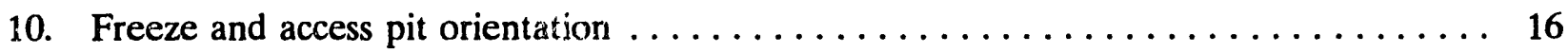

11. Plan view of freeze pipes for random dumped barrels and random dumped

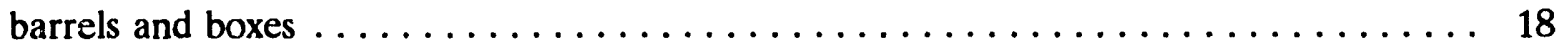

12. Elevation of freeze pipes for random dumped barrels and random dumped

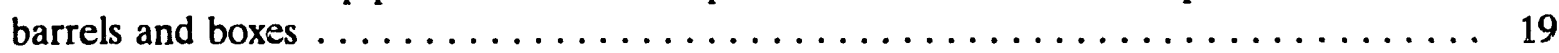

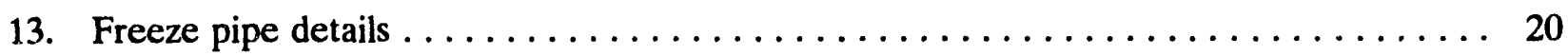

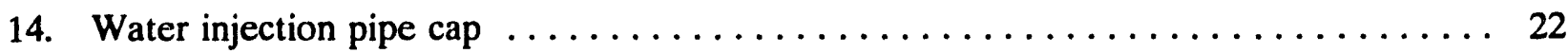




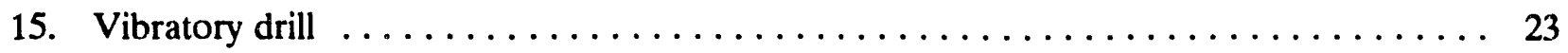

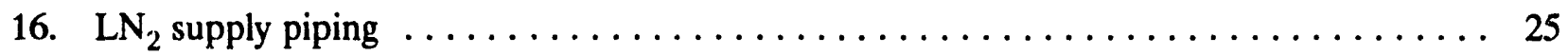

17. Typical freeze pit $\mathrm{LN}_{2}$ plumbing arrangement $\ldots \ldots \ldots \ldots \ldots \ldots \ldots \ldots \ldots \ldots \ldots \ldots$

18. Plan view of freeze pipes for stacked barrels and stacked boxes $\ldots \ldots \ldots \ldots \ldots \ldots 27$

19. Elevation of freeze pipes for stacked barrels and stacked boxes $\ldots \ldots \ldots \ldots \ldots 28$

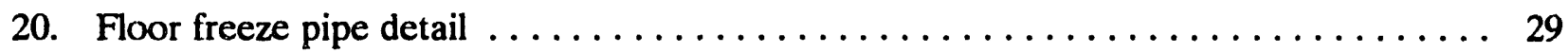

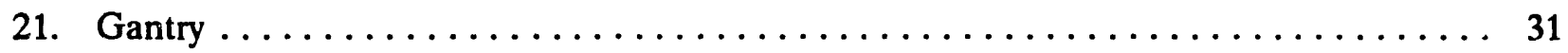

22. Breakout tool $\ldots \ldots \ldots \ldots \ldots \ldots \ldots \ldots \ldots \ldots \ldots \ldots \ldots \ldots \ldots \ldots \ldots \ldots \ldots \ldots \ldots \ldots \ldots, 32$

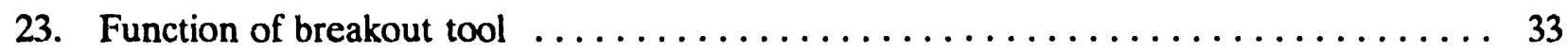

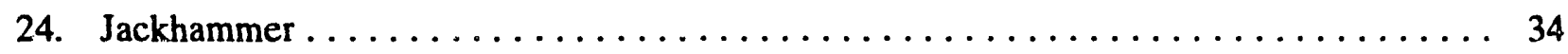

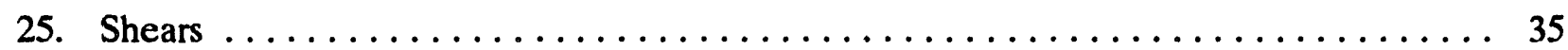

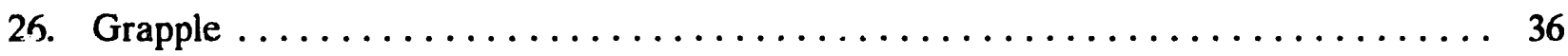

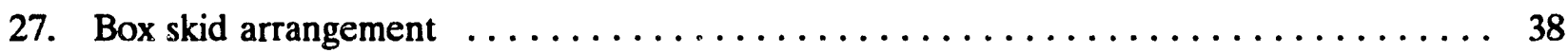

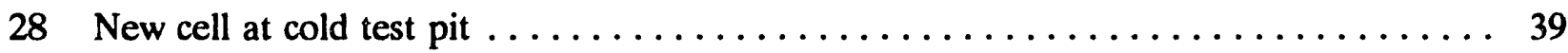

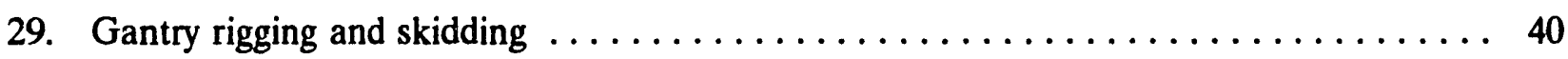

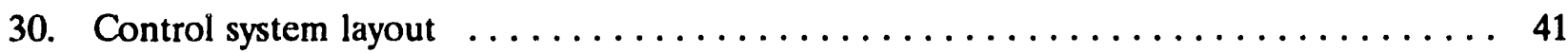

31. Control system block diagram $\ldots \ldots \ldots \ldots \ldots \ldots \ldots \ldots \ldots \ldots \ldots \ldots, 43$

32. Location of air monitors around the gantry $\ldots \ldots \ldots \ldots \ldots \ldots \ldots \ldots \ldots \ldots$

33. Top view of pit with the location of moisture and temperature probes $\ldots \ldots \ldots \ldots 47$

34. Side view of moisture/temperature probes $\ldots \ldots \ldots \ldots \ldots \ldots \ldots \ldots \ldots \ldots, 48$

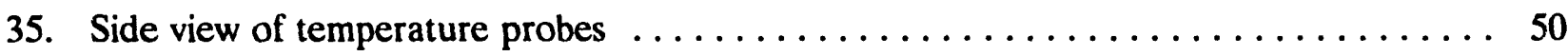

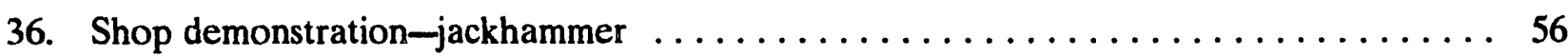

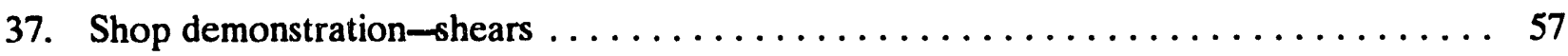

38. Shop demonstration-breakout tool $\ldots \ldots \ldots \ldots \ldots \ldots \ldots \ldots \ldots \ldots \ldots \ldots \ldots$ 


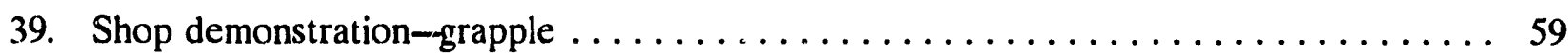

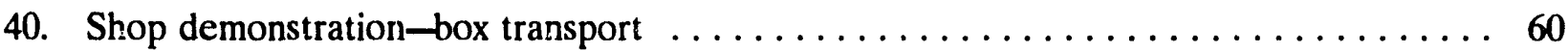

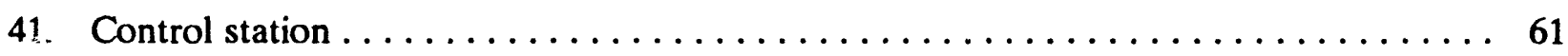

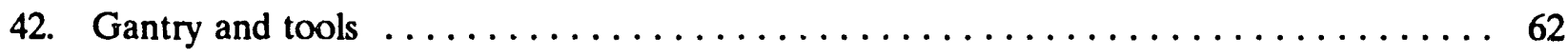

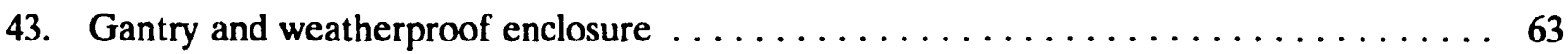

44. Layout of test equipment and facilities at cold test pit $\ldots \ldots \ldots \ldots \ldots \ldots \ldots \ldots$

45. Mobilization to cold test pit $\# 1 \ldots \ldots \ldots \ldots \ldots \ldots \ldots \ldots \ldots \ldots \ldots \ldots . \ldots 6$

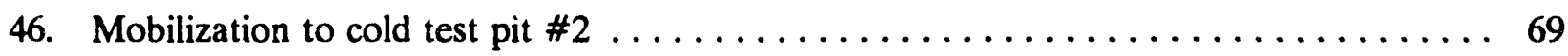

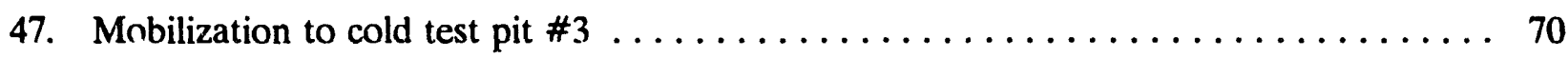

48. Random dumped barrels excavation $\# 1 \ldots \ldots \ldots \ldots \ldots \ldots \ldots \ldots \ldots \ldots \ldots \ldots$

49. Random dumped barrels excavation $\# 2 \ldots \ldots \ldots \ldots \ldots \ldots \ldots \ldots \ldots \ldots \ldots \ldots$

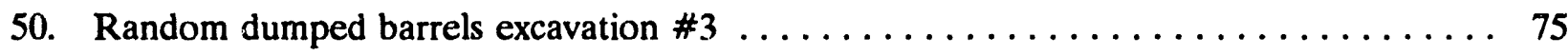

51. Random dumped barrels and boxes excavation $\# 1 \ldots \ldots \ldots \ldots \ldots \ldots \ldots \ldots$

52. Random dumped barrels and boxes excavation $\# 2 \ldots \ldots \ldots \ldots \ldots \ldots \ldots . \ldots$

53. Layout of stacked boxes freeze pipes $\ldots \ldots \ldots \ldots \ldots \ldots \ldots \ldots \ldots \ldots \ldots \ldots \ldots$

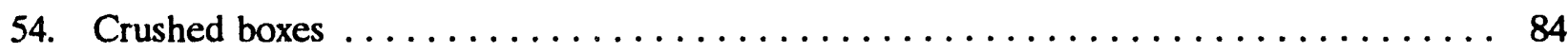

55. As-built of cold test pit at conclusion of cryogenic demonstration . . . . . . . . . 86

56. Averaged temperature profile for the three pits $\ldots \ldots \ldots \ldots \ldots \ldots \ldots \ldots \ldots$

57. Surface thermocouples in the random dumped barrels pit $\ldots \ldots \ldots \ldots \ldots \ldots \ldots$

58. All stacked probes on the dry side of the random dumped barrels pit $\ldots \ldots \ldots \ldots . . .92$

59. All stacked temperature probes on the wet side of the random dumped barrels pit .... 93

60. One stacked temperature probe on the dry side of the random dumped barrels pit .... 94

61. One stacked temperature probe on the wet side of the random dumped barrels pit ... 95

62. All surface thermocouples in the random dumped boxes and barrels pit $\ldots \ldots \ldots \ldots 99$ 
63. All stacked thermocouples in the random dumped boxes and barrels pit $\ldots \ldots \ldots 100$

64. One stacked temperature probe on the dry side of the random dumped

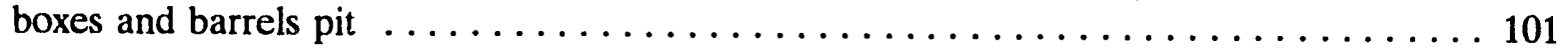

65. One stacked temperature probe on the wet side of the random dumped

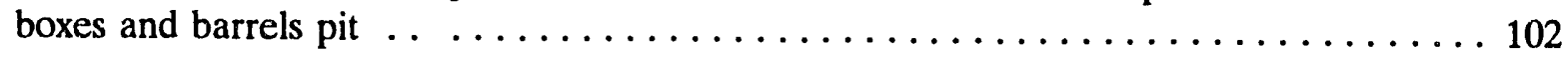

66. Moisture probes in the random dumped boxes and barrels pit $\ldots \ldots \ldots \ldots$

67. All thermocouples in the stacked boxes pit $\ldots \ldots \ldots \ldots \ldots \ldots$

68. One stacked temperature probe on the dry side of the stacked boxes pit $\ldots \ldots \ldots 107$

69. One stacked temperature probe on the wet side of the stacked boxes pit $\ldots \ldots \ldots 108$

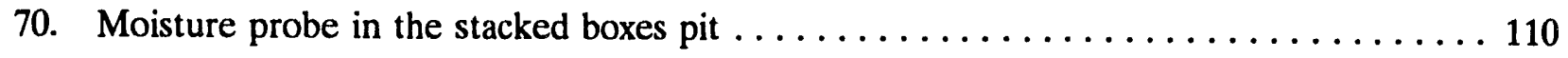

\section{TABLES}

1. Volumes of water and $\mathrm{LN}_{2}$ injected into each pit (gal) $\ldots \ldots \ldots \ldots \ldots$

2. Concentration of dysprosium found in random dumped barrels pit (ppm) . . . . . . 97

3. Background sampling in the random dumped barrels pit concentration of dysprosium $(\mathrm{ppm}) \ldots \ldots \ldots \ldots \ldots \ldots \ldots \ldots \ldots \ldots \ldots \ldots \ldots \ldots \ldots \ldots$

4. Concentrations of ytterbium found in the random dumped boxes and barrels

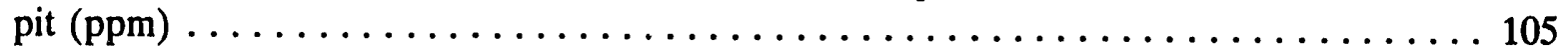

5. Background sampling in the random dumped barrels pit concentration of

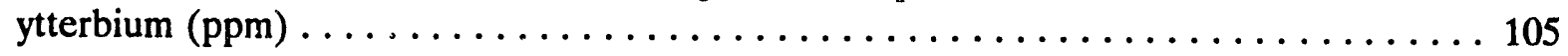

6. Concentrations of neodymium found in the stacked boxes pit $(\mathrm{ppm}) \ldots \ldots \ldots \ldots$ 
xviii 


\section{ACRONYMS}

AEC Atomic Energy Commission

BWID Buried Waste Integrated Demonstration

DOE U.S. Department of Energy

DOE-HQ U.S. Department of Energy Headquarters

DQO Data quality objective

EPA Environmental Protection Agency

hp horsepower

HPU Hydraulic Power Unit

IDC-MS Inductively Coupled Mass Spectrometry

INEL Idaho National Engineering Laboratory

I/O Input/output

ISV In situ vitrification

LLW Low-level waste

$\mathrm{LN}_{2} \quad$ Liquid nitrogen

NEPA National Envirormental Policy Act

P\&T Pan and tilt

PC Personal computer

psi pounds per square inch

ppm parts per million

RFP Request for Proposal

RWMC Radioactive Waste Management Complex

SCBA Self-contained breathing apparatus

SOW Statement of Work 
SDA Subsurface Disposal Area

TDR Time domain reflectometry

TRU Transuranic

TSA Transuranic Storage Area

Vac Volts alternating current

VCR Video cassette recorder 


\section{Final Report for the Cryogenic Retrieval Demonstration}

\section{BACKGROUND AND PURPOSE}

\subsection{Brief History of Buried Waste and the Subsurface Disposal Area}

The U.S. Department of Energy (DOE) and its predecessor agencies have operated numerous facilities throughout the United States for research, development, and production of defense and nucluar energy. Waste generated as a result of these and other operations has been buried in the ground or stored for future disposal at locations throughout the DOE complex. One of these sites, the Subsurface Disposal Area (SDA) is located at the Idaho National Engineering Laboratory (INEL) in the Radioactive Waste Management Complex (RWMC) (see Figure 1). The RWMC comprises about 144 acres, of which 88 are the SDA. The SDA was opened in 1952 for the disposal of solid low-level waste (LLW) generated by the operations at the INEL.

In 1954, per direction from the Atomic Energy Commission (AEC), disposal of transuranic (TRU) waste began at the SDA. The majority of TRU waste was generated from the Rocky Flats Plant in Colorado. In 1970, the disposal of TRU contaminated waste in the SDA was discontinued. Since 1970, the waste has been piaced in protected and monitored aboveground storage at the RWMC where it will remain until a suitable permanent disposal method is available.

Before 1970, waste disposal at the SDA corsisted of random dumping and orderly placement of containers in pits and trenches. A variety of large contaminated items including cranes, tanks, vaults, and bulky equipment were also buried. The total volume of buried TRU waste is approximately 2 million $\mathrm{ft}^{3}$. It is intermixed with about 1 million $\mathrm{ft}^{3}$ of $\mathrm{LLW}$ and 5 million $\mathrm{ft}^{3}$ of soil resulting in a total waste volume of 8 million $\mathrm{ft}^{3}$. The TRU waste received from Rocky Flats also contains hazardous waste, as defined by current Environmental Protection Agency (EPA) regulations, resulting in radioactive mixed waste.

Much of the waste contained within the SDA is representative of the type found at other DOE buried waste sites. About $30 \%$ of the DOE complex's buried TRU waste is stored at the INEL.

\subsection{Need for Restoration of the SDA}

Most of the waste buried at the SDA (and throughout the DOE complex) was initially stored in metal barrels, boxes, or other similar containers. Over time these containers have deteriorated and many have breached, contaminated the surrounding soil, and posed a threat to local groundwater. It is the intent of DOE to remediate the SDA thereby restoring the area to a condition that is not a threat to people or the environment. This remediation will consist of extensive characterization, monitoring, retrieval, treatment, and final disposal of the waste. 


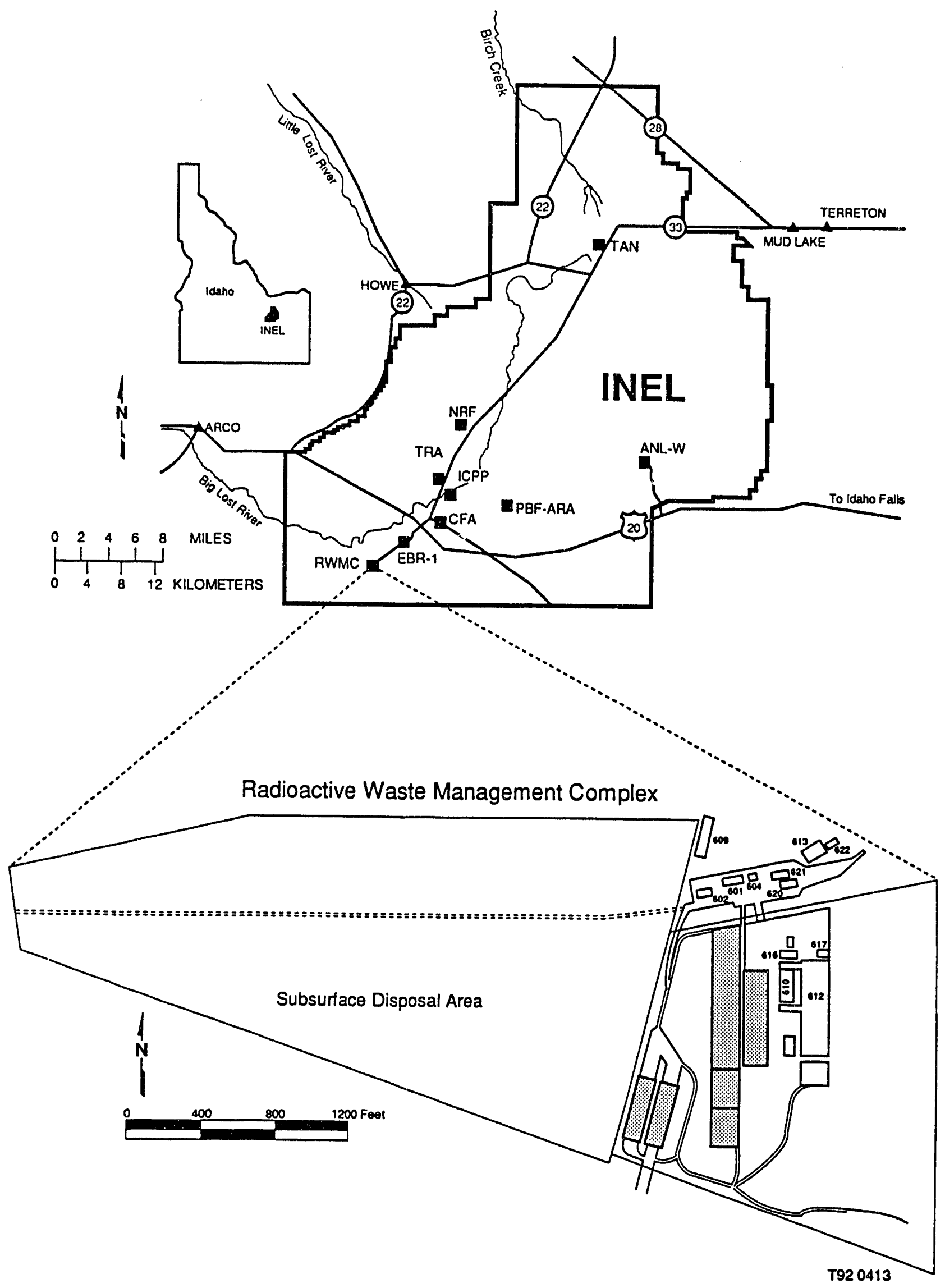

Figure 1. Location of INEL/RWMC. 


\subsection{Overview of Retrieval Technologies}

A key aspect of the remediation effort is retrieval or the physical removal of buried waste from the ground. DOE is currently engaged in evaluating the merits of several technologies that could be used for retrieval of wastes buried at the SDA (and throughout the DOE complex). Some of these technologies include in situ vitrification (ISV), conventional retrieval, robotic and remote-operated retrieval methods, and cryogenic retrieval. ISV is a technology that energizes large ground electrodes to melt the buried waste in the immediate area where the electrodes are placed. The melted waste solidifies and forms a glassy material (usually in the shape of a ball), immobilizing hazardous and radioactive constituents. This material may be left in place or removed by conventional excavation methods. Conventional excavation uses commercially available and modified equipmènt, such as front end loaders, power shovels, and backhoes, to dig and remove buried waste. Typically this approach has a person directly operating the equipment. Robotic and remote operated excavation may use commercially available and/or modified equipment or custom built machinery that is operated via remote controls. Cryogenic retrieval is a relatively new retrieval technology that freezes the waste, taking advantage of the inherent contamination control features associated with frozen soil, i.e., no airborne particulates or migration of free liquids.

\subsection{Development of the Cryogenic Retrieval Concept}

The idea of freezing and retrieving buried waste and soil was formulated about 5 years ago. It is generally acknowledged that U.S. Department of Energy Headquarters (DOE-HQ) postulated the con rept and supported funding and field development of the technology. In November 1990, a pilot scale test was held at a contractor's facilities in Carnation, Washington. The Contractor, RKK, Ltd., performed ground freezing tests on a small block of soil and extracted the soil using a system of thawing devices and hydraulic jacks. Complete details of this work are given in Reference 1 . After this initial field testing, further demonstration of the concept of ground freezing was pursued. A request for expressions of interest was published in the Commerce Business Daily. Responses were received from 16 firms who expressed an interest in participating in the development/demonstration of cryogenic retrieval technology. The primary difference between the pilot scale demonstration and the new proposed demonstration was the technology had to show merit for working in a tual buried waste as opposed to just soil. Therefore, it was decided to perform the demonstration at the cold test pit near the RWMC. The cold test pit was built in 1988 to be used as a safe and noncontaminated test bed for retrieval and other technologies. A more complete description of the cold test pit is contained in Section 2.1.

After a rigorous formal bidding process, a contractor, Sonsub Services, Inc., of Houston, Texas, was selected to demonstrate their innovative technology. The purpose of this report is to document salient aspects of the testing. A complete description of Sonsub's proposed technology is given in Section 2.4 . 


\section{PROPOSED TECHNOLOGY}

\subsection{The Cold Test Pit}

In 1988 a nonhazardous and nonradioactive (or cold) simulated waste test pit was developed near the RWMC. This area, known as the cold test pit, is located about 300 -ft south of the south fence of the RWMC (see Figure 2). The concept of a cold test pit was conceived when it was realized that to effectively test retrieval, characterization, contamination control, and related technologies, a safe and noncontaminated test bed would be essential.

The cold test pit was initially divided into five cells. Each cell represented a different configuration of the waste. The cells contained random dumped barrels, random dumped barrels and boxes, stacked barrels, stacked boxes, and the large objects pit (see Figure 3). The overall length of the cold test pit was about $145 \mathrm{ft}$, the width $40 \mathrm{ft}$ and the depth about $13 \mathrm{ft}$ (the waste seam was about 8-ft thick with a 4 to 5 -ft soil cap). Each of the barrels and boxes was filled with simulated waste of the type expected to be encountered at the SDA. Items such as metals, tools, plastics, concrete, asphalt, wood, and simulated sludge were placed in each container. Figures 4 and 5 show some of the types of debris placed in the barrels and boxes.

To roughly simulate the presence of radioactive waste for migration and detection purposes, rare earth tracers were placed into each container. These tracers would prove valuable when measuring the effectiveness of contamination control technologies. If a contamination control technology is effective, no rare earth tracers would be detected during removal operations. However, if the tracers are detected, then it indicates that the contamination control feature may not function as well as envisioned. The following kinds of tracers were placed in each of the cells:

- Random dumped barrels: Dysprosium

- $\quad$ Random dumped barrels and boxes: Ytterbium

- Stacked barrels: Terbium

- $\quad$ Stacked boxes: Neodymium

Only one kind of tracer was placed in each cell. No tracers were placed in the large objects pit.

Figures 6, 7, and 8 depict activity during construction of the cold test pit. Cardboard containers were used to hasten the deterioration of the barrels and boxes-a condition most likely to be encountered at the SDA. ${ }^{a}$ Water was also sprayed on the containers just before burial to accelerate the deterioration.

a. Engineering Design File, G.G. Loomis, "Design and Construction Details of the INEL Simulated TRU Test Pit," BWP-151-009, EG\&G Idaho, Inc., March 1989. 


\section{Radioactive Waste Management Complex}

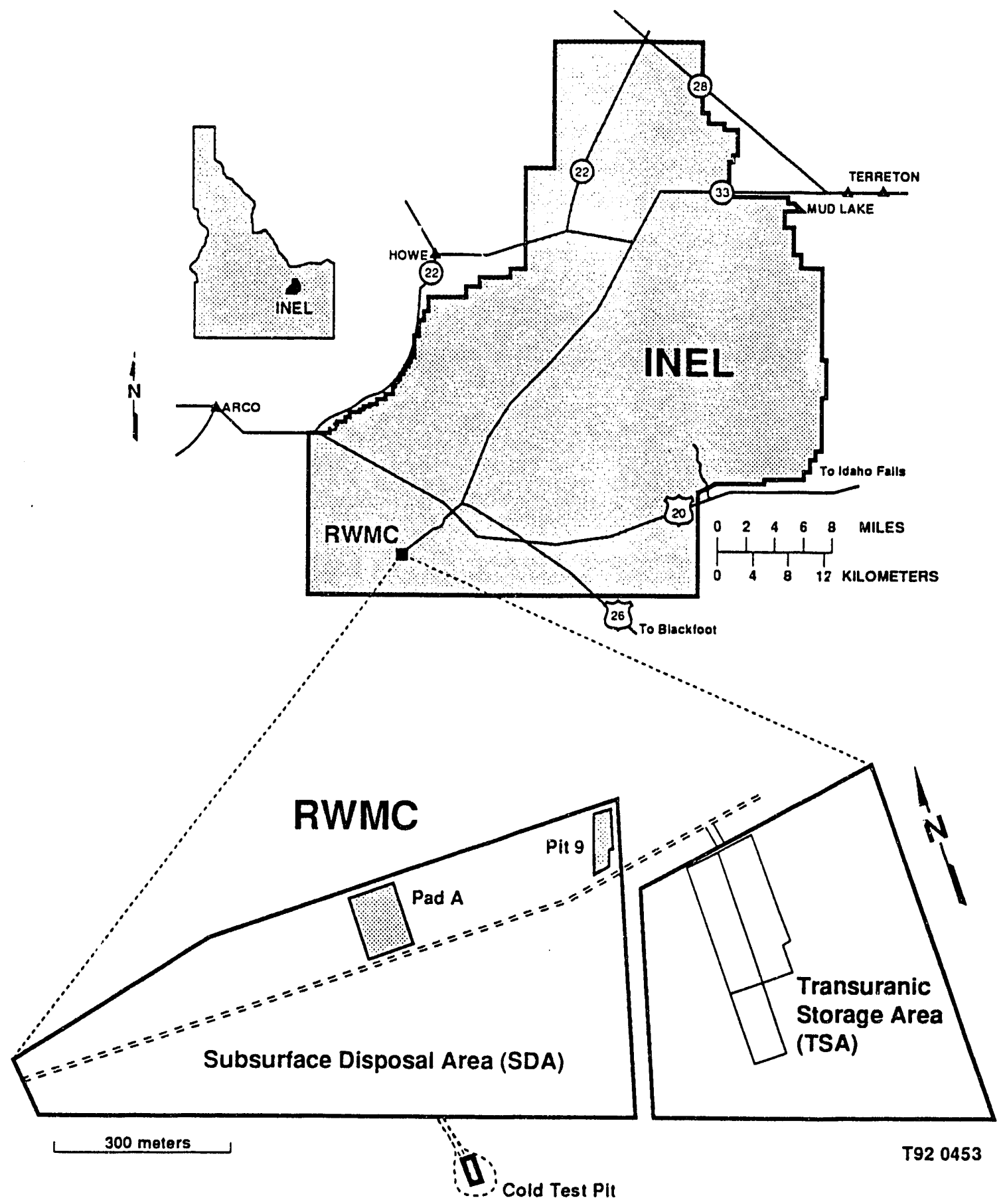

Figure 2. Location of cold test pit. 


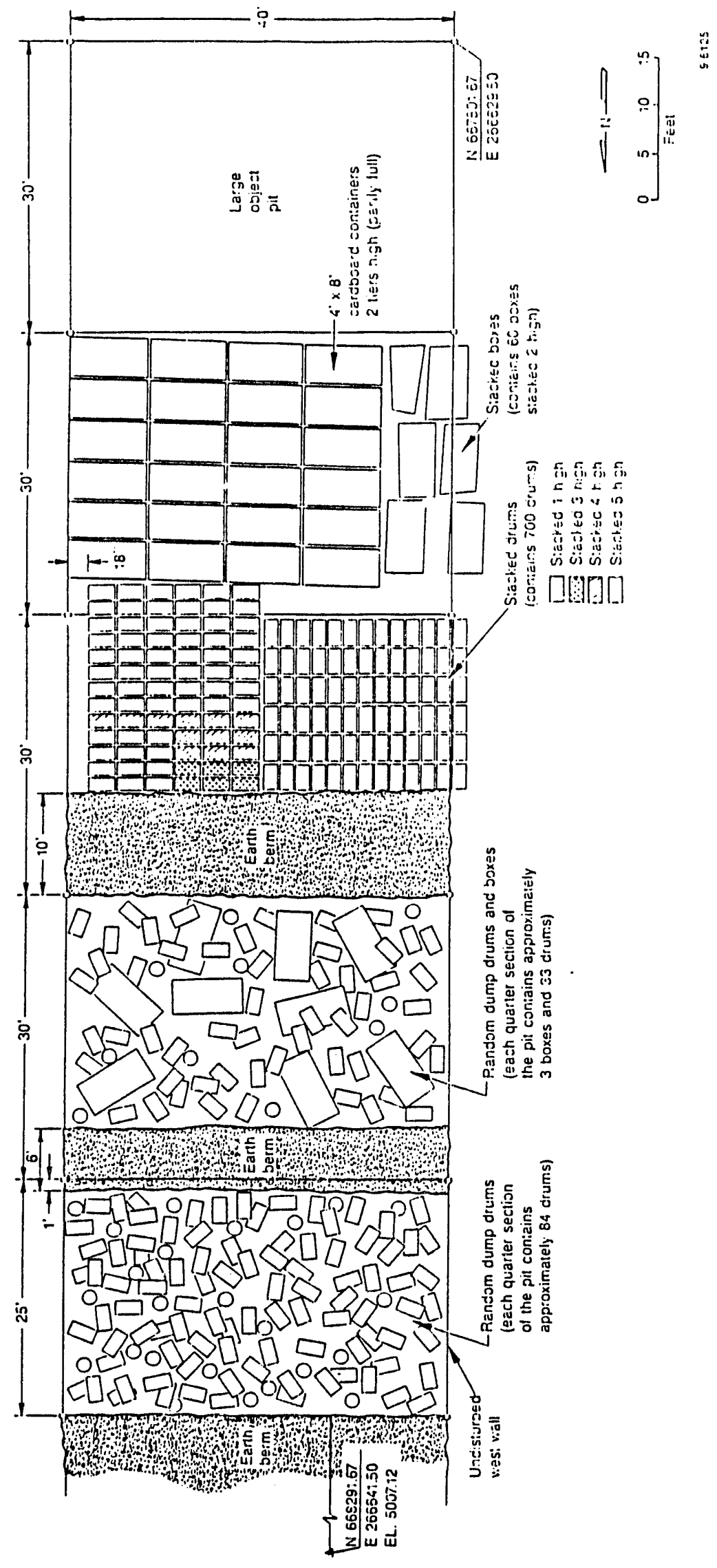

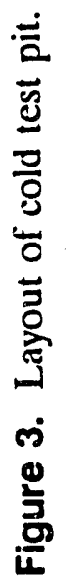




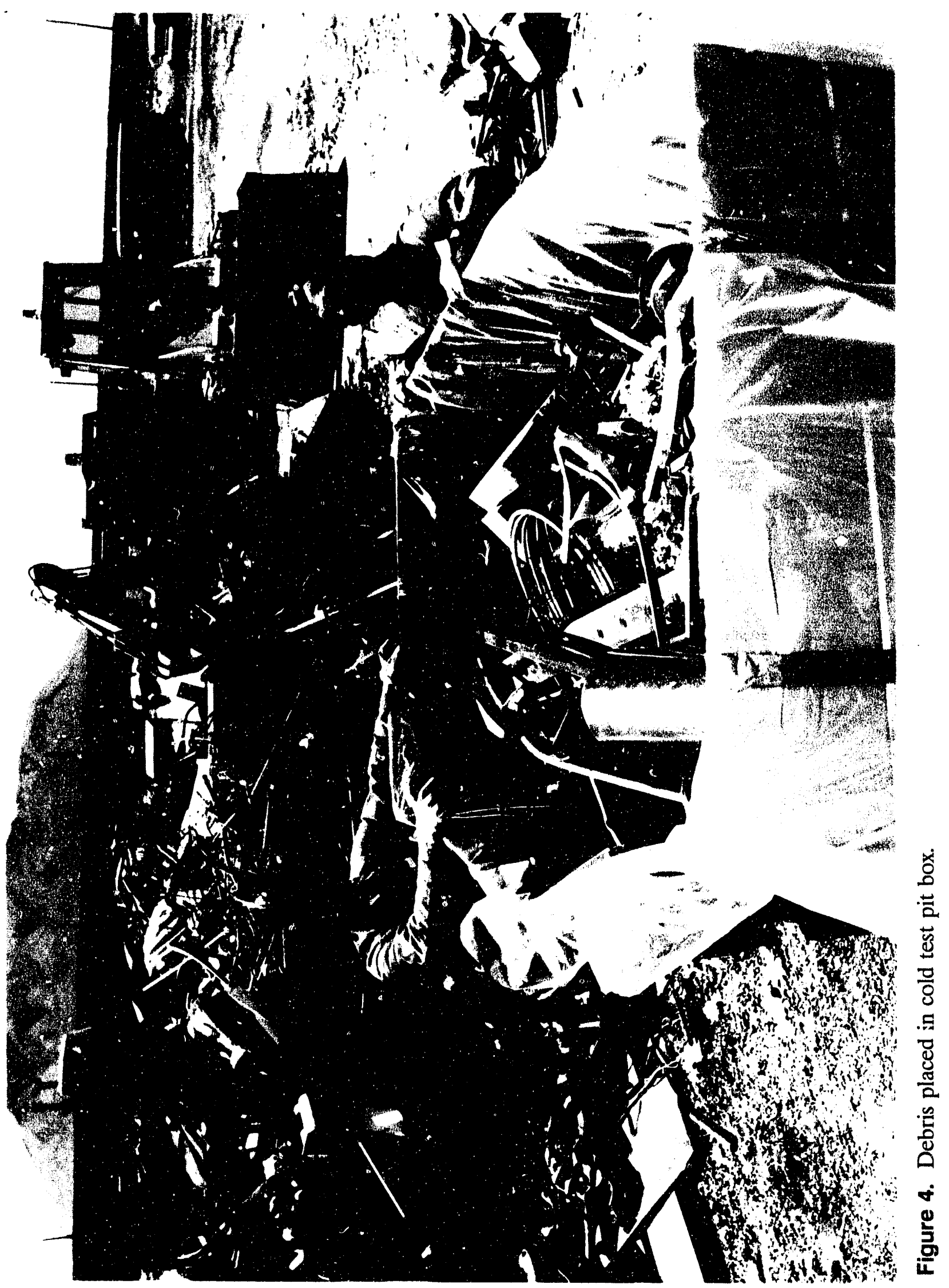




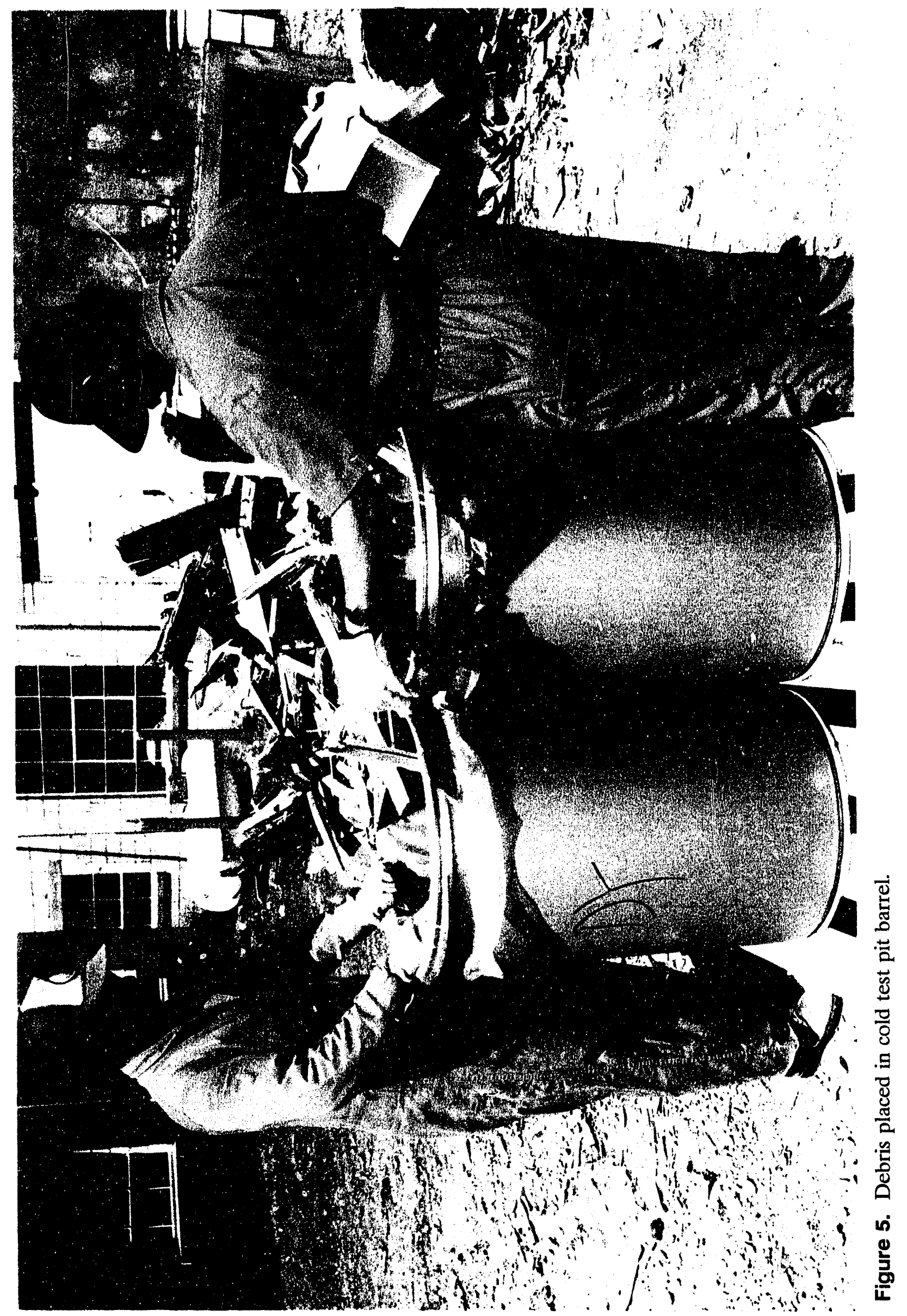




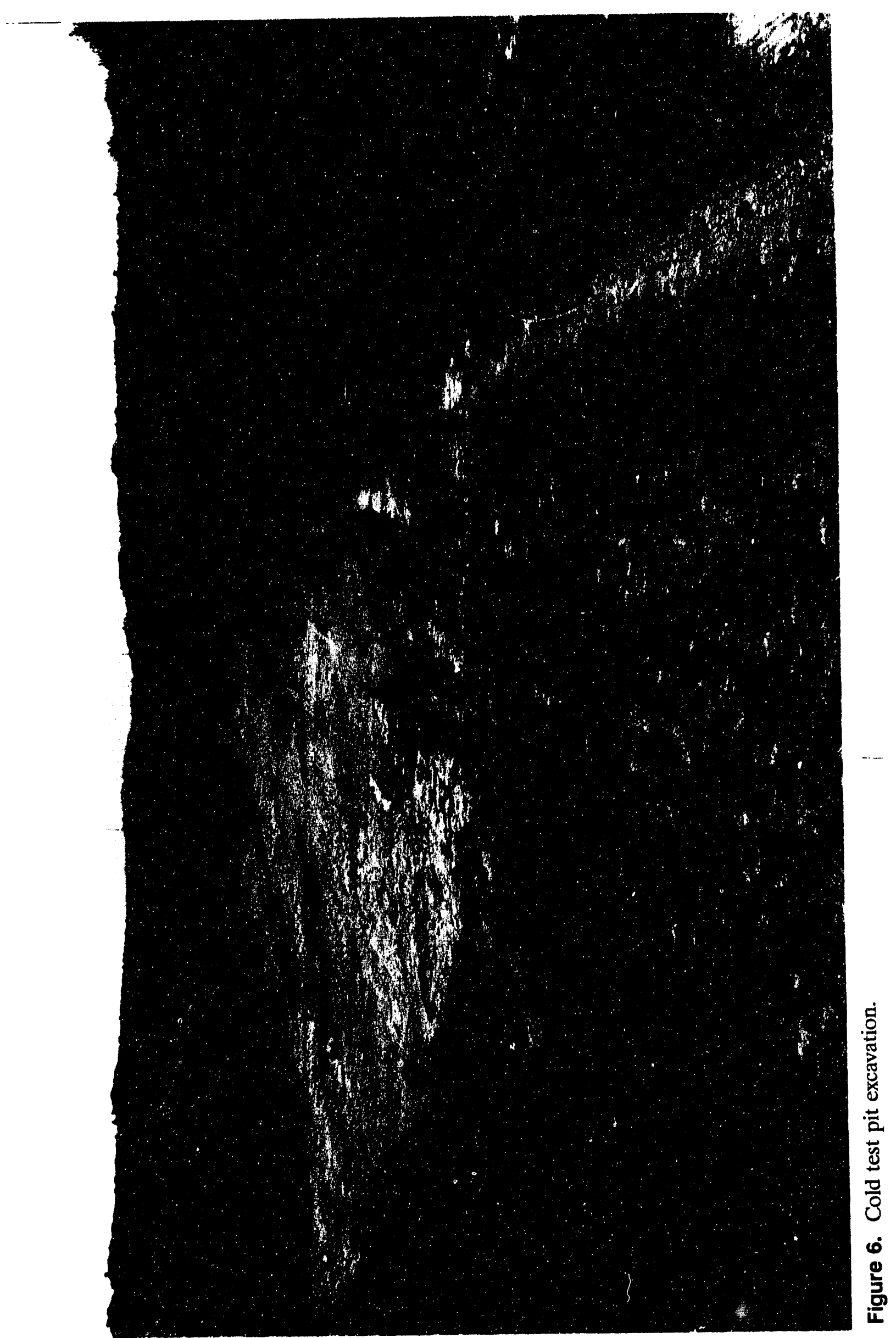




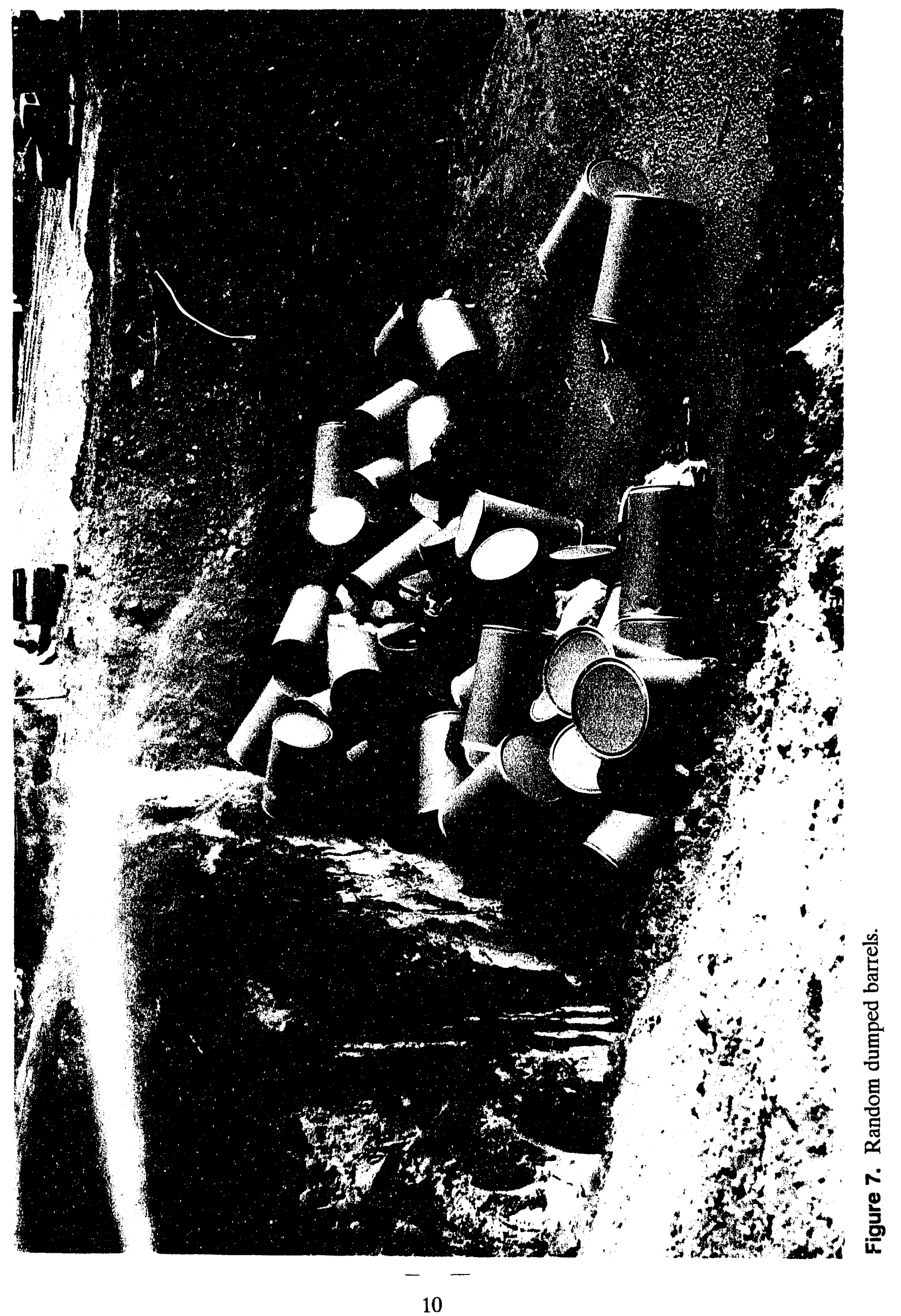




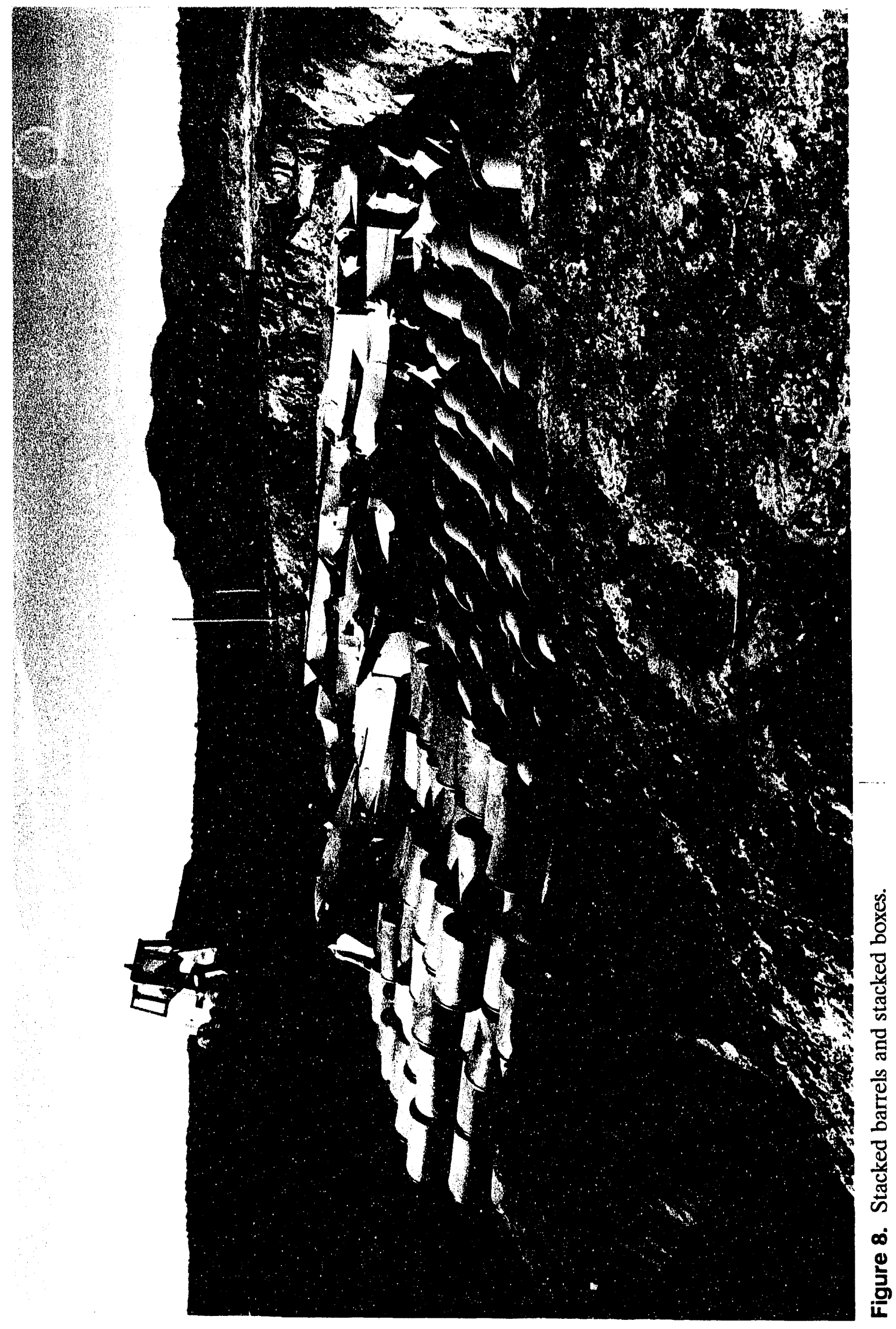




\subsection{Testing of the Cryogenic Retrieval Technology at the Cold Test Pit}

Demonstration of the cryogenic retrieval technology at the cold test pit is a safe and effective way to perform testing because there are no hazardous or radioactive substances present. For this reason and because the cold test pit affords an environment that closely simulates the configuration of buried waste anticipated at the SDA, it was decided to conduct field testing at this site.

It was decided early in the project to freeze a total of four pits, one from each cell (except the large objects cell). Each pit would be $9 \times 9 \times 10 \mathrm{ft}$ or approximately $810 \mathrm{ft}^{3}$. The areas to be frozen and excavated were located on the west side of the pit because there is a higher concentration of barrels and boxes near this boundary than on the opposing side, and because there is a clear and relatively level area for access by equipment and personnel. A layout of the cold test pit and the precise location of the areas to be frozen and removed are shown in Figure 9. Four pits were selected to be frozen because each represents a different configuration of the type of waste expected at the SDA. The size and volume of the pit was based on a combination of results from the previous ground freezing demonstration, ${ }^{1}$ budget considerations, and engineering judgment. It was believed that the proposed scheme for testing would yield data depicting a representative cross section of the conditions anticipated at the SDA.

Testing at the site was planned for July and August 1992. It was originally planned to have the testing conducted during late May and June, but because of schedule considerations the later time frame was selected. The contractor performing the field demonstration, Sonsub planned to work 7 days/week, 12 hours/day to maximize the use of equipment and personnel and minimize costs.

The cold test pit is sited in close proximity to the RWMC. The RWMC provided a variety of services required to perform the work in a safe and effective manner. Services such as security and safety assistance, emergency response, and equipment and operations personnel were available upon request from the RWMC.

\subsection{Selecting a Demonstration Contractor}

To ensure that the most technically advanced cryogenic retrieval method at a competitive cost was obtained, a rigorous bidding, evaluation, and award process was followed to select the demonstration contractor. ${ }^{b}$ In January 1991, a notice was placed in the Commerce Business Daily requesting expressions of interest from firms technically capable of performing a ground freezing demonstration. Responses were received from 16 companies. Further discussions with the interested parties as well as investigations concerning the aspects of ground-freezing technology were performed and used as the basis for developing a Statement of Work (SOW). The SOW was issued with a Request for Proposal (RFP) asking firms to submit formal technical and cost proposals for performing a field demonstration at the cold test pit. Two responses to the RFP were returned.

b. Internal Technical Report, D.J. Valentich, Technical Evaluation of Cryogenic Retrieval Proposals, WTD-91-031, February 1992. 


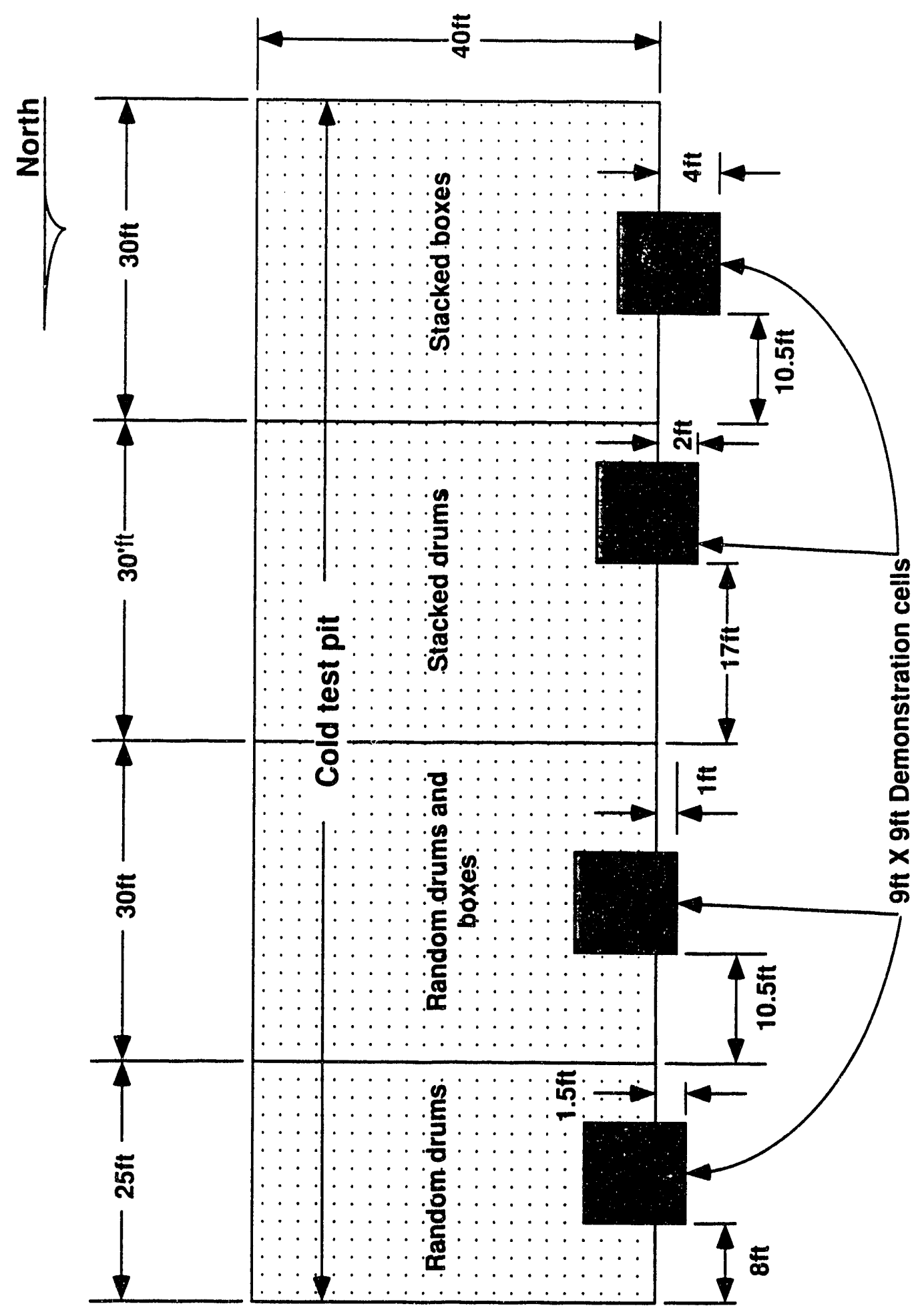

Figure 9. Location of pits to be frozen. 
A selection panel was formed to evaluate the proposals. The evaluation was based on four pre-established criteria:

1. Technical adequacy of the proposed technology (a more complete explanation of the technical criteria is given in Section 2.4)

2. Ability to maintain schedule

3. Company expertise

4. Historical success.

Proposals were received from two firms: Sonsub Services, Inc. of Houston, Texas, and RKK/SEG, Ltd. of Bellevue, Washington. The panel's evaluation concluded that Sonsub's proposal was superior and recommended that their technology be demonstrated. After a required preaward audit of the proposal and a series of negotiations focusing on certain technical and cost aspects of the work, the contract was awarded to Sonsub on February 7. 1992.

\subsection{Objectives and Requirements of the Field Demonstration}

Objectives for the field demonstration were

- Provide a system that effectively controls the spread of airborne dust and contaminants and free liquids during the exhumation process

- Provide a system that can effectively remove cryogenically frozen buried waste within a reasonable length of time

- Perform the field demonstration in a reasonable time frame (approximately 6 weeks) and for a reasonable budget $(\$ 1.5$ to $\$ 2 \mathrm{M})$.

Requirements for the field demonstration were

- Develop a method to freeze the soil/waste mass

- Provide a technical reason for selecting an optimum temperature

- Limit the use of water to promote freezing of the soil/waste mass, or provide rationale for the addition of water and measures used to mitigate or prevent flow of water

- Provide a means to detect the flow of water (or other liquids) beyond the region of the frozen soil/waste mass

- Freeze and exhume a total of four $9 \times 9 \times 10$-ft pits at the cold test pit

- Size simulated waste to fit in a standard $4 \times 4 \times 8$-ft storage box 
- Devise a method tor cutting or removing "bridged" materials between the frozen block and the surrounding nonfrozen region

- Provide a way to measure and record temperature in each of the test pits

- Measure temperature in a way that gives a representative sampling of the entire volume being frozen

- Suppress airborne dust during all phases of freezing and removal activities

- Ensure all work is performed in a safe manner that does not pose a threat to the environment or people

- Ensure no toxic, flammable, or explosive substances are used as a part of the freezing or removal activity

- Ensure the freezing and extraction methods do not create substantial quantities of new waste to be added to the original volume of simulated waste being removed

- Minimize contact between people and the simulated waste during all phases of exhumation.

\subsection{Detailed Explanation of the Planned Technology Demonstration}

\subsubsection{Overview}

Sonsub's approach includes driving a series of freeze pipes into the soil/waste and trickling liquid nitrogen $\left(\mathrm{LN}_{2}\right)$ into the pipe to promote freezing of the surrounding area. A series of in $_{4}$ aisture and temperature probes are driven into the area to be frozen at the same time the freeze pipes are placed. A separate and detailed discussion of the temperature, moisture, and air monitoring is covered in Section 3. At the same time the freeze pipes are placed directly in the soil/waste mass, an access pit (located in clean soil) is defined by a series of perimeter freeze pipes (see Figure 10). After freezing, the access pit is excavated and used as a work area to size and handle the retrieved simulated waste. A gantry equipped with a series of overhead crane mounted tools (shears, grapple, jackhammer, and hydraulic jack) is then positioned over the frozen area and access pit. The hydraulic jack, or breakout tool, is used to pry the frozen soil/waste out in a "popsicle." The jackhammer is used to chip or loosen the frozen soil/waste that is not loosened by the breakout tool. As material breaks free, it falls into the access pit where it can be sized using the shears as required. Once properly sized, the soil/waste is picked up by the grapple and placed in storage boxes. The boxes are handled by forklift and stacked at the north end of the cold test pit. They will be used to create a new cold cell for testing of other retrieval technologies. 


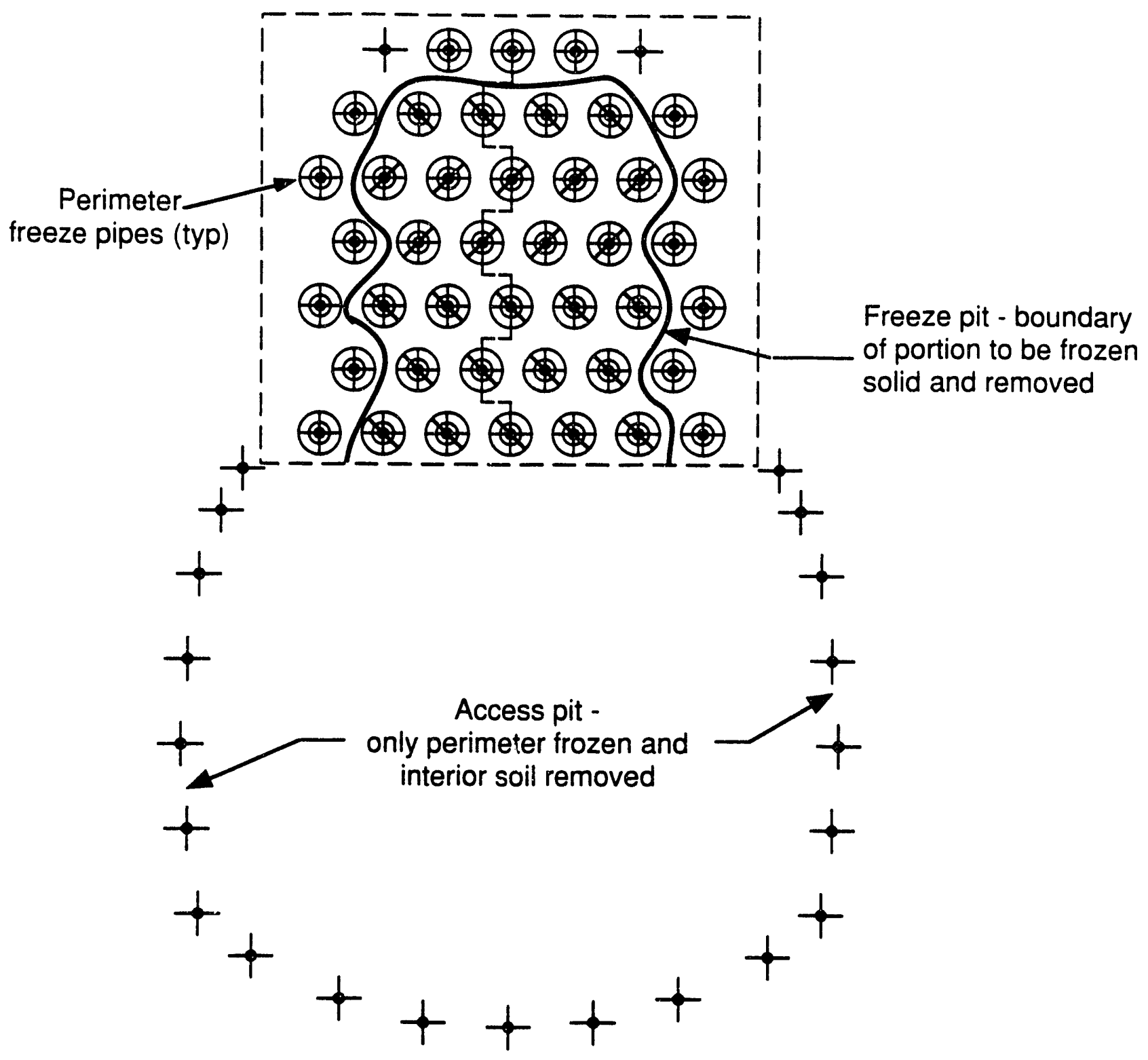

Figure 10. Freeze and access pit orientation. 


\subsubsection{Freeze Pipes and Pits}

As indicated in Figure 9, there are a series of four pits slated for excavation. There are specific arrangements for freeze pipes, water injection pipes, and construction materials for each pit. The primary advantage of employing the cryogenic retrieval technology for removing buried waste is contamination control. It is desirable to minimize the addition of water to buried waste for two reasons. First, the risk of spreading contamination by the migration of free liquids is mitigated by minimizing the amount of water added to the ground. Second, if successfully frozen, the water still contributes to an increase in the overall volume of waste that must be handled and ultimately disposed.

For these reasons, a scheme was chosen to add varying quantities of water and no water to certain pits. Also, the method by which water is introduced into the pit may or may not influence the migration of water below the area to be frozen and retrieved. For this reason different injection techniques were included as a part of the demonstration to test if water could successfully be added to the buried simulated waste, and if it could be contained. Another aspect of the test includes the use of carbon and stainless steel for certain applications. Generally for pipes that will be subjected to high stresses during the breakout phase, it was determined that stainless materials would be best suited. However, to test suitability of carbon steel, some of the breakout pipes were designed with this material. An explanation about the unique features that have been designed for each of the test pits follows.

\subsubsection{Freeze Pipe Arrangement for the Random Dumped Barrels and Random Dumped Barrels and Boxes Pits}

Figures 11 and 12 indicate the plan and elevation of the first two pits. Each pit has the following quantity of freeze pipes installed:

- $\quad 38$ carbon steel wall freeze pipes

- 14 stainless steel waste freeze pipes

- $\quad$ Nine stainless steel water injection freeze pipes

- $\quad$ Four carbon steel water injection freeze pipes.

A steel collar is placed around each pipe within the perimeter of the freeze pit, and the wall freezes the pipes directly outside of the freeze pit. This collar is necessary to promote breakout of the freeze pipes. Figure 13 shows details for each of the different types of freeze pipes and collar.

The 38 carbon steel wall freeze pipes are installed around the perimeter of the freeze and access pits. These pipes are carbon steel because there will be either no or minimal force placed on them during the breakout process. It is an economical choice to use a carbon based material instead of stainless steel wherever possible. Carbon steel is susceptible to breaking because of the extreme cryogenic temperatures and stresses introduced to the member that could cause failure. These pipes 


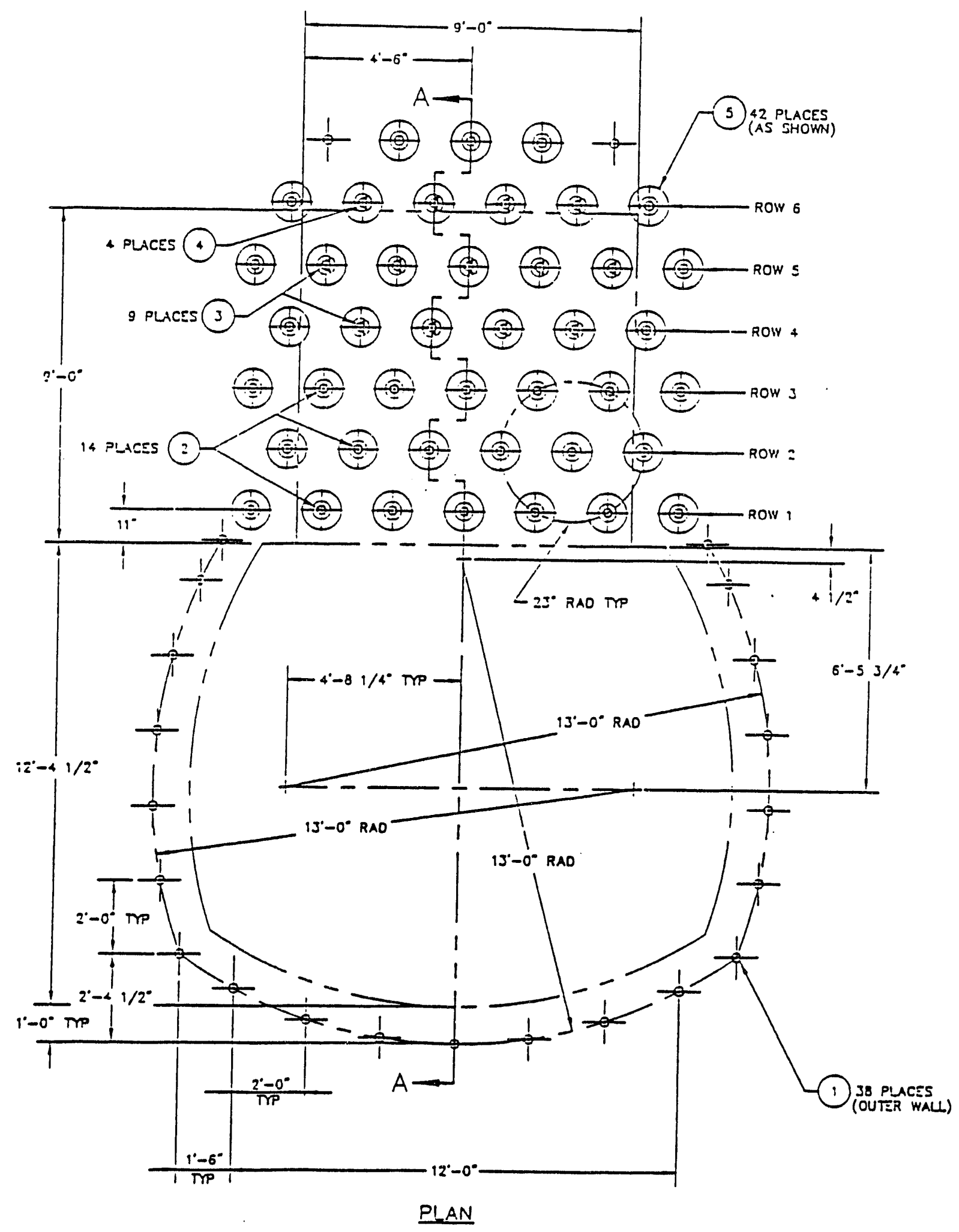

Sections A-A shown on Figure 12

$\otimes$ - call outs shown on Figure 12

Figure 11. Plan view of freeze pipes for random dumped barrels and random dumped barrels and boxes. 


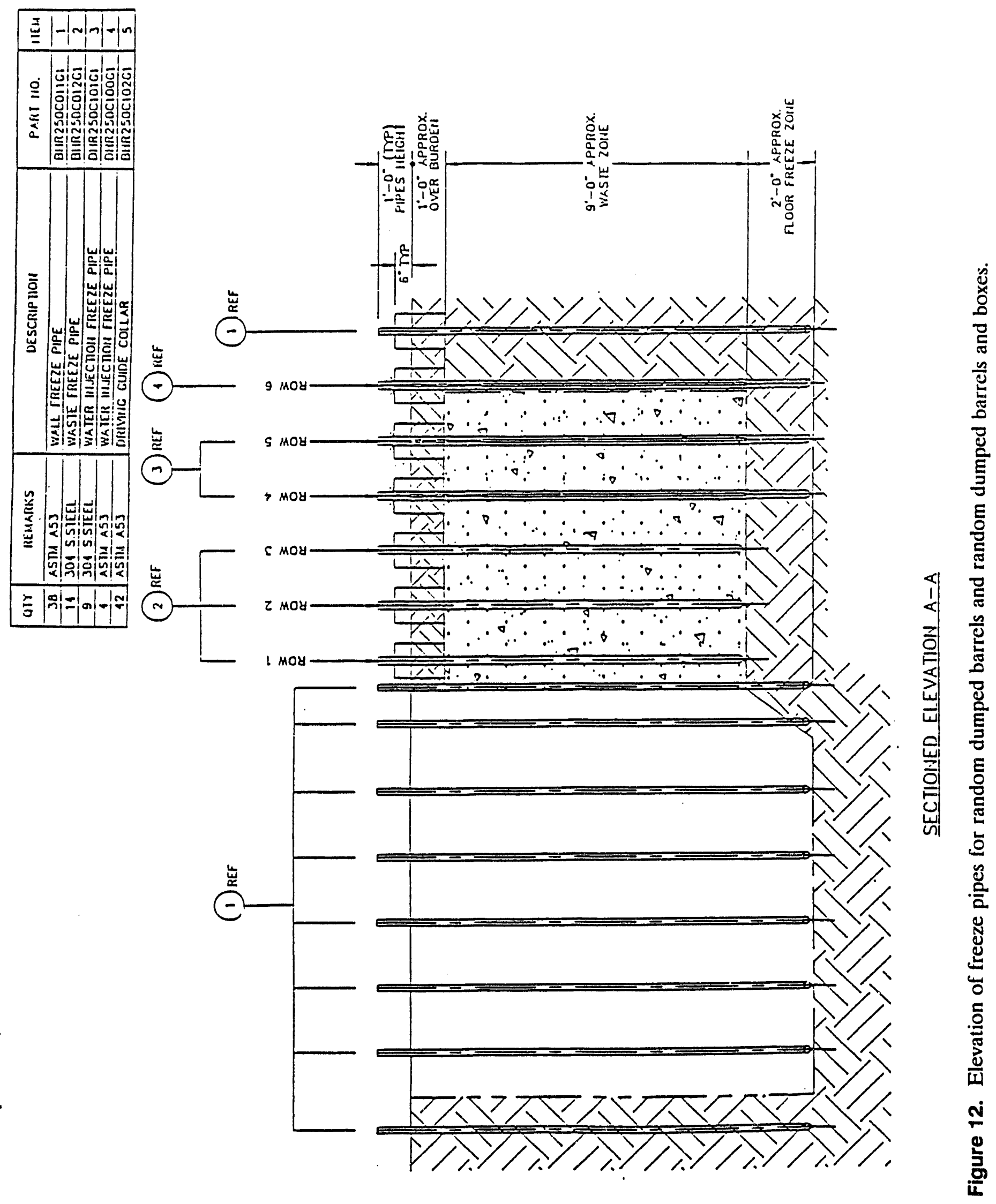


Carbon or stainless steel wall or waste freeze pipe

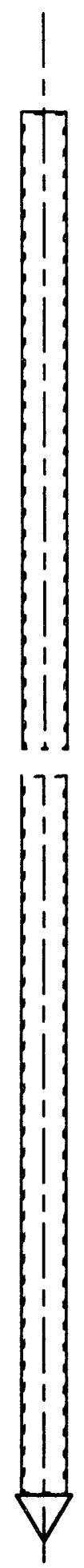

Carbon or stainless steel water injection freeze pipe

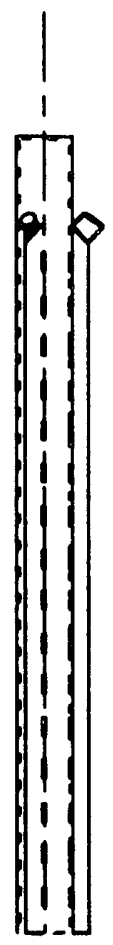

Th Angle iron welded to side of pipe

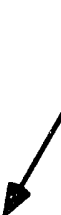
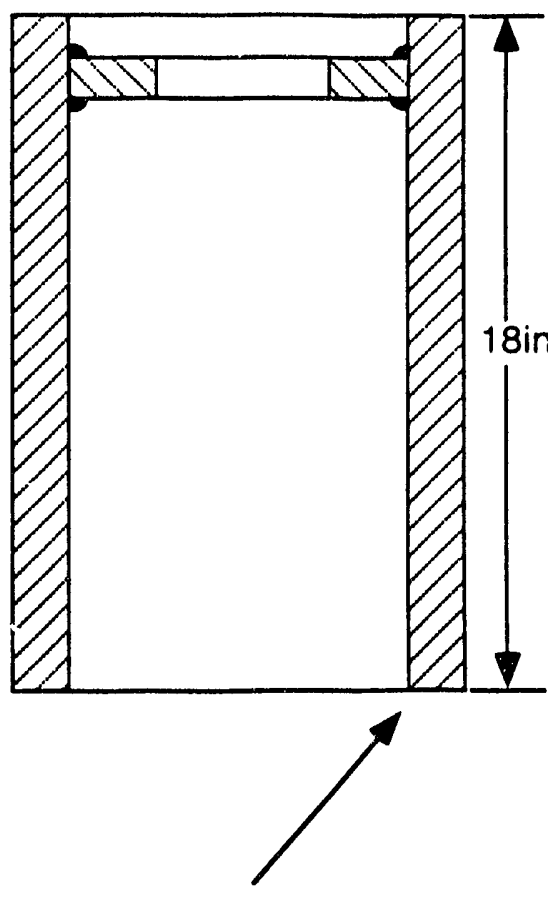

Carbon steel schedule 80

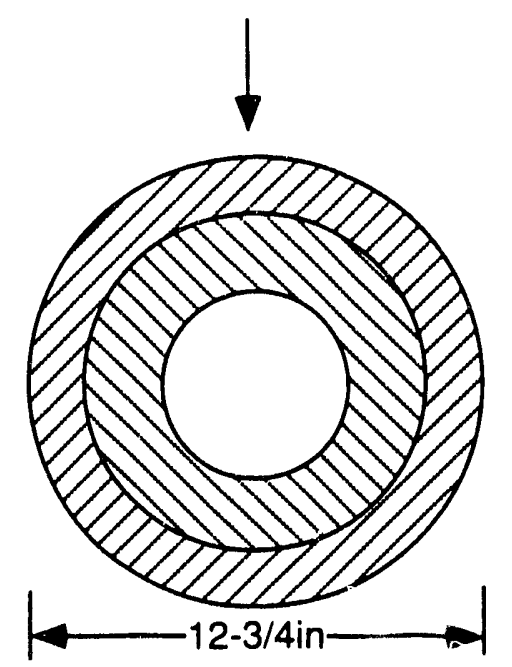

Figure 13. Freeze pipe details. 
are driven to a depth of about 12-lt belowgrade. This depth is chosen because it provides a good envelope of cold to promote the overall chilling of the access and treeze pits.

Fourteen stainless steel waste freeze pipes are placed in the front three rows of the freeze pit. These are driven to a depth of 10-ft belowgrade, which is estimated to be at or near the bottom of the original cold test pit. Stainless steel has been selected because these pipes will be used to breakout the simulated waste.

The test plan for freezing and breakout of the pits calls for adding water to promote freezing and create a cohesive mass. In the random dumped barrels pit, the front half of the pit (rows 1,2 , and 3 ) is left dry (no water added). In the back half of the pit (rows 4, 5, and 6), nine stainless steel and four carbon steel injection and freeze pipes are used to tirst add a known quantity of water to the pit and then freeze the water. The rationale for this approach is to test the effectiveness of freezing the naturally occurring moisture in the soil surrounding the simulated buried waste and observe the effect of adding known quantities of water. In an actual retrieval demonstration, adding no or minimal water is desirable to lessen the chance for the spread of contamination. At the INEL (including the cold test pit), the soils are particularly dry and tend to readily disperse to the air. The test is a representation of the worst conditions relative to dry soils that could be expected during an actual hot retrieval operation. The second half of the random dumped barrels pit is sat'uated with water. An estimate is made about how much of the volume is void, and a corresponning amount of water is injected through the special pipes designed for this purpose. The injection of the water into the pipes in rows 4 through 6 does not vecur until the entire perime er piping and rows 1 through 3 are cooled to the optimum freezing temperature. The design for the fr $€ \varepsilon z$ pipes is simple. Pieces of angle iron are stitch welded on the side of the pipe, with threaded nipples seal welded into the angle iron (see Figure 14). It is postulated that as the water is injected it freezes rapidly before migrating past the bottom of the pit. Although adding water is not an optimun chuice, it is prudent to test this configuration to determine if water is a required element o! the technology. A series of temperature and moisture probes are placed throughout the pit to provide indications of how cold the soil/waste mass is and if there is any movement of water below the bottom of the pit. An explanation of the instrumentation for the project is given in Section 3.

The four carbon steel combination water injection and ireeze pipes are used at the back half of the pit to determine the suitability of using carbon steel for both freezing and subsequent breakout. It is probable that the carbon steel will become brittle after the $\mathrm{LN}_{2}$ comes in contact with ihe pipe and shatter when the breakout tool is used to pry the lipe away from the frozen soil/simulated waste mass. However, if the carbon steel works in this application, it would mean a cost savings over the stainless steel used for the other freeze pipes.

All the freeze and injection pipes are designed to be driven with a commercially available air-track vibratory drill (see Figure 15). The tips of the pipe are designed to penetrate soil, concrete, 1/4-in. mild steel plate, and other debris expected to be encountered during the demonstration. If a pipe cannot oe driven, an attempt is made to extract it. If this is not possible, the top part of the pipe is cut off and the bottom left in place. An attempt to place another pipe in close proximity to the abandoned piece is made. A safety requirement for drilling (as well as all other equipment) activities that occur within the boundary of the cold test pit is that a 4 pounds per square inch (psi) soil pressure not be exceeded. This is nee. ied to minimize the potential danger posed from 

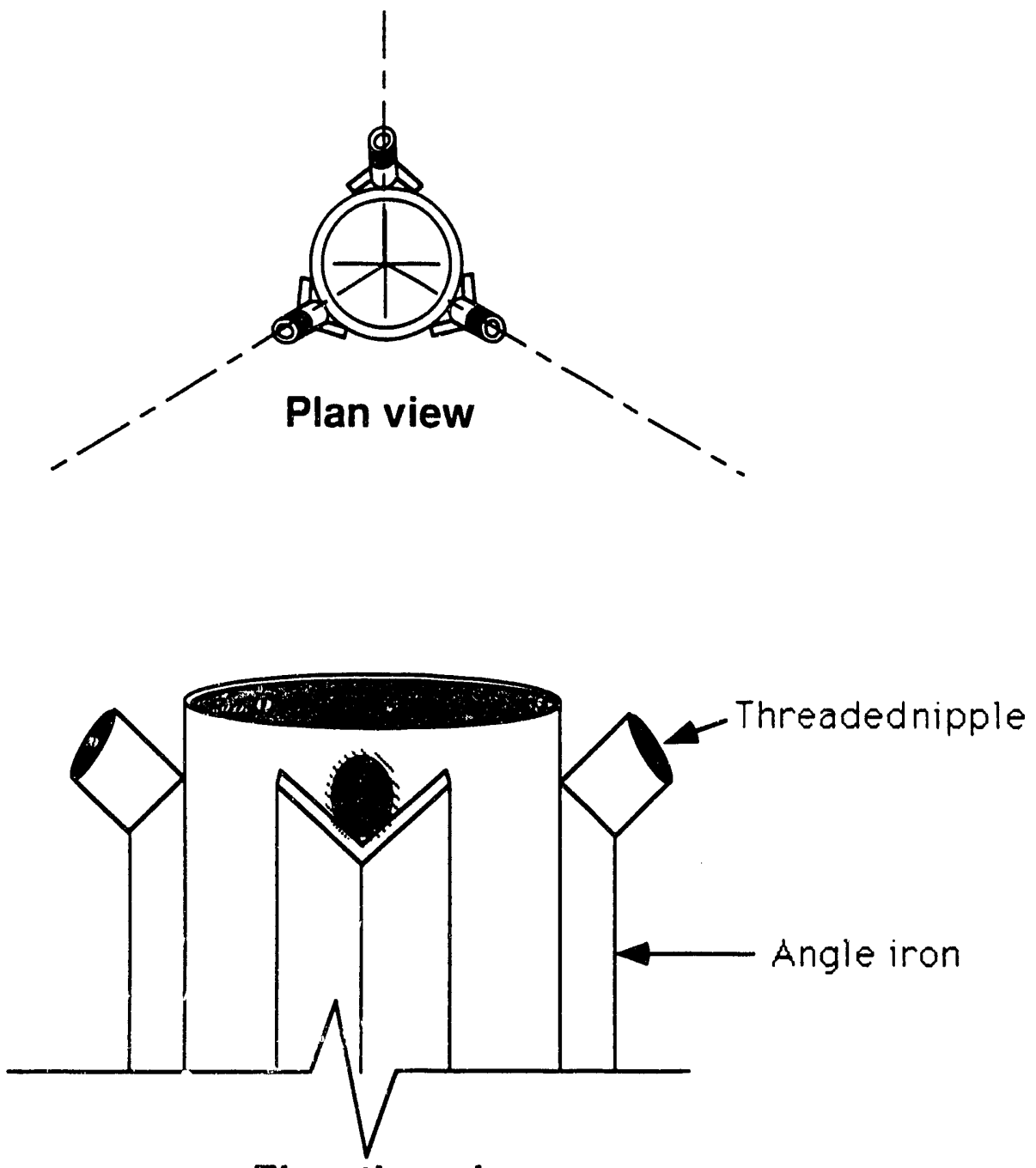

\section{Elevation view}

Figure 14. Water injection pipe cap. 


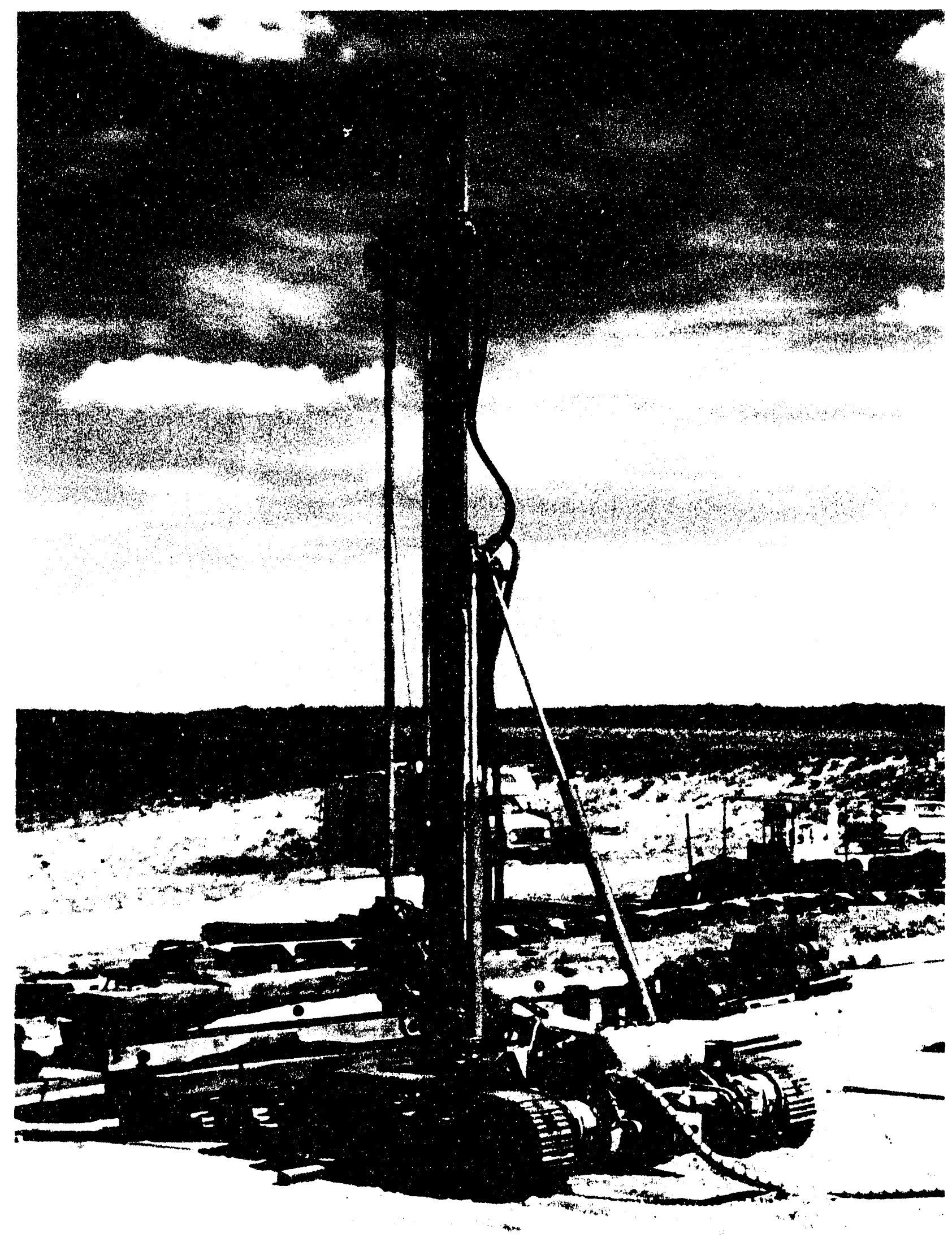

Figure 15. Vibratory drill. 
subsidence. Because of this requirement, much of the drilling is accomplished from timber mats that help to evenly distribute surface loads.

$\mathrm{LN}_{2}$ is stored in a tank and distributed to the freeze pipes through a feeder like the one shown in Figure 16. This storage and distribution system is provided by Air Products, a Sonsub subcontractor. The piping is designed to safely and efficiently deliver $\mathrm{LN}_{2}$ to the test pits. The piping has been insulated to help maintain thermal efficiency. Figure 17 shows the configuration of distribution piping for $\mathrm{LN}_{2}$ at the test pit. Copper tubing, stainless steel flex hose, and carbon steel fittings were used for this system.

\subsubsection{Freeze Pipe Arrangement for Stacked Barrels and Stacked Boxes Pits}

Figures 18 and 19 show the plan and elevation of the piping arrangement of the stacked barrels and stacked boxes pits. The configuration is similar to the freeze pipes in the first two pits. Each pit will have the following quantity of freeze pipes installed:

- $\quad 38$ carbon steel wall freeze pipes

- 14 stainless steel waste freeze pipes

- $\quad$ Nine stainless steel floor freeze pipes

- Four carbon steel floor freeze pipes

- 14 carbon steel water injection pipes.

As with the first pits, a steel collar is placed around each pipe within the perimeter of the freeze pit and the perimeter freeze pipes.

The 38 carbon steel and 14 stainless steel waste freeze pipes are identical in location and purpose as the first two pits (see Section 2.5.3). The main difference between these two freeze pits and the first two is the method in which the wet side of the pit is frozen. The front half of each of these two pits does not have water added, as was the case with the random dumped barrels and random dumped boxes and barrels pits. Previously, in the random dump pits, water was injected through a series of pipes and dispersed the fluid through the region to be frozen. In the latter two pits, the floor is frozen first, using the nine stainless steel and four carbon steel floor freeze pipes (see Figure 20). A line is threaded into the bottom section of the pipe and filled with $\mathrm{LN}_{2}$. The section filled with $\mathrm{LN}_{2}$ is about 2-ft long. These 13 floor freeze pipes are filled in this manner, and using the natural moisture in the soil, just the floor of the pit is initially frozen. Once temperature readings indicate the area is frozen, a small quantity of water is trickled in the 14 carbon steel water injection pipes. A series of moisture probes (discussed in Section 3) are below the frozen floor area. As water is introduced, these probes sense the flow of moisture below the bottom of the frozen floor region.

Varying quantities of water are added to the last two pits depending on how well contamination is controlled during the breakout of the first two pits. Currently, it is planned to saturate the random dumped barrels pit, add about 50\% moisture to the wet portion of the random dumped barrels and boxes pit, and probably add $25 \%$ and $10 \%$ moisture content to the stacked barrels and stacked boxes 


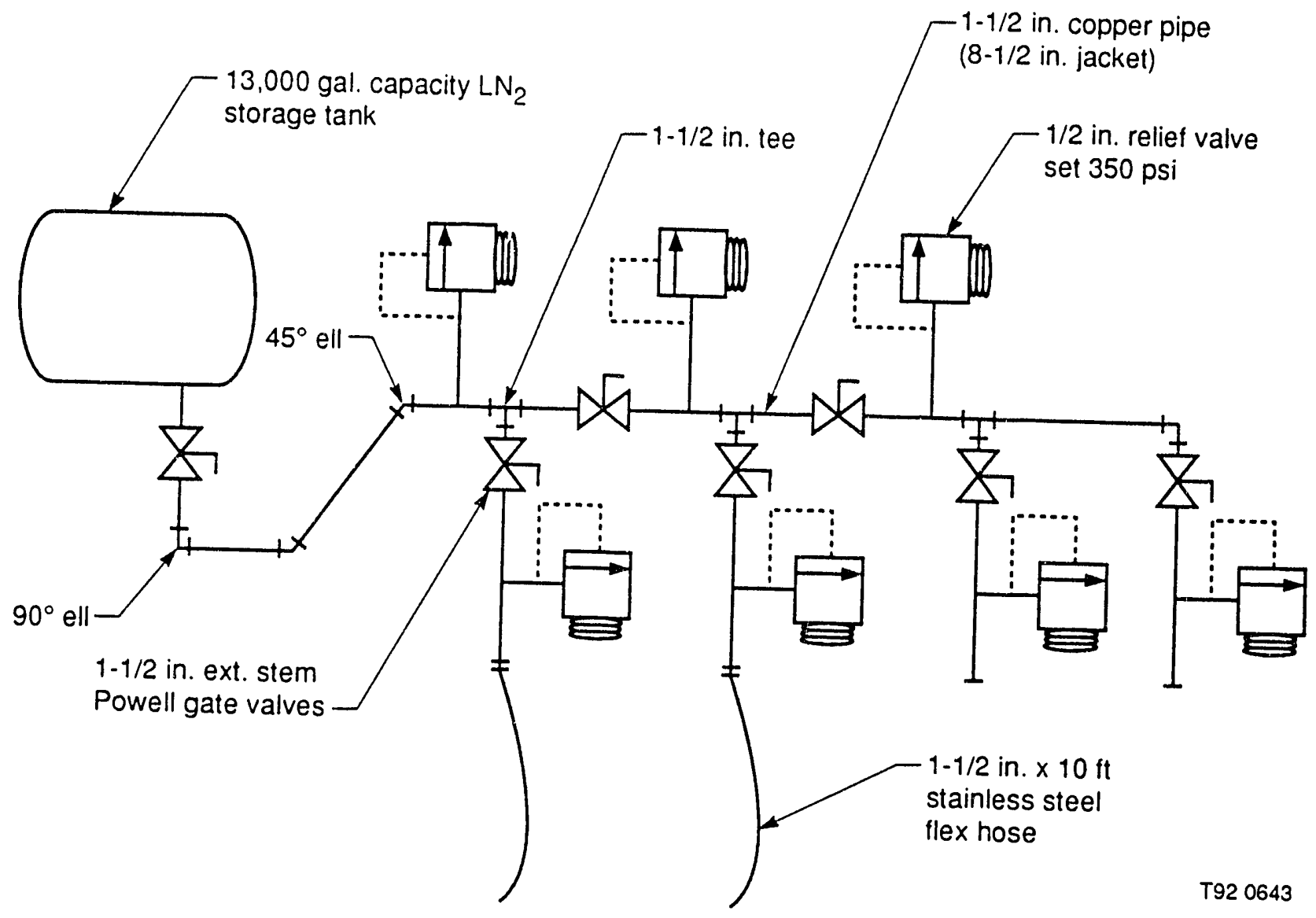

Figure 16. $\mathrm{LN}_{2}$ supply piping. 


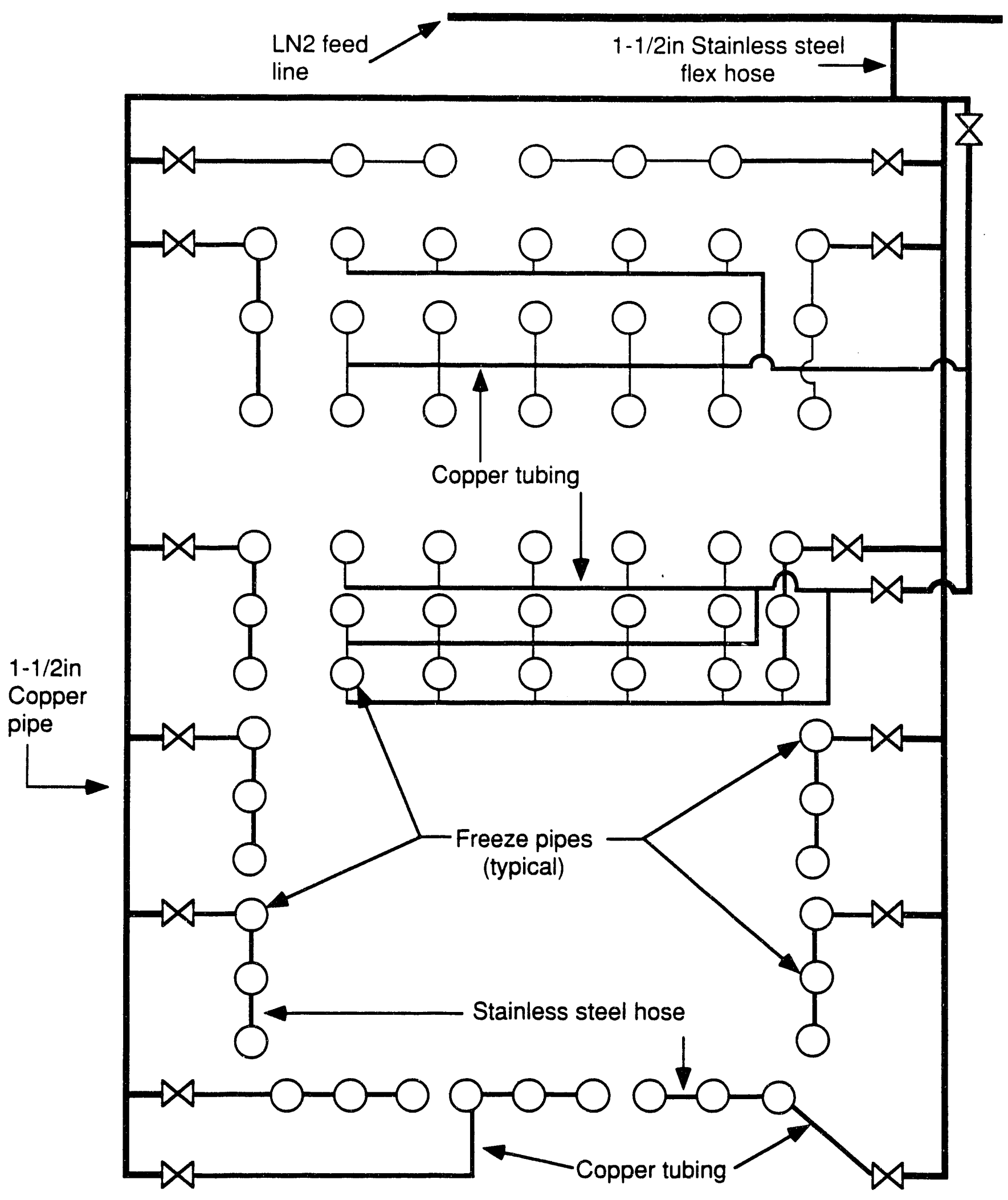

Figure 17. Typical freeze pit $\mathrm{LN}_{2}$ plumbing arrangement. 


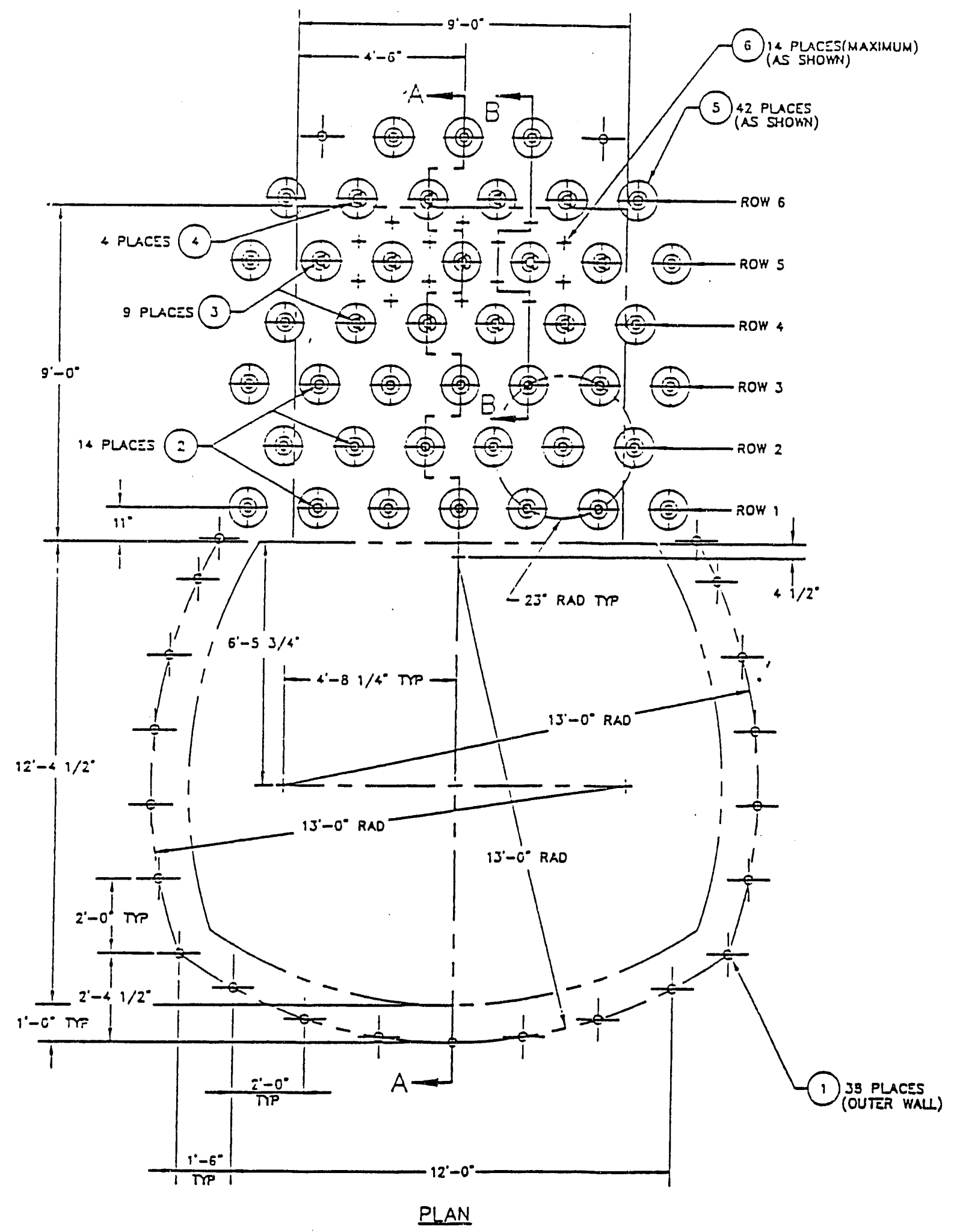

Sections $A-A$ and $B-B$ shown on Figure 19

$\otimes$ - call outs shown on Figure 19

Figure 18. Plan view of freeze pipes for stacked barrels and stacked boxes. 

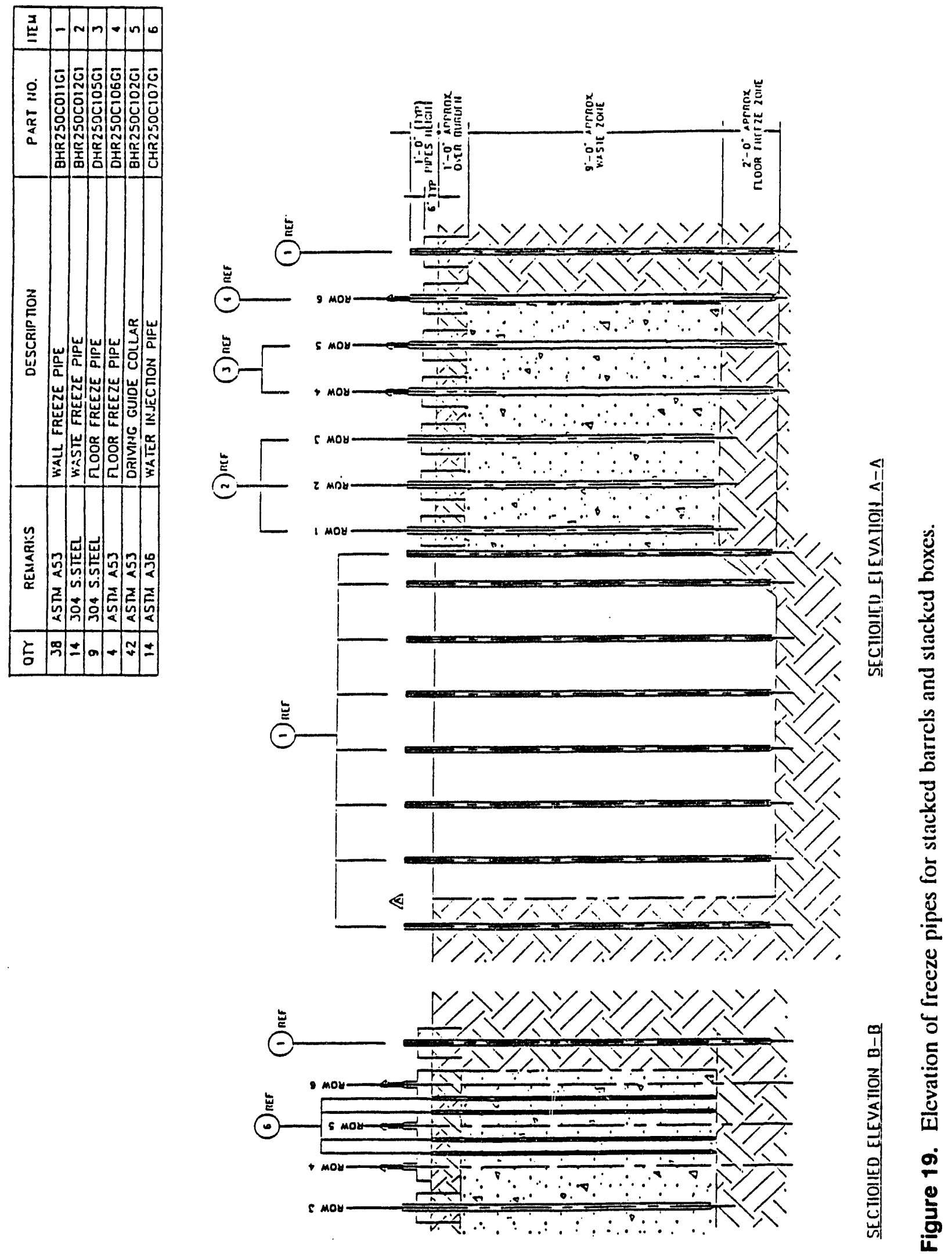


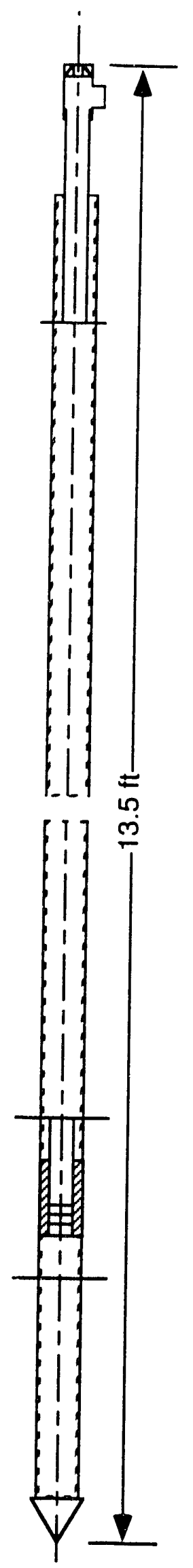

Figure 20. Floor freeze pipe detail. 
pits. The purpose of varying the quantity of water is to derive a basis for optimum moisture content while performing breakout and minimize the dispersal of contamination.

\subsubsection{Gantry and Remote Operated Tools}

After a pit has been frozen and the access pit excavated, the next step is to remove the frozen material and place it in storage boxes. This is accomplished by use of a gantry with bridge cranemounted remote operated tools. The tools are mounted above the work to minimize disturbing the soil and waste and potentially stirring up contamination, which would be the case if tracked or wheeled equipment were employed. The tools are remote operated because this is a safe and preferred approach to working in an actual contaminated environment. The remote feature removes personnel from direct exposure to potentially harmful contaminants.

The gantry is a large steel structure that is designed with two sets of crane rails and moved by means of skidding (see Figure 21). It has also been designed to withstand necessary operating loads, earthquake loading, wind, and weather. A tarp is placed over the gantry to create an enclosed and weather protected area. The tarp is a waterproof and fire retardant material. The tarp allows some natural sunlight to be emitted so there is good visibility during daylight hours. A separate lighting system is also included in the gantry, and a light is mounted on each of the tools. This lighting is sufficient to operate the system at night.

The breakout tool is shown in Figure 22. It consists of two large diameter hydraulically driven cylinders that develop a total of 340 tons of force. This tool is positioned to capture one pipe collar (see Figure 23) and is then extended to pry or force frozen columns of soil and waste away from the main block. This tool is mounted on the lower bridge crane and can be moved as required to locations inside the gantry, adjusted vertically, and rotated. This tool was custom designed and built for this project, although it was supplied by a firm that routinely fabricates large hydraulic cylinders.

The jackhammer (see Figure 24) is a 60 horsepower (hp) hydraulically driven unit that is used to chip and break frozen waste. This tool is provided under a subcontract from Louis Grant, Inc., a Pennsylvania firm, to Sonsub. The jackhammer comes equipped with several hardened steel bits for different types of soil and simulated waste that may be encountered during the demonstration. This equipment is capable of telescoping, rotating, and articulating into a full range of motion. The bridge crane that this equipment is mounted on is not self powered, rather, the jackhammer is used to drag itself and the crane into working position. The jackhammer is mounted on the gantry lower bridge crane rail.

Figure 25 depicts the cutting shears. This equipment is capable of producing up to 1200 tons of cutting force. The shear is mounted on a bridge crane from the gantry upper bridge crane rail. This equipment is capable of being moved almost anywhere inside of the gantry and can be rotated both horizontally and vertically. It can cut through schedule 4012 -in. mild steel pipe, small plate, concrete, frozen soil, and other types of debris that are expected to be encountered during the demonstration. The shear is a commercially available piece of equipment that is typically used in junkyards and salvage operations. It is hydraulically powered.

The last tool, the grapple (see Figure 26) is used to load debris from the bottom of the access pit into storage boxes. This tool is likewise a commercially available item that has been slightly 


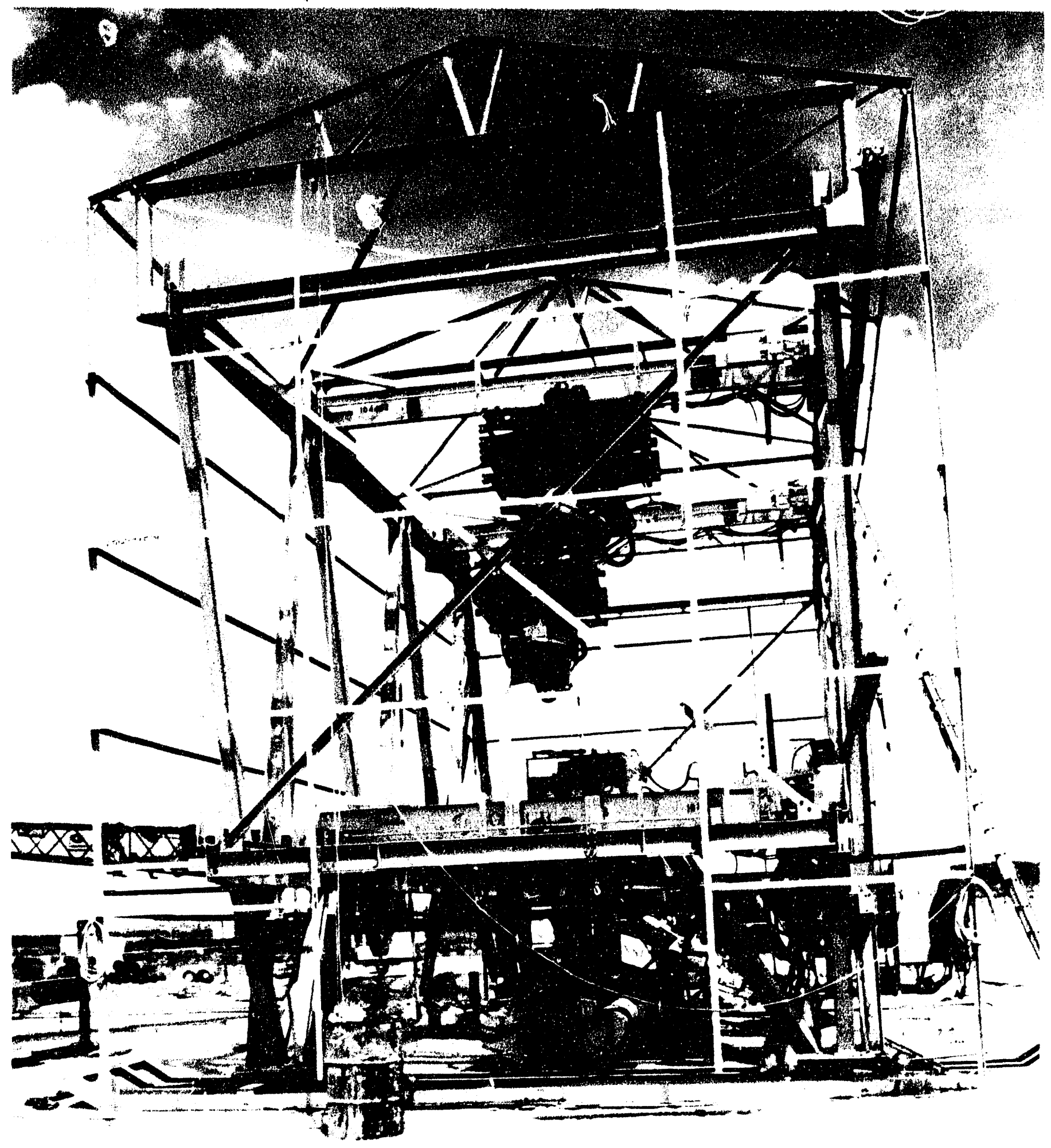

Figure 21. Gantry. 


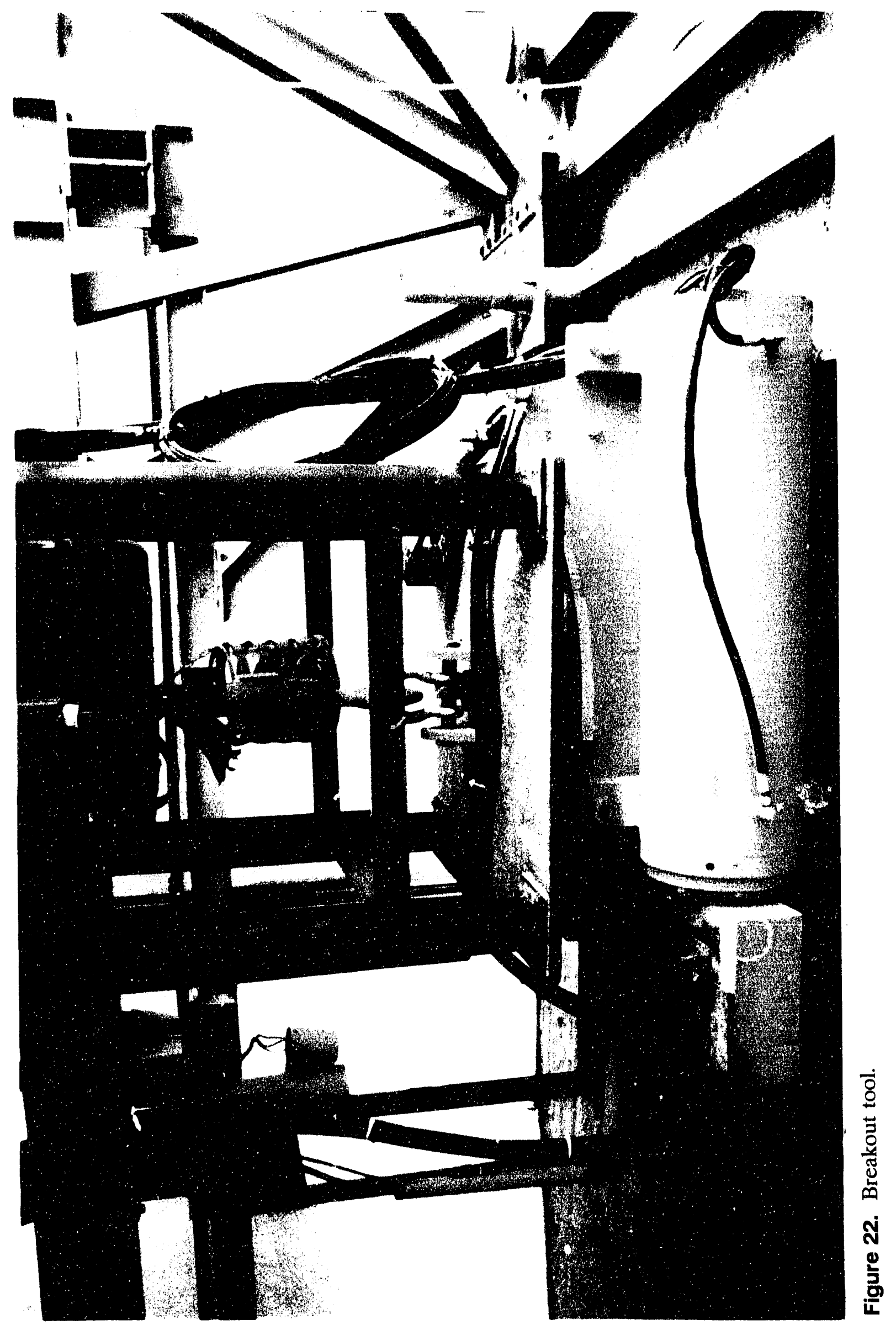



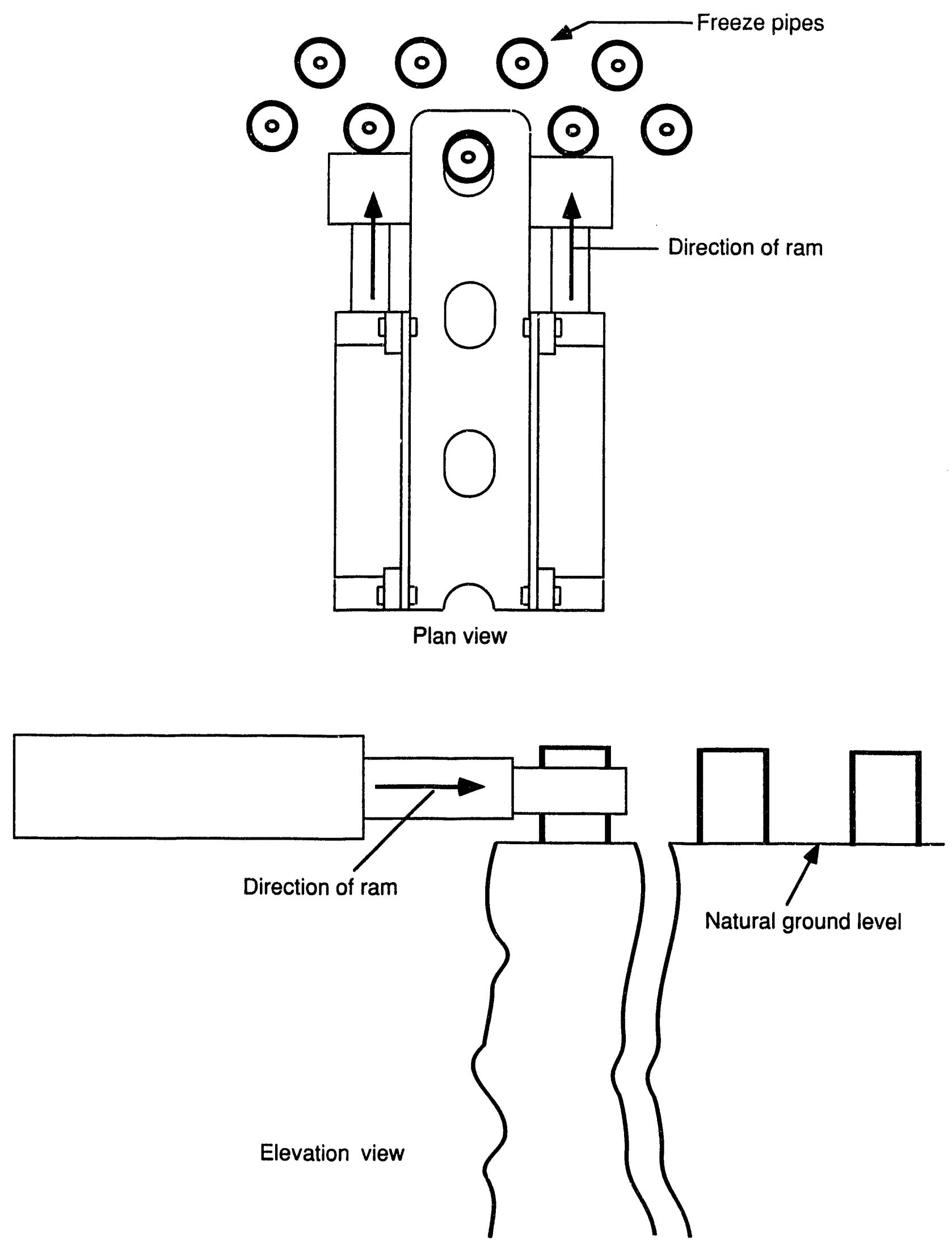

Figure 23. Function of breakout tool. 


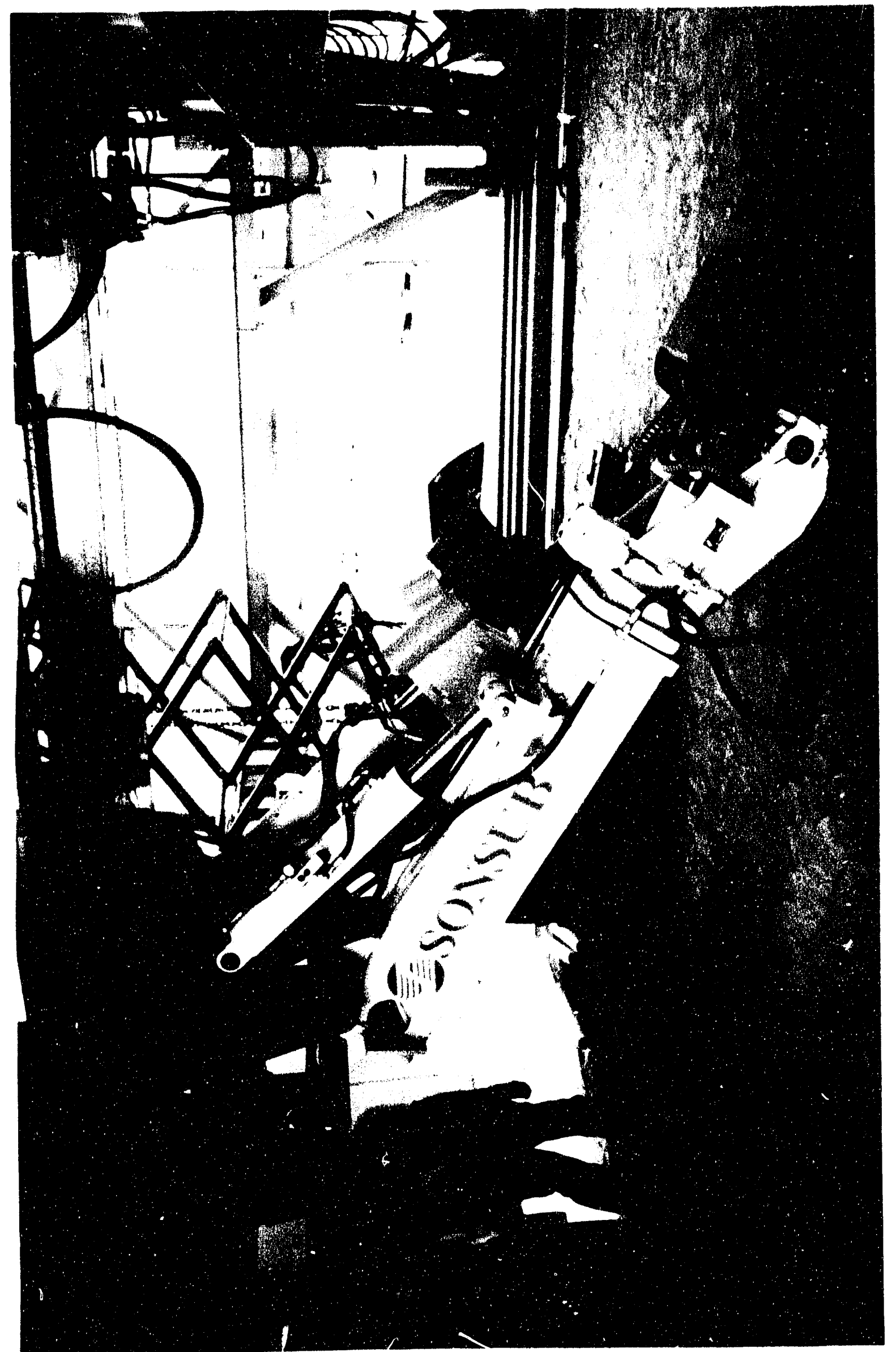

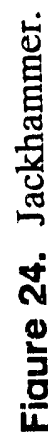




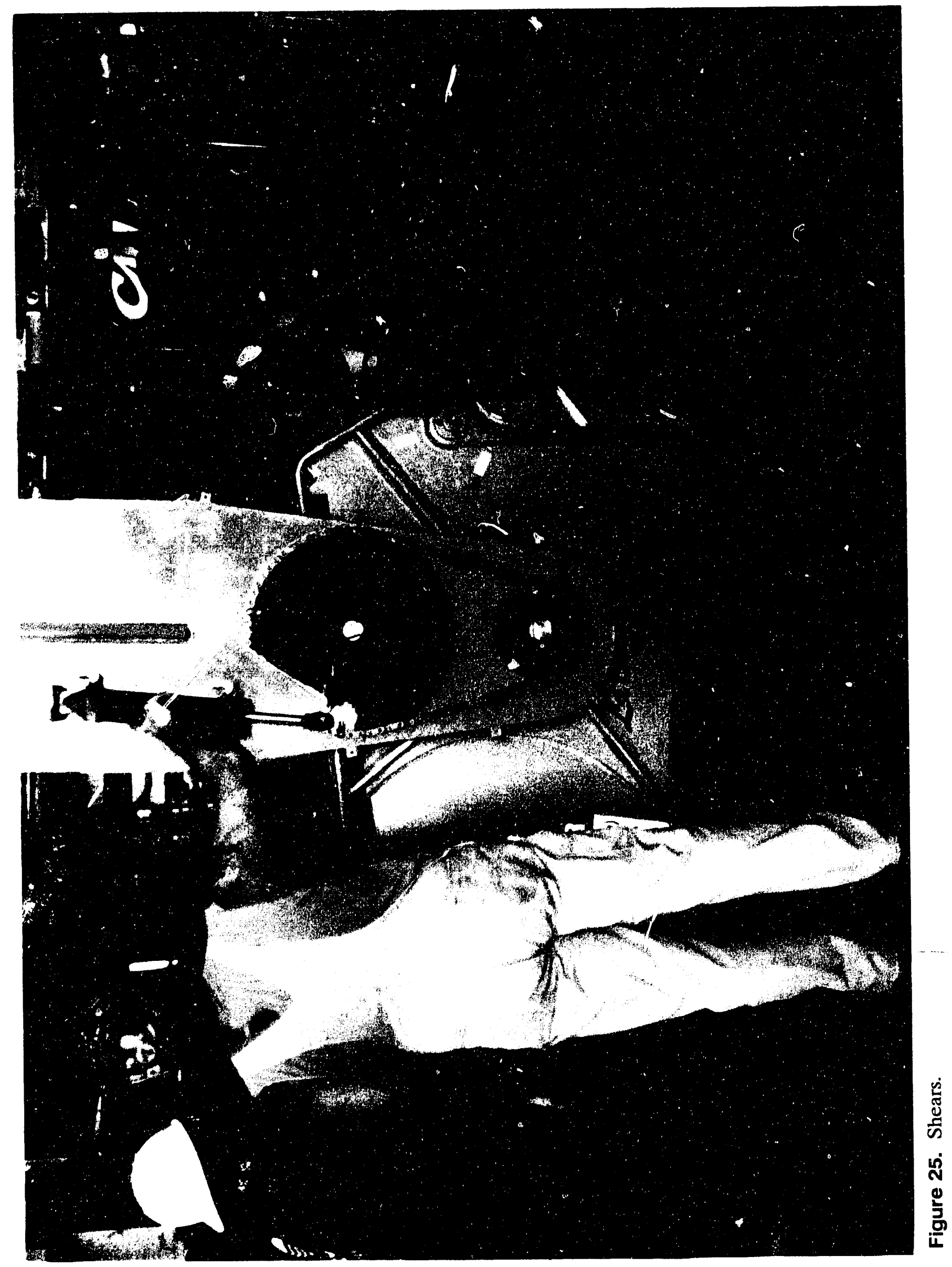




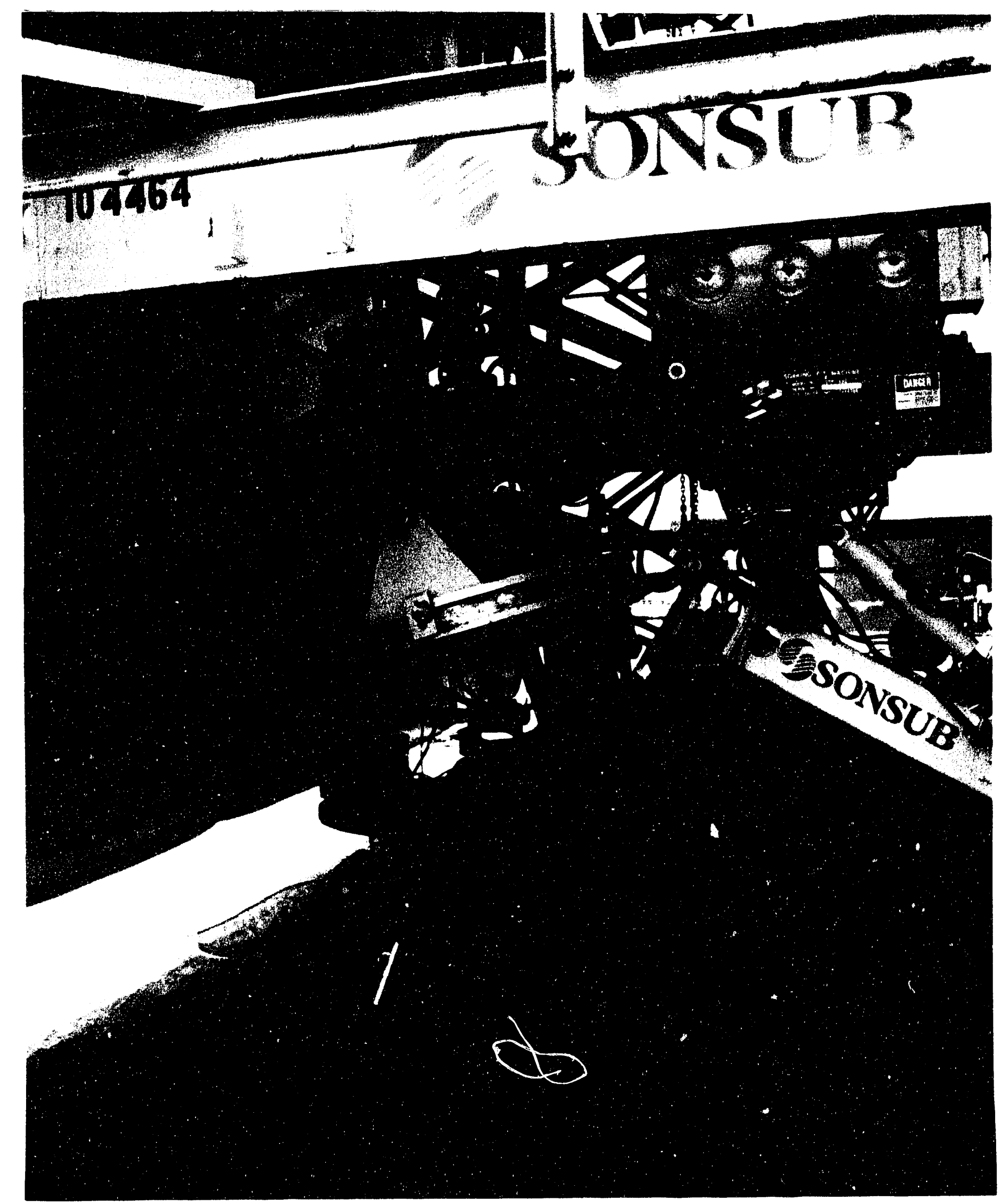

Figure 26. Grapple. 
modified for use in this demonstration. The grapple is bridge crane mounted from the upper crane rail on the gantry. It has a full range of motion and is hydraulically powered. The grapple is capable of lifting about $1 / 4$ yd of material, although because of the way the debris will be retrieved, it is not likely that much material would be handled at one time.

All of the tools have been sized to handle design loads and are hydraulically powered. A $50 \mathrm{hp}$, $440 \mathrm{~V}, 80$ gal capacity hydraulic power unit is used to drive the shears, grapple, and breakout tool. The jackhammer is provided with a separate hydraulic power unit. Each unit develops around 3000 psi of operating pressure. The hydraulic fluid used in both units was selected for performance and safety. It is a nonhazardous and nonflarnmable vegetable oil based fluid that is not harmful to people or the environment.

A skid arrangement has been developed to move storage boxes in and out of the gantry. A storage box is set on the skid and moved inside of the gantry through an air lock. Once a storage box is inside, it is filled with debris and skidded back outside. A forklift removes the box and a new one is set in place. Figure 27 shows the arrangement of the skid and a storage box. The storage boxes are a standard DOE design $(4 \times 4 \times 8 \mathrm{ft})$ and are made of plywood and framing lumber. They are capable of holding about $6000 \mathrm{lbs}$. For the field demonstration, a maximum of 15 boxes per pit are used, or a total of 60 boxes. At the conclusion of the field work, these boxes are stacked at the north end of the existing cold test pit to form a sixth cell. This cell will be used for testing and demonstrating equipment and training operations personnel involved with the retrieval of the Transuranic Storage Area (TSA). Once the boxes are in place (see Figure 28), they are covered with plastic sheeting and dirt.

The gantry has been designed to be skidded into position over the test pits to be excavated. After the gantry is assembled and all tools are in place, it is moved using a winch. Before actually moving the gantry, a runway constructed of steel plate and low friction high density plastic is placed on the ground. The ground has been previously leveled, and the runway is moved in front of the gantry as it is advanced by the winch. Figure 29 shows the basic set up of how the gantry is rigged and moved into position.

\subsection{Control System}

The gantry tools are controlled by two control stations, and input/output (I/O) module control box, a central power control station, and a 19-in. rack containing the Pan and Tilt (P\&T) camera controllers, a custom video switcher, and two each quad monitor racks (see Figure 30). The two control stations are identical and consist of a right hand joystick that controls the bridge/trolley functions and P\&T camera, left hand joystick that controls the tool functions, a tool select switch that selects the specific trolley and tool the station is controlling and which camera is displayed on the control station tool monitor, and camera select switch that controls which video camera is displayed on the control station monitor and which P\&T camera is being controlled by the right hand joystick. Inside each control station is a printed circuit board that translates the joystick outputs to digital logic levels and performs interlocking on some functions to prevent logic conflicts if contradictory commands are given (two or more mutually exclusive switches are pressed). The two control consoles are connected to the tool $\mathrm{I} / \mathrm{O}$ module box. 


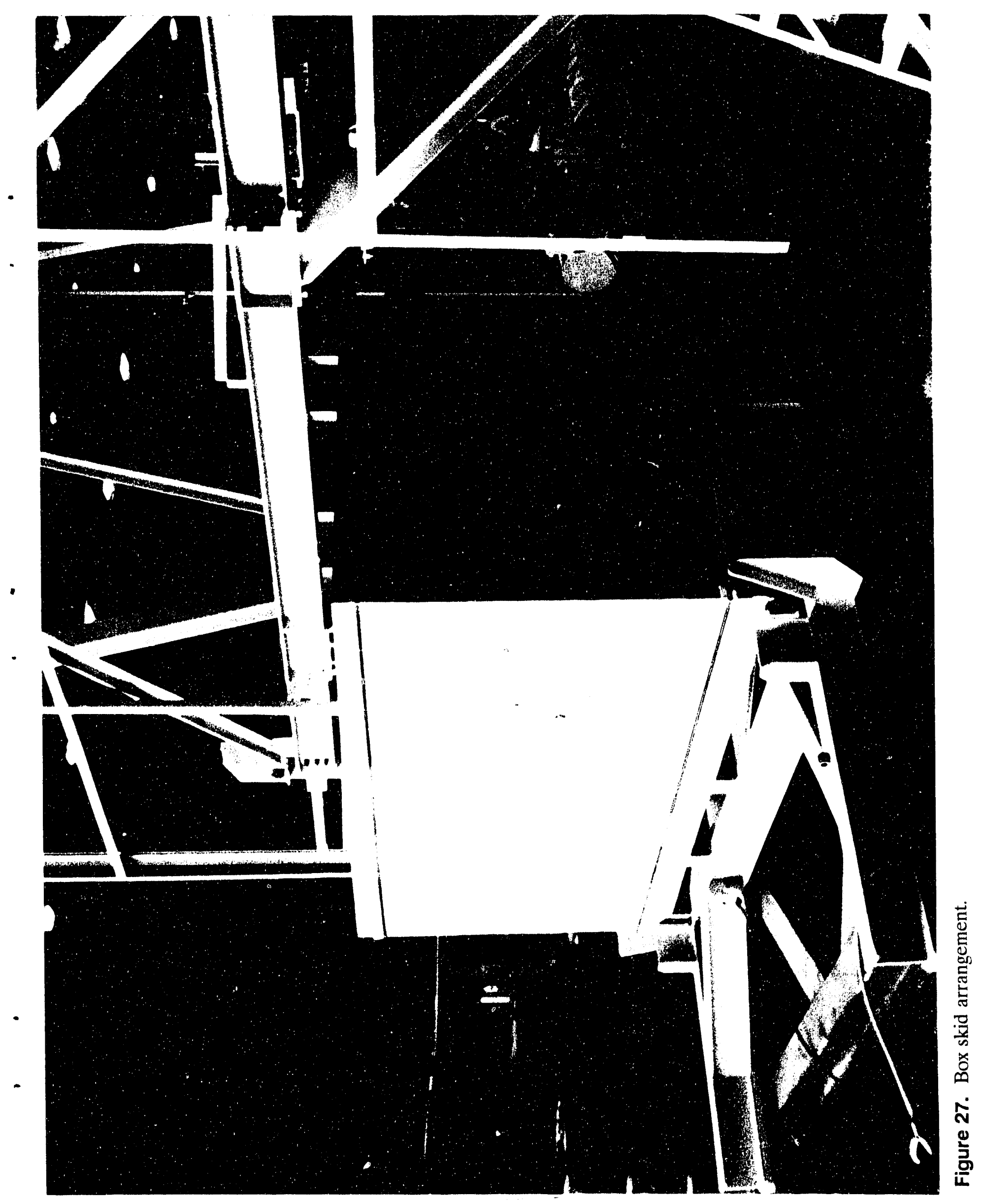


Existing random

dumped barrels cell in cold test pit

$\checkmark$

v

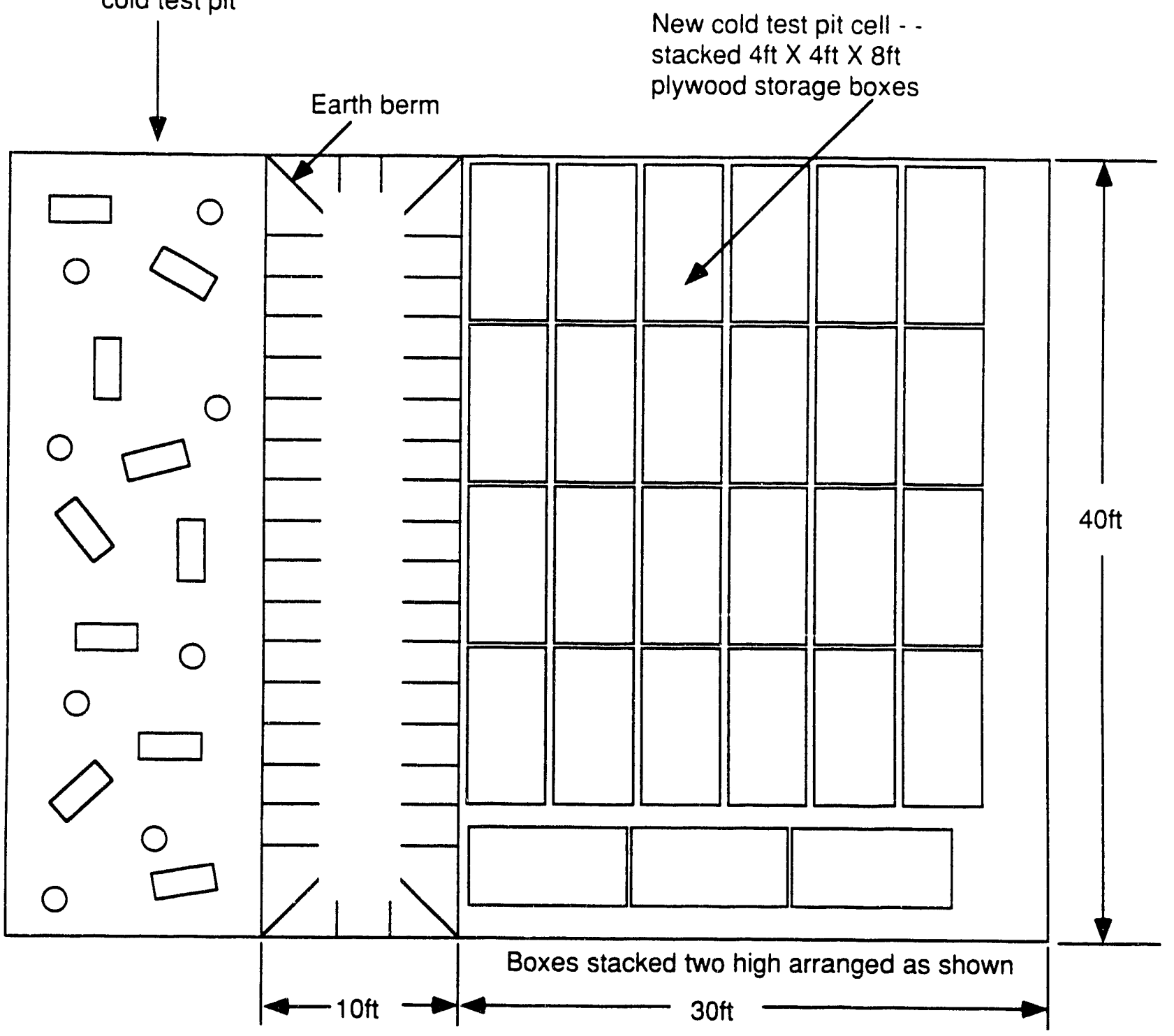

Figure 28. New cell at cold test pit. 


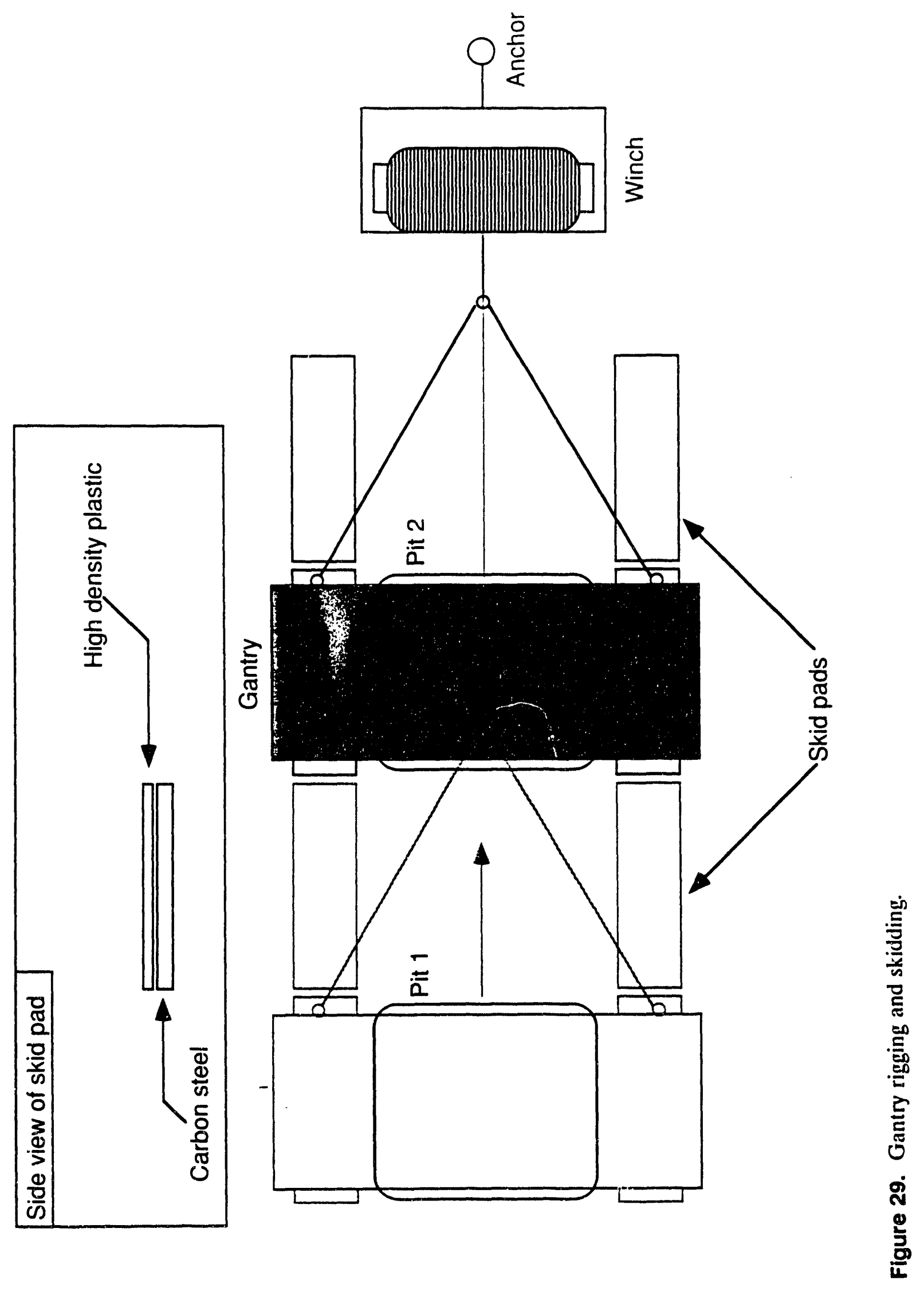




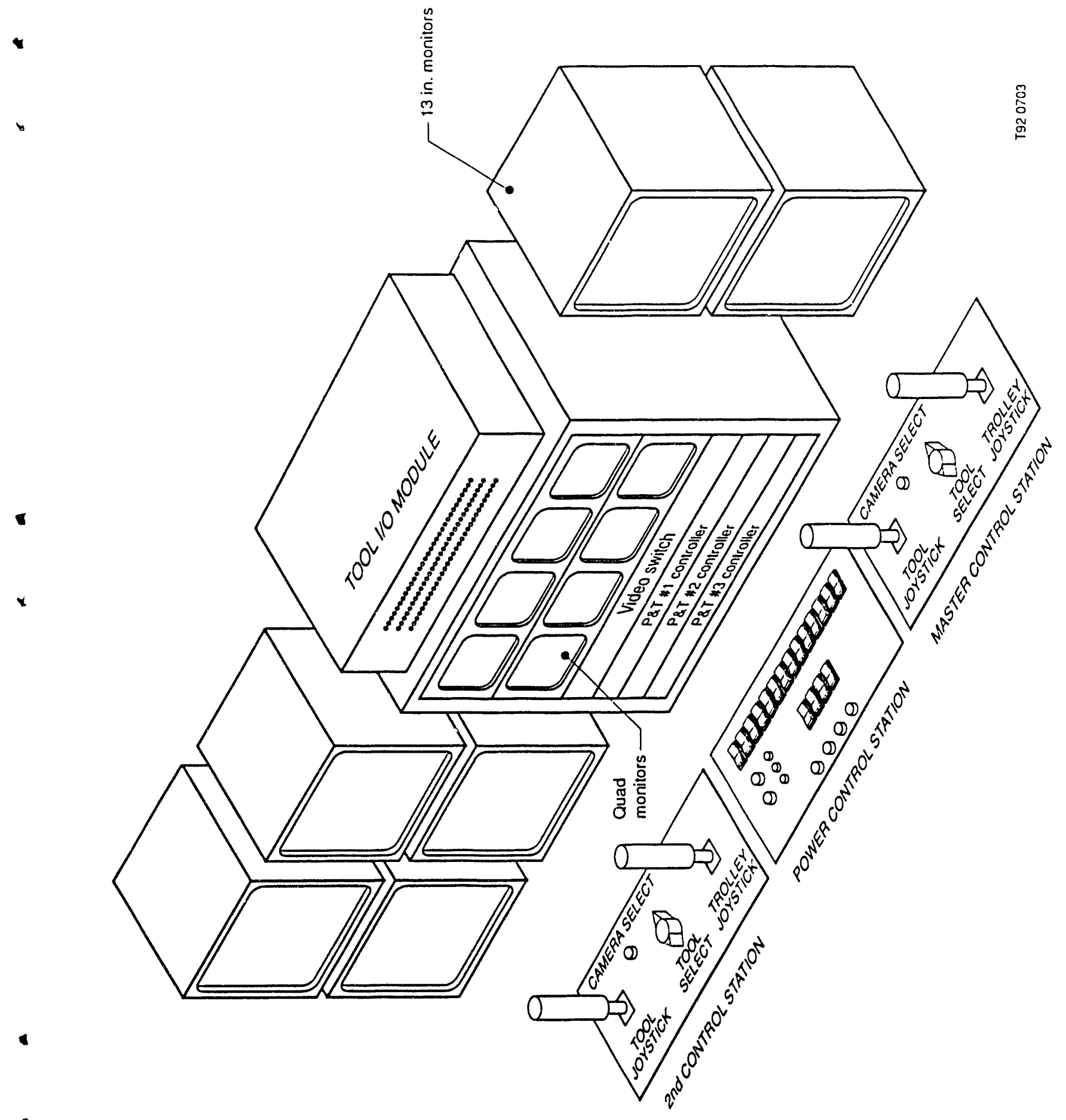

疍 
The tool I/O module box contains the necessary logic board that determines which tool each control console is operating. The tool sclection is set up on a master selection basis so that the \#1 control station has priority on tool and P\&T camera selection. The \#2 control station must choose one of the other two tools available. The $\mathrm{I} / \mathrm{O}$ module box also performs the video selection logic that is then routed to the custom video switcher via a 25 pin interconnect cable. The tool $\mathrm{I} / \mathrm{O}$ module also contains the driver modules that switch the $115 \mathrm{~V}$ control signals from the logic level signals. There is one $\mathrm{I} / \mathrm{O}$ back plane lor each tool trolley. Each back plane is capable of switching 16 each 115 volts aiternating current ( $V a c$ ) control signals. The tool $\mathrm{I} / \mathrm{O}$ module box interconnects to the gantry distribution box via a 50 pin interconnect cable.

The center power distribution console consists of 18 breaker switches for power control. These breakers control individually the power distribution for the tool camera, tool lights, P\&T cameras, and the two gantry lighting banks. ON-OFF control and alarm status for the gantry Hydraulic Power Unit (HPU) is included in the center console, and four channels of video output selection is made from the center console. Two of the video controls are for the optional fourth tool (the jackhammer), and the other two channels are used for video cussette recorder (VCR) recording selection. The center console interconnects to the gantry distribution box via a 24 pin cable and interconnects to the gantry HPU via a 9 pin cable.

The 19-in. rack console contains the three P\&T control units, custom video switcher, and two quad monitor racks. All video from the gantry cameras comes to the center console where it is switched out on a selection basis to the proper monitors.

The gantry distribution box accepts the 50 pin interconnect cable from the tool I/O box and the 24 pin interconnect cable from the center power distribution control console and breaks out the signals to a 24 pin interconnect cable for each trolley and 4 pin interconnect cables for the P\&T cameras and light banks. The distribution box also serves as a tie-point for all camera video signals.

The block diagram in Figure 31 depicts the control system and the interface with field equipment.

The video and camera syster jonsists of a camera attached to each tool (total of four tools/four cameras), three P\&T cameras with zoom lens attached to the gantry structure and one wide angle lens camera mounted on the structure. Any one of the cameras may be switched so that the particular view is recorded on one of two VCRs. The arrangement of the cameras gives good visibility for virtually all operations and remote activities. Each tool is also equipped with a separate light, and a bank of high intensity lighting is mounted on either side of the gantry. The lighting is adequate to perform work during nondaylight hours. 


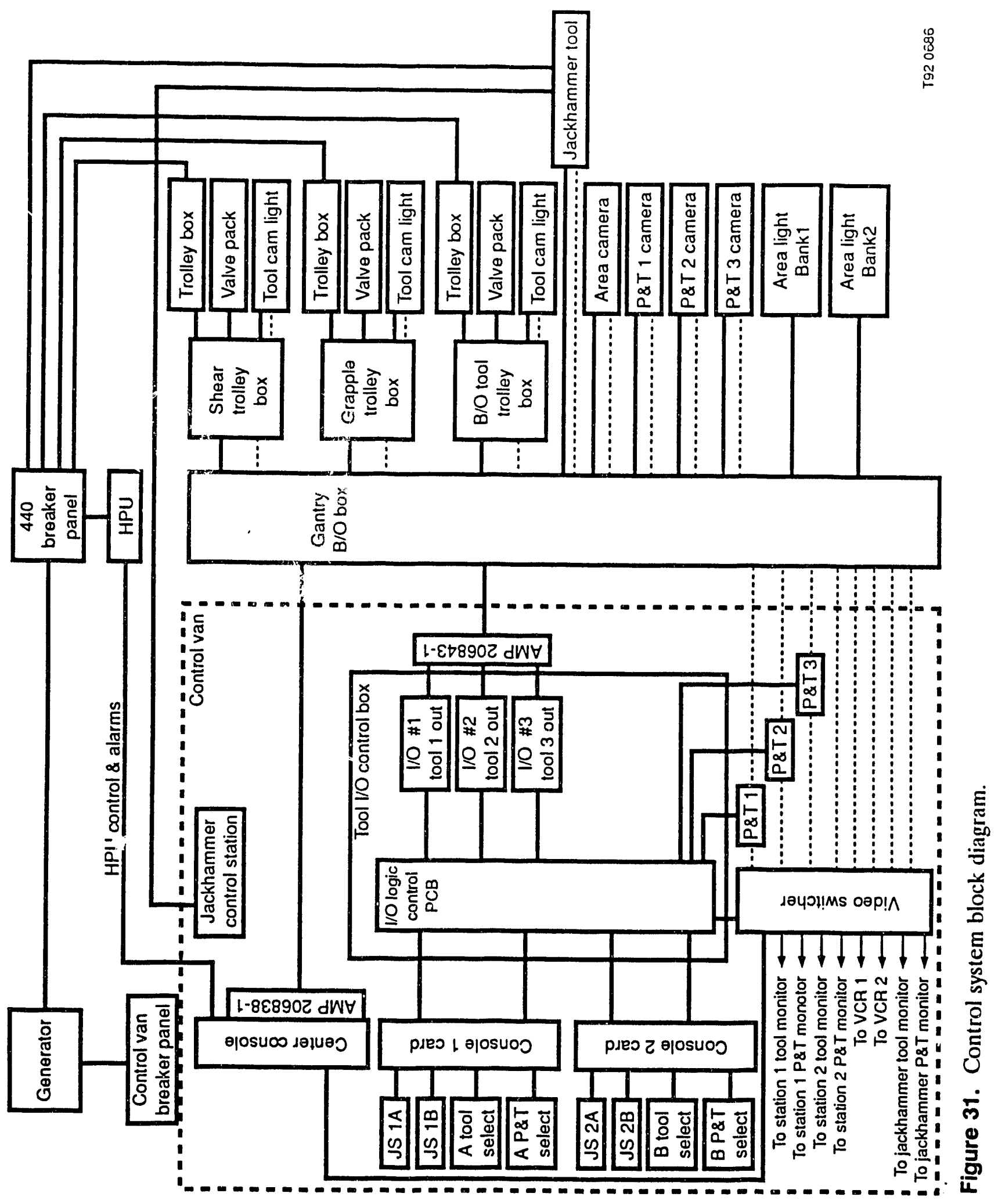




\section{TESTING AND MONITORING}

Three physical parameters were monitored throughout the demonstration to determine its suceess in meeting the established criteria outlined in the RFP. These parameters were the spread of rare earth tracers during the demonstration, migration of water added to the "wet" portion of the pits. and temperature distribution throughout the pits.

\subsection{Air Monitoring}

A potential advantage of cryogenic retrieval is that aglomoration of dust particles into larger particulates minimizes the aerosolation of dust and thus the airborne radioactive particle released (from a contaminated buried waste site). To take quantitative measures of the dust aerosolation, air monitoring stations were set up around the gantry. The monitors collected dust during the demonstration. The filters were removed after each portion of the demonstration and sent to the INEL Environmental Chemistry Unit to be analyzed for the presence of rare earth tracers on the filters. Each zone of the cold test pit was spiked with a single rare earth tracer as listed below: ${ }^{c}$

\author{
Stacked boxes \\ Stacked barrels \\ Random dumped barrels and boxes \\ Random dumped barrels
}

$\begin{array}{lr}\text { Neodymium oxide } & 630.0 \mathrm{~g} \\ \text { Terbium oxide } & 15.5 \mathrm{~g} \\ \text { Ytterbium oxide } & 116.0 \mathrm{~g} \\ \text { Dysprosium oxide } & 40.5 \mathrm{~g}\end{array}$

The Data Quality Objective (DQO) for the air monitoring and filter analysis were to determine if the levels of tracer on each of the filters were above the natural background level for each tracer. The term "level" was quantified as the ratio of micrograms of tracer on the filter to the total grams of residue on the filter. This quantity is abbreviated as parts per million (ppm).

\subsection{Establishing Baseline Data for Air Monitoring}

Twenty-four air samples were collected on the SDA during March and April 1992 to establish the background levels of the tracers on the filters. ${ }^{d}$ These background samples were analyzed using Inductively Coupled Mass Spectrometry (IDC-MS). IDC-MS was also used to analyze the samples taken during the demonstration. A statistical analysis was done on the data from this background sampling to determine the maximum amount of each tracers that could have been generated from the natural background. See Appendix A, "Summary of Statistics for Background Measurements," for the results from this background study and the statistical analysis.

c. Engineering Design File, G.G. Loomis, Design and Construction Details of the INEL Simulated TRU Test Pit, BWP-151-009, EG\&G Idaho, Inc., March 1989.

d. Internal Technical Report, M. R. Winberg, E. L. Yokuda, Test Plan for Background Air Sampling of Rare-Earth Tracers on the Subsurface Disposal Area, WTD-92-36, EG\&G Idaho. Inc., March 1992. 


\subsection{Air Monitoring During the Demonstration}

The air monitoring during the demonstration incorporated 10 low volume air samplers spaced along the north and south side of the gantry (see Figure 32). Each air monitor held a single 47-mm glass tiber filter. The filters were to be changed after excavalion of the dry section of each zone and after excavation of the wet section for each zone. A background sample was taken before excavation began on each dry and wet portion. The background samples were taken with high volume air samplers. ${ }^{2}$

\subsection{Data Quality Objective for Moisture Monitoring}

The DQO for the moisture monitoring was to determine if the water added to moisten the wet side of each pit could be contained within the pit. While establishing the DQO, it was assumed that if water was to breach the pit boundary, it would most likely tlow down through the bottom of the pit tloor. The wet side of each pit was instrumented with tour moisture probes. The moisture probes were to be driven down to a depth of $14 \mathrm{ft}$, approximately 4 -ft below the bottom of the waste (see Figures 33 and 34 . The DQO for the probes was that each probe should be capable of recording at least a $10 \%$ rise in soil moisture content for example. a rise from 20 to $30 \%$ soil moisture content.

\subsection{Description of the Time Domain Reflectometry Used for Moisture Monitoring}

The instrumentation used for the moisture monitoring was Time Domain Reflectometry (TDR). This technology was chosen because Sonsub was familiar with using TDR technology for fault detection in cables. A TDR cable tester measures the change of impedance of a cable by sending a pulse down the wire and measuring the reflected energy caused by the impedance change. Thus a change from one impedance level (i.e., normal cable impedance) to a higher impedance level (i.e., a break in the wire) will cause more signal to be reflected back to the TDR instrument. Conversely, a change to a lower impedance level (i.e., a short in the cable) will dampen the reflections. A cable that is terminated with a matching impedance will not reflect any signal back. The further away the fault (impedance change) is located, the more time is taken for the signal to reflect back to the cable tester. The amount of reflected signal as well as the distance to the reflection are displayed on an liquid crystal display graphics display with the vertical deflection representing the amount of reflected signal and the horizontal deflection representing distance. The same basic physical principles that are employed by a TDR for fault detection are used for moisture monitoring. However for moisture monitoring, a uniauely designed probe end was employed to terminate the end of the cable. The probe end was calibrated to give a known impedance reflection in dry soil. Thus, a baseline impedance was established. As the soil moisture increases, the dielectric constant decreases, changing the impedance between the probe contacts. For moisture measurement, fixed lead lengths between the TDR tester and probes were used. This allowed the display to be used with several different probes without being adjusted. ${ }^{3}$

To automatically log the TDR signal as a digital readout of soil moisture content, a Campbell Prom OS106720 was used. This device digitizes the TDR output into a numerical output, which is converted to a moisture reading in the personal computer (PC). More detail on the Campbell data logging system is given in the test plan in Appendix B, "Test Plan for the Cryogenic Retrieval Demonstration." 


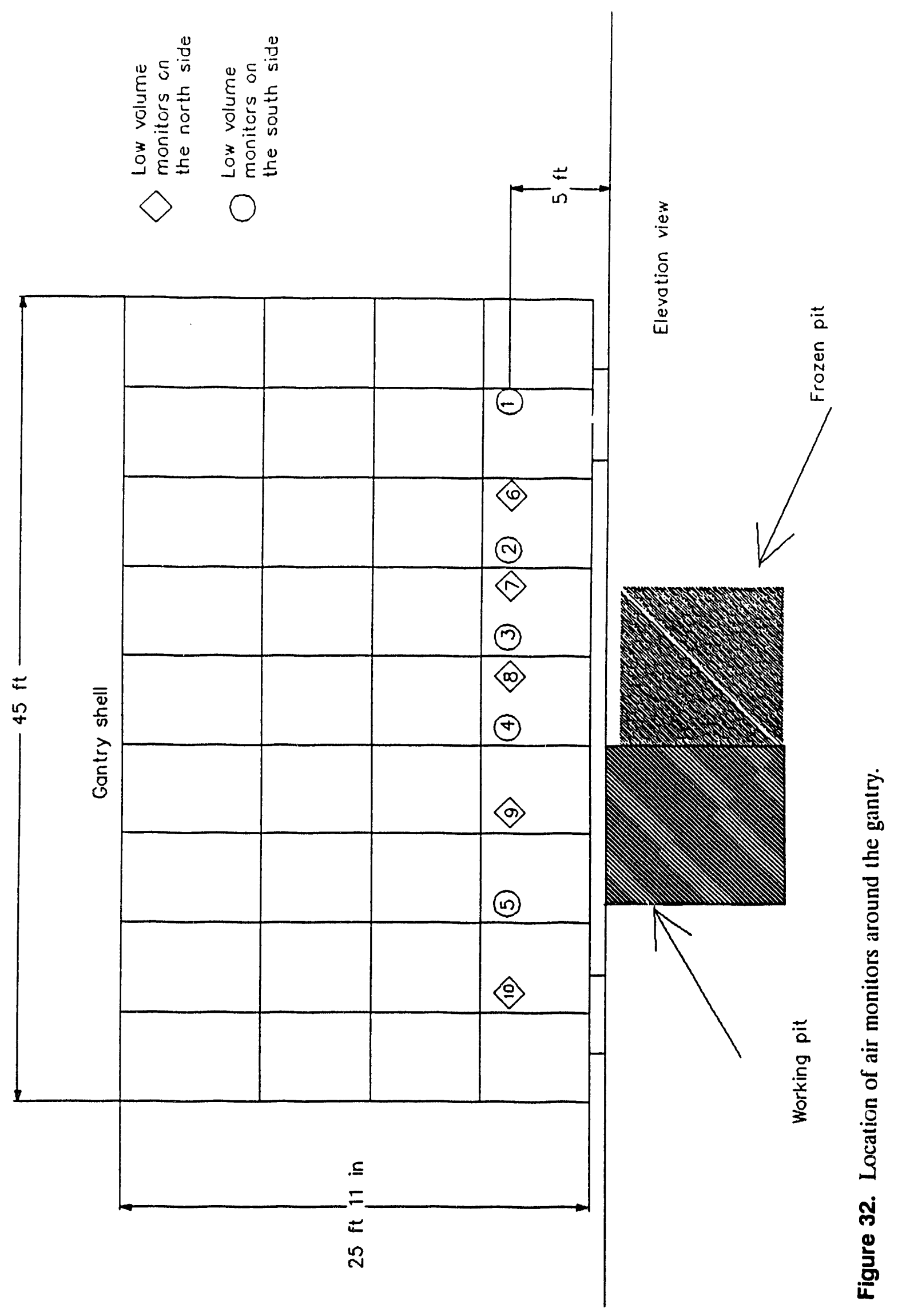




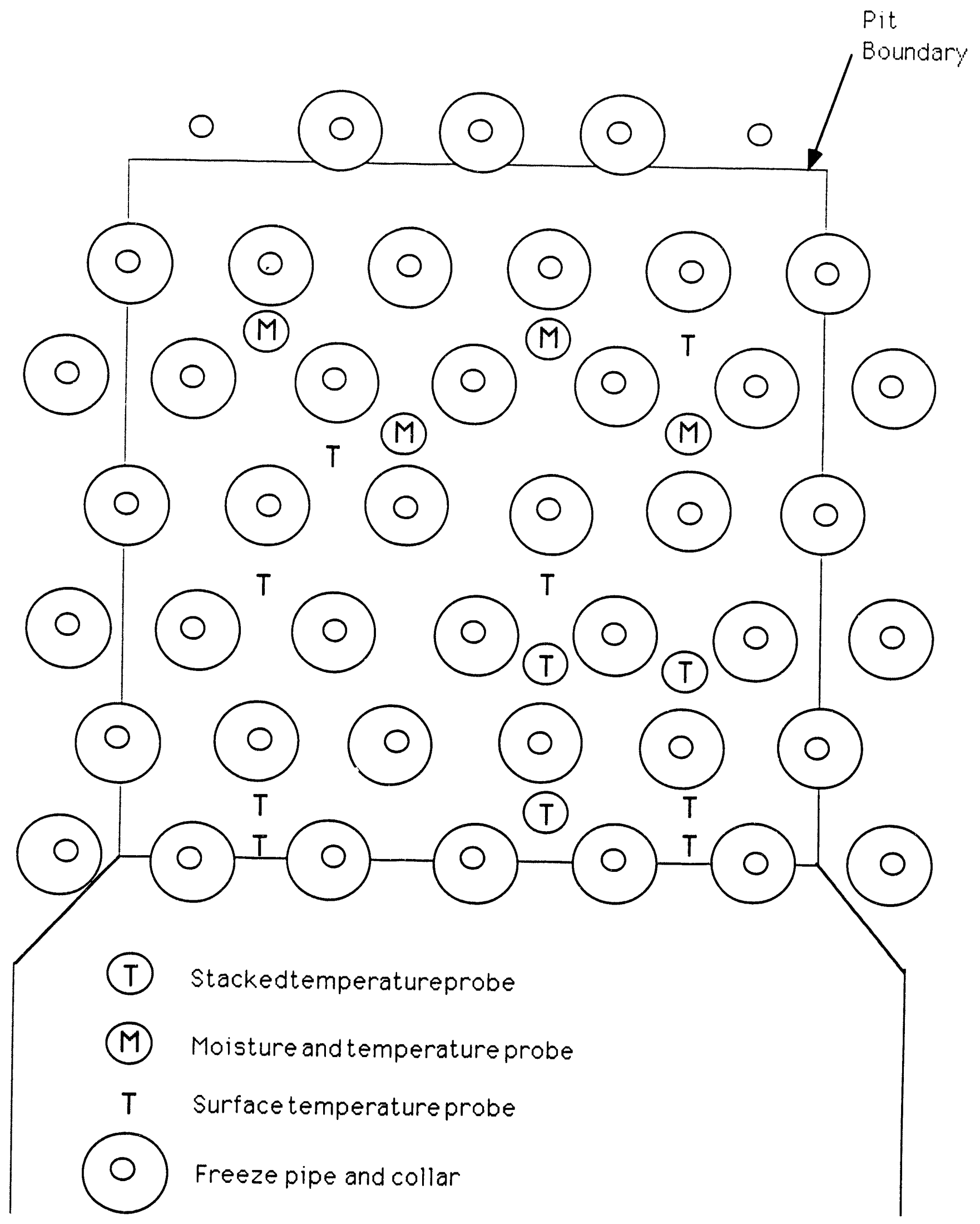

Figure 33. Top view of pit with the location of moisture and temperature probes. 


\section{Moisture/temperature probe}

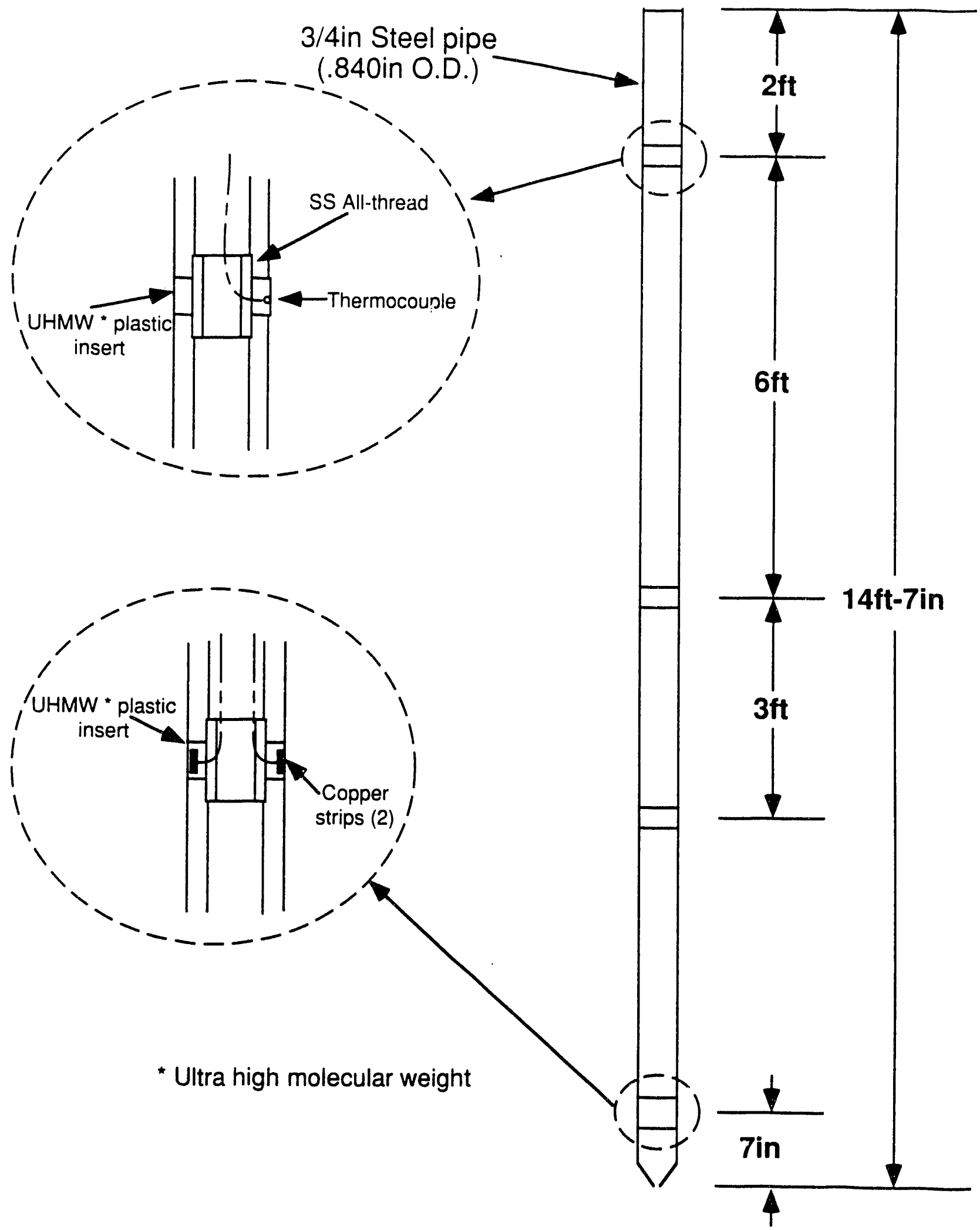

Figure 34. Side view of moisture/temperature probes. 
The greatest challenge of instrumenting the demonstration was to develop a TDR probe that would be resilient enough to be driven into the ground in the same manner that the freeze pipes would be placed. Sonsub developed such a probe. The new probe is simply two copper strips imbedded in a plastic collar on the pipe that was driven into the ground (see Figure 34). The width of the gap between the copper strips is critical for calibrating the TDR probe for the proper lead length. Predemonstration tests indicated that the probes would work at least well enough to satisfy the DQO (see Appendix C). See Section 7 of this report for results from the different zones during the cryogenic retrieval demonstration.

\subsection{Temperature Monitoring}

Type $E$ thermocouples were distributed throughout each pit to monitor the freezing, (see Figures 34 and 35). Thermocouple probes were divided into two categories, surface probes and stacked temperature probes. The surface probes were conventional 1-ft. long thermocouple probes that were pushed into the soil by hand to a depth of 10 in. Data from these probes were to be used to determine when the surface soil reached the required $-20^{\circ} \mathrm{C}\left(-4^{\circ} \mathrm{F}\right)$ for the breakout of the waste to begin. The stacked temperature probes were embedded into the pipes that were driven into the ground (see Figures 34 and 35). Data from these probes were gathered for future research on ground freezing. More information on the thermocouples and the related data logging system is listed in Appendix B. 


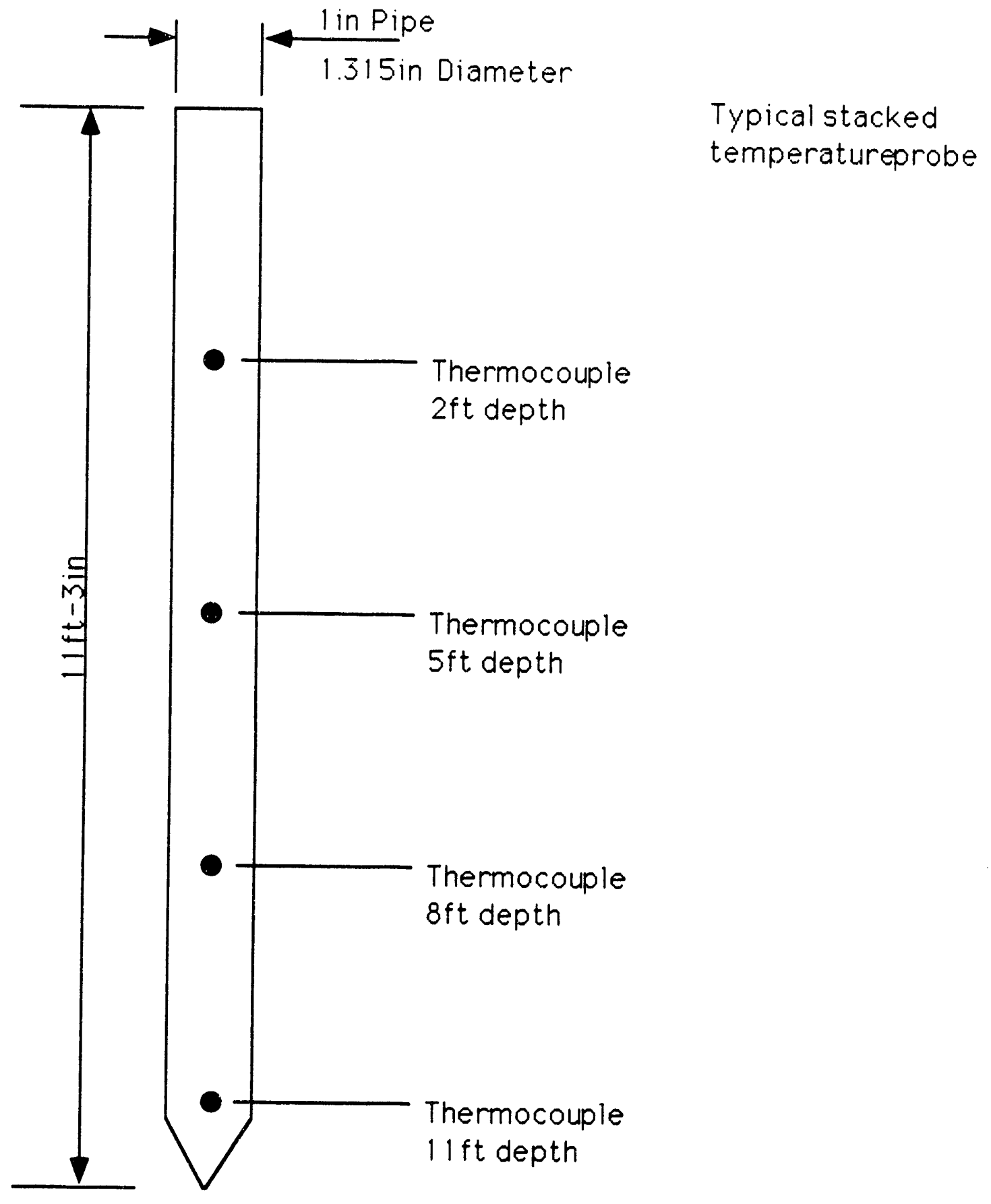

Figure 35. Side view of temperature probes. 


\section{TECHNOLOGY DEVELOPMENT}

\subsection{Design and Engineering}

Sonsub Services, Inc. performed all design, engineering, and analysis tor the hardware and control systems associated with the cryogenic retrieval demonstration. A subcontractor to Sonsub, GEC Alsthom, performed the structural design and analysis for the gantry structure. EG\&G Idaho, Inc. developed design requirements for the hardware and performed an independent review of Sonsub's design work. Additionally, EG\&G Idaho designed, procured, and installed in the field an air monitoring system for the detection of rare earth tracers that could be dispersed during excavation of the test cells. Sonsub started design work in late February and completed the same in early in July 1992. The engineering, procurement, and fabrication was performed on a fast track accelerated basis to ensure support of a July field demonstration.

Design and engineering focused on system integration of existing technologies to create an innovative approach for the retrieval of buried waste. Much of the design work was highly customized but relied on off the shelf components and standard materials to ensure availability and maintainability. For instance, Sonsub selected as part of the removal system a grapple and shear commercially available and typically used in the salvage industry. The basic component was then integrated into a customized positioning system including elevators, stabilizers, and rotators. This assembly was in turn interfaced with a standard bridge crane and hoist mechanism. Mechanical assemblies had to be coordinated with the design of the electrical and control system. This effort was not intended to develop new high end technologies, rather to effectively integrate existing technologies into a functional final product to demonstrate the validity of the concept.

The deliverables for the engineering effort include a full set of drawings, procurement specifications, and vendor manuals, and a Control System Operations and Maintenance Manual.

\subsection{Procurement}

Sonsub performed all procurement of materials and services for the project, with the exception of materials procured by EG\&G Idaho for fabrication of the air monitoring system. To the greatest extent possible, equipment and material was leased if economically feasible; however, in many instances, it was not possible to lease the required item, and an outright purchase was necessary. A large dollar volume of capital equipment items were purchased for the demonstration and will be retained by the INEL at the conclusion of the field work. Most of the capital equipment items were purchased in the Houston, Texas, area and in some cases nationally depending on the material item and availability. Some of these items included the shears, gantry, grapple, bridge cranes, breakout tool, control system, and hydraulic power unit. Many other material and equipment items such as self-contained breathing apparatus (SCBA), oxygen monitors, variety of tools, freeze pipes, and instrumentation probes were procured with operating funds and were likewise procured in Houston and the surrounding area. These items will be turned over to the INEL when the field work is completed. Certain services were supplied under subcontract. Key subcontracts include Freezewall, Inc., a New Jersey firm responsible for placement of the freeze pipes and ground freezing; Louis Grant Inc., a Pennsylvania company, who owns and operates a remote controlled jackhammer, which was an integral part of this demonstration and necessary for removal of frozen debris; and Air 
Products from Salt Lake City supplied the $\mathrm{LN}_{2}$ for the project. Other suppliers provided services and equipment including earth moving equipment, water, contract labor, and storage boxes for the retrieved simulated waste. Generally, all of the latter type of services and materials were obtained from local (Idaho Falls, Idaho) and regional vendors.

All procurement is performed in strict accordance with DOE rules and regulations, which among other requirements, state that a subcontracting plan must be prepared and adhered to for all procurement related activities.

\subsection{Fabrication}

Sonsub is located in Houston, Texas, a major industrial center with excellent resources to support equipment fabrication and materials delivery. Most purchased and fabricated items were obtained in the Houston area, which provided an economical and efficient method of acquiring equipment and material associated with the direct fabrication of the gantry, tools, and freeze pipes. Because of the large industrial base, Sonsub was able to obtain competitive prices on most items. Quick turn around was the rule and not the exception in supporting a tight fabrication schedule. The technical capability of suppliers in the Houston area is unsurpassed and for the simplistic hardware associated with this project, there was not a problem locating qualified vendors.

One of the major fabricators was the vendor who supplied the gantry. This vendor was set up to detail, supply, fabricate, and erect the gantry in their facilities in preparation for the shop demonstration test. This had several major advantages. First, any problems with the steel could be corrected at the vendor's facility. Their personnel were experienced iron workers and erected the gantry steel in minimal time (about 4 days). The shop had large overhead cranes that were used to place equipment and tools in the structure. The gantry was erected indoors out of the weather, which allowed around the clock work to proceed. The steel fabricator's facility was located in an industrial area that was close to many other services and suppliers needed during shop testing of the equipment.

Enviromarine Systems, Inc., located in Baltimore, Maryland, was responsible for fabricating the temperature and moisture probes. The probes were a unique and highly specialized design. Enviromarine was responsive to project needs and supplied the product within the agreed schedule and budget. There were some minor quality problems with the completed probes, but this was discovered during calibration and testing of the probes, before placement, and was corrected. There were no other exotic materials or equipment items that required fabrication. There was a significant amount of welding, close tolerance machining, some castings, and circuit board fabrication, but all were well within the technical capabilities of the local industries.

\subsection{Project Management}

During the engineering, procurement, and fabrication phases, the work was managed by a Sonsub project manager and project engineer and by EG\&G Idaho project management personnel. Standard documentation such as a project management plan detailing how the work would be accomplished, budgets, schedules, and work scope was developed and used as a basis for controlling the job. Other documentation included a safety plan, quality plan, and test plan. Management of 
the project was focused on clearly defined work scope, meeting pre-established schedule milestones, careful budget management, and emphasis on quality and salety. In the field Sonsub's management approach included a field project manager and superintendent to organize and execute the activities.

Sonsub management was responsible tor completing the engineering and related tasks and the field demonstration. EG\&G Idaho was responsible for ensuring that Buried Waste Integrated Demonstration (BWID) program objectives and guidelines were established and followed during the work, availability of proper funding, contract management, tield work was properly interfaced with INEL services and organizations; maintaining technical, salety, and quality oversight of the work, developing a final report, and performing a variety of internal program management functions. Copies of Sonsub's and EG\&G Idaho's project management plans and other project management literature are contained in the project file (WTD-CRYO92-004). 


\section{SHOP DEMONSTRATION AND READINESS REVIEW}

\subsection{Shop Demonstration}

An integral part of the cryogenic retrieval project is the shop assembly and testing of hardware before mobilization to the field. The purpose of this activity is to verify that separate components fit with one another, components and systems function as intended and are properly interfaced, and to the greatest extent possible simulate expected field conditions in the shop.

Specifically, the following activities were performed during the shop demonstration:

- Assemble the gantry

- Install the bridge cranes for the breakout tool, shear, and grapple

- Install the breakout tool, shear, grapple, and associated positioning systems

- Install the hydraulic and electrical systems necessary for operation of the tools

- Install the jackhammer

- Set up, test, and operate the video and control systems

- Install and operate the lighting system

- Test full operation of each major tool, including demonstrating full range of motion and intended function

- Install gantry weatherproof covers

- Test and operate equipment to failure to discover problem areas; correct and continue testing until equipment has developed a measure of reliability

- Calibrate temperature and moisture probes

- Verify that data logging system including data logger, computer, and software function as intended.

Testing of the above equipment was conducted by Sonsub. The gantry and tools were erected and tested at Superior Ironworks, Houston. Superior was Sonsub's gantry structure fabricator. The instrumentation (moisture and temperature probes) and data logging systems were tested at Sonsub's shop. Testing of all systems occurred from June 30 through July 7, 1992. Critical shop testing was witnessed by EG\&G Idaho personnel.

There were many equipment failures uluring the shop demonstration. However, all of the failures were corrected by either adjustments or minor repairs. At the conclusion of the testing, the 
equipment was operating at a level deemed acceptable for starting the field testing, although it was felt that more "exercise" of the equipment and systems in the shop would be beneficial. Shop testing consisted of putting each tool through a full range of motion and demonstrating that the tool could perform its designed function. First, the jackhammer was tested. A $400 \mathrm{lb}$ piece of reinforced concrete was brought in and demolished in about 5 minutes by the jackhammer (see Figure 36). The jackhammer was exercised through a full range of motion and demonstrated that it could be easily manipulated and positioned to gain access to anticipated locations for the field demonstration. One drawback of the shop test was that the jackhammer was not operated from a remote location. The operator worked the tool directly from a pendant control within $20-\mathrm{ft}$ of the jackhammer.

Next the shears were worked. Several large pieces of pipe ranging from 4 to 8 in., and steel I beams were cut by the shears. The shears experienced difficulty picking pieces directly off the floor, but once they were positioned in the jaws (see Figure 37), there was no problem cutting the material. A 6-in. piece of schedule 160 drill string could not be cut by the shears. There were limitations to the vertical rotation of this tool, and modifications were performed to provide an acceptable range of motion. The bridge crane, hoist, elevator, and rotator mechanisms were all tested to satisfaction. The shear was operated from a remote position, which relied completely on the camera and control system to demonstrate the capability of the tool.

Figure 38 shows the breakout tool. An effective test for this equipment could not be devised in the shop without significant expense. However, the tool, crane, and positioning hardware were all worked to verify positioning capability. A check was made to see that the proposed 12-in. schedule 80 pipe collars fit as designed in the breakout tool. The cylinders on the tool were extended and retracted over a half dozen times to check that they worked properly. This tool was successfully operated from a remote location.

The grapple shown in Figure 39 was then tested. Debris from the jackhammer and shear test as well as dirt and several barrels were scooped up by the grapple and transported to a storage box (see Figure 40). The collection and handling of the debris worked well. There were some difficulties positioning the grapple over the top of the $4 \times 4 \times 8$-ft storage box, and consequently there was some spillage. The grapple was also operated from a fully remote position. The storage boxes were located on a transport mechanism. A forklift would place the box on the transport, slide it into position for loading, and after the box was filled, slide it back out, and pick it up.

The camera, control, and lighting systems were all tested while operating the tools. Numerous adjustments were made on the camera system; however, the controls functioned very well with minimal tuning or repair. Figure 41 shows the control station.

Figure 42 shows the completely assembled gantry with the tools installed. The weatherproof cover for the gantry was fitted during the demonstration to ensure it could be installed in the field and function as intended. Figure 43 shows the gantry with a portion of the weatherproof cover in place. The cover is fabricated from a fire retardant material and is transparent allowing natural sunlight to illuminate the work during daylight hours.

Testing of the instrumentation, data logging, and computer system was performed at Sonsub's shop to ensure the system could be field deployed. Testing consisted of installing the PC software for monitoring and logging data and verifying the temperature and moisture probes functioned 


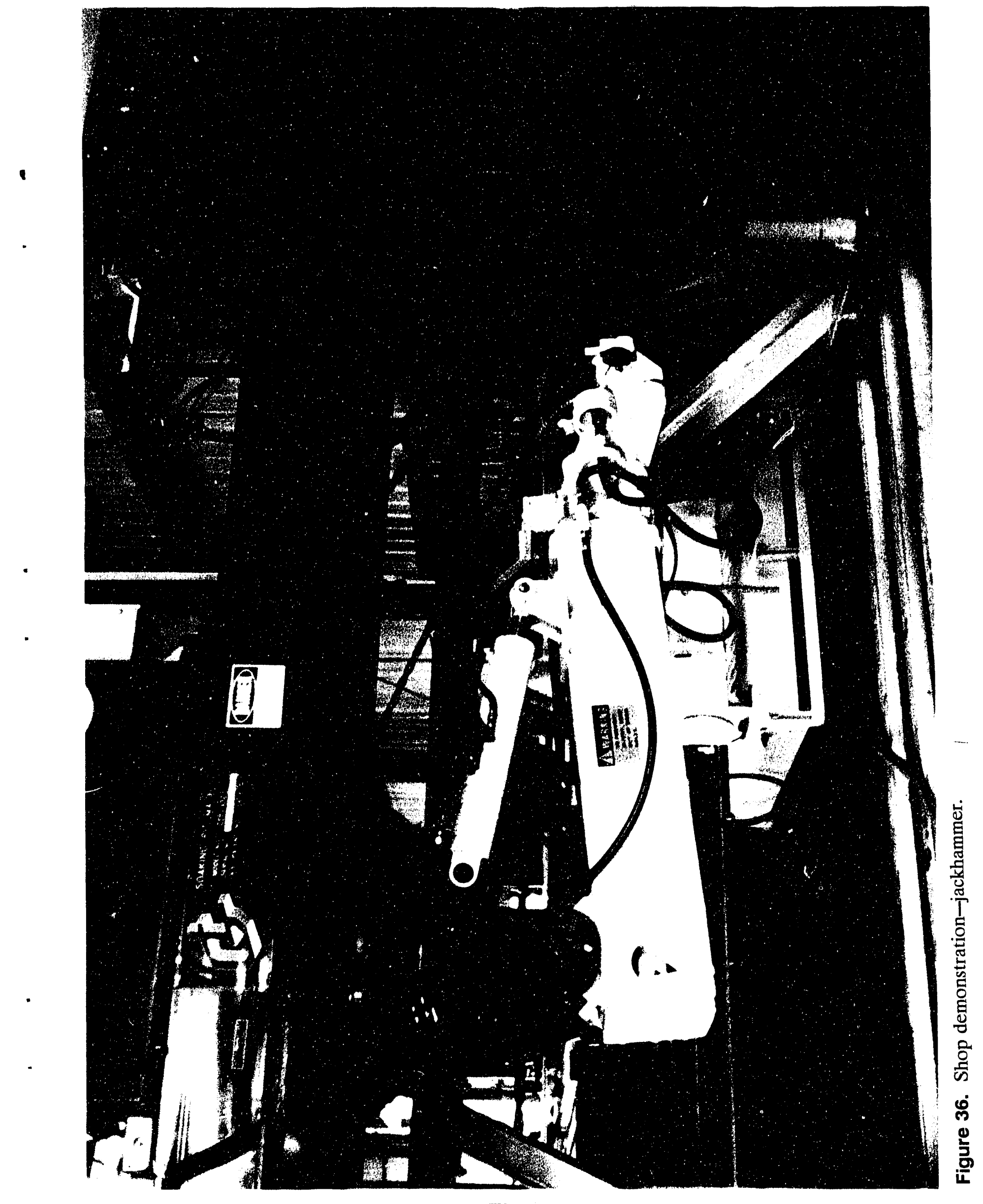




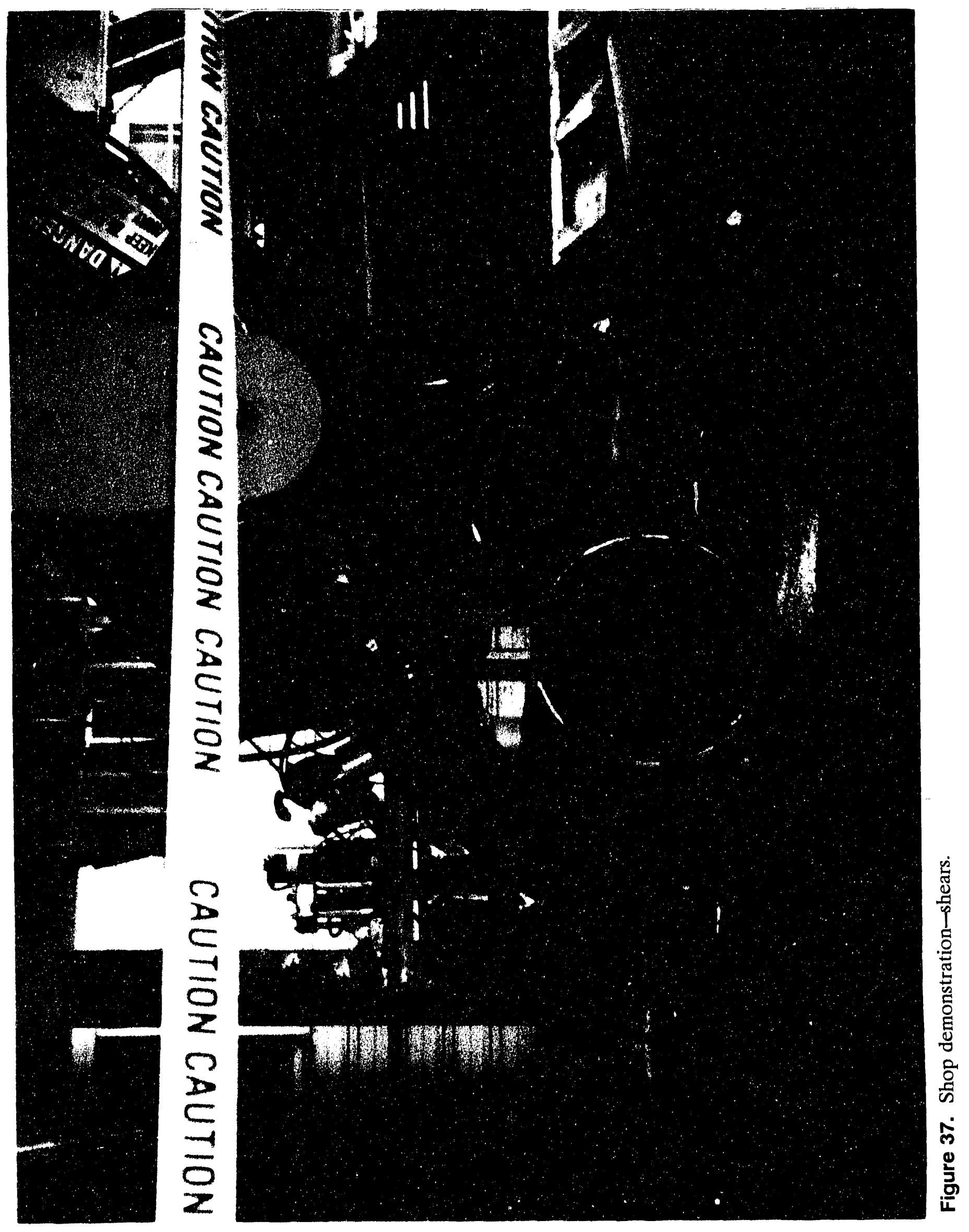




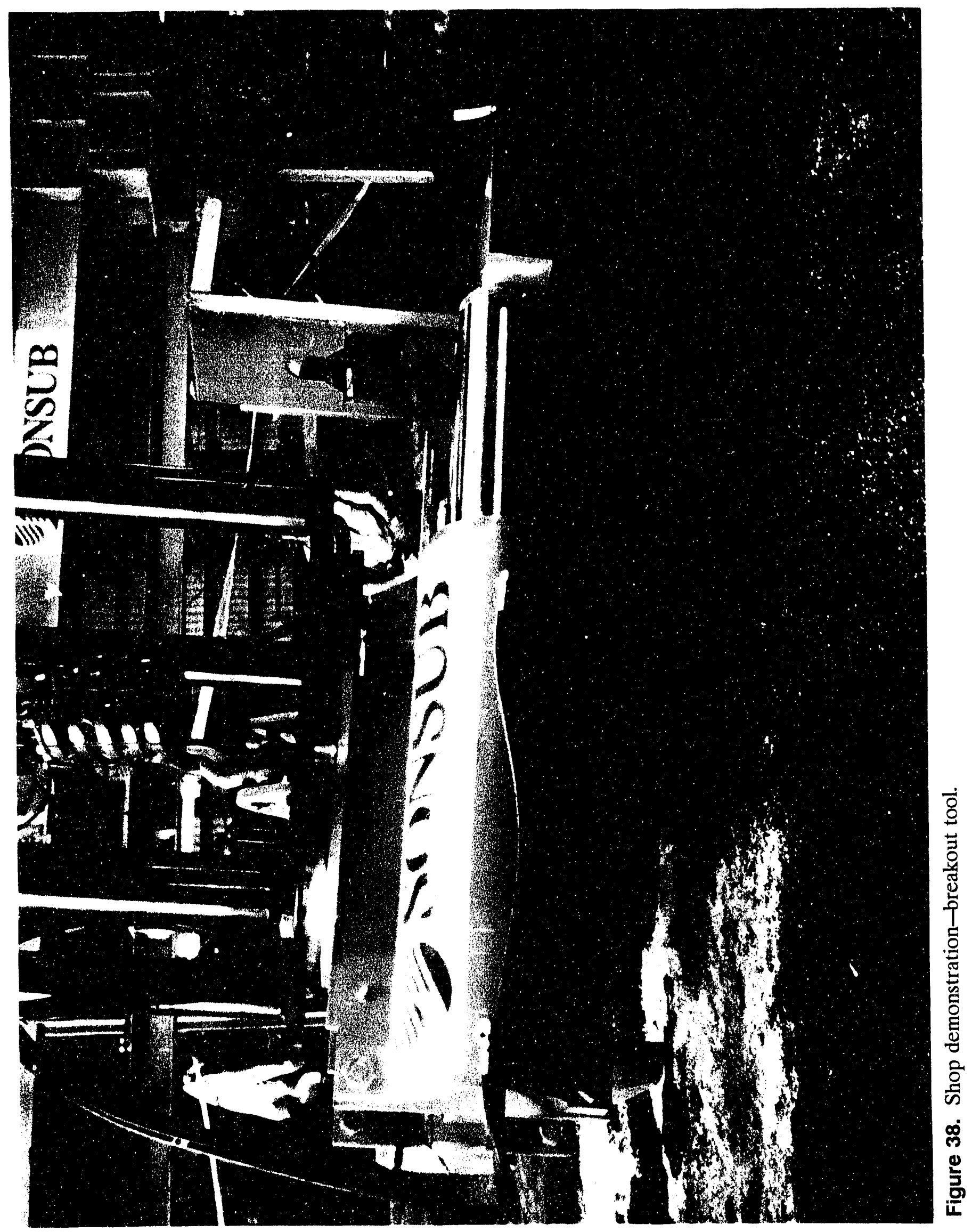




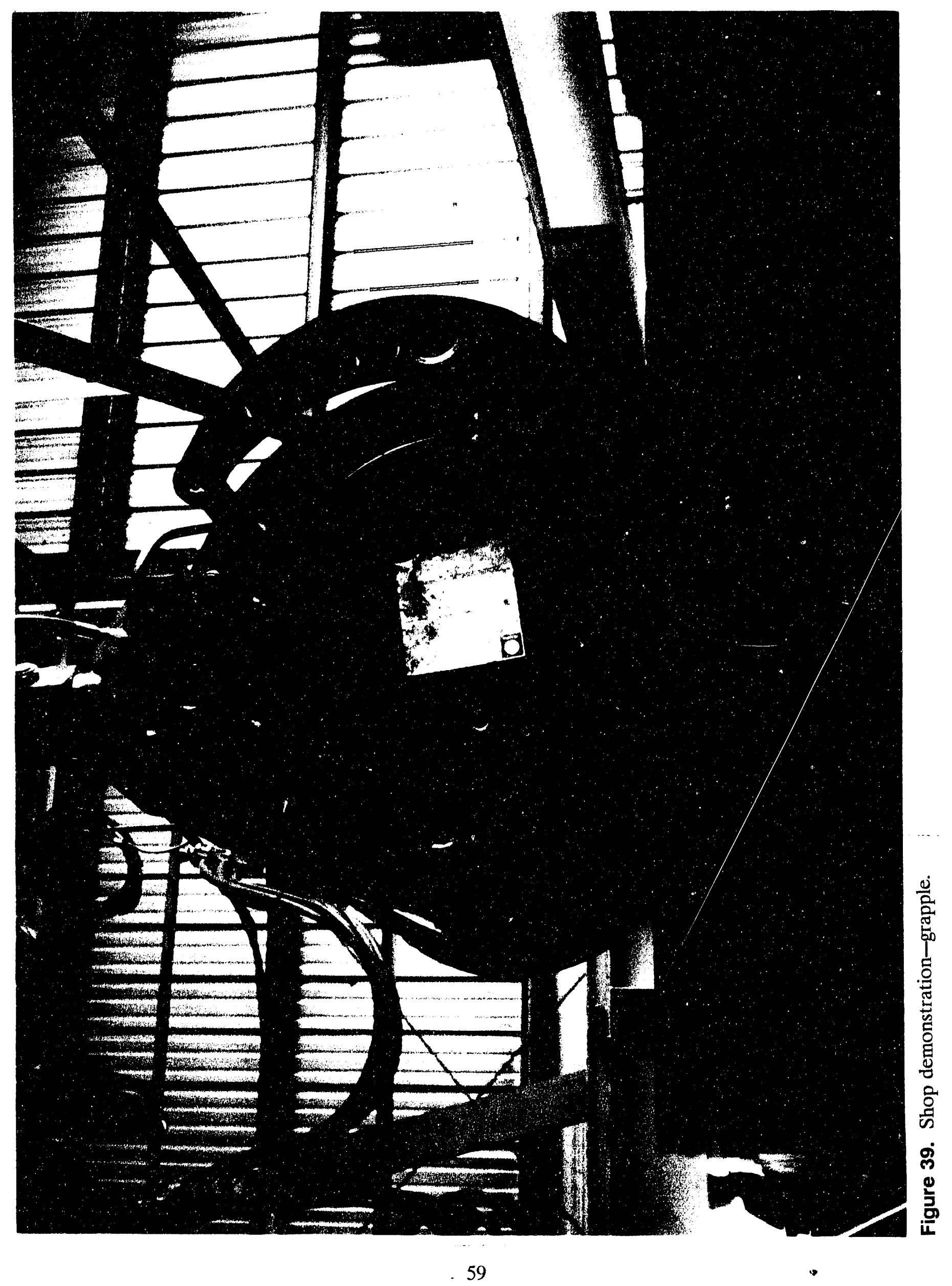




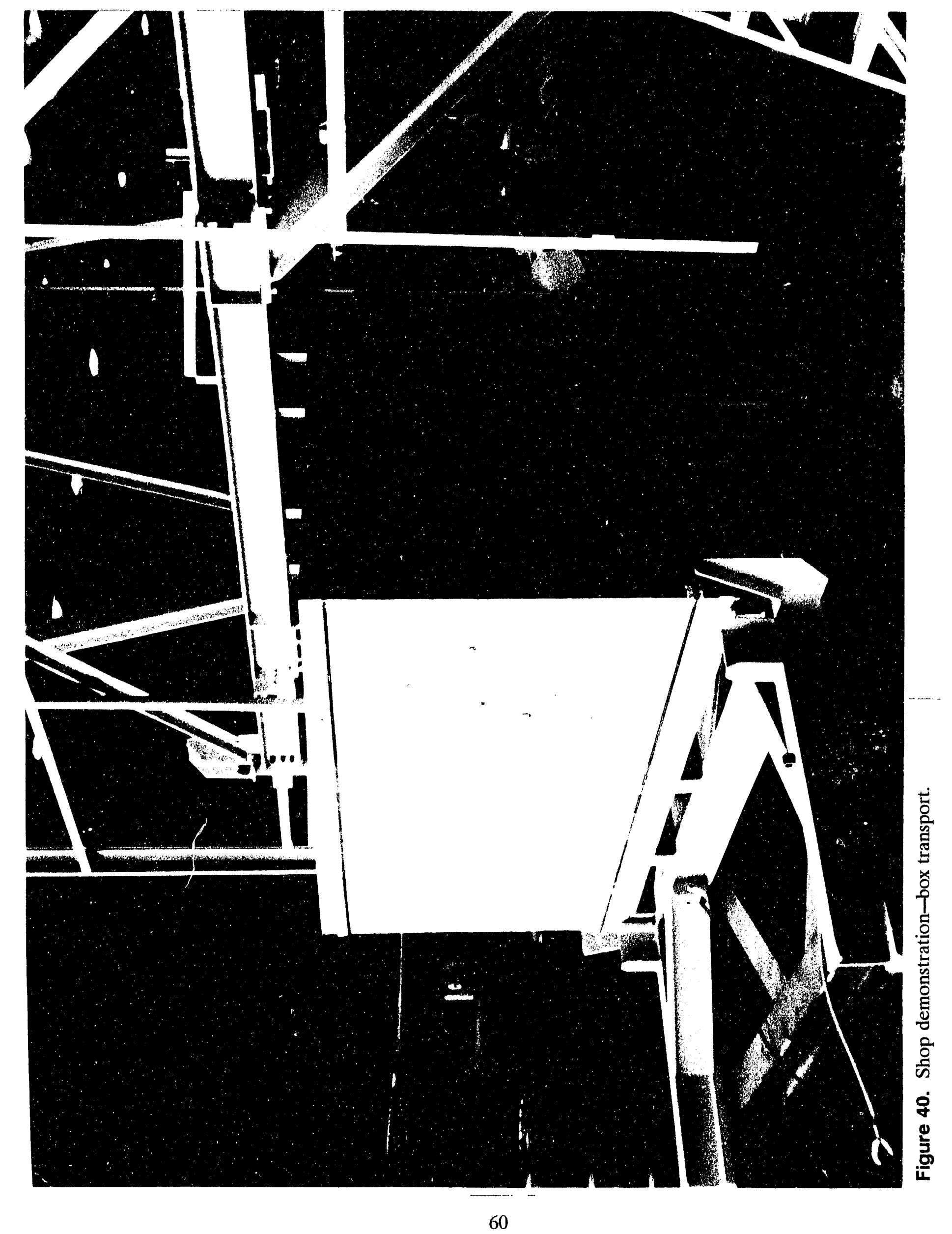




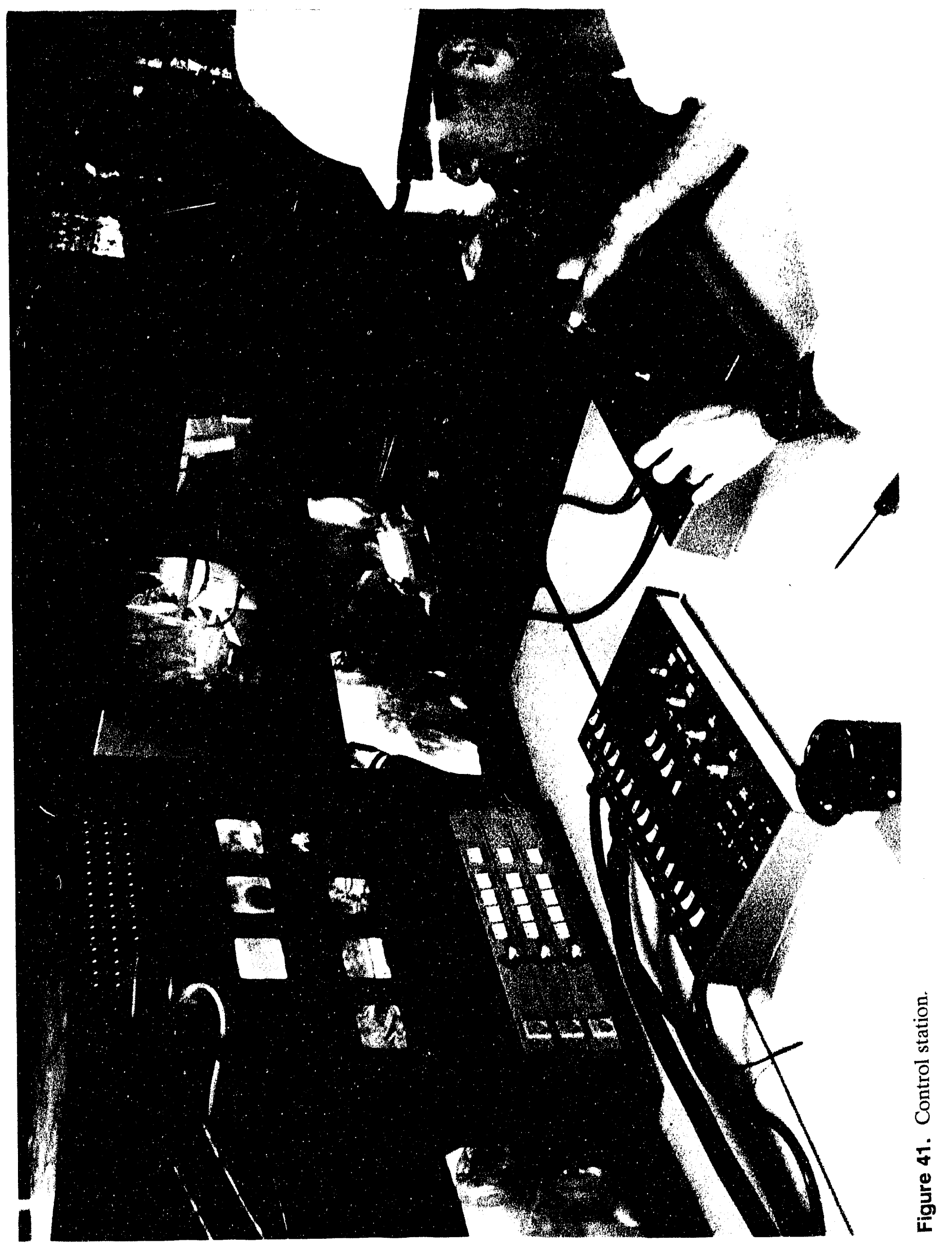




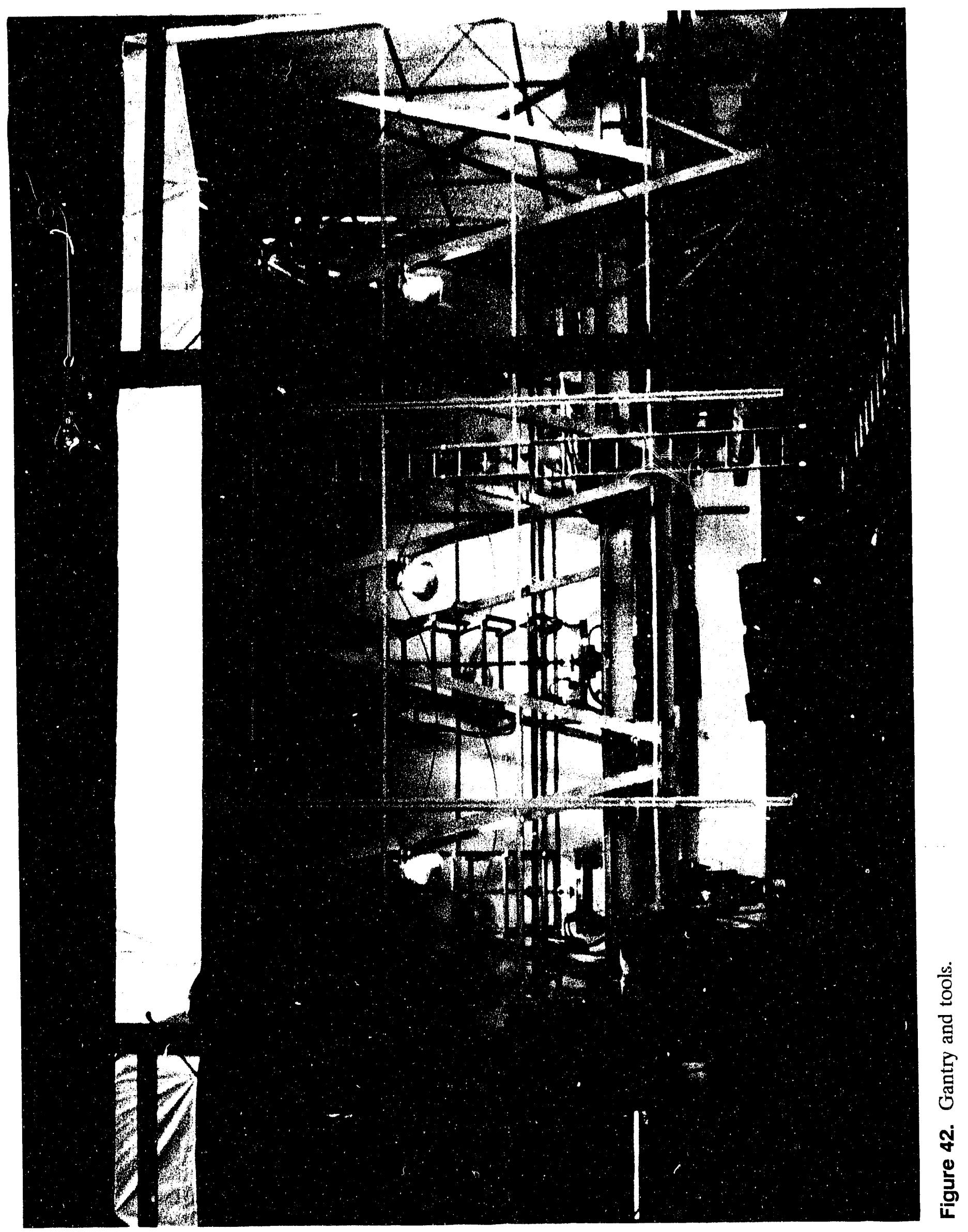




$$
14
$$


properly. The PC software performed many functions such as providing real time readings, recording and storing data, and executing algorithms to calculate mean temperatures and other calculated data. Some of the specific software functions that were tested include

- $\quad$ Reading and storing individual temperature and moisture data

- Collecting sets of input into a separate file to ensure that data from one pit would be collected into one file and not mixed with readings from other pits

- $\quad$ Creating a tagging system to identify each separate instrument reading

- Taking a prescribed number of temperature readings over a fixed time interval

- Calculating mean temperature readings after data are collected

- Verifying availability of sufficient storage space for collecting the anticipated quantity of data to be generated during the field demonstration.

The computer, data logger, and other monito:ing and recording hardware was connected and tested to verify proper operation. The software was also installed and tested to ensure it functioned as intended. Several thermocouples were tested at varying temperatures including cryogenic and ambient. The results from these tests were used to simulate input through the monitoring system and further verify correct operation.

A moisture probe was checked to demonstrate proof of principle. First, a quantity of soil was oven dried. A known quantity of water was added, and the moisture content of the soil calculated. The moisture probe was placed in the soil, and a reading taken and compared with the known moisture content. Determining moisture content is one function of the moisture probe; another function is to indicate if there is an increase or decrease in the moisture content of the soil. To simulate this condition, a small quantity of water was poured into the soil over the probe. A reading that indicated an increase in the moisture content of the soil was obtained. Numerous adjustments and calibrations were performed to ensure that accurate moisture content readings were obtained. Only one moisture probe was calibrated in the shop; however, all other probes (about 15) were calibrated in the field before placement in the test pits. During the calibration process, moisture content data were stored and, as with the temperature data, checked to ensure the software was functioning properly. More detailed information about the shop calibration and testing is contained in Appendices B and C.

The shop testing phase of the project was hectic. There was tremendous pressure to meet schedule and in doing so a concerted effort from all Sonsub and EG\&G Idaho team members was required. Assembling and testing of the entire gantry, tool, and instrumentation systems took place over a 2 week period. To the extent possible, equipment and systems were worked to produce confidence in the hardware's ability to perform. Systems and tools were continuously and repeatedly worked through all phases of their intended functions. Equipment was worked to failure, repaired, and again worked until failure. Thi i process was repeated until in effect the system or tool would not fail. Although this method for ensuring reliability lacked sophistication, it was the most effective within the time available. Ideally and under different conditions, it would have been desirable to 
operate and test the systems for several thousand hours to increase the confidence level. Shop testing worked the tools for 150 to 200 hours. The reliability of the equipment could have been improved by increasing the hours of testing, but this was not possible within the imposed budget and schedule guidelines.

\subsection{Readiness Review}

A readiness review in accordance with BWID requirements was held at the same time the shop testing was in progress. Two documents were used as a basis for conducting the review. A BWID document entitled the "Preparedness and Consent Checklist" was used to help identify and address program level issues and concerns. A separate readiness review checklist addressing detailed working level issues was also developed. The readiness review was held at the Sonsub's offices in Houston, on June 30 and July 2, 1992. Technical and managerial personnel from both Sonsub and EG\&G Idaho were in attendance. The purpose of the meeting was to ensure that safety and technical adequacy issues had been identified and addressed before field mobilization and initiation of the site demonstration.

Appendix D contains the documented results of the readiness review meetings. The meeting concluded that Sonsub and EG\&G Idaho were prepared to begin field work. There were minor issues being worked or that would be addressed before mobilization, but all major safety, security, environmental, and technical concerns had been accounted for. 


\section{FIELD DEMONSTRATION}

\subsection{Mobilization}

Sonsub mobilized to the cold test pit on July 7, 1992. Initial activity included grading and leveling the area over the cold test pit for vehicle and gantry access. A local earthwork contractor from Idaho Falls accomplished the grading in about $21 / 2$ days. EG\&G Idaho personnel then staked out the location of the four $9 \times 9-\mathrm{ft}$ freeze pits to be frozen and excavated. A trailer was brought onsite to serve as the control room and a rest area for Sonsub crew members. Other equipment that was located onsite within the first week included a diesel generator, diesel fuel storage tank, utility water tank, $\mathrm{LN}_{2}$ storage tank, and tool and small equipment storage box. A general layout of the site and the location of key equipment and structures is shown in Figure 44. Other equipment items that were delivered to the site during mobilization included an excavator, forklift, crane, winch, and the vibratory drill and compressor for placing freeze pipes.

By the start of the second week the gantry and tools, freeze pipes, video and control equipment, and other small tools and consumable items were delivered to the site. The gantry and tools were assembled at the south end of the work area (almost directly over the large objects pit). After assembly, the structure was skidded to the random dumped barrels pit at the north end. This scheme was chosen because of the need for a spacious work area to erect the gantry. Simultaneous with the gantry and tool assembly, installation of the random dumped barrels pit freeze pipes was commenced. More detail on this activity is provided in Section 6.2. The $\mathbf{L N}_{2}$ storage tank was filled, and distribution piping was installed and insulated. The data logging and monitoring system for pit thermocouples and moisture probes was installed, tested, and readied for use during freezing and retrieval of the first pit. The air monitoring system was brought onsite, installed, checked, tested, and made operational for the first test pit. Sonsub also set up and tested the complete control and video system for remote operation of the gantry and tools.

As an integral part of the mobilization effort, multiple safety inspections by both Sonsub and EG\&G Idaho personnel were conducted. A safety kick-off meeting was held with Sonsub and EG\&G Idaho personnel to review key safety issues and procedures. Sonsub's Corporate Safety Manager performed an assessment of site safety before initiating the demonstration.

Figures 45,46 , and 47 show the site and equipment in various stages of the mobilization effort. When mobilization was complete ( 2 weeks), all systems checked out, and actual freezing and retrieval activities were initiated. Observations and recorded technical data from each test pit are provided in the following sections.

\subsection{Random Dumped Barrels}

The random dumped barrels cell is located at the north end of the cold test pit. The first key effort associated with freezing the soil and simulated waste and extraction was to install the freeze pipes. Freezewall, Inc., Sonsub's subcontractor, was responsible for this effort. Placing of freeze pipes started on July 14 and ended July 17 . Initially there were mechanical problems with the vibratory drill that caused down time. An adapter for the 12 -in. freeze pipe collars had to be fabricated, and the drive collet failed and required replacement. Most full lengths of freeze pipes 


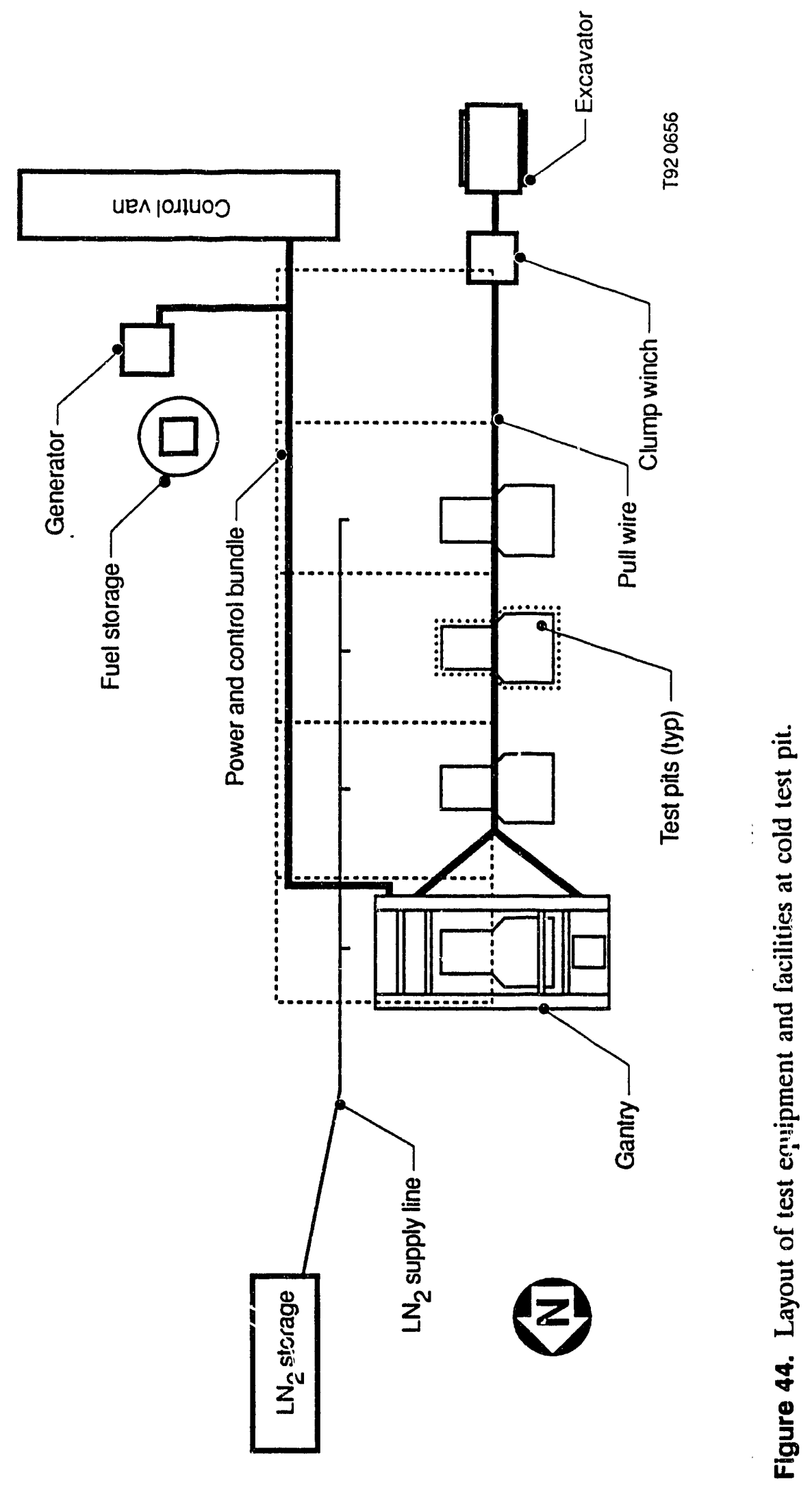




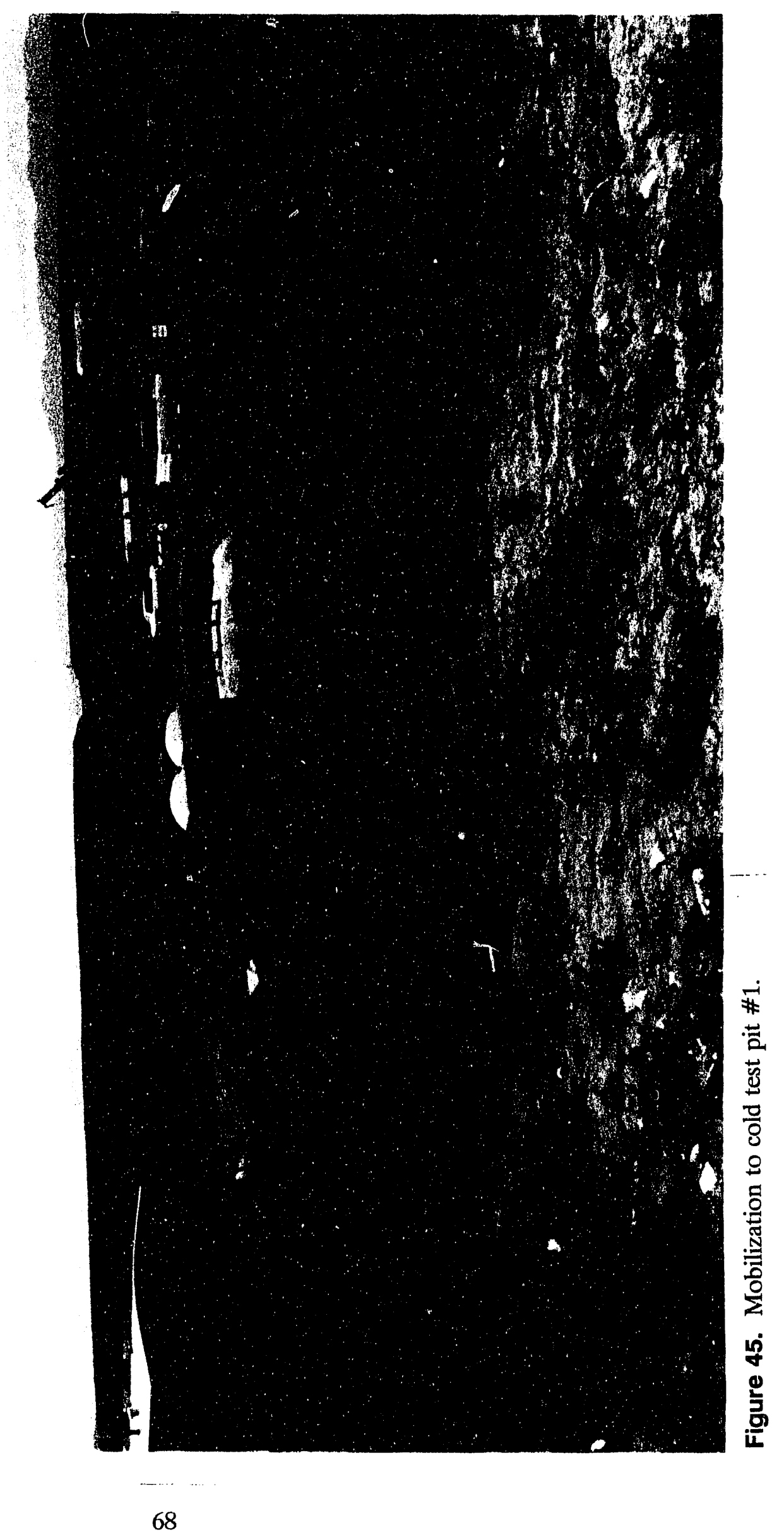




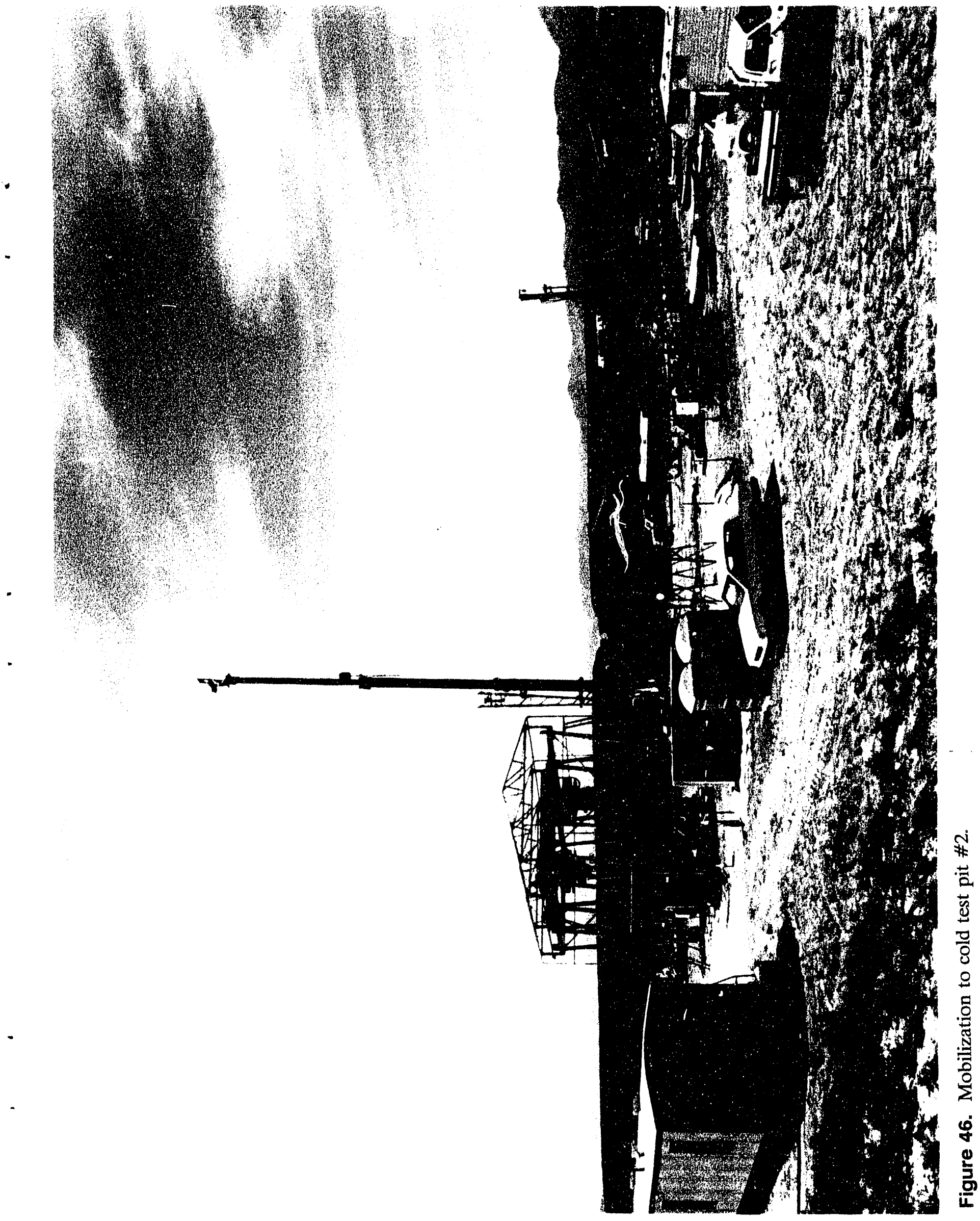




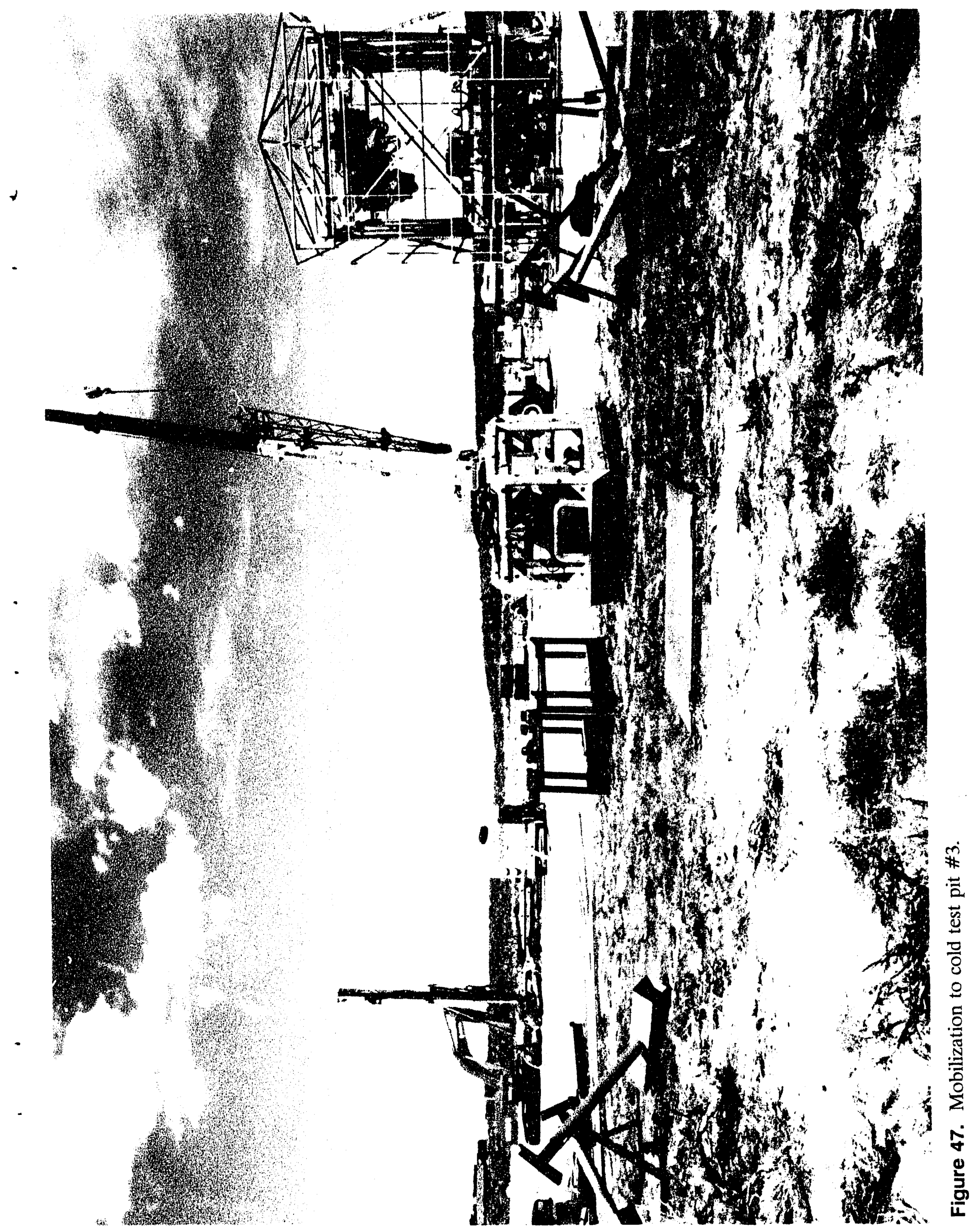


required less than a minute to place once drilling started. The 12 -in. collar was the first piece installed for pipes located in the freeze pit. The collars were 18 -in. long and initially were installed without a drill adapter fitting, which did not work well. An adapter fitting was fabricated and placement went much easier. A further refinement was to bevel the penetrating end of the collar, as they were initially fabricated with a square end. The collars were placed about 12 in. in the ground with 6 in. exposed above the surface. After a collar was placed, the freeze pipe was placed directly through it. For many of the pipes placed in the freeze pit, it was apparent that waste was being encountered because of the variation in drill speed. As was later confirmed during excavation, there was no significant deflection of the pipes during placement. Most of the waste in this particular area was computer paper, clothing, wood, and simulated sludge. The freeze pipes around the perimeter of the access pit were also placed with relative ease. The pipes around the access pit did not require collars, because these pipes would not be used for breakout, only freezing. Occasionally a freeze pipe would bottom out at the basalt layer underlying the cold test pit. However, almost the full length of freeze pipe was placed and rarely was more than 6 to 12 in. of piping trimmed from the top of pipe. After the perimeter pipes were in place, nipples (threaded by beveled end) were welded on to the exposed ends of the freeze pipes. These fittings were used to connect the $\mathrm{LN}_{2}$ feed lines to the freeze pipes.

Concurrent with placement of the collars and pipes, temperature and moisture probes were installed. Placement was accomplished in the same manner as the pipes, although the probes were much more delicate and could not be driven to refusal. One thermocouple probe had to cut off because it protruded too far above the surface of the pit. Others had to be trimmed, but no instrumentation was lost.

After the freeze pipes were placed, the surface piping or "plumbing" was installed. This included stainless steel hoses, carbon steel fittings, and copper tubing. Connections to the instrument probes were also completed at the same time the plumbing was being installed. Additional trouble shooting was required to ensure that the temperature and moisture probes were properly connected and working and that data were being generated and logged properly. There was an interference problem with the site radio telephones and the data logger, which required relocation of the data logger to nullify the "antenna" effect.

With the plumbing in place and the instrumentation systems functioning properly, the pit was ready for the introduction of $\mathrm{LN}_{2}$. With the random dumped barrels pit, the entire perimeter of the freeze and access pits and front half (dry half-no water added) of the freeze pit were frozen. Initial readings before the introduction of $\mathrm{LN}_{2}$ showed a rough average temperature of $70^{\circ} \mathrm{F}$. This number is rough because there was a temperature gradient through the pit at different locations and e!evations. $\mathrm{LN}_{2}$ was first added on July 21 . On July 24 , the pit temperature indicated that the front half of the pit was well below freezing, and the back half of the pit was near $50^{\circ} \mathrm{F}$. These conditions were judged appropriate for adding water to the back half of the pit. About 1800 gal of water were injected into the pit over a 2-1/2 hour period. This quantity of water represented over one half the calculated volume of the pit and in theory should have saturated the soil and waste $(100 \%$ moisture content). During injection of the water, the moisture probes indicated an increase in the moisture content, which in turn indicated that water was flowing through the bottom of the pit. After the water was added, $\mathrm{LN}_{2}$ was injected into the back half of the pit to promote freezing. 
In preparation for breakout of the freeze pit, the access pit was excavated on July 26 , and the gantry skidded into place. It took about 7 hours to move the gantry over the test cell from the south end of the cold test pit. Most of this time was not actual sliding, rather, it was positioning the gantry, adjusting the winch, and placing the skid plates. Excavation of the access pit went smoothly. It required a few hours of time, but this was mostly due to exercising care not to damage any of the freeze pipes or $\mathrm{LN}_{2}$ plumbing. During excavation a drum was exposed near the face of the freeze pit and punctured but otherwise left undisturbed. The pit was dug to the proper elevation, and the walls were frozen solid. The gantry had been previously assembled, checked, and tested at the south end of the cold test pit and was ready for operation. It was moved next to the random dumped barrels pit, and when it was determined that actual breakout could occur, the gantry was positioned directly over the pit. Final preparation for the air monitoring system had also been completed concurrent with placement of the gantry. The air monitoring system had been installed and tested and was ready for operation. All filters were in place, and mechanical and electronic equipment had been checked for proper function. Also immediately before starting breakout of the dry pit, the high volume air samplers were turned on for 2 hours, and samples collected for analysis. Analysis of the sample taken from this initial background test showed a dysposium concentration of $43 \mathrm{ppm}$, or $14 \mathrm{ppm}$ higher than the established background quantity of $29 \mathrm{ppm}$. A probable cause for this increase was the release of dysprosium from the drum that was breached during excavation of the access pit.

Readiness for breakout was determined by temperature readings. There was some variation of readings, but this was expected because of the position and depth of the thermocouples. Generally all readings were below freezing and most were well below $0^{\circ} \mathrm{F}$. Some of the highest temperatures were near the bottom of the pit. This could have been explained several ways. It could have been that the probe was far enough below the bottom of the freeze pipe so that the penetration of the cold was not measured by the thermocouple. Another possibility is that a probe could be positioned in a void and not in direct contact with soil, which would tend to generate higher temperature values. Just before the start of breakout, the flow of $\mathrm{LN}_{2}$ to the frozen pit area was stopped. $\mathrm{LN}_{2}$ was continuously flowed during nonworking hours to the perimeter piping at both the access and freeze pit during the remainder of the breakout. Up until the time breakout started, a total of approximately $69,700 \mathrm{gal}$ of $\mathrm{LN}_{2}$ were consumed in the freezing process.

Initial breakout began on July 26 on the front, dry half of the pit. The breakout tool was initially used to test how well the popsicles of soil and simulated waste had been formed during the freeze down. After trying the first row of five freeze pipes, it was apparent that in the dry soil the popsicles had not formed very well. The breakout tool functioned as planned, but only the 12-in. pipe collar, and a small amount of soil directly around the freeze pipe was loosened during the removal process. The jackhammer was then used to help dislodge the soil and freeze pipes. This tool worked very effectively and was easy to manipulate and position from the remote stance. After the first row of freeze pipes were broken out, the shears were used to size the pipes. No other waste had been encountered by this time. The grapple was activated and worked well in picking up the soil and pipes. However, positioning the grapple over the storage boxes was a problem, and there was a fair amount of soil spilled, dust aerosolized, and ultimately rare earth tracer (dysprosium) indicated on the air monitoring filters. Figures 48,49 , and 50 show some of the ongoing activity during breakout and retrieval of the random dumped barrels pit. Work continued for about 4 days on the dry side of the pit. During this initial breakout process, very little or no visual dust was generated from the breakout, jack hammering, and grappling operation; indicating that whatever moisture was 


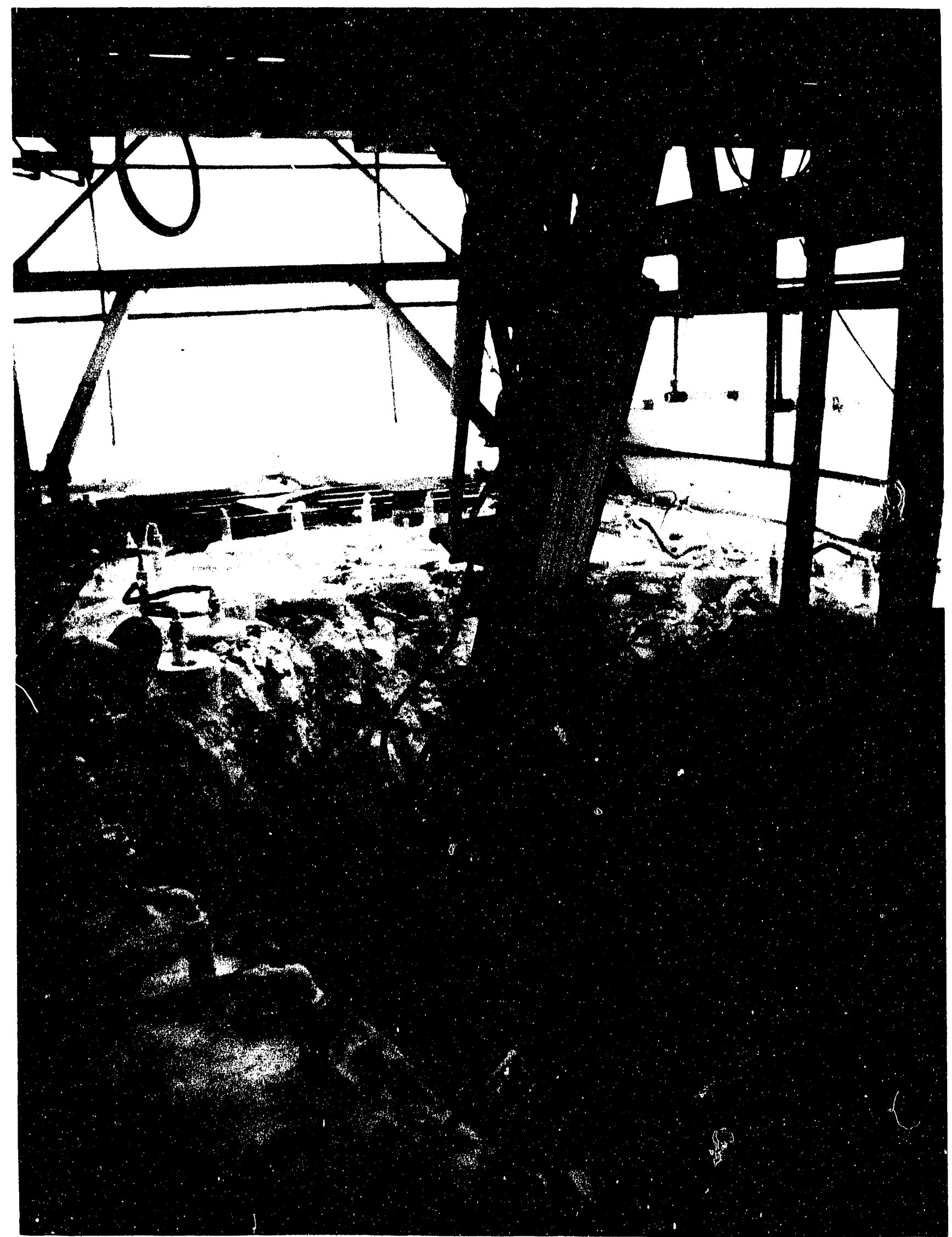

Figure 48. Random dumped barrels excavation \#1. 


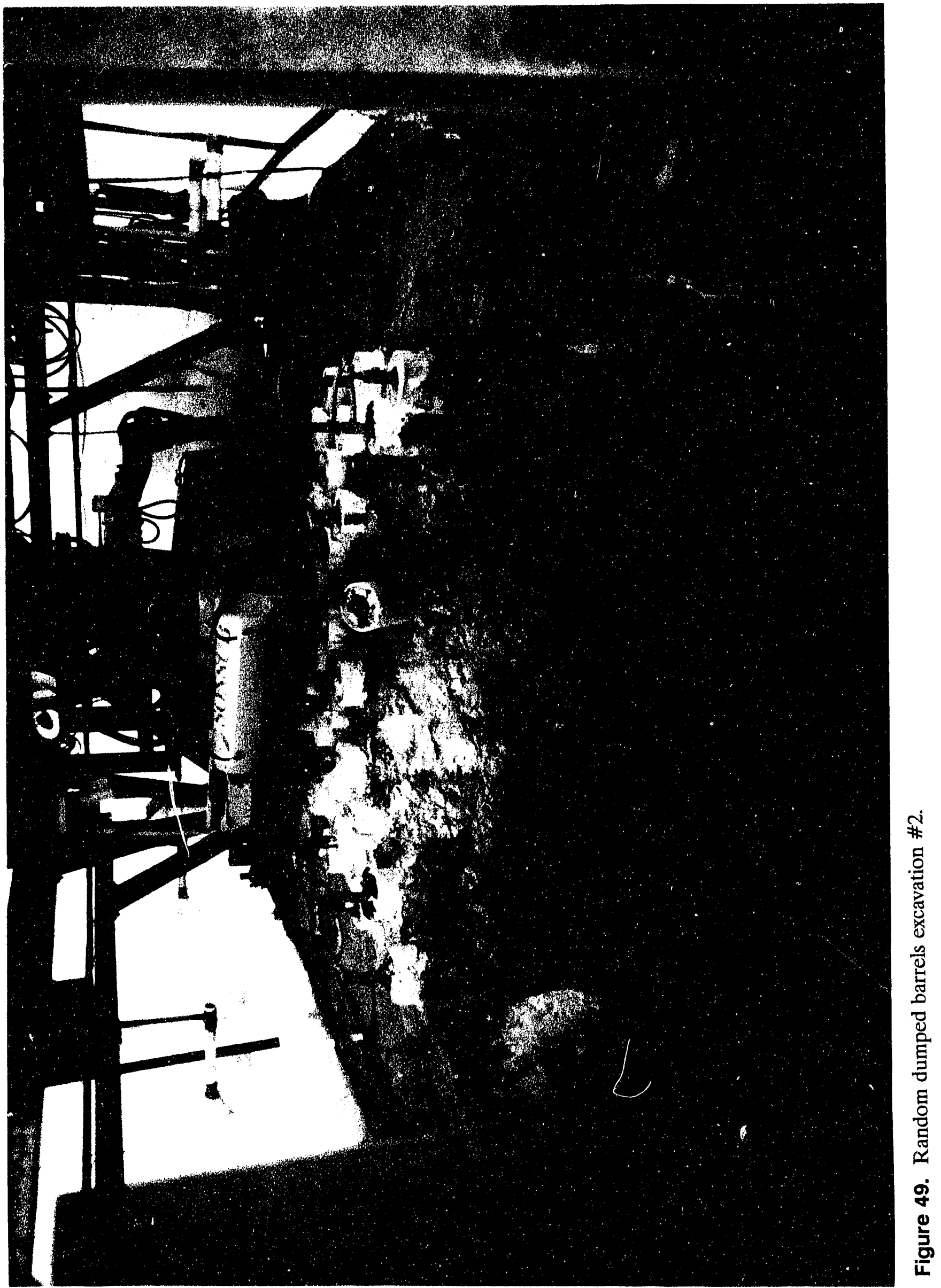




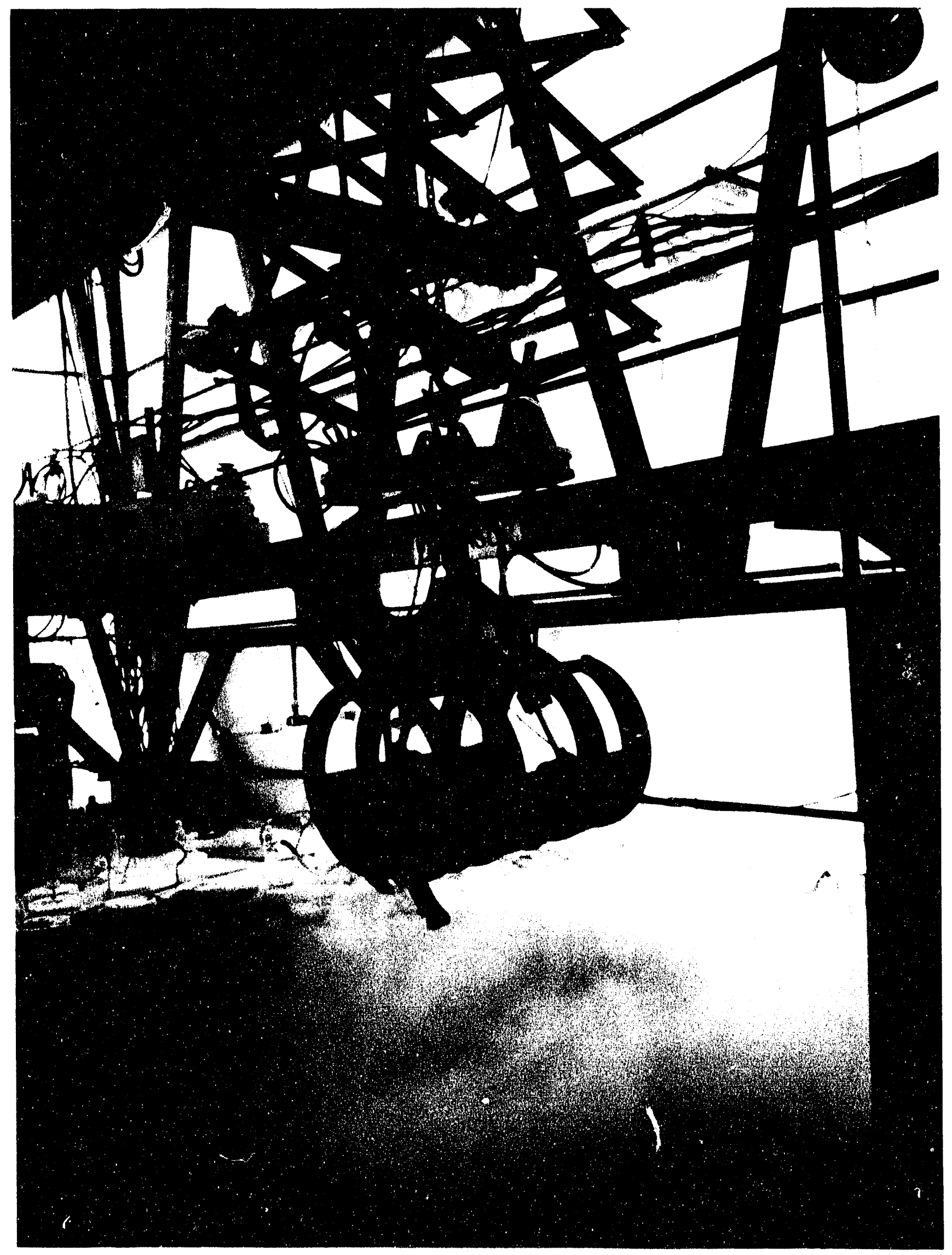

Figure 50. Random dumped barrels excavation \#3. 
contained in the soil was effectively frozen. During this time there were numerous equipment problems, such as camera failures, shear rotator faults, frozen hydraulic hoses on the jackhammer, vibrations from the tools rattled some nuts and bolts on the gantry and other equipment loose, and contactors malfunction on the grapple hoist. These problems were corrected, but the result was a significant amount of down time. A rough estimate for down time during the first half of the pit is 65 to $70 \%$ of the total working time expended. Problems with equipment failures were often compounded because of the remote site and difficulty experienced in obtaining parts and repair services.

Other observations about the breakout of the dry side of the pit include

- The first set of air monitoring filters had to be replaced early during the breakout because dust that had previously accumulated on equipment and gantry steel on the interior of the gantry was knocked loose during operation of the tools. The filters quickly became clogged and had to be replaced. A new set of filters was installed.

- Severa! flow sensors located in the air monitoring instrumentation shed failed. Probable cause was the heat in the shed (estimated at $110^{\circ} \mathrm{F}$ ). The sensors were replaced, and a portable air conditioner was installed in the shed to help keep temperatures cooler.

- First a plywood and later a metal funnel was built and fitted on the storage boxes. The purpose of the funnel was to help direct the placement of retrieved waste from the grapple into the boxes. The first funnel made of plywood, lasted for about three box loads of material and then broke. It was replaced with a metal funnel that functioned much better.

- The $4 \times 4 \times 8$-ft plywood storage boxes were generally filled to 70 to $90 \%$ of capacity. A total of 10 boxes were filled during the initial demonstration.

- Barrels of simulated waste were encountered during removal of the second row uf freeze pipes. The barrels contained computer paper, clothing, wood, simulated sludge, and plastic debris. Of all the material retrieved, none appeared to have decomposed or have absorbed moisture (the computer printouts were dry and legible). Grappling and placing computer paper in the storage boxes was sometimes difficult because the paper tended to unfold. In a hot or contaminated situation, this could readily spread contamination.

- There were interference problems with the data logger for the temperature and moisture monitors caused by the mobile radio phones in the control trailer (by which the data logger was initially located) and by the pump motors located in the air monitoring instrumentation shed (where it was relocated from the control trailer). The data logger was finally placed on a post about $10 \mathrm{ft}$ from the equipment shed in a weatherproof enclosure so there would not be a problem with interference from other electrical equipmeni.

- Because the distance between the field instrumentation, data logger, and PC was significantly more than during shop testing, additional hardware and some software changes were necessary to compensate for the spacing. This was not a major problem but did cause some minor delays during initial set up and testing of the system 
- The initial concern about an oxygen depleted atmosphere while working around the $\mathrm{LN}_{2}$ and especially inside the enclosed gantry was unfounded. At the start of the project personnel were required to wear full SCBA units as a precautionary measure for working in a potentially oxygen depleted atmosphere. Oxygen monitors were also worn by personnel to warn when the oxygen level was low. After several days of working around the venting $\mathrm{LN}_{2}$, it was apparent that rarely, if ever, was the enclosed atmosphere lacking oxygen. This safety requirement was relaxed (with the prior knowledge and con srence of the project safety engineer). Personnel were still required to wear oxygen monitors and work in groups of two or more, and SCBA units were kept close by in case of an alarm but were not worn.

Excavation of the second half of the pit, the wet side, started on July 31. Again the breakout tool was used to test the popsicle theory. Ice columns were better defined in the second half of the pit than the first half but were still not nearly as large as predicted. The breakout tool removed as much of the fourth row as possibie, and then the jackhammer was again used to loosen the remaining material. The grapple continued to clean up debris as it accumulated in the bottom of the pit. Temperatures on the wet side of the pit continued to lower, and some readings of -50 to $-100^{\circ} \mathrm{F}$ were observed. The temperatures of soil and debris did not seem to have much effect of the actual removal process. Again, more barrels of paper, wood, and clothing were retrieved. There was no visual dust during the breakout sequence. The fifth and sixth rows of the pit were loosened using the breakout tool, and about three quarters of the entire pit was excavated. Because of the time and budget limitations, the breakout and removal effort ceased on August 1, and preparations were made to move on to the next (random dumped barrels and boxes) pit. The flow of $\mathrm{LN}_{2}$ to the perimeter pipes was stopped. An additional 15,800 gal of $\mathrm{LN}_{2}$ were used since the initial breakout commenced, for a total quantity of 85,500 gal of $\mathrm{LN}_{2}$ for the random dumped barrels pit. The gantry was moved off the pit and over the random dumped barrels and boxes pit that were directly adjacent. After a day of "thawing," an attempt was made to remove the perimeter freeze pipes by means of pulling them out with the excavator. The pipes did not budge and were left in place. They were cut belowgrade and buried. The pit was backfilled and compacted.

\subsection{Random Dumped Boxes and Barrels}

As with the other test areas, the first activity associated with development of this pit was the

2 placement of the freeze pipes and instrumentation probes. The configuration of freeze pipes and instrumentation prebes described in Section 6.2 is the same used as the random dumped boxes and barrels. The same vibratory drilling equipment was used to place the pipes. Placement started on July 20 and was completed on July 21. After the freeze pipes were in place, the $\mathrm{LN}_{2}$ and water injection feed piping was installed from July 22 until July 25 . Nitrogen was flowed through the freeze pipes starting on July 27 . The plan to freeze this area was to initially freeze the perimeter of the waste, access pits, and first row of the waste pit. At the same time the initial freeze down was under way, water was poured around the pipe collars at the surface. Water was introduced at the surface to determine if better ice columns could be formed by introducing more moisture around the freeze pipe. From July 27 to July 31 about 130 gal of water were poured around the collars of the 14 freeze pipes in the front half or dry side of the random dumped boxes and barrels pit. Freezing of the 
perimeter and front row of freeze pipes continued through July 31 . A total of 50,000 gal of $\mathrm{LN}_{2}$ were used during this time. On July 30 , the access pit was excavated.

On August 1, 1,700 gal of water were injected into the back half, or wet side, of the pit. The water was added over $11 / 2$ hours. As with the random dumped barrels pit, this pit used the same type of freeze pipes to inject water throughout the simulated waste and soil mass. At the same time the water was injected, $\mathrm{LN}_{2}$ was flowed into the freeze pit. The freezing process continued until August 3, and an additional 14,000 gal of $\mathrm{LN}_{2}$ were used. A short time after the water was injected into the freeze pit, a large quantity of water had leaked into the access pit. There was not an accurate means to measure how much water had flowed into the access pit, but it is estimated that several hundred gallons had accumulated. At the same time the water was leaking into the access pit, the moisture probe indicated a significant increase in the amount of moisture in the soil surrounding the probe. This situation suggests two things (1) there was an obvious pathway between the freeze and access pits, probably caused by voids in the waste and (2) freezing the perimeter of the pit did not effect the creation of a bairier for containment of water between the freeze and access pits. It is also theorized that the water injected into the random dumped barrels pit as well as the pit migrated east beyond the test cell boundary. This would account for the lack of saturation experienced in these two pits.

The gantry and tools were positioned over the random dumped boxes and barrels pit on August 2, and breakout started late in the afternoon of August 3. Figures 51 and 52 show the breakout in progress. Before the start of breakout, a 2 hour high-volume air sample was obtained, and the air monitoring system was installed, verified to be fully operational, and new low-volume air filters installed for the test. The dry side of the pit consisted of rows one, two, and three. The breakout tool was used initially to test if full ice and simulated waste columns could be broken out. This worked slightly better than the first pit, probably because of the addition of water on the surface that helped to form a more cohesive mass. It was not a great improvement but indicated that the formation of the ice column or "popsicle" was dependent on how well the water was dispersed around the freeze pipe. A few barrels were encountered during excavation of the dry side of the pit. These barrels contained the same type of debris and waste found in the random dumped barrels pit. Items such as computer paper, sludge, wood, and clothing were found. All items were very dry and did not exhibit signs of deterioration. Much of the soil excavated towards the bottom of the pit was dry and crumbly. There was very little or no visual dust generated during the breakout. The jackhammer was the primary tool used to remove the soil and debris from the wet side of the pit. The shears were used to size the freeze pipes, and the grapple was used to pick up the soil and waste from the bottom of the pit and place it in storage boxes. Breakout and excavation of the first three rows were completed on August 5.

The second half, or wet side of the pit, was then readied for breakout on August 6. Again, a high-volume air sample was obtained before actually starting breakout. There was not a significant difference between the dry and wet sides of the pit relative to the appearance of the soil and simulated waste. The injected water had not readily penetrated or dispersed through the soil. Therefore; the condition of the soil and simulated waste during breakout was fairly dry and crumbly. All of the fourth row and most of the fifth row were removed during this phase of the work. During breakout and removal, a box was encountered that contained much of the same type of debris that had previously been retrieved from the barrels. Because of time and budget limitations, the remainder of the pit was not removed. The breakout of the wet side of the pit was concluded on 


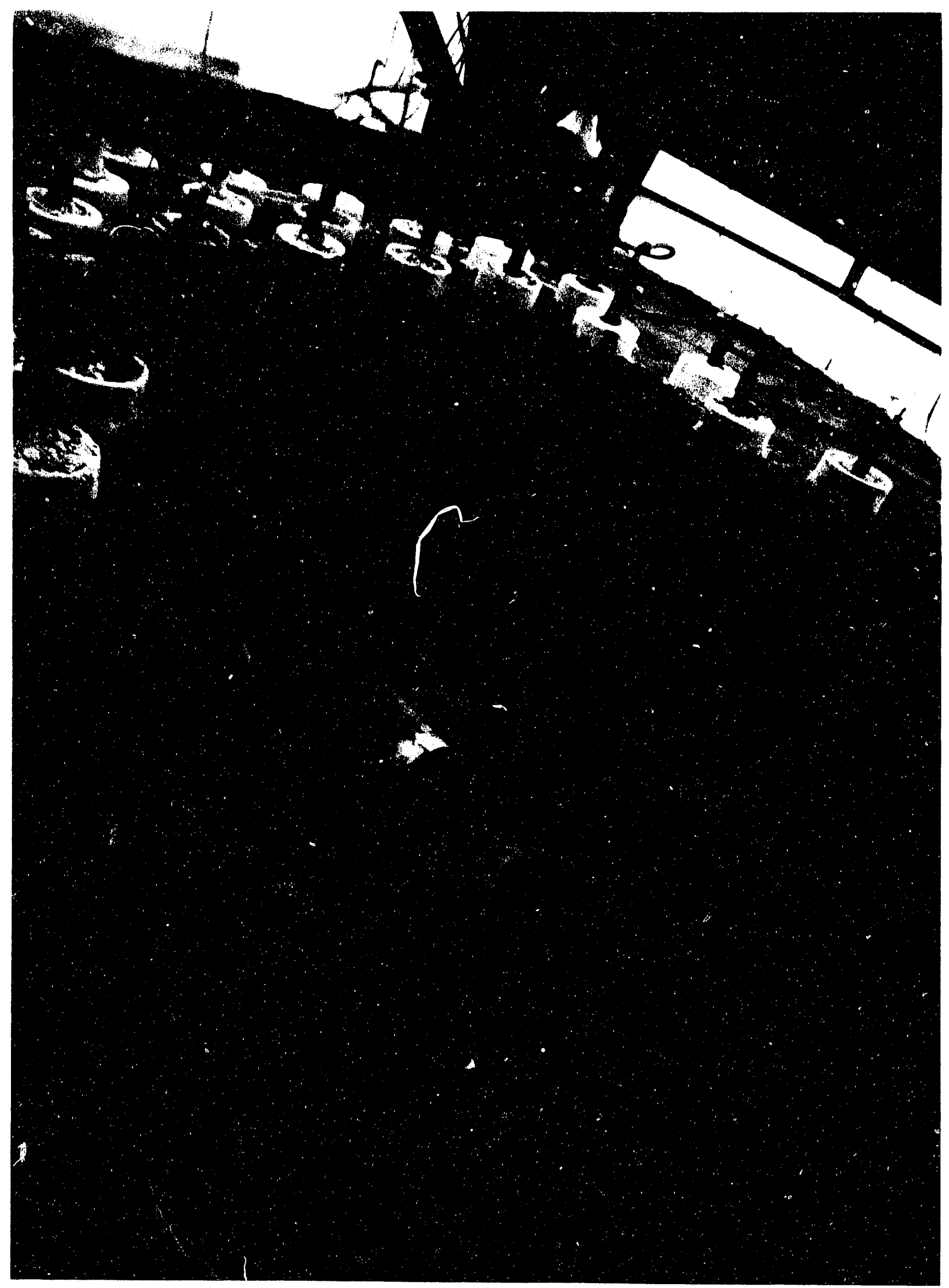

Figure 51. Random clumped barrels and boxes excavation \#1. 

August 7. The gantry was moved ofl on August 7 and onto the stacked boxes pit. The pit was barricaded and covered with visquene for 2 days to determine if any thawing would occur to allow removal of the perimeter freeze pipes. Alter 2 days (August 9), it was attempted to pull the freeze pipes out with the crane. This action was not suceessful, therefore, the pipes were cut off belowgrade and buried. The pit was then backfilled and compacted with clean till dirt.

During the breakout of the dry and wet sides of the pit an additional 12.700 gal of $\mathrm{LN}_{2}$ were used, bringing the total consumption for this pit to 76,700$) \mathrm{gal}$. A total of six storage boxes were tilled with soil and debris from this pit. Each box was filled 70 to $90 \%$ full. As with the other filled boxes, they will be stacked at the north end of the cold test pit to form a new sixth cell to be used for future testing.

There were a series of equipment problems during breakout of this pit, and although no single problem was difficult, most proved to be time consuming and caused down time. Hydraulic hoses continuously broke on the jackhammer, there was a cracked bearing shaft, and the tool jumped the crane rail. There were problems with the grapple and some minor mechanical difficulties with the shears.

\subsection{Stacked Barrels}

The planned testing at the stacked barrels pit did not occur. By the time work was completed on the random dumped boxes and barrels pit, there was only enough funding left to support one more test. The stacked boxes were chosen for the third and final test.

Freeze pipes were placed in the stacked barrels pit but lat/er removed because the test was canceled.

\subsection{Stacked Boxes}

Freeze pipes, water injection pipes, and instrumentation probes for the stacked boxes pit were installed on July 23 and 24. Placement went well and there was no down time with the vibratory drill. Only one of four moisture probes was functioning because two were inoperable after placement and a third was damaged during placement. The configuration of the freeze pipes in this pit was slightly different than the first two pits. Figure 53 shows the layout of the stacked boxes pit freeze and water injection pipes. A side experiment was conducted during the placement of freeze pipes in the stacked boxes pit and the random dumped barrels and boxes pit. A slurry mix was placed in the collar before driving the freeze pipe. The pipe was then driven through the mud. The reason for this test was to see how effective the mud would be as a barrier for suppression of contaminants that could be released during the drilling process in an actual hot retrieval exercise. Each of these pits was laced with rare earth tracers that could have become airborne during the drilling operation. To detect the tracer, smears were obtained from the drill collar during placement of pipes with and without the slurry. In theory, the tracer should appear on collars that were drilled without mud and no tracer should be present on the collars where mud was used. The results of this testing are given in Appendix E. 


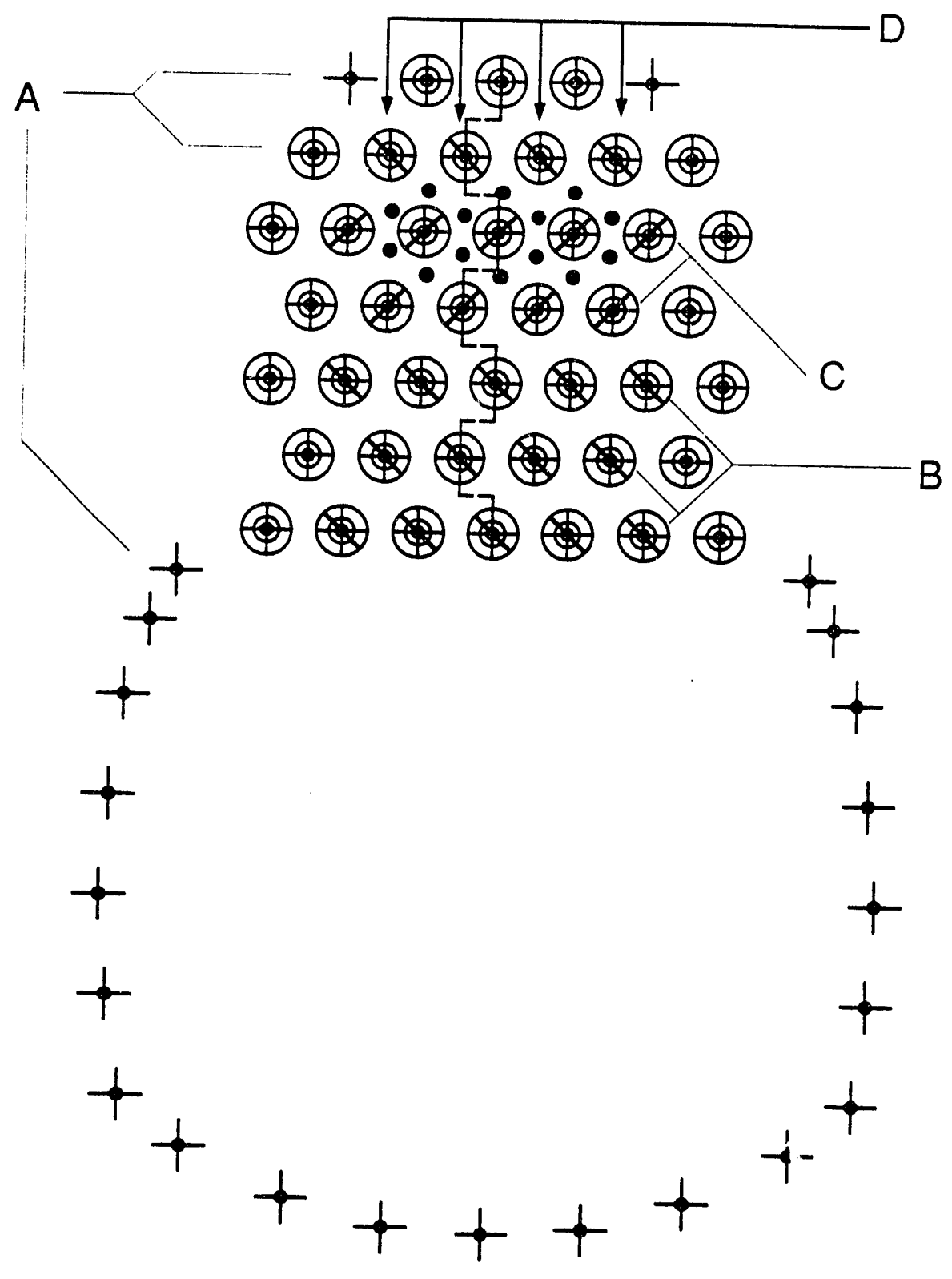
A 38 - Carbon steel wall freeze pipe $=13 \mathrm{ft}$
B 14 - Stainless steel waste freeze pipe $=11 \mathrm{ft}$
C 9 - Stainless steel water injection freeze pipe $=13 \mathrm{ft}$
D 4 - Carbon steel water injection freeze pipe $=13 \mathrm{ft}$
- 14 - Carbon steel water injection pipe $=10 \mathrm{ft}$

Figure 53. Layout of stacked boxes freeze pipes. 
The difference between the stacked boxes pit and the lïrst (wo pits that were frozen and excavated is the method in which the pit is frozen for the containment of water. Previously, the perimeter of the pit was trozen and water added, the assumption being that by chilling the soil and waste sufficiently, the water would freeze on contact and form a barrier. In this pit the approach will be to freeze the perimeter and at the same time freeze the lloor (bottom $2 \mathrm{ft}$ ) of the back half of the pit before the introducing water.

$\mathrm{LN}_{2}$ was tlowed to the perimeter and tloor piping of the freeze pit on August 2. This area was chilled tor 2 days and consumed $21,000 \mathrm{gal}$ of $\mathrm{LN}_{2}$. At this time about $2000 \mathrm{gal}$ of water were injected through the water injection pipes. The injection occurred from August 4 to the 5 th. At the time the water was added, it was subsequently detected flowing at the bottom of the pit by a moisture probe, again indicating that the fluid had found a pathway through the waste and soil, and was not freezing on contact. An additional approximate $500 \mathrm{gal}$ of water were added at the surface. A small berm was built around the perimeter of the pit and the water allowed to soak through the soil. Water was added at the surface because the breakout of the dry side of the previous two pits indicated that the addition of moisture is desirable to help form larger soil pieces and reduce the risk of airborne contamination. On August 5, freezing of the perimeter of the access pit and the first row of freeze pipes in the waste pit was started. On August 6, the remainder of the interior of the waste pit had $\mathrm{LN}_{2}$ added. On August 8 , the initial freeze down of the pit was complete. An additional $47,600 \mathrm{gal}$ of $\mathrm{LN}_{2}$ were used during this process.

The access pit was excavated on August 7, and the gantry was positioned over the pit later the same day. Equipment was checked and readied for breakout. Air monitoring high-volume samples were obtained, and the breakout started on August 8. As with the other pits, the formation of ice columns was limited, even with the addition of the water added at the surface. The breakout tool removed about the top $2 \mathrm{ft}$ of pipe, collar, and soil, and then the pipe was bent over. The jackhammer was then used to remove the remainder of the pipe and soil. There was not a significant difference in the soil between the front and back half of the pits. With the addition of water sorne fair sized pieces of frozen soil (bowling ball and bigger) were formed during the breakout.

As explained before, the stacked boxes pit was selected because of the potential for a different type of waste than had been previously encountered. Most of the boxes in this region were filled with metal, concrete, asphalt, and industrial debris. This test was intended to determine how well the jackhammer and shears would work extracting this type of waste. Unfortunately during the excavation of the pit, no waste was encountered. Originally it was surmised that the pit was incorrectly located. or the as built information pertaining to the location of the cold test pit was inaccurate. What occurred is the stacked boxes located on the west boundary of this cell were compressed during the backfilling operation (see Figure 54). They were flattened below the level of the bottom of the freeze pit that was excavated and were never encountered during the excavation. This suggests that the boxes did not contain the type of debris that was hoped for and probably had significant void areas. Another possible condition that could have occurred and would help explain the "flattening" of the boxes, is the boxes could have sunk some distance during initial construction of the cold test pit. When the pit was first built, large quantities of water were added to hasten the deterioration of the cardboard containers. If enough water pooled beneath the boxes to form a soft mud layer, then the containers might have sank a few inches. The freeze pipes probably penetrated the boxes, but the waste was never seen or removed. A test hole was dug immediately in back of the waste pit, and it was discovered that the boxes had 8 to $9 \mathrm{ft}$ of soil cover. The breakout and retrieval 


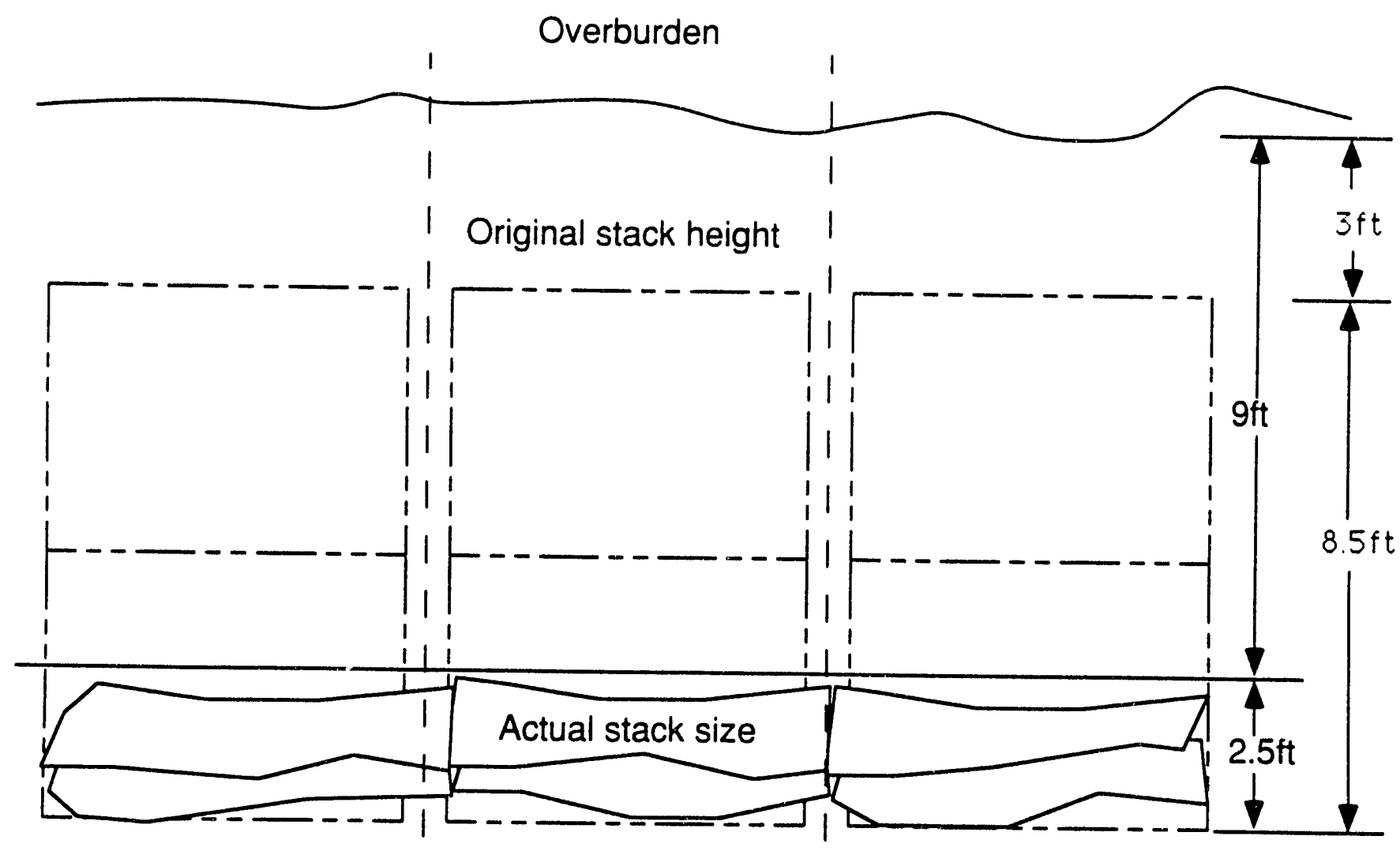

Figure 54. Crushed boxes. 
activities were stopped during the early morning of August 10. An additional 4,(f)() gal of $\mathrm{LN}_{2}$ were used during breakout, bringing the total usage for the stacked boxes pit to $72,6(0)$ gal.

Observations and occurrenees during the breakout included several sparks that were produced when the jackhammer hit one of the freeze pipes. This could be a potentially dangerous situation in a hazardous environment if there were ignitable vapors present. As before, there was very little or no visual dispersal of dust during breakout. The equipment reliability was much better for the last pit. There were only three small repairs that had to be made during the entire sequence, resulting in only a tew minutes of down time over a 20 hour period. A total of 10 storage boxes were used during to the removal of soil from the pit. A fair amount of visual dust was generated when the grapple was placed the soil in the storage box, but this appeared to settle out quickly.

At the conclusion of the breakout, air samples were obtained and the gantry was moved off for disassembly. The pit was backfilled on August 12 and protruding freeze pipes were cut off belowgrade.

\subsection{Demobilization}

Demobilization from the cold test pit site commenced on August 10 and was completed 4 days later on August 14,1992. The following is a summary of how various equipment and supplies were dispositioned and the final condition of the cold test pit at the conclusion of the field work:

- The gantry was positioned in the extreme southwest corner of the cold test pit area (as shown in Figure 55). All tools, tarps, cameras, cables, and wiring were removed and only the steel structure left standing. The gantry will be left at the cold test pit for possible future use in other cold test pit demonstrations.

- Miscellaneous equipment, tools, consumables, and stock items such as scrap pine, wood, insulation, environmentally friendly hydraulic fluid, tools, and other odds and ends were stored in a weatherproof transport box near the gantry.

- The jackhammer was a leased piece of equipment from Louis Grant, Inc., and was removed from the site by the owner. The other tools (shears, grapple, and breakout) were purchased outright and as such became the property of the government. Each tool includes the bridge crane, elevator, and rotator. The tools will initially be stored at the cold test pit. They will be weatherproofed with visquene and tarps and left on elevated stands near the gantry (location as shown in Figure 55).

- The video and control equipment was likewise purchased outright and is government property. These items were wrapped in visquene and place:d in one of the spare $4 \times 4 \times 8$-ft storage boxes. The SCBA units were placed in the same box along with the oxygen monitors. The storage box was then transported to the Central Facilities Area monitored storage facility.

- Spare $4 \times 4 \times 8$-ft storage boxes (about 30 ) were left near the entrance road by the northeast corner of the cold test pit. These will probably be taken by other INEL contractors for use in the near future. 


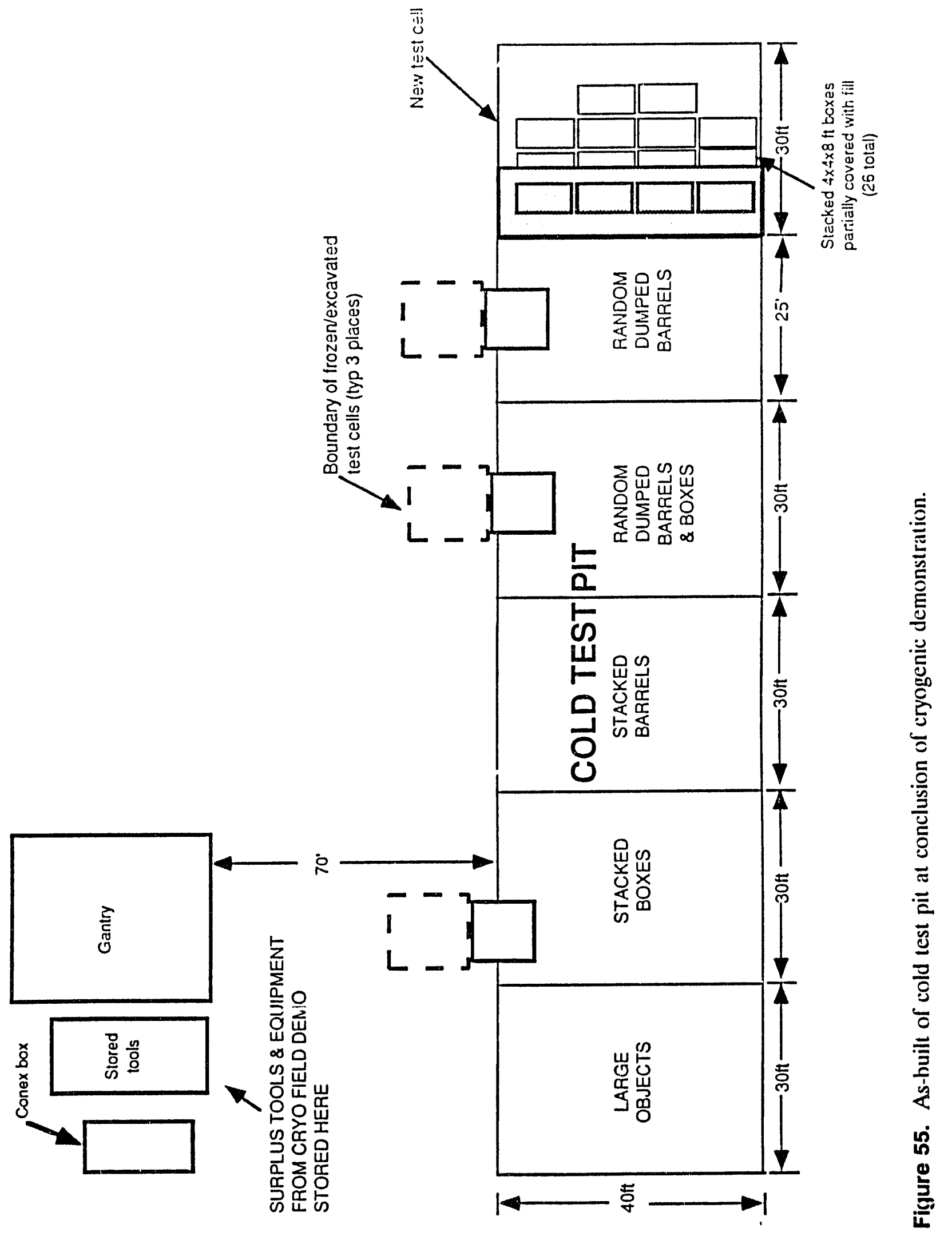


- All the test pits were backlilled with clean soil. The pipes were cut off belowgrade and left in place in the random dumped barrels, random dumped barrels and boxes, and stacked boxes pits. The freeze pipes were pulled from the stacked barrels pit. Figure 55 shows the location of the pits and the freeze pipes and fill material left in each.

- The air monitoring equipment was removed from the site by EG\&G Idaho technicians. Most of these materials were low dollar value items such as tubing, filters, tlow sensors, and other miscellaneous fittings. The instrumentation shed and data logger were taken back to the Test Reactor Area.

- The storage boxes that were filled during the exhumation process were stacked at the north end of the existing cold test pit to form a new cell (see Figure 55). About half of the boxes were covered with visquene and soil and the other half left exposed.

- Fill material was placed on the west side of the cold test pit, and it was graded to the original contours.

- All other equipment, tools, the control trailer, vehicles, etc.., were removed from the site by Sonsub.

The site was inspected by Sonsub and EG\&G Idaho personnel to ensure that all debris, trash. equipment, and other materials were removed and the site was restored to its as found condition. 


\section{RESULTS AND INTERPRETATIONS}

\subsection{Overview}

This section presents the parameters that were recorded during the cryogenic retrieval demonstration. Indepth analyses of the data from the thermocouples, moisture probes, and air monitoring system are presented in Sections 7.2 through 7.5. Section 7.6 includes a general comparison of the demonstration results with preestablished performance criteria.

As detailed in Section 6, freezing each pit consisted of tirst chilling the perimeter of the pit and then freezing the actual waste. These processes can be seen by the two distinct slopes on each of the lines in Figure 56.

Figure 56 is a plot of the average temperature readings from all of the thermocouples in each of the three pits. An average of 90 hours was required to freeze each of the perimeters, and a total of about 140 hours on average was required to chill the pit to the point where breakout of the waste could be attempted.

As shown in Sections 7.2 through 7.5, the actual traces of each thermocouple are quite complicated. The instantaneous temperatures we dependent upon parameters such as the location of the thermocouple in the pit, if water was being acided and whether the $\mathrm{LN}_{2}$ was being run or not. Two characteristics of the temperature profiles that were typical for all of the temperature probes in all of the pits were

1. The temperatures rose on an average of $5^{\circ} \mathrm{F} /$ hour when the flow of the $\mathrm{LN}_{2}$ was shut off.

2. Once the temperature at a probe dropped below freezing, the rate of the temperature drop increased and the temperature at the probe did not record a temperature above freezing through the rest of the breakout activity.

Tabie 1 presents the volumes of $\mathrm{LN}_{2}$ and water that were injected into each pit.

The total volume of each pit was 6,060 gal. Assuming a $25 \%$ void fraction within each pit, a maximum of 1,515 gal of water were needed to saturate each pit. A minimum of 1700 gal were added to each pit. Thus it is clear from these figures that water did migrate through the pit boundaries in all of the pits. Such migration was recorded by the TDRs in the random dumped barrels and the stacked boxes pit. In the random dumped barrels and boxes pit, water migrated laterally and seeped into the working pit, but no recordable moisture reached the TDR probes.

Table 1. Volumes of water and $\mathrm{LN}_{2}$ injected into each pit (gal).

\begin{tabular}{lll}
\hline & $\mathrm{LN}_{2}$ & Water \\
\hline Random dumped barrels & 85,500 & 1792 \\
Random dumped barrels and boxes & 76,700 & 1700 \\
Stacked boxes & 72,600 & 2500 \\
\hline
\end{tabular}




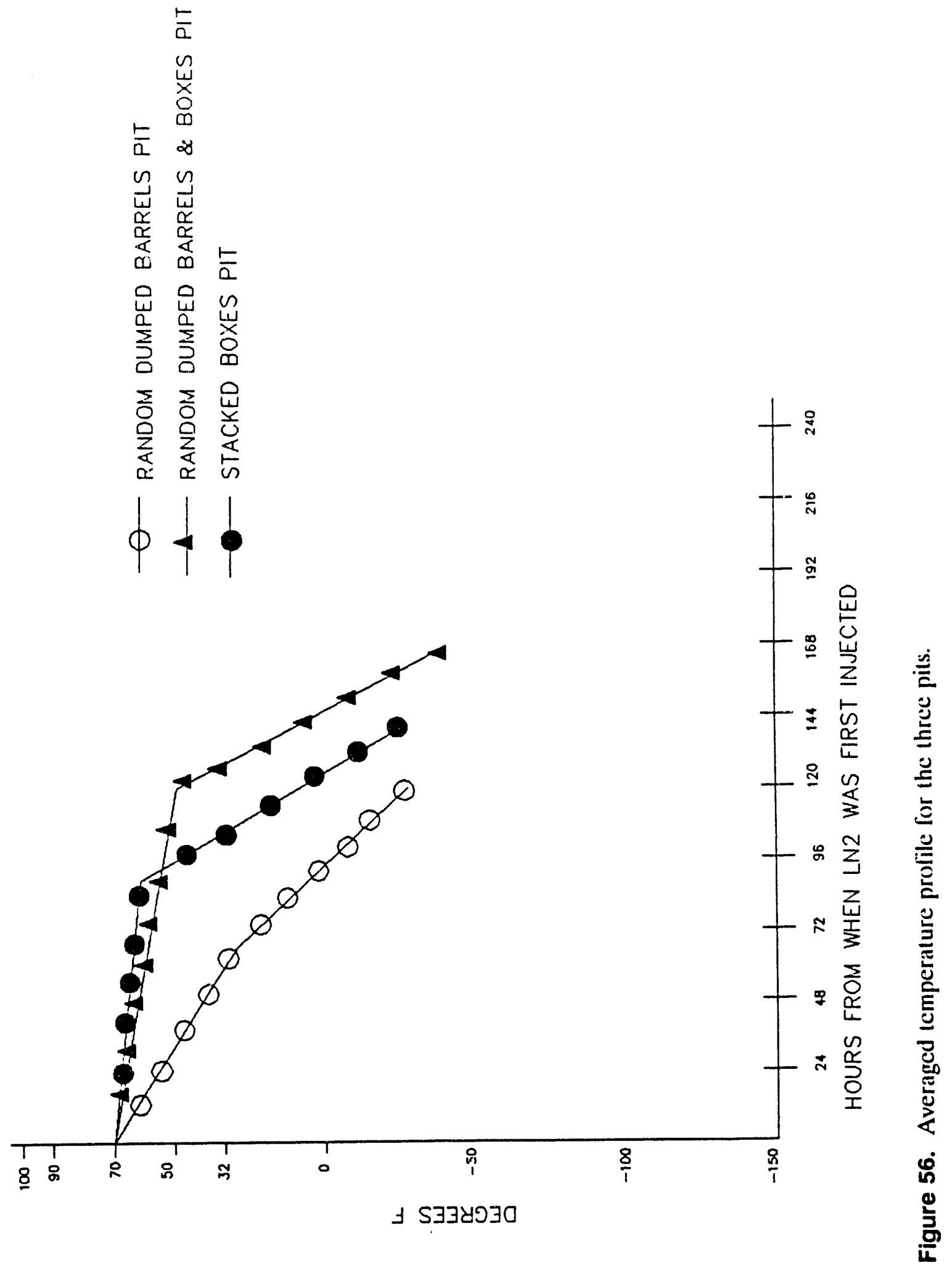


The air monitoring data showed that significant amounts of tracers were released from the random dumped barrels pit, but only background levels on the tracers were detected from the other two pits. Data in Section 7.2 imply that the maximum tracer release in the random dumped barrels pit occurred in the areas close to where the debris was being demped into the box and visible dust was observed.

\subsection{Results from Random Dumped Barrels}

Generally, the temperature profiles for the probes that were embedded into the wast "the random dumped barrels pit did not show strong correlations between temperature gradients and probe depth. This pit had a heterogeneous mixture of waste and soil. In a pit of a homogeneous media, such as a pit of all soil, one would predict that the temperature profile would show cooler temperatures toward the bottom of the pit, where the $\mathrm{LN}_{2}$ would collect in the bottom of the freeze pipes, and warmer temperatures toward the top of the pit, where the air would warm the nit. The lack of such a correlation for this pit indicates that the wide variety of simulated was.: in the pit provided varying levels of thermal insulation throughout the pit. Thus, the heterogeneity of the media in the pit had a direct effect on the freezing process in the pit.

Strong correlations between depth and temperature are evident with the temperature probes that were driven $11 \mathrm{ft}$ deep. These thermocouples were positioned $1-\mathrm{ft}$ below the floor of the pit. Consequently, there was $1-\mathrm{ft}$ of soil insulating these probes from the freeze pipes. The result was smaller temperature gradients for the thermocouples below the pit than for the thermocouples that were embedded in the waste inside of the pit.

Figures 57 through 61 show various temperature profiles of we random dumped barrels pit. This pit is unique from the others because it was the only one that followed the original plan of freezing the perimeter of the waste and access pit with the front row of the waste pit, freezing the front three rows of the waste pit, adding water to the last three rows of the waste pit, and then, freezing the last three rows of the waste pit. As a result of this procedure, one can compare Figures 60 and 61 and see that the drop in temperatures on the "wet side" of the pit lags the drop on the "dry side" of the pit. After Sonsub began the breakout of the pit, $\mathrm{LN}_{2}$ was added to the pit only at night (during nonworking hours). This can be seen from all of the figures by the rise in temperature during the day hours. The time is shown along the $x$ axis of these graphs. Time zero is defined as when $\mathrm{LN}_{2}$ was first injected to begin freezing the perimeter of the pit.

Large spikes of low ternperatures indicate areas where $\mathrm{LN}_{2}$ pooled around the probe on the surface of the pit. Figure 57 is a profile of all the surface temperature probes. The pooling of the $\mathrm{LN}_{2}$ had more impact on the temperature profile on the surface than the configuration in which the $\mathrm{LN}_{2}$ was being injected. For these surface probes, there is no distinguishing characteristics between the profiles on the dry side and the profiles on the wet side of the pit.

The addition of water to the wet side of the pit had the effect of raising the temperature on the wet and dry side of the pit. Figure 58 is a profile of all of the stacked temperature probes on the dry side of the pit. Temperature probes at the $11-\mathrm{ft}$ depth did not reach freezing on the dry side of this pit. The temperature difference between the probes at $11-\mathrm{ft}$ and the probes at 8 - $\mathrm{ft}$ is an 


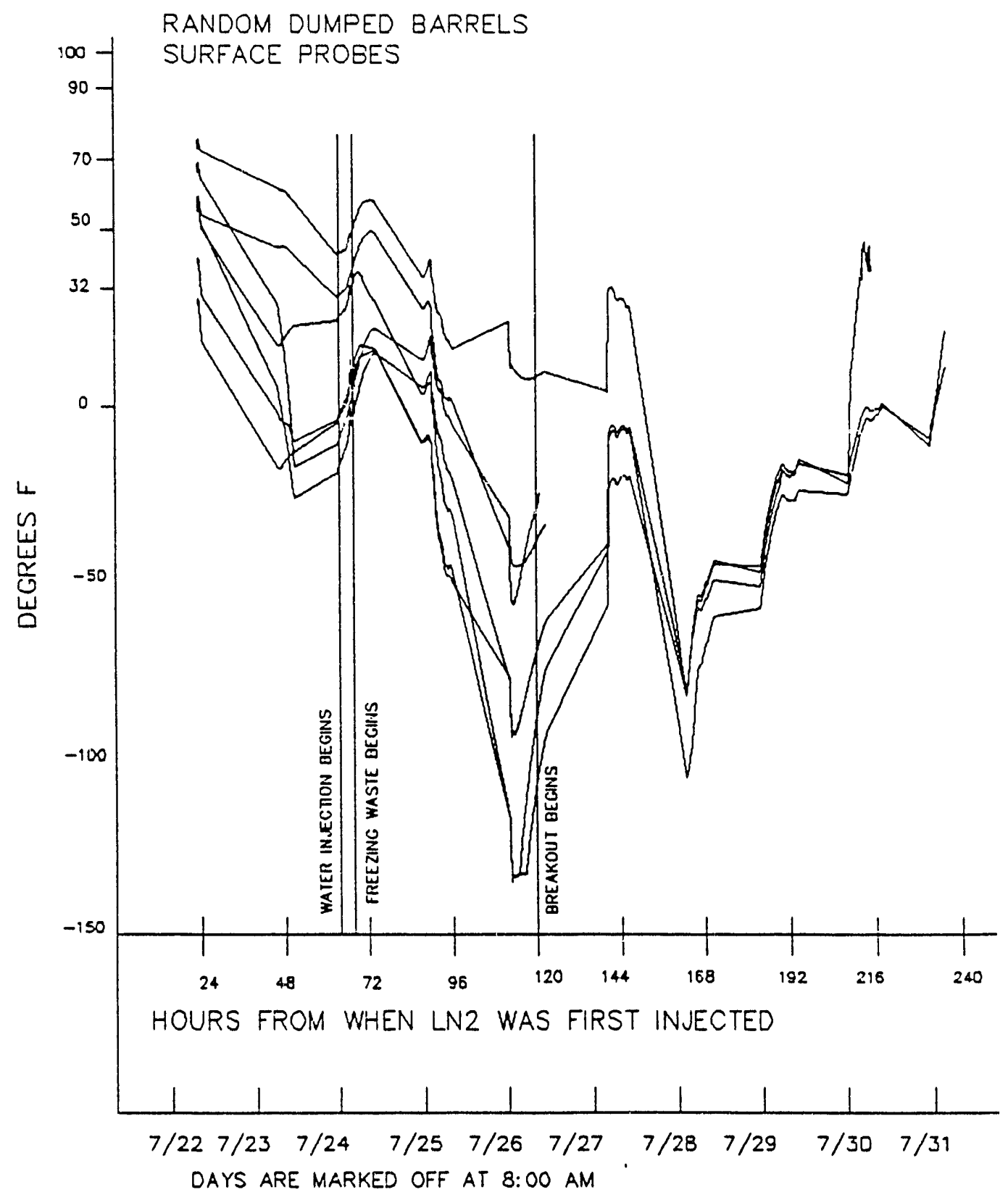

Figure 57. Surface thermocouples ir t the random dumped barrels pit. 


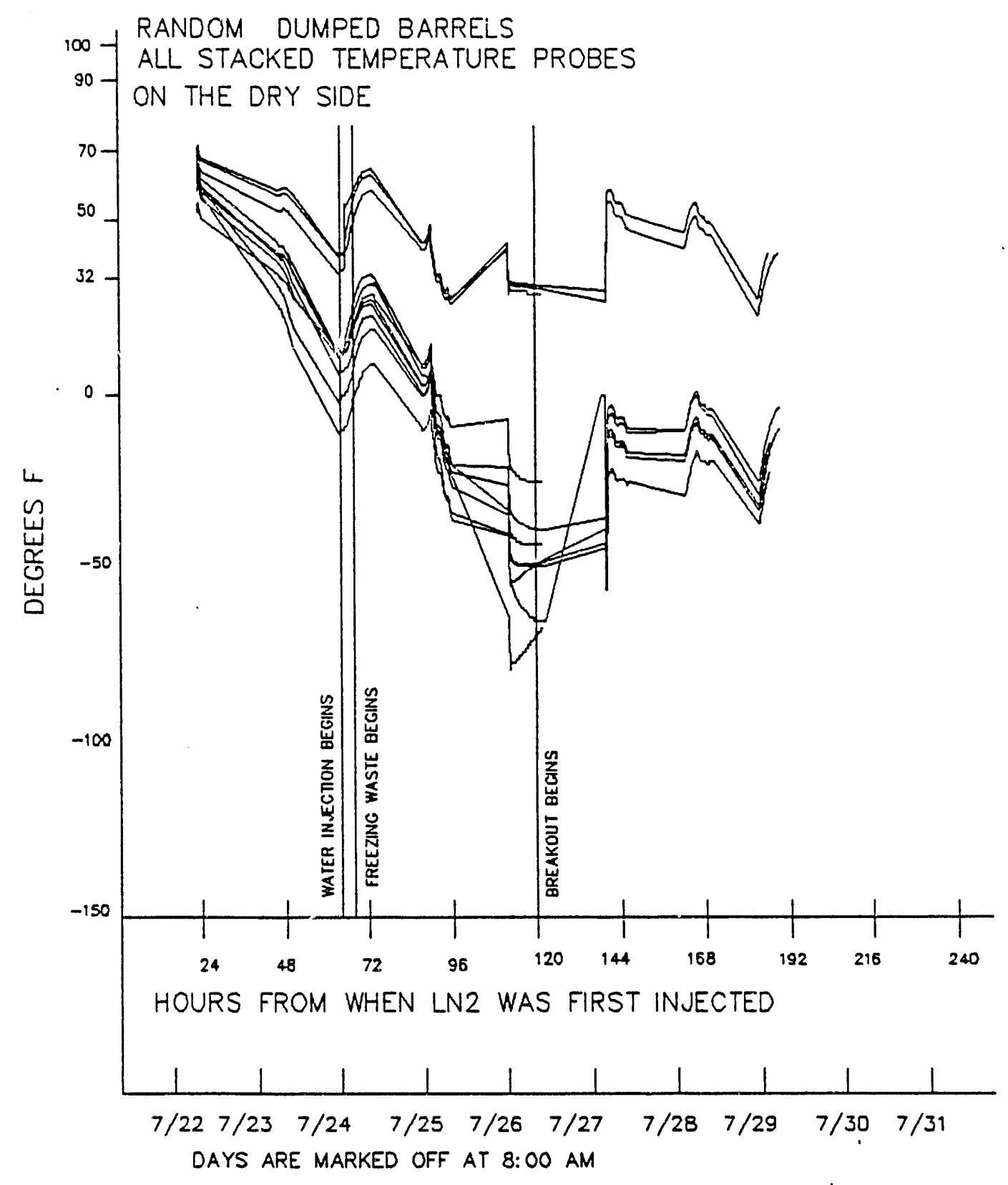

Figure 58. All stacked probes on the dry side of the random dumped barrels pit. 


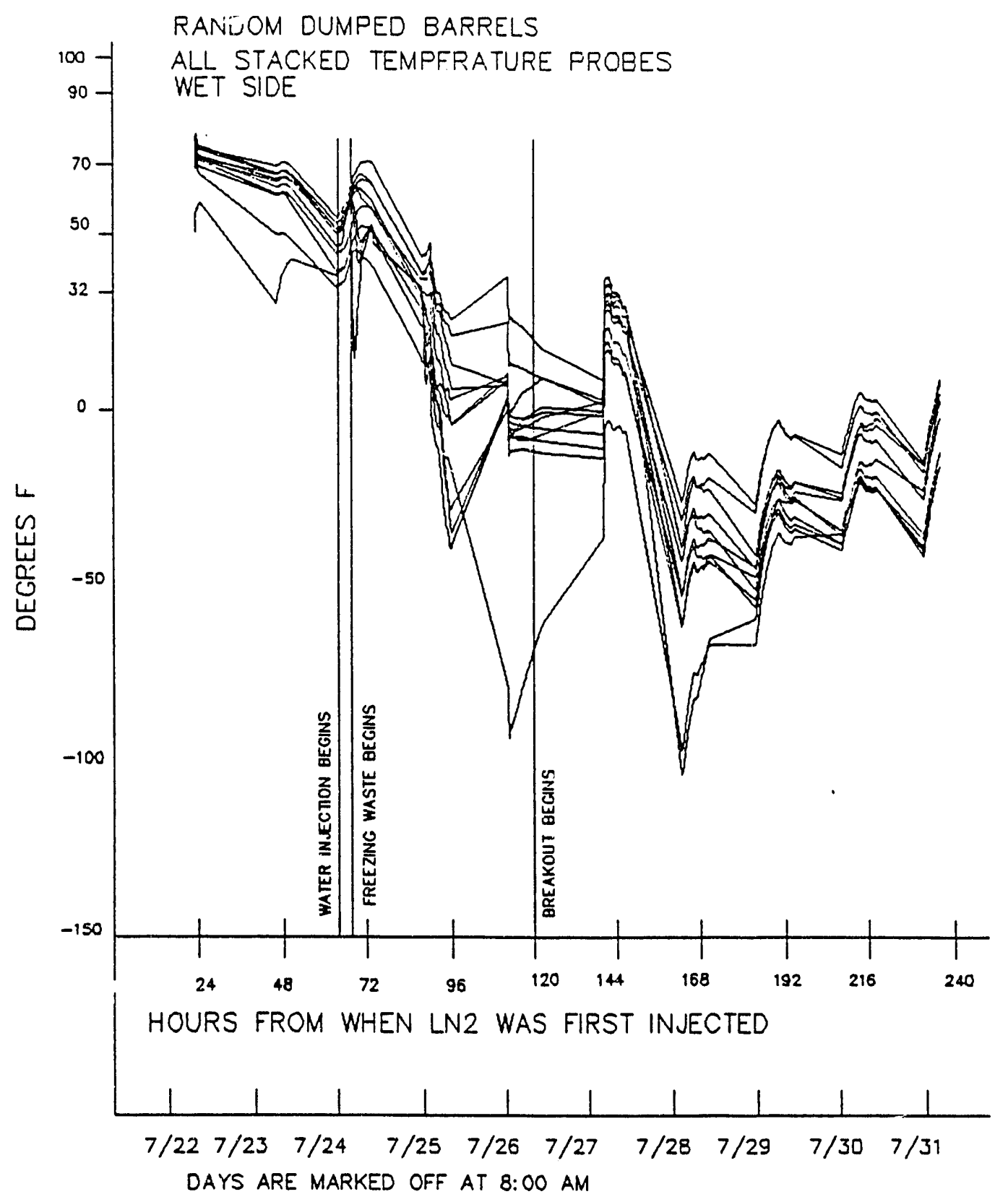

Figure 59. All stacked temperature probes on the wet side of the random dumped barrels pit. 


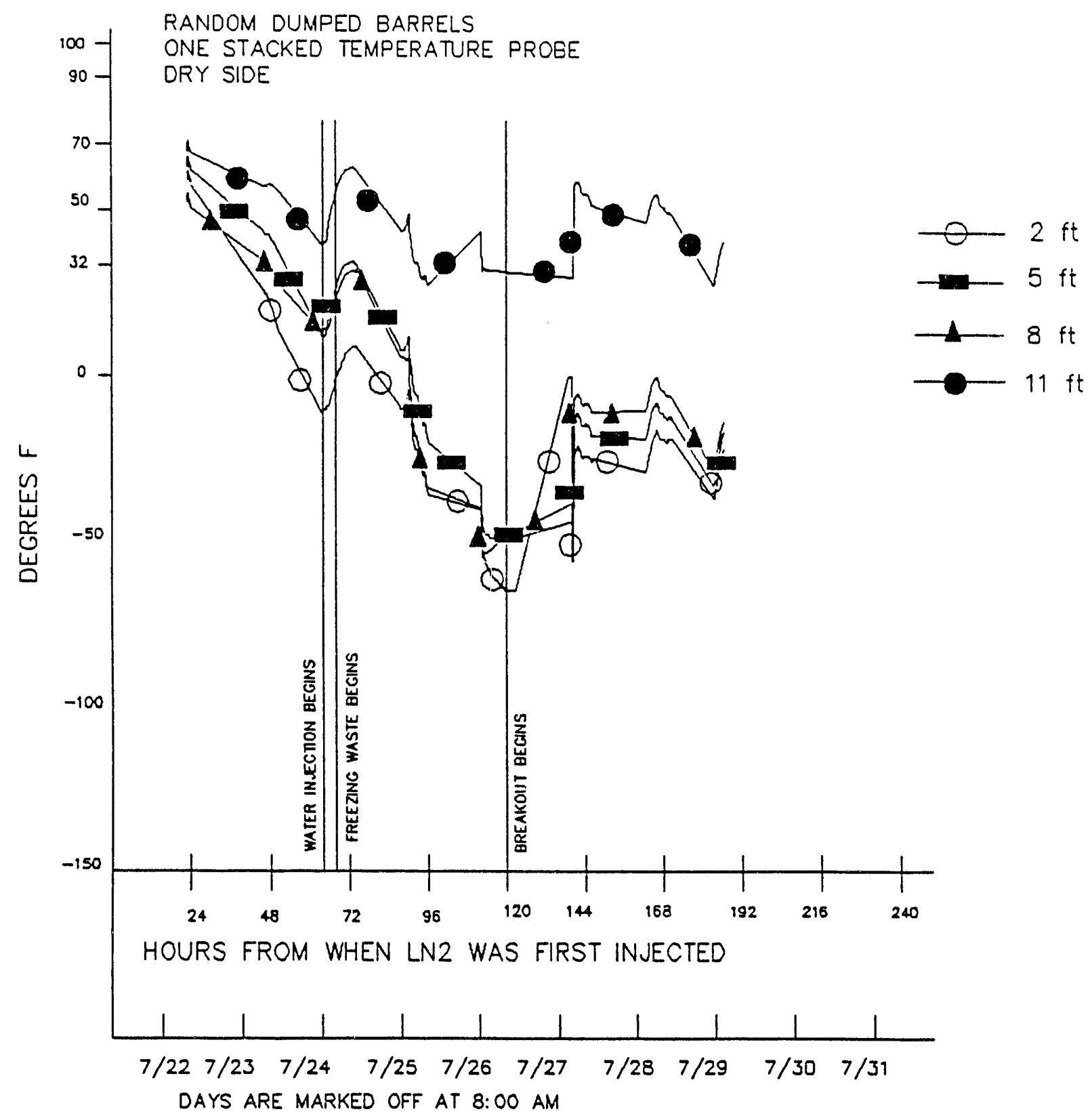

Figure 60. One stacked temperature probe on the dry side of the random dumped barrels pit. 


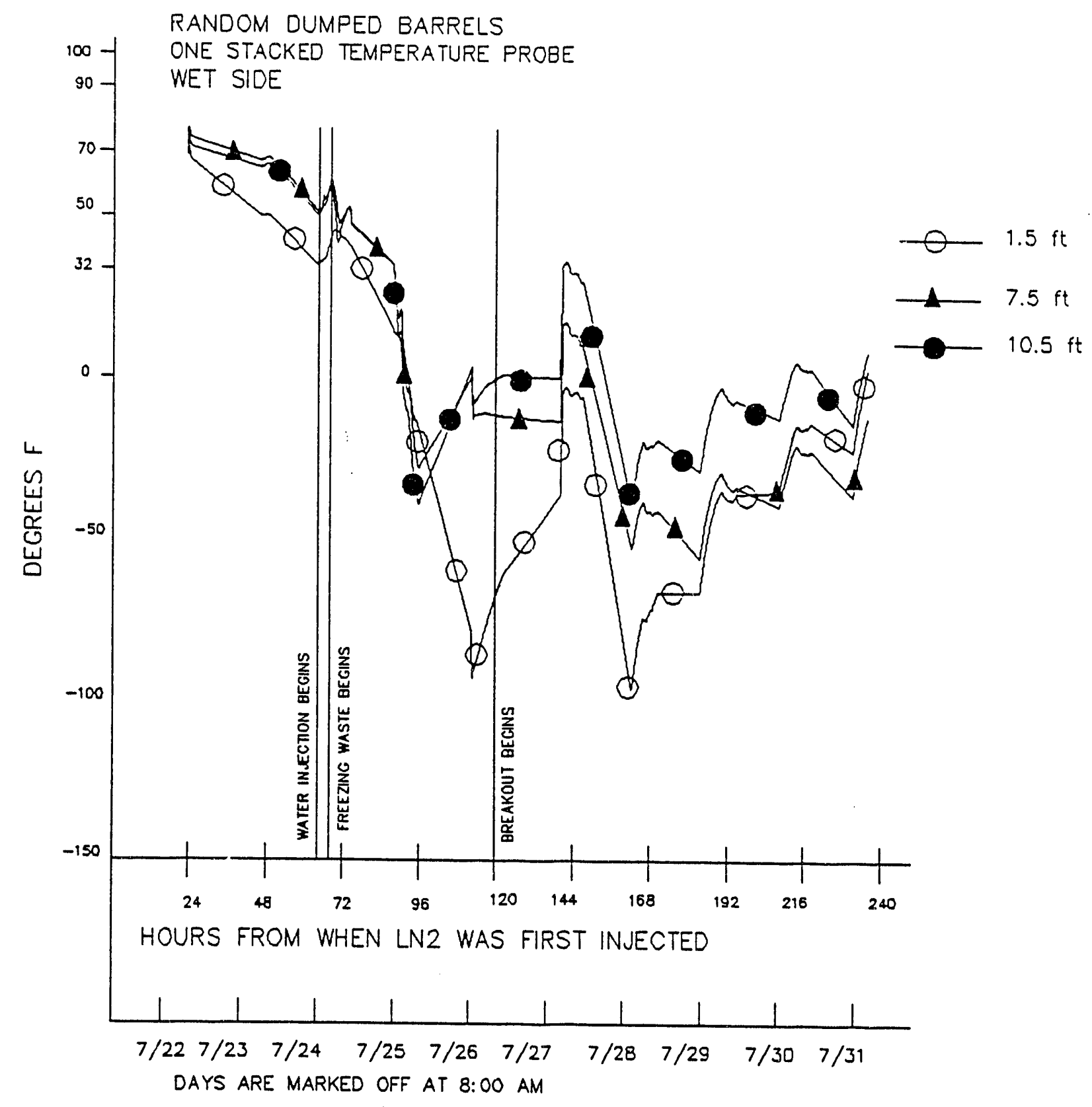

Figure 61. One stacked temperature probe on the wet side of the random dumped barrels pit. 
indicated the amount of insulation provided by the 1 if of soil between the freeze pipes and the deepest thermocouples.

The temperature prolile for the wet side of the pit appears significantly different than the profile for the dry side of the pit. This difference was caused by shallower probe depths on the wet side of the pit. Because of problems with the vibratory drill on the wet side of the pit, all of the probes resided 1 to $2-\mathrm{ft}$ above their design depth. Figure 59 is a profile of all of the stacked temperature probes on the wet side of the pit. The lowest temperatures were all recorded by probes that were 1 to 2-ft below the surface. Such low temperatures were all the result of $\mathrm{LN}_{2}$ pooling on the surface of the pit as was the case with the surface probes. Also, the probes that were designed to reside at a depth of $11-\mathrm{ft}, 1 \mathrm{ft}$-below the waste, were actually positioned at depths of 9 to $10.5 \mathrm{ft}$ and thus embedded in the waste. The actual profiles may have been similar for the wet and dry side of the pit, but differences in probe depths resulted in a difference in the data that were recorded for the two sides of the pit.

For the dry side of the pit, the trend was for cooler temperatures closer to the surface. Figure 60 shows the cross sections of temperatures along a typical stacked temperature probe on the dry side of the pit.

For the wet side of the pit, the cooler temperatures seem to be closer to the surface of the pit. However, the low temperature spike around the thermocouple with a $1.5-\mathrm{ft}$ depth indicates that there was some pooling of $\mathrm{LN}_{2}$ around the probe. Figure 61 illustrates a typical cross section of temperatures along a stacked temperature probe on the wet side of the pit.

The data logging system for the TDR probe indicated that water did migrate through the pit floor. Before any of the water was added, the TDRs read $20 \%$ moisture. When the water was added, the TDR reading immediately jumped up to $40 \%$ moisture and then to $60 \%$ moisture content. ${ }^{e}$ Thus water was not contained within the pit boundaries. The original plan for containing the water was that the water would be added after the ground around the water injection pipes were at or near freezing. However, Figure 59 shows that the median temperature on the wet side of the pit when the water was injected was about $50^{\circ} \mathrm{F}$. The packed clay layer on the pit floor was not a sufficient barrier to water migration.

\subsubsection{Air Monitoring}

Tracers were released from the waste during the excavation of both the dry and wet sides of this pit. The random dumped barrels pit was spiked with the tracer dysprosium oxide. According to the test plan, ${ }^{2}$ one could be $90 \%$ confident that the tracer was released from the pit during the

e. It is unlikely that the soil moisture content rose to $60 \%$. When soil is saturated, the maximum TDR reading will be the percentage of the soil porosity. The soil underneath the cold test pit is likely to have a maximum porosity of $40 \%{ }^{4}$ Thus, the maximum expected soil moisture content would be $40 \%$. Higher readings could be recorded if there are large voids around the probe that would increase the effective porosity seen by the instrument. Such voids could have been created by the vibratory motion of the probe as it was inserted. Higher probe uncertainties around saturation could have also contributed to these high readings. 
demonstration if at least one of ihe air tilters detected more than $20.8 \mathrm{ppm}$ of dysprosium. As listed in Table 2, more than $20.8 \mathrm{ppm}$ of dysprosium was detected on every tilter used during this portion of the demonstration. Thus, this portion of the demonstration failed in terms of contamination control. As expected, there was less contamination from the wet side of the pit than from the dry side of the pit. However, the concentrations from the dry side of the pit still exceed the criteria for contamination release from the pit.

Refer to Figure 32 for the location of the monitors ralative to the waste and working pits.

A statistical $\mathrm{T}$ test was run on the data from the dry side of the pit. Two conciusions were drawn.

1. The concentration of dysprosium was statistically higher on the north side of the gantry than on the south side of the gantry. This information implies that the prevailing southerly wind had an effect on the dust dispersal inside of the gantry, despite the gantry covei: The gantry cover was not air tight.

2. The dysprosium concentration on monitors in locations 9 and 10 are statistically higher than the concentrations on the other monitors. Monitors 9 and 10 were on the north side of the gantry, closest to the working pit and the box where grappling activity occurred.

Two high volume background samples where taken in this pit. One sample was taken before the dry portion of the pit was excavated. The other background sample was taken after the dry portion of the pit was excavated and before the wet half of the pit was excavated. See the test plan ${ }^{2}$ for more information on the background sampling. The results of the background sampling are listed in Table 3.

It was expected that the first background sample concentration would be within the range of the natural background concentrations for dysprosium, less than $20.8 \mathrm{ppm}$. However, the air monitoring logbooks indicate that a drum was punctured during the excavation of the working pit. The only explanation for this curiously high concentration is that some of the dysprosium in that punctured drum resuspended and migrated to the high volume sampler. The second background sample was within the background range for dysprosium as expected. This was expected since this

Table 2. Concentration of dysprosium found in random dumped barrels pit (ppm).

\begin{tabular}{ccc}
\hline Location & Dry side & Wet side \\
\hline 1 & 95.4 & 29.1 \\
2 & 97.9 & 32.3 \\
3 & 96.1 & 25.9 \\
4 & 97.3 & 39.6 \\
5 & 102.4 & 44.6 \\
6 & 104.8 & 22.8 \\
7 & 105.9 & 41.8 \\
8 & 98.0 & 25.9 \\
9 & 116.9 & 37.0 \\
10 & 115.3 & 37.1 \\
\hline
\end{tabular}


Table 3. Background sampling in the random dumped barrels pit concentration of dysprosium (ppm).

\begin{tabular}{cc}
\hline Before the dry side & Betore the wet side \\
\hline 43.7 & 11.3 \\
\hline
\end{tabular}

sample was taken at 7 a.m., nearly 12 hours after the excavation for the dry portion of the pit had ended. Particles of 1 micron in diameter and larger will typically settle out of the air in 3 hours or less. $^{2}$

\subsection{Results from the Random Dumped Barrels and Boxes}

In this pit, the correlations between the depth of the probe and the probe temperatures were more obvious than they were for the random dumped barrels pit. One explanation for this is that, for this pit, the soil was the insulation material between the freeze pipes and the probes for most of the thermocouples in this pit. Significantly fewer waste forms were found in this pit than were found in the random barrels pit.

The difference in temperature gradients between the probes below the pit and the probes embedded in the waste is minor. Because soil is the dominant insulator throughout this pit, the difference in the gradients between the deepest probes and the probes embedded in the waste is a function of the distance of the probes from the freeze pipes. The probes at $11-\mathrm{ft}$ deep had $12 \mathrm{in}$. of soil insulation between the thermocouples and the freeze pipes. All of the other stacked temperature probes had 9 in. of insulation between the thermocouple and the freeze pipe. Figures 62 through 65 show various temperature profiles of the pit with random dumped boxes and barrels. With the exception of August 1, when the $\mathrm{LN}_{2}$ was run all day, Sonsub froze this pit by trickling the $\mathrm{LN}_{2}$ overnight and letting the pit warm during the day. This can be seen from all of the figures by the rise in temperature during the day hours. One should be cautious interpreting the apparent linear drop in temperature during the overnight cooling. Temperature data were not collected during the overnight cooling because the generator that powered the data logger was shut down overnight. The time is shown along the $x$ axis of these graphs. Time zero is defined as when $\mathrm{LN}_{2}$ was first injected to begin freezing the perimeter of the pit.

Early in the freezing process, the four surface thermocouples along the edge of the waste pit cooled down faster than the others. This is because Sonsub froze the front row of the waste along with the perimeter of the waste pit and working pit before freezing the rest of the waste pit. Figure 62 illustrates the profile of all of the surface thermocouples for the pit. Again, the low te mperature spikes are probably more of an indication of the $\mathrm{LN}_{2}$ pooling on the surface of the pit than any freezing process.

All of the thermocouples on the stacked temperature probes followed the same cooling and warming cycle. Figure 63 shows a profile of the stacked temperature probes in the pit. The consistency of these cycles illustrates that the wet and dry side of the pit were froze at the same time, and the thermal conductivity must have been fairly uniform throughout the pit.

Figure 64 illustrates the temperature response along a stack of thermocouples in the dry portion of the pit. While the perimeter of the pit was being frozen, the thermocouples lower in the stack read 


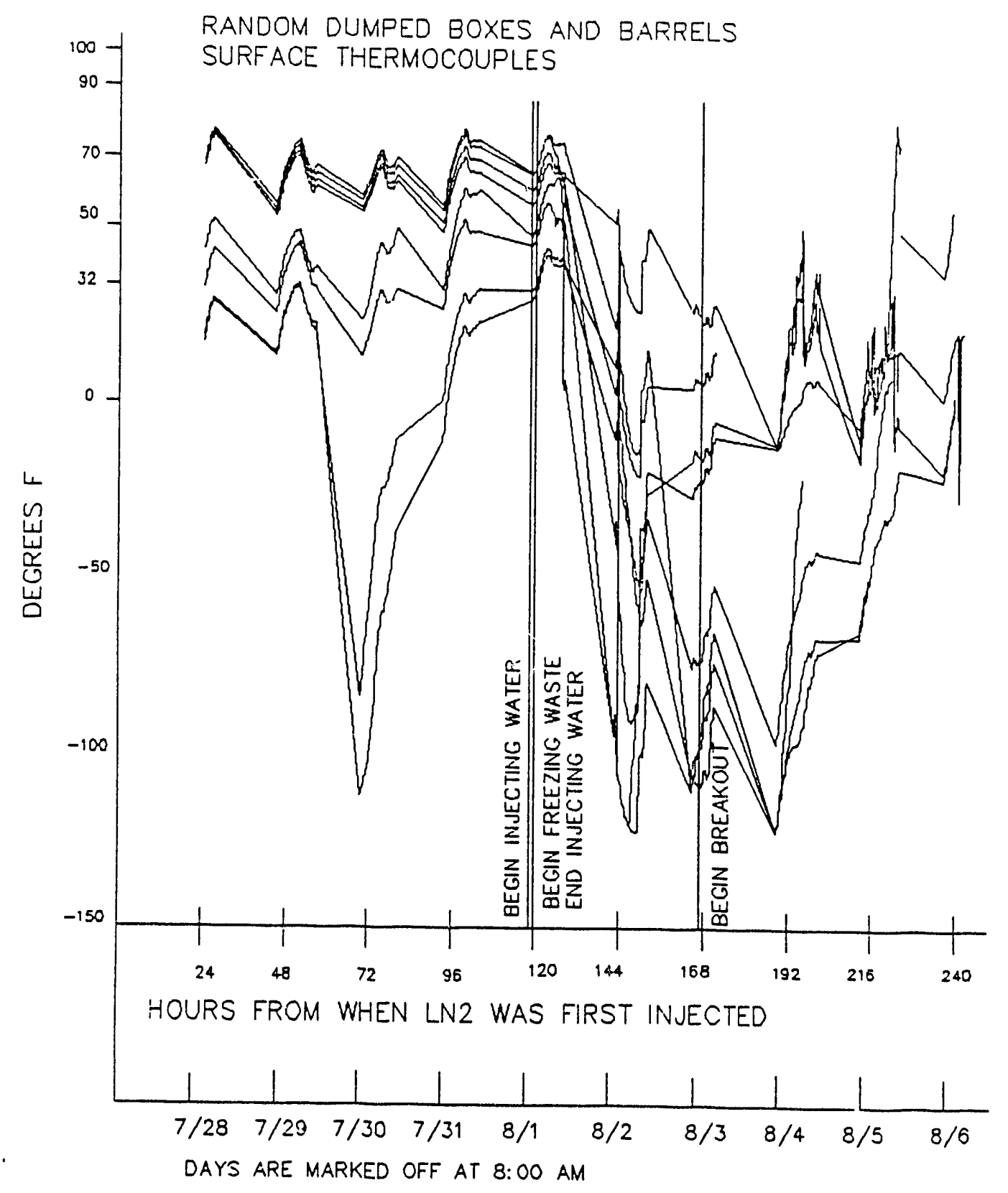

Figure 62. All surface thermocouples in the random dumped boxes and barrels pit. 


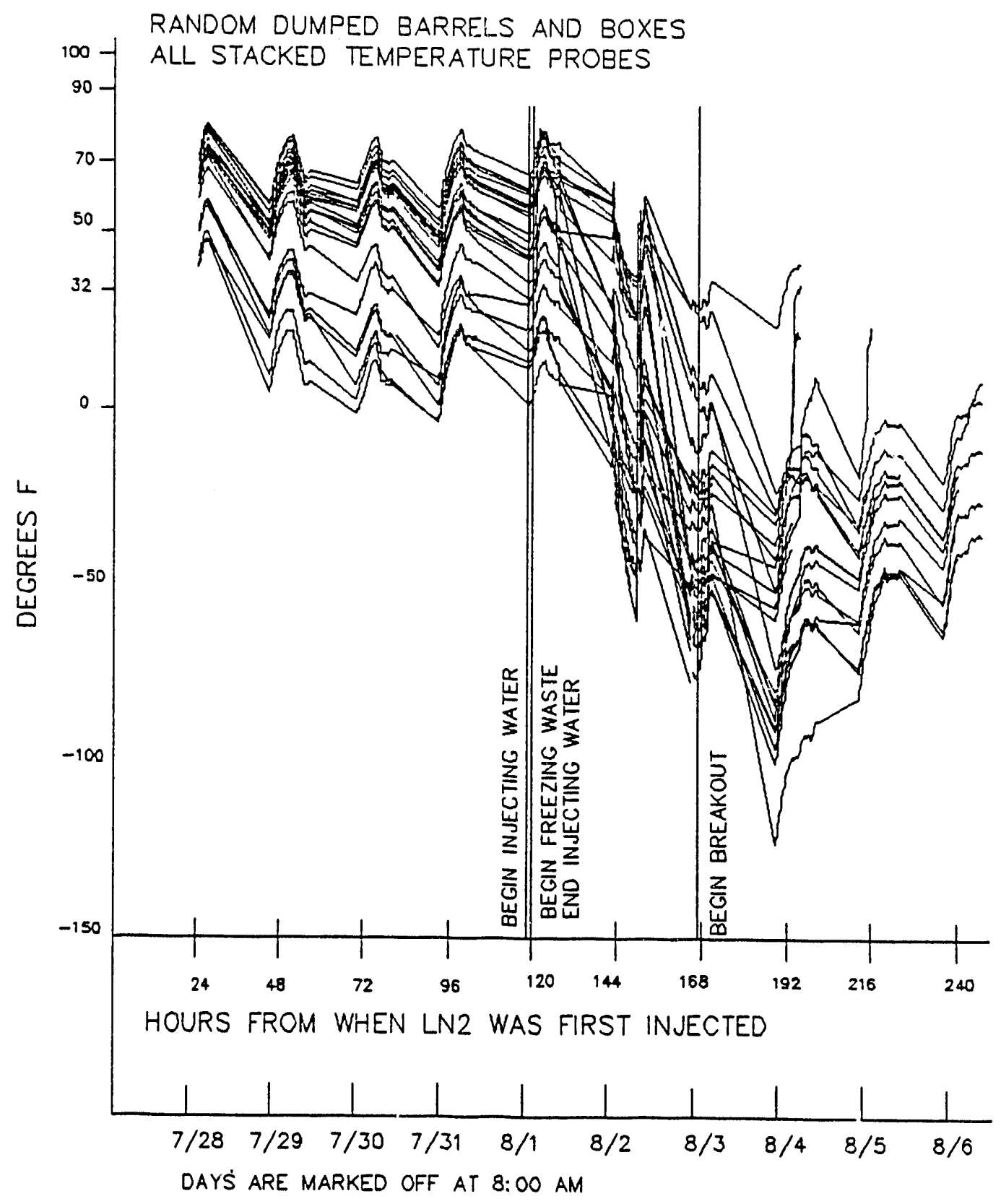

Figure 63. All stacked thermocouples in the random dumped boxes and barrels pit. 


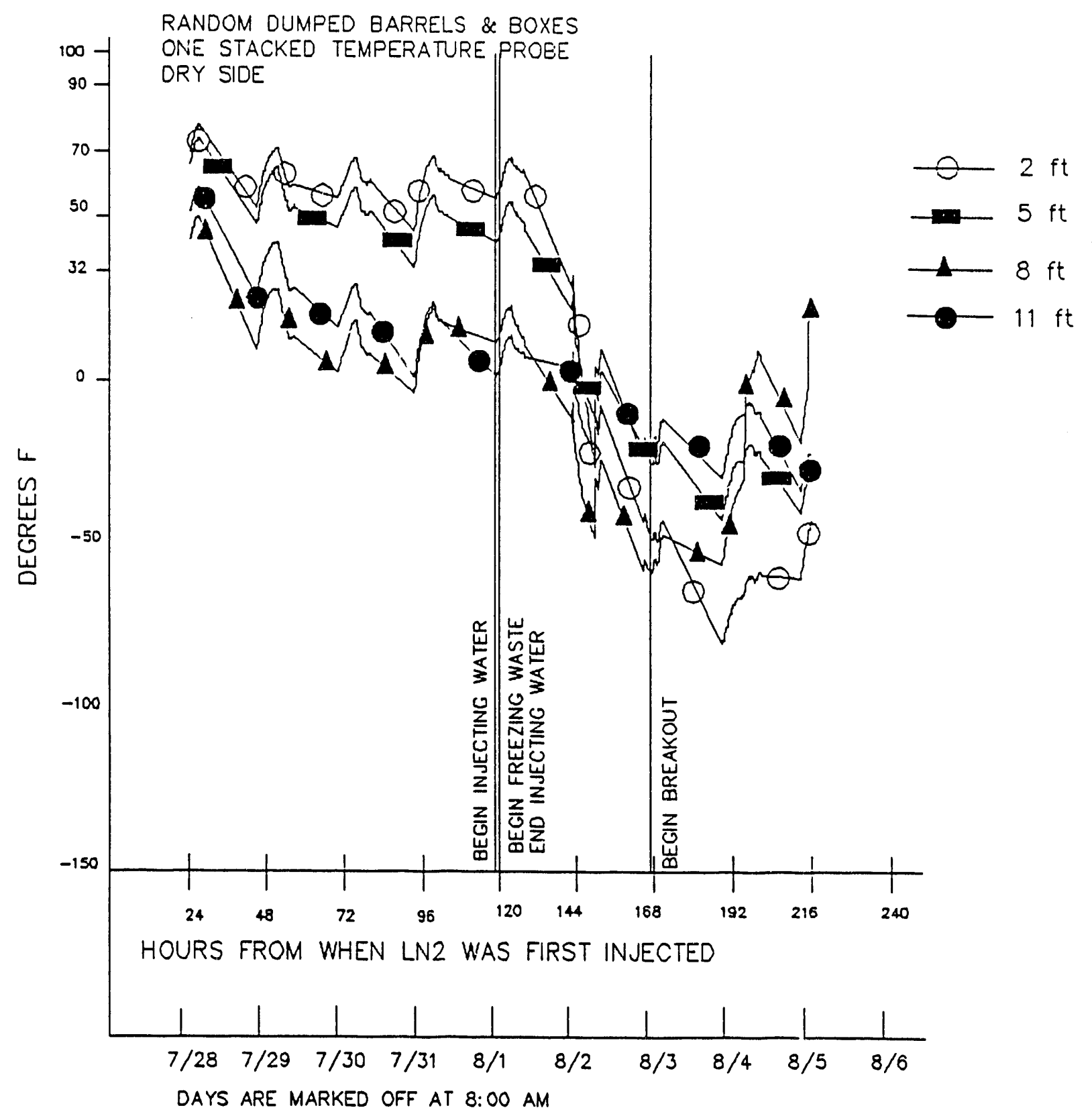

Figure 64. One stacked tempcrature probe on the dry side of the random dumped boxes and barrels pit. 


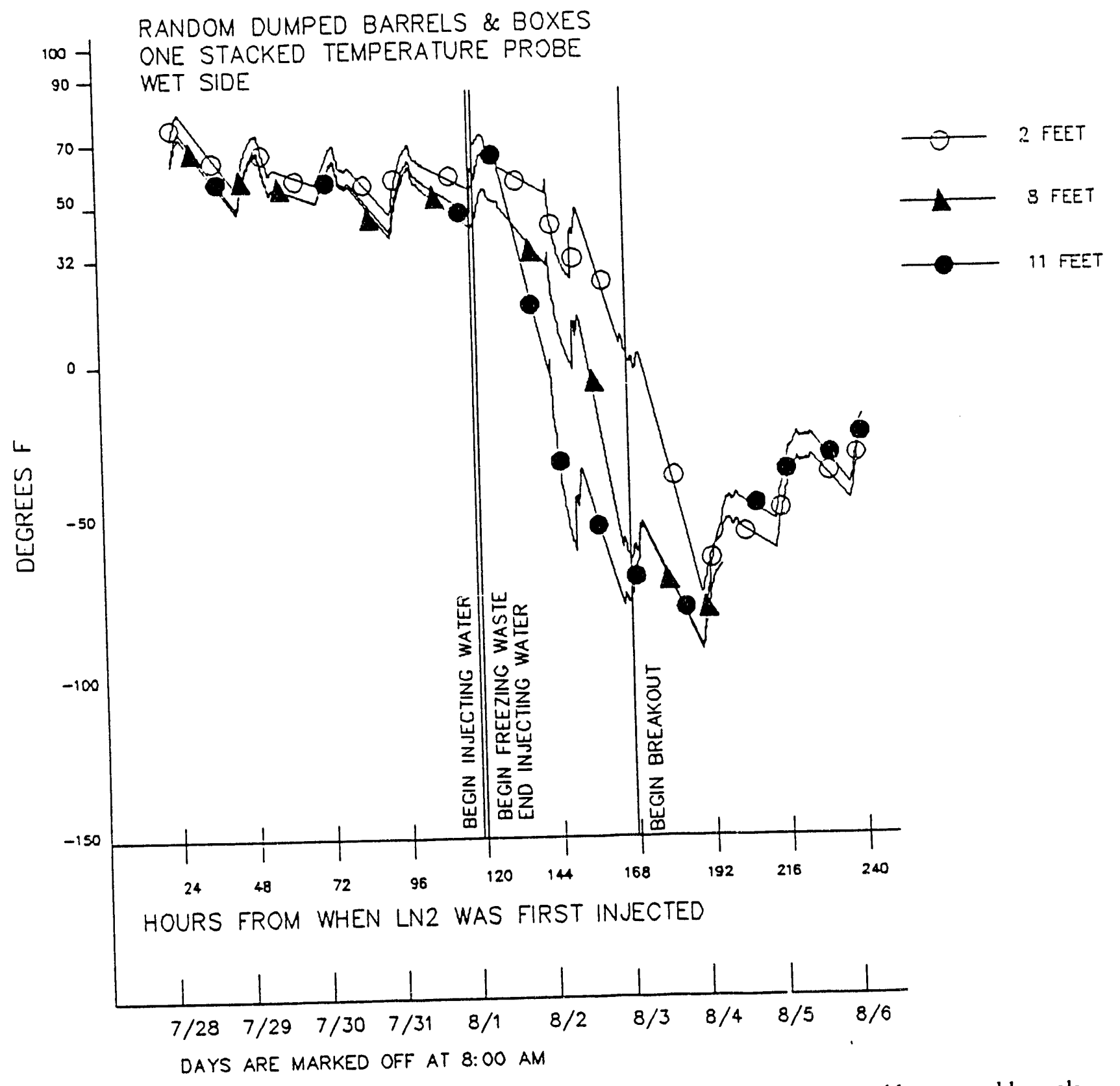

Figure 65. One stacked temperature probe on the wet side of the random dumped boxes and barrels pit. 
lower temperatures. However, once the $\mathrm{LN}_{2}$ wals injected in the area around the probe, the relation between probe depth and lemperature became random

Although the freezing of the front row along with the perimeter belore the rest of the pit caused some initial gradients, the pit eventually reached an equilibrium. Evidence of these processes can be seen by comparing Figures 64 and 65 . The temperatures were signilicantly lower, and a temperature gradient had already been established on the dry side of the pit betore the freezing of the waste began. However, by the time the breakout began, there was no significant difference between the temperature ranges on the two sides of the pits.

It is known that water was not contained within the pit boundary because water was observed draining from the waste pit into the access pit. This lateral water movement should have been expected. In a 1991 test on infiltration in the SDA, it was found that $60 \%$ of the water added to the surface migrated laterally, ${ }^{4}$ apparently, in this pit no significant amount of water migrated vertically to reach the TDR probes. Figure 66 illustrates the response of the moisture probes to the water injection. Two of the TDR probes showed a distinctive rise in the soil moisture content from 23 to $29 \%$ about 2 hours after the water was injected. However, these data are inconclusive since the error on the probes was defined as plus or minus $10 \%$ moisture content in the test plan.

\subsubsection{Air Monitoring}

No significant levels of tracer were released from the waste in this pit. The random dumped barrels and boxes pit was spiked with the tracer ytterbium oxide. According to the test plan ${ }^{2}$, one could be $90 \%$ confident hat the rare earth, ytterbium, was released from the pit during the demonstration if at least one of the air filters detected more than $20.6 \mathrm{ppm}$ of ytterbium. None of the filters exceeded this concentration. In fact, all of the concentrations fell well within the range of the known natural brekground concentrations of ytterbium. See Section 3 for information on how the background concentrations were determined. Table 4 lists the concentrations by monitor location.

Refer to Figure 32 for the locations of the monitors relative to the pit and gantry.

Two high-volume background samples where taken in this pit. One sample was taken before the dry portion of the pit was excavated. The other background sample was taken after the dry portion of the pit was excavated and before the wet half of the pit was excavated. See the test plan ${ }^{2}$ for more information on the background sampling. The results of the background sampling are listed in Table 5.

\subsection{Results from Stacked Barrels}

Because of budget limitations, a test was not conducted using this pit, thus there are no data to report.

\subsection{Results from the Stacked Boxes}

It was predicted that the tenperature profile for the pits would show cooler temperatures toward the bottom of the pits, where the $\mathrm{LN}_{2}$ would collect in the bottom of the freeze pipe, and warmer temperatures at the surface of the pit where the air temperature would warm the pit. The results from this pit were more consistent with this theory than the results were from the other two 


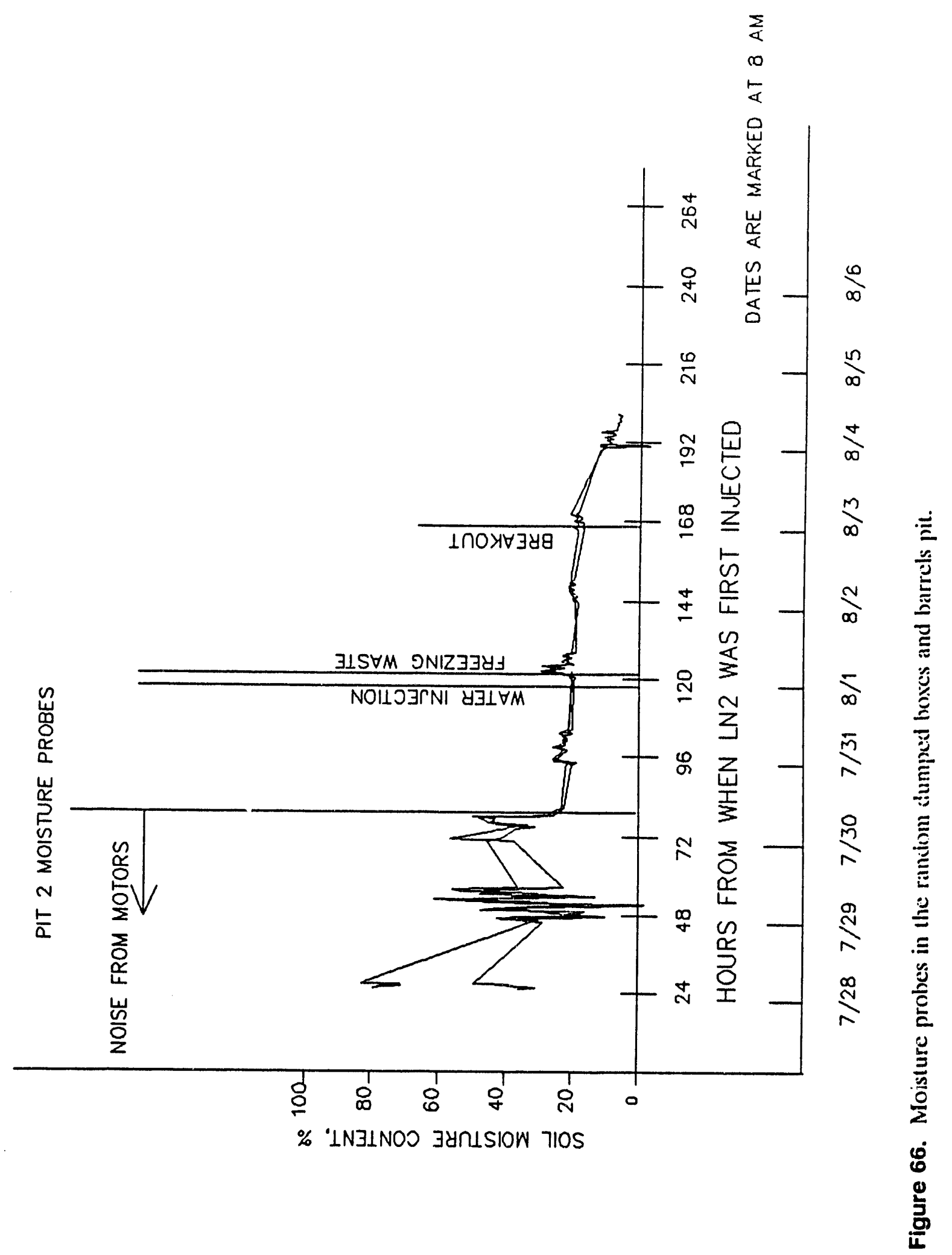


Table 4. Concentrations of ytterbium lound in the random dumped boxes and barrels pit (ppm).

\begin{tabular}{ccc}
\hline Location & Dry side & Wet side \\
\hline 1 & 8.5 & 6.6 \\
2 & 9.3 & 5.7 \\
3 & 10.3 & 5.2 \\
4 & 7.7 & 4.4 \\
5 & 7.9 & 4.3 \\
6 & 9.5 & 6.3 \\
7 & 11.8 & 4.8 \\
8 & 9.3 & 1.3 \\
9 & 9.8 & 4.3 \\
10 & 10.8 & 4.6 \\
\hline
\end{tabular}

Table 5. Background sampling in the random dumped barrels pit concentration of ytterbium (ppm).

\begin{tabular}{cc}
\hline Betore the dry side & Before the wet side \\
\hline 1.9 & 0.0 \\
\hline
\end{tabular}

pits. This may be because almost no waste was found in this pit. All of the thermocouples were insulated from the freeze pipes by soil, and thus the thermal conductivity was consistent throughout the pit.

Most of the stacked temperature probes had thermocouples at a depth of $11 \mathrm{ft}$. For the dry side of the pit, it would be expected that these probes would have been less affected by the $\mathrm{LN}_{2}$ because there was a 1-ft layer of soil between the bottom of the freeze pipe and the thermocouples. For the wet side of this pit, the freeze pipe extended down to $11 \mathrm{ft}$ so one wculd expect that the thermocouples at $11 \mathrm{ft}$ on the wet side of the pit would be the coolest in their respective stacks. As explained in Section 7.3, the homogeneous media found inside this pit should have minimized differences between temperatures read by thermocouples at 1-ft below the freeze pipes and temperatures experience by the other thermocouples.

Soil temperatures within the pit show variation depending upon the timing of the $\mathrm{LN}_{2}$ injection. Figures 67 through 69 show various temperature profiles of the pit with stacked boxes. Sonsub froze this pit by trickling the $\mathrm{LN}_{2}$ overnight and letting the pit warm during the day. There is a rise in temperature during the day hours. One should use caution when interpreting the apparent linear drop in temperature during the cooling. Temperature data were not collected during most of the cooling processes because the generator that powered the data logger was shut off overnight.

For the most part, there is very little temperature difference among the probes at different depths. Figure 67 illustrates the temperature profile for all of the temperature probes in this pit. Once the floor of the wet side of the pit was frozen, the rate of temperature drop for the probes at $11 \mathrm{ft}$ and $8 \mathrm{ft}$ on that side of the pit increased. Two probes on the wet side of the pit dropped very quickly while just the perimeter of the pit was being frozen. There is no explanation for this. However, these temperature drops could have been the result of one of the carbon steel perimeter freeze pipe cracking and leaking $\mathrm{LN}_{2}$ into the soil of the pit. Once the flow of $\mathrm{LN}_{2}$ was 


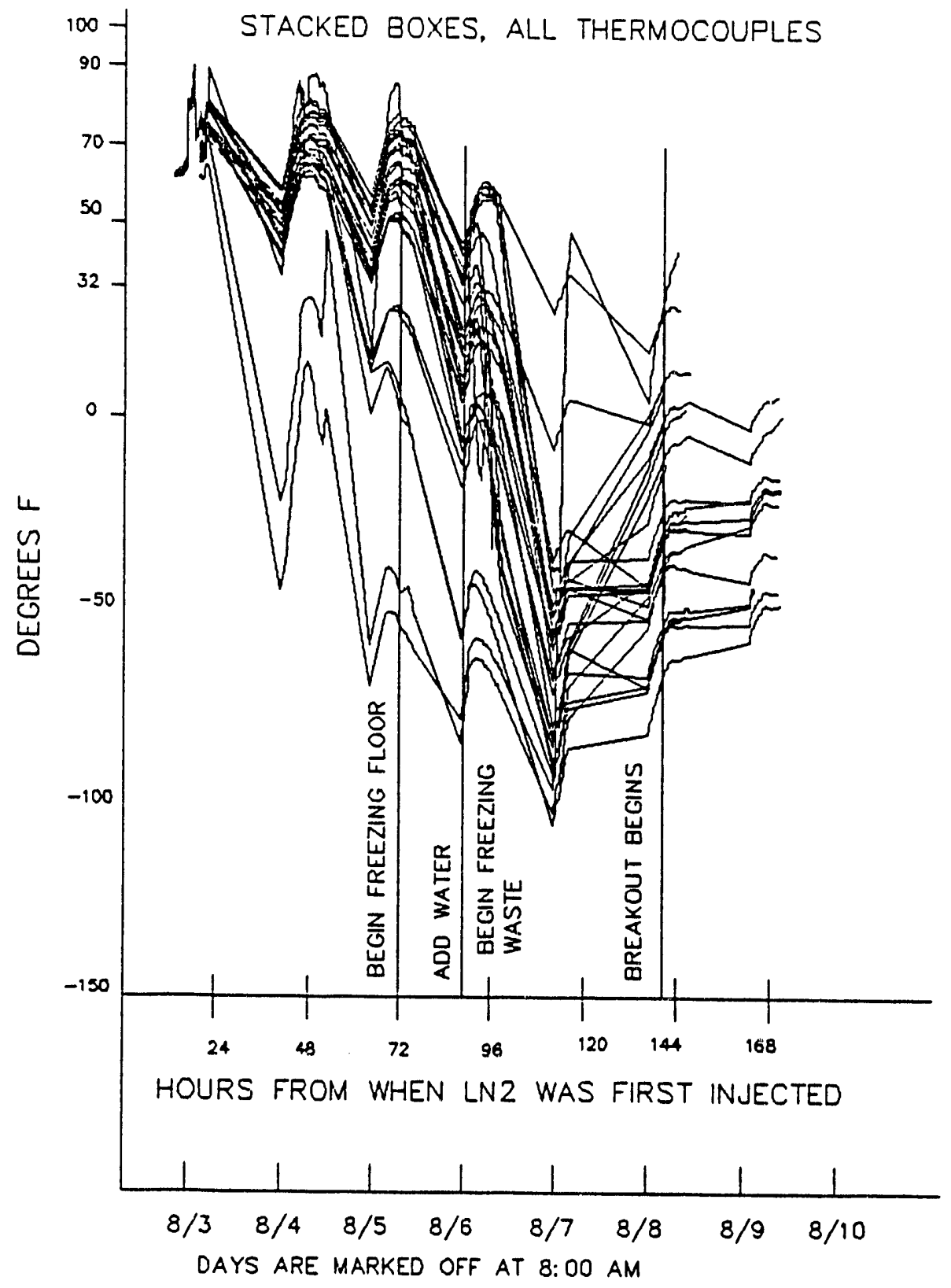

Figure 67. All thermocouples in the stacked boxes pit. 


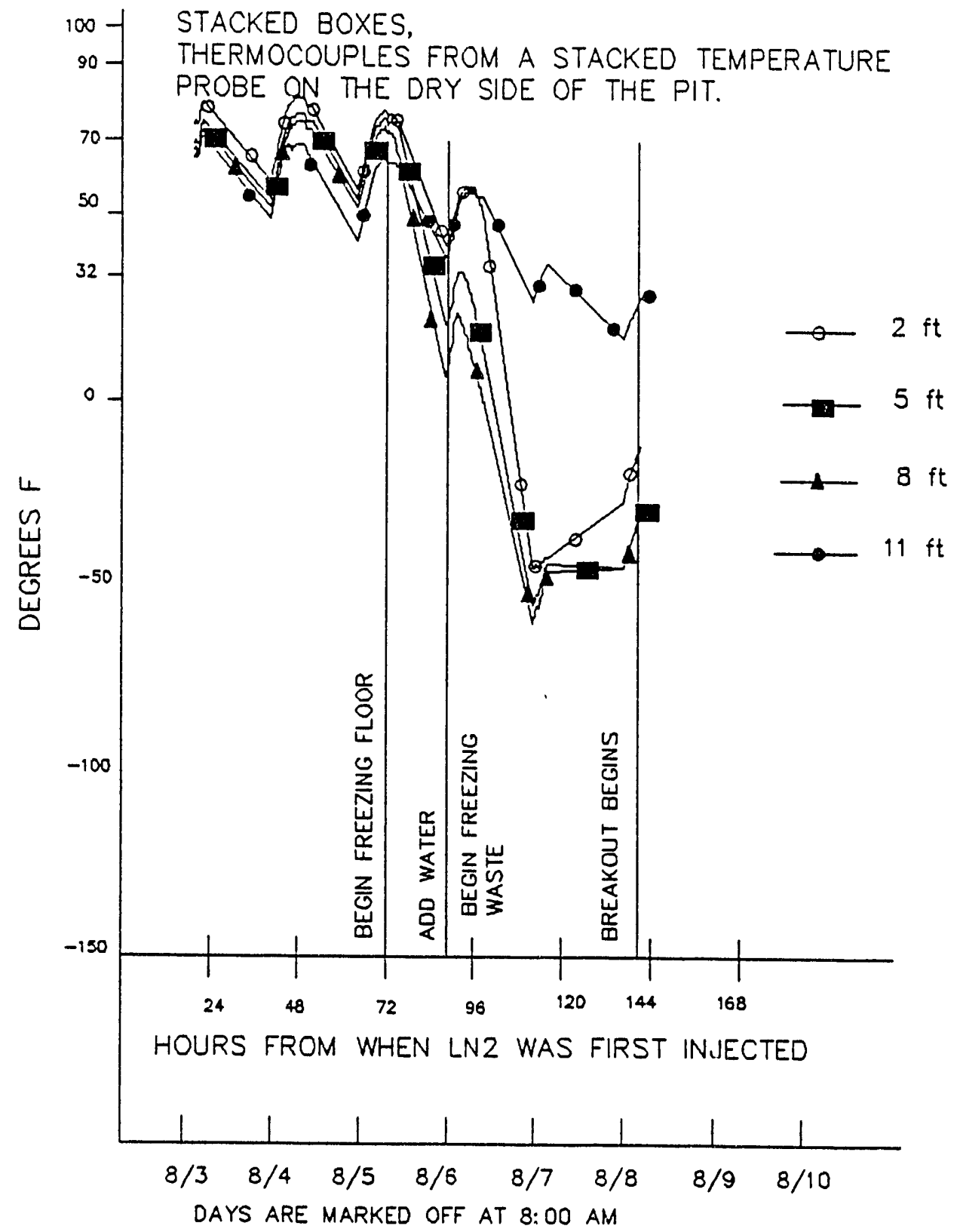

Figure 68. One stacked temperature probe on the dry side of the stacked boxes pit. 


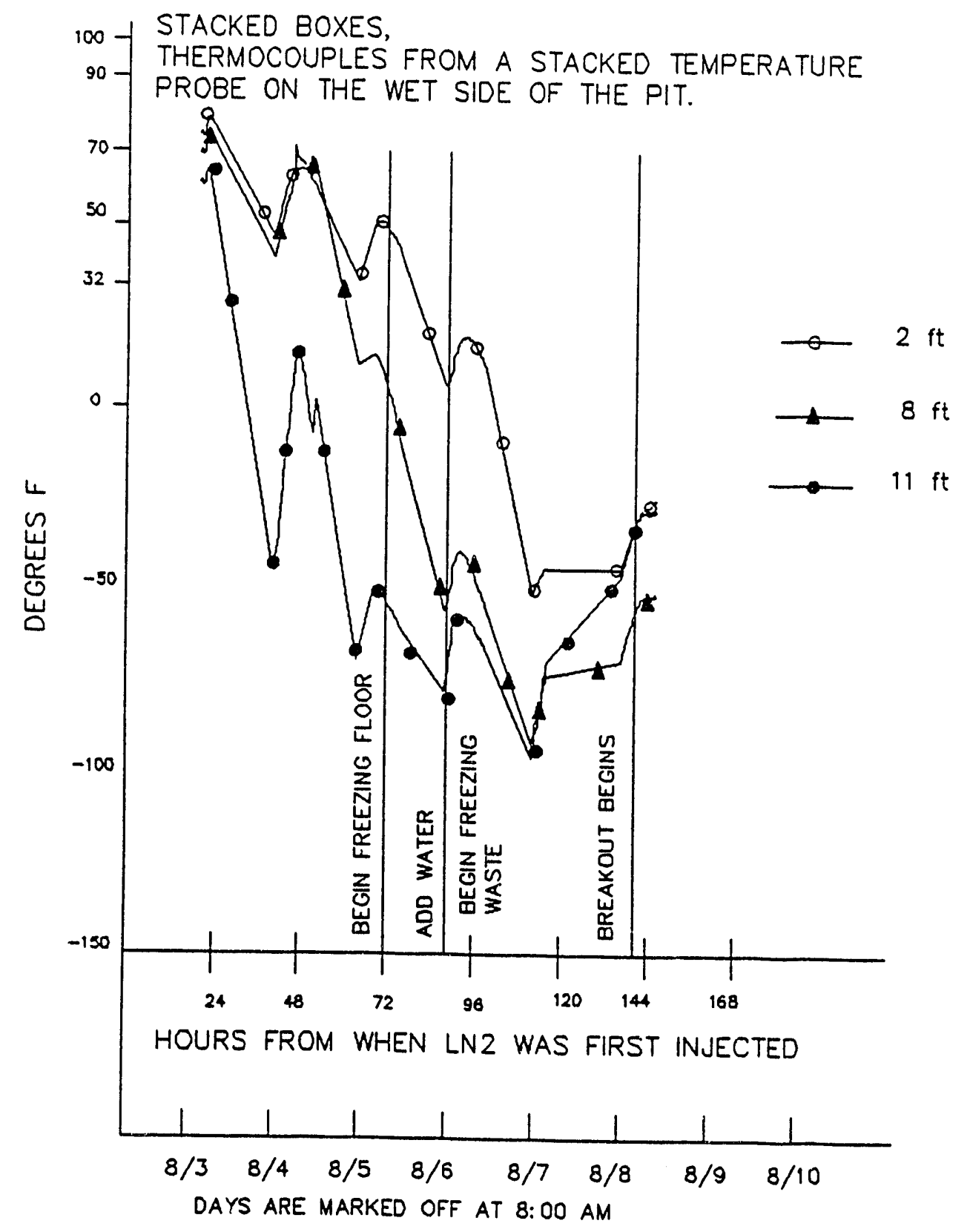

Figure 69. One stacked temperature probe on the wet side of the stacked boxes pit. 
stopped, the surface probes warmed at the faster rate. However, Figures 68 and 69 illustrate that among the stacked temperature probes, the thermocouples at the $11-\mathrm{ft}$ depth were the quickest to warm up.

Figure 68 profiles the temperature along one of the stacked probes on the dry side of the pit. As with Figure 58, the thermocouple at $11 \mathrm{ft}$ was insulated from the freeze pipe and did not chill as fast as the other thermocouples in the stack. This, however, was the exception for the stacked temperature probes on the dry side of this pit. The other two temperature probes show cooler temperatures at the $11-\mathrm{ft}$ depth.

Among the stacked probes, the deeper probes saw lower temperatures during the chilling operations, but they also warmed up the faster once the $\mathrm{LN}_{2}$ was shut off. Figure 69 illustrates the temperature profile for a typical stacked probe on the wet side of the pit. On the wet side of this pit, one would expect direct function between depth and temperature no matter if the probes were driven into their full depth or not. This is because the wet side of this pit had freeze pipes that extended to $11-\mathrm{ft}$ deep. These longer freeze pipes were used to freeze the floor.

The moisture probe data show that the pit saturated upon the addition of water caused the temperature of the pit to rise. Figure 70 depicts the moisture reading from the one TDR that operated in this pit. Once the floor of the pit was frozen, the temperatures of the thermocouples around this moisture probe read about $-58^{\circ} \mathrm{F}$. This temperature was apparently low enough to freeze the moisture in the soil, effectively drying the soil and resulting in a TDR reading of $0 \%$ moisture content. Once the water was injected, the soil quickly saturated. ${ }^{f}$ The heat from the injected water also brought the temperature of the soil around the TDR back up above freezing, so that the TDR could record the moisture increase. The thermocouples did not record such a fast temperature increase because their naturally slow' response time was furthered delayed by being insulated in the plastic casings that served to protect the thermocouples as they were driven into the ground.

\subsubsection{Air Monitoring}

No significant levels of tracer were released from the waste in this pit. The stacked boxes pit was spiked with the tracer, neodymium oxide. According to the test plan, ${ }^{2}$ one could be $90 \%$ confident that the contaminant, neodymium, was released from the pit during the demonstration if one of the air filters detected more than $54.6 \mathrm{ppm}$ of neodymium. Because no waste was seen during the excavation of the dry portion of this pit, a decision was made to not change out the filters for the wet portion of the pit. Consequently, only one background sample and 10 regular samples were taken for the stacked boxes pit. The results are listed in Table 6.

f. It is unlikely that the soil moisture content rose above $40 \%$. When soil is saturated, the maximum TDR reading will be the percentage of the soil porosity. The soil underneath the cold test pit is likely to have a maximum porosity of $40 \%{ }^{4}$ Thus, the maximum expected soil moisture content would be $40 \%$. Higher readings could be recorded if there are large voids around the probe which would increase the effective porosity seen by the instrument. Such voids could have been created by the vibratory motion of the probe as it was inserted. In this case, the combinations of large voids and a high volume of water could have created a slurry around the probe. 


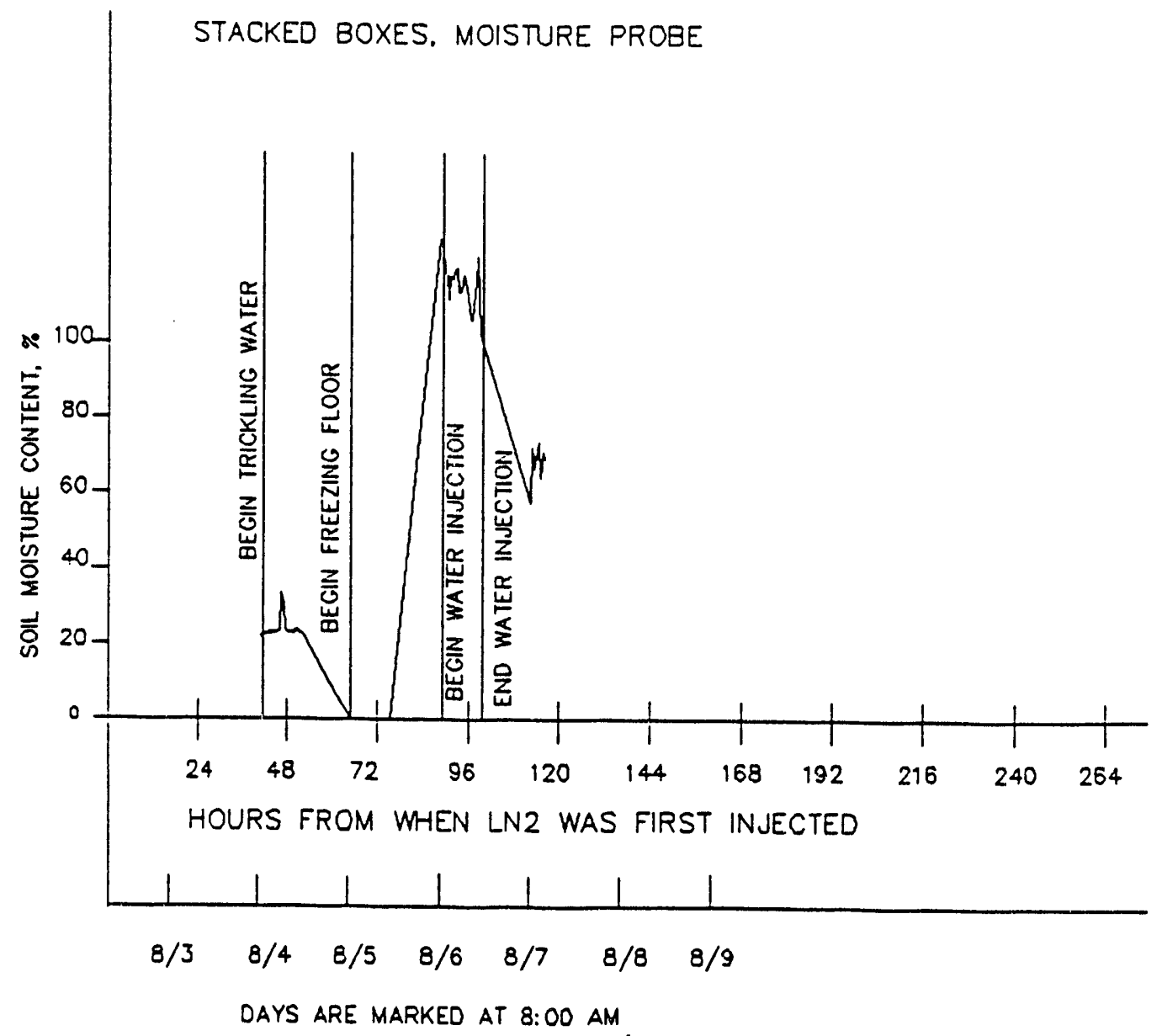

Figure 70 . Moisture probe in the stacked boxes pit. 
Table 6. Concentrations of neodymium found in the stacked boxes pit (ppm).

\begin{tabular}{cc}
\hline Location & Dry and wet side \\
\hline 1 & 31.2 \\
2 & 34.0 \\
3 & 32.5 \\
4 & 32.6 \\
5 & 31.9 \\
6 & 30.9 \\
7 & 29.2 \\
8 & 31.1 \\
9 & 30.4 \\
10 & 30.6 \\
Background sample & 27.8 \\
\hline
\end{tabular}

Almost no waste was uncovered in this pit, so the low background levels of neodymium were expected.

\subsection{Comparison of Results with Pre-established Criteria}

Before solicitation of bids for performing the cryogenic field demonstration, a set of criteria (see Section 2.4) were established by which the relative success or failure of the project would be evaluated. The following is a list of the criteria and a discussion of how each was met during the demonstration.

- Develop a method to freeze the soil/simulated waste mass.

This was accomplished by driving the freeze pipes into and circulating the $\mathrm{LN}_{2}$ through the soil and simulated waste. This method was effective, however, much $\mathrm{LN}_{2}$ was wasted during the process. For this first demonstration, consideration was not given to minimizing the use of $\mathrm{LN}_{2}$ (insulation, recovery systems, and optimizing freeze pipe design). A proposed follow on study would examine ways to conserve $\mathrm{LN}_{2}$.

- $\quad$ Provide a technical reason for selecting an optimum temperature.

A temperature of $-4^{\circ} \mathrm{F}$ was selected because at this temperature (and from 0 to $-6^{\circ} \mathrm{F}$ ) water is neither expanding or contracting, it is static with respect to thermal effects. Throughout the field testing, there was a wide variation in the temperature of the excavated material (approximately 0 to $-100^{\circ} \mathrm{F}$ ). There was some concern that freezing the mass to too low of temperature would result in severe surface and internal cracking (caused by contraction of the soil), and a warmer temperature might leave the mass in a relatively plastic condition that might not contain airborne contamination as readily. However, the observed variations in the temperature did not appear to make an appreciable difference in the condition of the simulated waste and soil during the freezing process or during exhumation. 
- Limit the use of water to promote freezing of the soil/simulated waste mass or provide rationale for addition of water and measures used to mitigate or prevent flow of the same.

The field demonstration was structured so that some pits had varying amounts of water added, and others had no water added. Predictably, those portions of the pits that did not have water added were crumbly and did not form ice columns or large cohesive chunks of soil and simulated waste. When water was introduced, the ice columns were still not well defined; however, there was much better formation of large pieces of frozen soil and waste, i.e., the soil was not as crumbly and fine.

Based on visual observation during the breakout process, there was minimal dispersal of dust either with or without water added. When soil and simulated waste was loaded from the access pit to the storage boxes, visual dust was generated (albeit in relatively small quantities) with the dry soil. Less visual dust was produced with the wetted debris.

For portions of pits that had water added, a scheme was devised to eliminate water migration past pit boundaries. By chilling the soil and simulated waste before introducing water, it was assumed that when fluid was added it would freeze on contact and establish a barrier to prevent migration of the water. To measure water migration beyond the frozen perimeter, a series of moisture probes were located beneath the area to be frozen and exhumed. In all cases when water was injected, the moisture probes indicated an increase in the local moisture content. This meant that water was seeping through the bottom of the frozen area and the concept of creating a barrier with the frozen soil and water did not work.

Water was added using several different techniques ranging from injection to surface soaking. The rate and quantity at which water was added was also varied.

The following conclusions are drawn from observations made during the field demonstrations:

- It is desirable to add water to the soil and waste mix

- The amount of water added must be sufficient to create a cohesive mass of soil and waste and contribute to dust suppression.

- The quantity of water added should be minimized to preclude migration

- The water addition technique is critical-it is preferable to let water soak through the soil and waste from the surface

- The heterogeneity of the soil and waste will greatly affect how much water is added

- A means should be provided to detect the flow of water (or other liquids) beyond the region of the frozen soil/waste mass.

A system of moisture probes was developed and installed in the field to monitor the flow of water beyond the region to be frozen and excavated. Several aspects of the system worked very well. First, any change in the amount of moisture surrounding a probe was readily detected. This was first 
confirmed during initial shop testing and calibration of the moisture probes and later verified in the field. In one instance after water was injected into an area to be frozen, a quantity of water leaked out into the adjacent access pit. At the same time, an indication that the moisture content had increased was given by the moisture probe. Second, besides providing a reading that a change has occurred, the moisture probes can give actual percentage of moisture present in the soil. This could be valuable for future applications when determining optimum moisture content of the soil before freezing. The data logging and computer software systems that were used also performed well.

- Freeze and exhume a total of four $9 \times 9 \times 10$-ft pits at the cold test pit.

A total of three $9 \times 9 \times 10-\mathrm{ft}$ pits were frozen and removed (random dumped barrels, random dumped barrels and boxes, stacked boxes). A fourth pit, the stacked barrels, was also planned for freezing and excavation; however, budget and schedule constraints did not allow the work to proceed.

- $\quad$ Size simulated waste to fit in a standard $4 \times 4 \times 8$-ft storage box.

All waste that was removed was sized and fit in the standard storage boxes. However, no metal waste (except for freeze pipes) was encountered during the demonstration. Items such as beams, cables, and tools were not recovered during the excavation process. Sizing and handling the freeze pipes worked well using the hydraulic shears.

- Devise a method for cutting or removing "bridged" materials between the frozen block and the surrounding nonfrozen region.

Significant bridged materials were not encountered during the field test, but the shears and jackhammer worked well on other waste types. It is postulated that these tools would work well in removing bridged materials between the frozen area and surrounding region.

- Provide a way to measure and record temperature in each of the test pits.

A series of temperature probes, data logging equipment, and a PC were used to measure and record temperatures in each test pit. The temperature detection and recording systems worked well. Good indications of temperature were given throughout most of the field demonstration.

- Measure temperature in a way that gives a representative sampling of the entire volume being frozen.

An array of 32 temperature probes was installed in each pit. Probes were installed at varying horizontal and vertical positions to give full representation of the temperature throughout the mass. Although the temperature readings varied at times, the position of each probe was known and enough information was availabie to make conservative estimates about the pit overall average temperature, and when required, localized temperatures for smaller portions of the pit.

- Suppress airborne dust during all phases of freezing and removal activities. 
Airborne dust was suppressed during the breakout phase. Almost no airborne materials were released during breakout and sizing operations. However, during the loading and transfer of soil and waste from the access pit into the storage boxes, small quantities of visual dust were generated, especially with soil that had not had water added. Based only on visual observations, it is surmised that the greatest amount of rare earth tracer was dispersed during the loading and transfer operation. Even though visual dust was generated during the loading process, it was significantly less than what would have been generated if the soil and waste had not been frozen.

- Ensure all work is performed in a safe manner that does not pose a threat to the environment or people.

Work at the site was conducted in a safe manner. Several thousand hours of field labor were expended, and there were no injuries. The field demonstration was planned and executed in a manner compatible with the environment. Work was conducted in a previously disturbed area. The only hazardous materials used on the site were diesel fuel and $\mathrm{LN}_{2}\left(\mathrm{LN}_{2}\right.$ is classified as hazardous only because of its burn potential, but it is not toxic or injurious to the environment). Both were stored, handled, and used safely so as not to present a danger to the environment. Air emissions were minimized and hydraulic fluids, paints, solvents, etc. were selected to be environmentally friendly.

- Ensure that no toxic, flammable, or explosive substances are used as a part of the freezing or removal activity.

No toxic, flammable, or explosive substances were used as a part of the freezing or removal activity. Only $\mathrm{LN}_{2}$ was used for freezing. During removal hydraulically driven tools were used. The hydraulic fluid was either alcohol or vegetable oil based, nonhazardous material.

- Ensure that the freezing and extraction methods do not create substantial quantities of new waste to be added to the original volume of the simulated waste being removed.

The freeze pipes added about 5 to $7 \%$ volume to the original quantity of waste being retrieved, and this is not considered significant. A follow on study to this work would be to investigate ways to (a) minimize the size and quantity of freeze pipes used in the freezing process, and (b) salvaging the freeze pipes during the extraction process for possible reuse or scrap value.

- Minimize contact between people and the simulated waste during all phases of exhumation.

Retrieval using a series of remote operated tools in an enclosed area is recommended, however, developing the inherent reliability in a system so that human contact is either eliminated or minimized is difficult. The intent for the cryogenic retrieval demonstration was to have no contact or very limited contact between personnel and the tools and equipment in the enclosed area. However, during the demonstration, the equipment required extensive and constant adjustment for much of the demonstration. In many instances it was necessary to locate personnel inside the enclosed work area during equipment operation to diagnose problems and perform repairs. Near the end of the demonstration, the equipment operated much more reliably and repairs (and human contact) were greatly reduced. Reliability and functionality of the equipment directly influences the amount of 
contact that can be expected. A follow on study has been proposed that would investigate ways to improve reliability during future demonstrations and actual retrieval operations. 


\section{CONCLUSIONS AND RECOMMENDATIONS}

\subsection{Overall Conclusions Drawn from the Demonstration}

Overall the field test was judged a success. The basic proof of concept using cryogenic retrieval was demonstrated as feasible. Conclusions and observations are divided into three key areas: Environmental, Safety, and Health, Technical, and Implementation.

\subsubsection{Environmental, Safety, and Health}

- Several thousand labor hours were expended during shop and field testing of the hardware. There were no injuries and no near misses. The project was conducted in a safe manner.

- The testing was environmentally responsible, and impact to the site was minimal and within guidelines as outlined in approved National Environmental Policy Act (NEPA) documentation.

\subsubsection{Technical}

- The remote capability of the tools was proven to work well for this application. The camera and video system provided full visual coverage from a remote location. Visual access to all positions in the excavation area was excellent, even in the cryogenic environment. Remote based systems for retrieval activities has been shown to be viable. The tools were able to be positioned and articulated with relative ease. For the most part, the tools performed their intended functions, although there are improvements that could be incorporated into future generations of the hardware. These improvements are discussed in Section 8.2.

- The concept of breaking out large ice columns or "popsicles" in waste with the freeze pipes was shown not to be feasible. However, the jackhammer was successful in loosening and removing the waste and frozen soil so that the grapple could remove the waste. Modifications to the jackhammer including improved blade design would be required to speed the removal operation. The shear was successful in cutting stainless steel and carbon steel pipes.

- Although dispersal of rare earth tracers occurred in some of the test pits, from visual observations the aerosolized soil particles did not remain suspended as the air cleared in a manner of seconds. This suggests the spread of respirable $(<5 \mu \mathrm{m})$ particles was minimized and that the small dust particles were agglomerated by the freezing process. For those areas in the test pits where water was not added, the dust spread was at a maximum. Therefore, adding water not only improves the waste removal process, but also reduces dust spread.

- Sensitive air monitoring measurements indicated that minimal amounts of rare earth tracer were dispersed during the excavation. Dysprosium was the only rare earth tracer detected (during excavation of the random dumped barrels pit). The dry side of the excavation 
showed concentrations well above the established background limit ( $29 \mathrm{ppm})$ of about $116 \mathrm{ppm}$. The wet side, or side of the pit that had water added showed concentrations of only about $44 \mathrm{ppm}$. These readings indicate that the addition of water helps reduce the spread of dust and contamination.

- The specially designed moisture probes used for the project showed a positive proof of concept. With further refinement, this technology promises to be useful in numerous other retrieval and nonretrieval activities where accurate in situ soil moisture content data are needed.

- The need for cold testing of retrieval technologies before attempting work in a het environment was proven a virtual necessity.

- Prelimin:-ily it appears that the technology has economic viability for buried TRU waste retrieval.

- Water added to promote cohesion tended to migrate beyond the test pit boundary. However, follow on studies could be performed to investigate better methods for determining optimum moisture content in the soil and more even disparsal of water through the soil and waste mass.

- Only cloth, paper, wood, and sludge were encol:stered during the demonstration. No metal or large objects were found, primarily because of limitations to the test schedule. The stacked drum region was not frozen and excavated, and the waste in the stacked box zone was compressed to a narrow seam at the bottom of the pit. T..is was nut discovered until after testing was completed. As a result, challeriging buried waske forms were not encountered; however, removal and sizing of the fre $\mathrm{fe}_{\text {. }}$ pipes provided a gond test for working with metal and large objects.

- Equipment reliability improved as testing progressed. Initially there was poor equipment reliability requiring constant mainienance. This was not due to poor quality, design, or fabrication, but a limitation on the amount of time that was spent on shop testing and adjustment of the hardware. Reliability could easily be improved by increased predeployment testing.

\subsubsection{Implementation}

- A major new technology involving extensive remote hardware design, fabrication, and testing was engineered, built, and deployed to the field in 5 months.

The logistics of field mobilization, obtaining and allocating resources during the demonstration, and demobilization were all performed in an efficient and cost effective manner. 


\subsection{Recommendations and Justification for Follow on Work}

This field demonstration was the first step in a development process aimed at full-scale retrieval activities. Although not perfect, there were initial successful aspects of the testing to warrant nurturing of the technology. It is recommended that development of cryogenic retrieval technology continue for the following reasons:

- Results from the field demonstration show that the technology is a viable alternative for the retrieval of buried waste.

- $\quad \$ 2.3 \mathrm{M}$ has been spent on the technology and proof of concept has been demonstrated.

- Development of a technology such as cryogenic retrieval directly supports the Environmental Restoration mission.

- The technology combines some of the most attractive aspects of a number of other proposed retrieval methods, namely, contamination control, remote operated tools, bridge crane mounted equipment, and personnel removed from contact with the waste.

- The project has demonstrated that private industry and the INEL can work together - which is a desirable and fosters the DOE vision of teaming private industry and the government to develop retrieval technologies.

Proposed follow on work targeted at developing the technology for use in full scale retrieval of buried waste would entail the following activities:

- Perform follow on studies to refine the design of remote operated tools, conserve $\mathrm{LN}_{2}$, .mprove reliability, and determine an optimum method for ground freezing.

- Performi a series of additional tests at the cold test pit. These would include large scale retrieval (of the entire cold pit test area) and retrieval of large objects.

- Evaluate methods to reclaim freeze pipes used in process so waste is minimized.

- Perform a study to determine what regulatory guidelines, safety, and environmental concerns would be applicable to permit a small scale demonstration of the technology at a contaminated location within the SDA.

- Pet iorm a small scale demonstration of the technology at the SDA. This would include necessary design, fabrication, and shop and field testing of hardware to be used.

- Perform a large scale demonstration of the technology at the SDA.

- Develop the final design, fabricate and test the hardware, mobilize to the field for full scale retrieval. 
The above work will require concurrent development with characterization, treatment, handling, and permanent disposal technologies. If a truly functional, safe, and effective alternate means of buried waste retrieval is to be achieved, it will require a long term commitment with respect to the resources and effort needed to develop the technology. 


\section{COST ESTIMATE FOR FIELD APPLICATION}

A cost estimate for the field application of the cryogenic retrieval technology appears in Appendix F. This estimate projects costs for application of the cryogenic retrieval technology for contaminated buried waste removal. The basis for the estimate is given in the appendix. 


\section{LESSONS LEARNED}

\subsection{Need for Cold Testing}

This demonstration has dramatically underscored that full scale cold testing of virtually any technology before deployment in an actual retrieval situation is mandatory. Testing at the cold pit in this instance proved to be invaluable from the standpoint of uncovering problem areas-those either easily corrected during the cold pit demonstration, or so noted for correction during refinement of a future generation of the technology. The concept of cold pit testing should be expanded to include (a) development of other cold test pits at other DOE sites, (b) making full scale cold testing a mandatory step in the development of virtually any buried waste retrieval technology.

\subsection{Adding Moisture}

The DOE stated policy that adding moisture to buried waste during retrieval and treatment is not desirable due to the potential for enhanced migration of contaminants. However, it appears that if cryogenic retrieval is to have viability, the addition of minimal quantities of water (at least in dry climates like INEL and Hanford) is required. During the cryo field demonstration, varying quantities of water were added to known volumes of soil and simulated waste. In some instances no water was added but a rough measurement was made to determine the natural moisture content of the soil. The field testing revealed two key issues regarding the addition of water; first, how to minimize the amount of water that is added, and second how to disperse it more evenly through the soil/waste mass to help control contamination. During the field demonstration, partial answers to these questions were observed. Generally, the more water that is added to an area to be retrieved, the better the likelihood that there will be no dispersal of contamination. There was not enough field testing performed to draw a firm conclusion from this observation, but generally the pits that had water added did not disperse as much dust as those that had little or no water added. There was not an elaborate testing scheme established to accurately measure the percentage of water added or how well water was dispersed through the soil and simulated waste mass. Also, trickling small quantities of water around the surface of the freeze pipes over a long period of time seemed to form a better ice column during the ensuing breakout. Both of these questions will require more research to formulate a comprehensive answer.

\subsection{Drilling and Placement of Freeze Pipes}

The current design of the freeze pipes incorporates a cone shape driving point. The base diameter of the cone extends beyond the outside diameter of the freeze pipe that it is attached to. The result of this configuration is when the pipe is driven into place, a gap is created between the pipe and the soil (because of the large diameter of the cone), which creates a potential pathway for the migration of contamination. The driving point should not extend beyond the diameter of the pipe, i.e., it should be flush to prevent this problem.

Since the concept of forming ice columns around the freeze pipes and then breaking them out did not work as well as expected, an alternate idea might be to design an inexpensive drill/freeze pipe that could be placed in the soil and waste mass, $\mathrm{LN}_{2}$ introduced, and the area frozen. Instead of using the freeze pipe as a type of pry bar, the pipe could be left in place and the face of the area to 
be excavated would be "mined" with a jackhammer and possibly other tools. As evidenced during the excavation process, the jackhammer was able to readily remove frozen soil and debris working along the exposed face of the pit.

\subsection{Conservation of Liquid Nitrogen}

About 200,000 gal of $\mathrm{LN}_{2}$ were used during the field demonstration of the cryogenic retrieval technology. There are a number of methods that could be employed to potentially reduce the usage of $\mathrm{LN}_{2}$. They are

- Perform a thermodynamic study to determine optimum volume of $\mathrm{LN}_{2}$ versus surface area of freeze pipe

- Investigate the optimum shape of a freeze pipe for improving available surface area to conduct heat

- Add insulation to the surface distribution plumbing

- Prechill water before adding it to the soil

- Investigate the rate at which $\mathrm{LN}_{2}$ is added to the mass to be frozen

- Study different sequences for performing the freezing, i.e., best to freeze entire mass, freeze the perimeter first then the waste, etc.

- Insulate the ground surface while $\mathrm{LN}_{2}$ in flowing into the freeze pipes

- Perform an overall study to determine the theoretical volume of $\mathrm{LN}_{2}$ that is required to freeze a given quantity of waste in a given configuration as a function of time

- Improve the reliability of the breakout and removal tools. Down time means having to keep extra $\mathrm{LN}_{2}$ flowing while repairs and adjustments to equipment are made

- Investigate the feasibility of providing a waste heat recovery system for $\mathrm{LN}_{2}$ while it is boiling off

- Determine a theoretical optimum moisture content for soil/waste when undergoing freezing

- Evaluate all materials used in the system to optimize heat retention or convection as required

- In future field tests and applications, use a flow meter to accurately measure the quantity of $\mathrm{LN}_{2}$ that is used to freeze a known volume. 


\subsection{Reliability}

To improve the reliability of the equipment, more time for design and shop testing should have been allowed. Errors that were uncovered in the field during crucial breakout activities caused excessive down time. If many of the problems discovered in the field had been corrected in the shop, the overall quality and scope of the field testing would have been improved. For this particular test, as noted in Section 10.5, to meet schedule, the shop testing schedule was shortened. There is a direct correlation between the reliability of a system once deployed to the field and the amount of shop testing performed before deployment. The more testing, adjustment, changes, and repair performed in the shop and the more closely the shop testing can simulate the actual conditions expected in the field, the higher the system reliability.

Most field problems centered around the jackhammer and hydraulic and electrical systems servicing the other tools. Most failures involved individual components such as electrical contactors, fittings, and hoses. To the greatest extent possible preventive maintenance and inspection were performed to try and anticipate which components were prone to frequent failure, and this was reasonably successful. What often caused down time was a component that was not available at the remote site and had to be air freighted in. This routinely caused a 24 hour delay, but on occasion work arounds were found.

In addition to shop testing, it would be desirable for some systems to perform a full reliability, availability, and maintenance analysis during the design phase to add a measure of certainty. This type of activity can be expensive and time consuming, but depending on the project, may be worthwhile.

\subsection{Air Tight Enclosure}

For demonstration and future work that may be performed on the INEL, it is highly desirable to have not just weather proof enclosures, but to have them air tight (negative pressure) as well. During the course of the cryogenic retrieval demonstration, the wind blew constantly and dust and grime infiltrated every tool and equipment item on the site, including those protected by the gantry weather cover. The dust was so bad that during the initial breakout of the random dumped barrels pit, the filters on the air monitoring system were clogged in a matter of hours. This was not from dust generated by the excavation, but from dirt particles that had previously settled on equipment inside the gantry during assembly and were later shook off during the excavation sequence. Considerable dust was also introduced inside the gantry by wind.

Creating an air tight or near air tight work area should be carefully evaluated for each technology that may be tested at the cold test pit site. If work is going to commence during the summer months, it is recommended that an air tight shelter be provided.

\subsection{Continuous Power Source for Instrumentation}

The cold test pit site was supplied with power from a single source during the course of the cryogenic retrieval demonstration. During normal working hours, which were 7 day/week, 12 hours/day, the generator that supplied power was left running. However, on off hours the 
generator was shut off. When the power was terminated, so was the data collection effort. Temperature and moisture data were not collected during nonworking hours. The generator would have been extremely expensive to operate 24 hours/day. An alternative would have been to keep a small generator running during the nonworking hours to collect data continuously.

\subsection{Sound}

Although the interior of the gantry was well covered from a visual/operation standpoint, it would have been helpful to have had sound as well. The addition of a few microphones would have allowed operators to "hear" the performance of their equipment and tools. Seeing was frequently not enough. Certain equipment sounds different under certain operating conditions. Often, when an item is nearing a failure condition, sound is an early warning (much like a rattle or squeak in a car of impending failure. In several instances, and especially while operating the jackhammer, hearing the equipment would have probably helped to prevent break down. It is recommended that for future remote demonstrations, the ability to monitor and record sound be incorporated as an integral part of the design.

\subsection{Moisture Probe Calibration}

During the shop testing of the hardware to be used for the field demonstration (conducted in Houston, Texas, at Sonsub's facilities), a moisture probe, or TDR probe, was calibrated using soil imported from the INEL cold test pit. Although fairly accurate, it was proven later that performing the actual calibration of the remaining TDRs at the cold test pit site was more accurate. The TDRs were a sensitive instrument, and variables such as humidity and soil $\mathrm{pH}$ tended to affect the calibration. If possible, it is advisable to perform calibration of TDRs at the actual test site. The same approach may be warranted for other instrumentation as well.

\subsection{Grapple/Storage Box Design}

Although visually dust appeared to be virtually nonexistent during the actual breakout of soil and simulated waste during the cryogenic retrieval field demonstration, much dust and therefore, rare earth tracers were aerosolized during the dumping of the waste into storage boxes. This occurred for several reasons. First, the grapple full open width was greater than the open dimension of the waste storage box. This resulted in a sizable amount of dirt spilling over the edges of the box. When it spilled, occasionally there were small quantities of visible airborne dust generated. To help alleviate the spillage, a steel funnel was fabricated to fit inside the box. This helped increase the amount of dirt and waste directed into the storage box but did not totally stop the spillage. A second problem with the placement of the dirt was the drop distance from the grapple to the box, which was around 4 to $6 \mathrm{ft}$. This is more than adequate for dry fine particulates to aerosolize. There was significantly less airborne dust generated during the placement of the soil and waste because it was frozen, than there would have been without the benefit of freezing the soil. However, a key improvement could be made to help reduce the amount of dust that becomes airborne by changing $t^{\prime}$ ie way dirt is placed in the waste storage box, i.e., eliminate the drop distance the soil is subjected to. 


\subsection{Quality of Air Filters}

The filters used in conjunction with the field air monitoring were not specified to be free of rare eririh tracers. This was not a major problem but required an additional analysis to determine very minute residual quantities of tracers left on the filter during the manufacturing process and to account for this quantity of material during subsequent measurements. A simpler approach would have been to obtain filters with no rare earth tracers.

\subsection{Lateral Movement of Moisture}

Additional moisture probes placed beyond the frozen boundary of the pit would detect lateral migration of moisture. This item is not so much a lesson learned, as it was recognized as a desirable feature of the cryogenic retrieval demonstration early in the project but could not be included because of funding limitations. Under certain conditions, moisture is more likely to travel through soil laterally than vertically. ${ }^{4}$ To get a truly comprehensive indication of how well the frozen area is containing liquids, it would be necessary to include these additional moisture probes. 


\section{REFERENCES}

1. T. D. Chatwin, Phase I Isocell Demonstration Test Performance Review, EGG-WTD-9595, April 1991.

2. E. L. Yokuda, Test Plan for Air Monitoring During the Cryogenic Retrieval Demonstration, EGG-WTD-10320, June 1992.

3. Campbell Scientific, Inc., Campbell Scientific TDR Soil Moisture Measurement System Manual, Revision 2/92, 1991.

4. J. F. Kaminsky, In Situ Characterization of Unsaturated Hydraulic Properties of Surficial Sediments Adjacent to the Radioactive Waste Management Complex, Idaho National Engineering Laboratory, Idaho, Idaho State University, 1991. 


\section{BIBLIOGRAPHY}

John McQuary, A Summary of the Environmental Restoration Program Retrieval Demonstration Project at the Idaho National Engineering Laboratory, EGG-WTD-9291, Revision 1, February 1991.

Terrence, D. Chatwin, Phase I Isocell Demonstration Test Performance Review, EGG-WTD-9595, April 1991.

Kevin M. Kostelnik, Buried Waste Integrated Demonstration Plan, EGG-WTD-9870, December 1991.

S. L. Morton, Health and Safety Plan for Operations Performed for the Environmental Restoration Program, EGG-WM-8771, Revision 2, October 1991.

D. E. Menkhaus, L. C. Meyer, Functions and Design Requirements of the Contamination Control System, EGG-WM-8512, May 1989.

D. A. Arrenholz, J. L. Knight, Buried Waste Integrated Demonstration: Selection of Potential Demonstration Locations, EGG-WTD-9752, November 1991.

P. G. Cannon, Buried Waste Integrated Demonstration Configuration Management Plan, EGG-WTD-10081, February 1992.

J. M. Bower, Work Scope for the Retrieval Project of the Buried Waste Program, EGG-WM-8386, January 1989.

S. P. Fogdall, M. P. Plessinger, BWP Retrieval Demonstration Project Conceptual Design Report, EGG-WT-8146, August 1988.

G. C. Gergeson, H. M. Kline, J. M. Svoboda, Functions and Design Requirements of the Excavation System for the Retrieval Project of the Buried Waste Program, EGG-WM-8440, March 1989. 
Appendix A

Summary of Statistics for Background Measurements 


\section{Summary Statistics for Background Measurements}

The background air filter data were examined using exploratory techniques. Because there were high concentrations of tracers on the blank filters relative to what was in the dust, the results were adjusted for blank concentrations by subtracting off the mean blank concentration. This resulted in data that are very nearly normally distributed.

There were a number of factors that could affect the tracer concentrations. These included change of tracer concentration over time, air filter pump volume, and location. Of these, change in tracer concentration over time was the most important. For the purposes of later analyses, all sources of variation in the concentrations are included.

Overall, the concentrations are rather low. This causes problems in the analytical quantification of the concentrations and increases the uncertainty in the individual values. This affects both the precision and accuracy of the resulting statistical estimates; however, it is difficult to quantify the effect without more QC data.

The terbium data included some less-than-detectable (LTD) values. These are samples whose measured concentrations were less than the detection limit of the analytical method. Also, all the terbium blank concentrations except one were LTD. The one exception was apparently a gross outlier, as the chemist had marked it for deletion (no reason for the cause of the outlier is given). The LTD values were replaced with half the detection limit, including the blank data.

The summary statistics for the blank-adjusted data are shown in Table 1. These values are for the average tracer concentrations in the dust collected on the filter. The calculated standard deviations were compared to approximate theoretical values, and were concluded to be in agreement.

Note that some of the mean blank-adjusted concentrations are less than zero. This is due to variation in the tracer concentrations of the filters and precision of the measurement systems. Because the values are corrected for using a mean blank concentration, individual sample values can be less than zero. However, the true mean must be greater than or equal to zero. This is taken into account in the next section when calculating prediction limits.

Table 1. Summary statistics for blank-adjusted data. Estimates are based on 24 samples. The units are $\mu \mathrm{g} / \mathrm{g}$-dust.

\begin{tabular}{ccccc}
\hline Tracer & Mean & Std. Dev. & Minimum & Maximum \\
\hline Dy & -4.346 & 8.371 & -26.19 & 10.50 \\
$\mathrm{Nd}$ & 6.951 & 19.127 & -28.31 & 60.98 \\
$\mathrm{Yb}$ & -2.847 & 8.271 & -25.25 & 12.80 \\
$\mathrm{~Tb}$ & 4.219 & 6.074 & $\mathrm{NA}^{\mathrm{b}}$ & 24.21 \\
& & & \\
& &
\end{tabular}




\section{Prediction Limits}

If the cryogenic retrieval process works as hoped, then there should be no tracer release from the soil. A simple method for assessing whether there is a release is to compare the individual filter concentrations to the upper prediction limit on the background concentrations.

The upper prediction limit is an upper bound that will contain the next randomly selected observation(s) from the population with a specified degree of confidence. The basic form of calculation is $\mathrm{UPL}=\overline{\mathrm{x}}+\mathrm{r}_{(1-\alpha ; m, n)} \mathrm{s}$,

where $\bar{x}$ is the sample mean, $r$ is the prediction factor, $\alpha$ is the Type I error $(1-\alpha$ is the confidence level), $n$ is the number of observations in the original sample, $m$ is the number of observations in the future sample to be included in the prediction interval, and $s$ is the standard deviation. Values of $r$ are taken from Hahn and Meeker (1991); $n$ is 24.

The results for $m=10$ are shown in Table 2 and for $m=5$ in Table 3 . The values are given for 90 , 95, and 99\% confidence. Because the mean Dy and Yb concentrations were less than zero, the mean used in the calculations was set to zero for these tracers. Also, since the tabled values of $r$ in Hahn and Meeker do not include $n=24, n=25$ was used instead.

As an example of the application of Tables 2 and 3, say 10 observations are collected during the retrieval. If one of the Dy concentrations is greater than $29.5 \mu \mathrm{g} / \mathrm{g}$-dust, then from Table 2 there is at most a $1 \%$ chance that the observation came from background.

Table 2. Calculation of upper prediction limits when $m=10$. Values are in units of $\mu \mathrm{g} / \mathrm{g}-$ dust and assume the concentrations are corrected for blank contamination. See discussion in text.

\begin{tabular}{cccc}
\hline & \multicolumn{3}{c}{ Upper Prediction Limit } \\
\cline { 2 - 4 } Tracer & $\mathbf{9 0 \%}$ & $\mathbf{9 5 \%}$ & $\mathbf{9 9 \%}$ \\
\hline Dy & 20.85 & 23.61 & 29.49 \\
Nd & 54.60 & 60.91 & 74.84 \\
Yb & 20.60 & 23.33 & 29.14 \\
Tb & 19.35 & 21.35 & 25.62 \\
\hline
\end{tabular}

Table 3. Calculation of upper prediction limits when $\mathrm{m}=5$. Values are in units of $\mu \mathrm{g} / \mathrm{g}$-dust and assume the concentrations are corrected for blank contamination. See discussion in text.

Upper Prediction Limit

\begin{tabular}{cccc}
\cline { 2 - 4 } Tracer & $\mathbf{9 0 \%}$ & $\mathbf{9 5 \%}$ & $\mathbf{9 9 \%}$ \\
\hline Dy & 18.22 & 21.09 & 27.10 \\
Nd & 48.59 & 55.13 & 68.88 \\
Yb & 18.01 & 20.83 & 26.78 \\
Tb & 17.44 & 19.52 & 23.89 \\
\hline
\end{tabular}




\section{Power Study}

An alternative method for assessing whether a tracer release resulting in an increase in mean tracer concentrations occurs during retrieval operations is to compare the mean filter concentrations to the background mean concentrations using a two sample t-test. While emphasis will be on the individual filter results, a test comparing the means does allow us to assess the number of samples through a power study.

The power study considered here looks at the likelihood of detecting a given size of increase in the mean tracer concentration. The power curves for the tracers are shown in Figures 1 through 4 for samples of size 5 and 10 . For example, an increase in mean dysprosium concentration of $10 \mu \mathrm{g} / \mathrm{g}-$ dust has approximately a $75 \%$ chance of being detected if $\mathrm{m}=5$, and a $90 \%$ chance of being detected when $\mathrm{m}=10$.

The plots indicate that using 10 samples will result in the greatest increase in power near the midrange of the concentrations considered. Further, the test will be least sensitive to changes in neodymium concentrations, and most sensitive to changes in terbium concentrations. Power calculations were done with PowerPack (Lenth, 1987).

\section{Ratio of Tracer to Aluminum}

An analysis was done to describe the ratio of tracer concentration to aluminum concentration. The ratios were considered for both the uncorrected and blank-corrected data. The blank-corrected data did not show as strong a relationship as the uncorrected data and were dropped from further consideration.

The summary statistics for the ratios are shown in Table 4. The correlation is an indicator of the strength of the linear relationship between the tracer and aluminum concentrations; and hence is an indicator of the stability of the ratio estimator.

Table 4. Summary statistics for the tracer to aluminum ratios. The statistics are based on the uncorrected results (i.e. not corrected for blanks) as discussed in the text. The correlation measures the strength of the relationship between the tracer and aluminum concentrations. Calculations based on 24 observations, except as noted.

\begin{tabular}{cccc}
\hline Tracer & Mean & Std. Dev. & Correlation \\
\hline $\mathrm{Dy}$ & $1.154 \mathrm{E}-4$ & $1.749 \mathrm{E}-5$ & 0.995 \\
$\mathrm{Nd}$ & $4.941 \mathrm{E}-4$ & $3.568 \mathrm{E}-4$ & 0.986 \\
$\mathrm{Yb}$ & $8.759 \mathrm{E}-5$ & $1.630 \mathrm{E}-5$ & 0.995 \\
$\mathrm{~Tb}^{\mathrm{a}}$ & $9.726 \mathrm{E}-5$ & $1.460 \mathrm{E}-5$ & 0.859
\end{tabular}

a. Calculations based on 17 observations. The seven other observations were below the detection limit and not included.

\section{References}

Hahn, Gerald J. and William Q. Meeker (1991), Statistical Intervals, A Guide For Practitioners, John Wiley \& Sons, Inc., NY.

Lenth, Russell V. (1987), PowerPack Version 2.2 User's Guide, Iowa City, Iowa. 


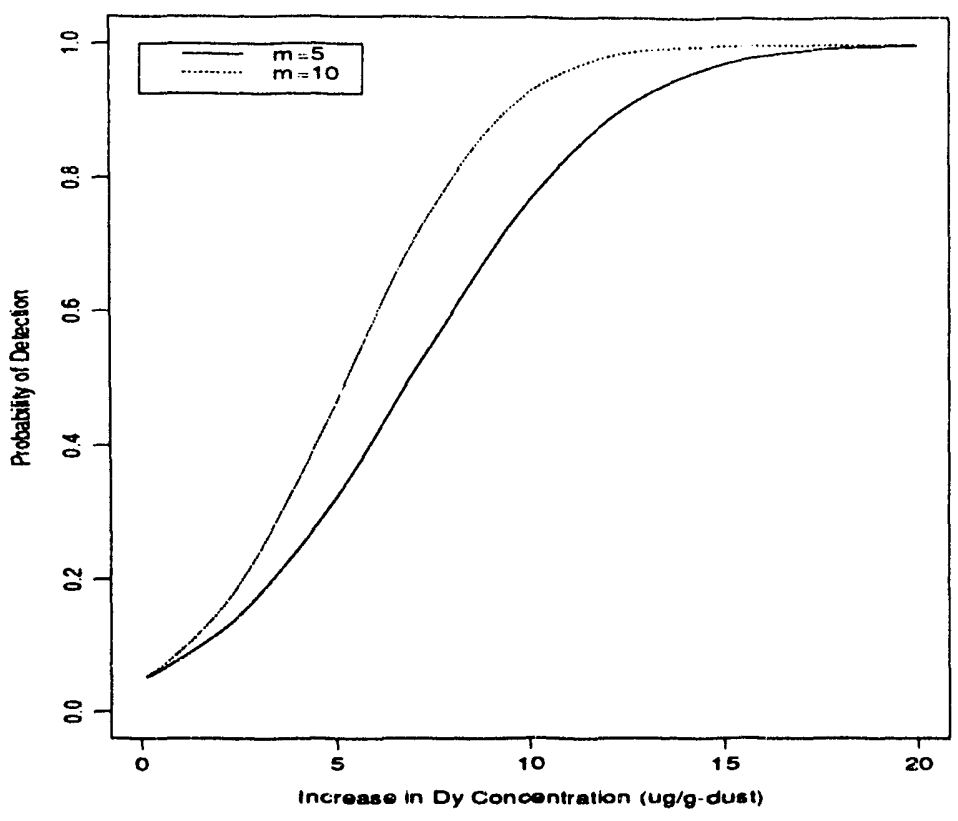

Figure 1. Plot of the power curves for testing for a difference between mean dysprosium concentrations for samples of size 5 and 10.

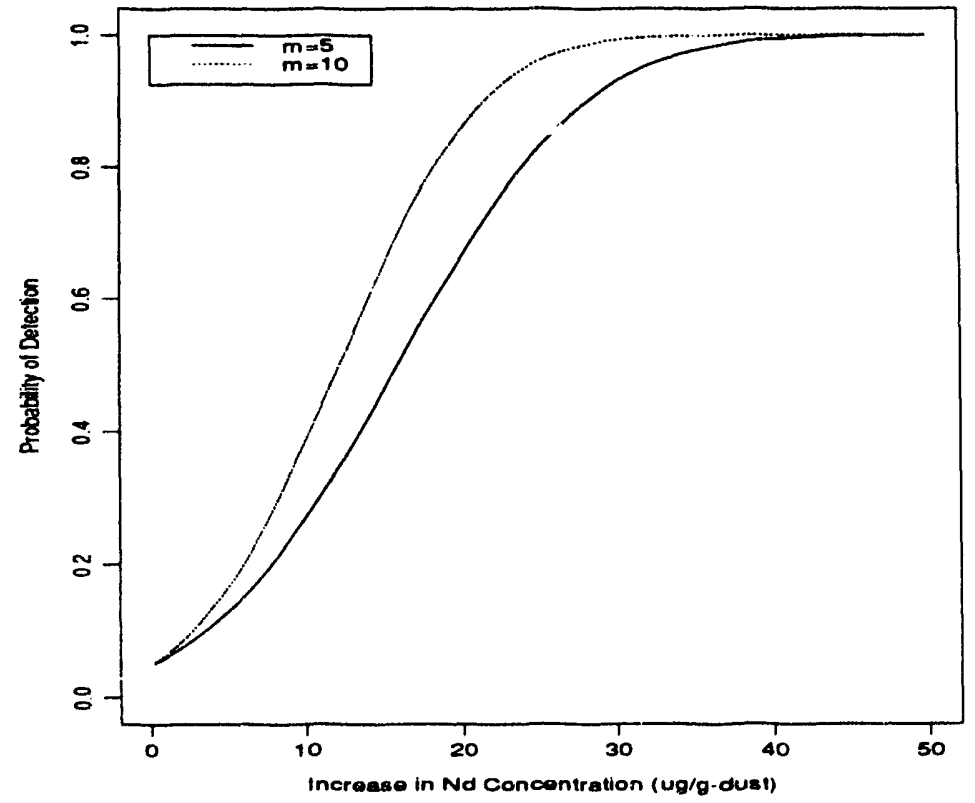

Figure 2. Plot of the power curves for testing for a difference between mean neodymium concentrations for samples of size 5 and 10. 


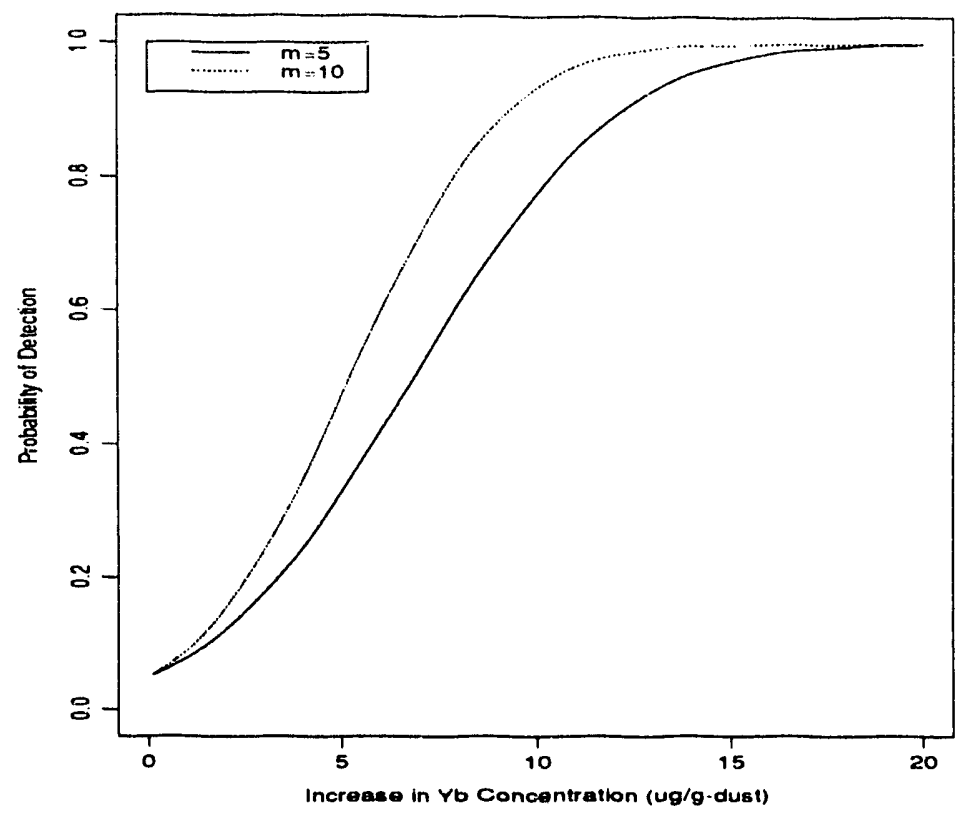

Figure 3. Plot of the power curves for testing for a difference between mean ytterbium concentrations for samples of size 5 and 10.

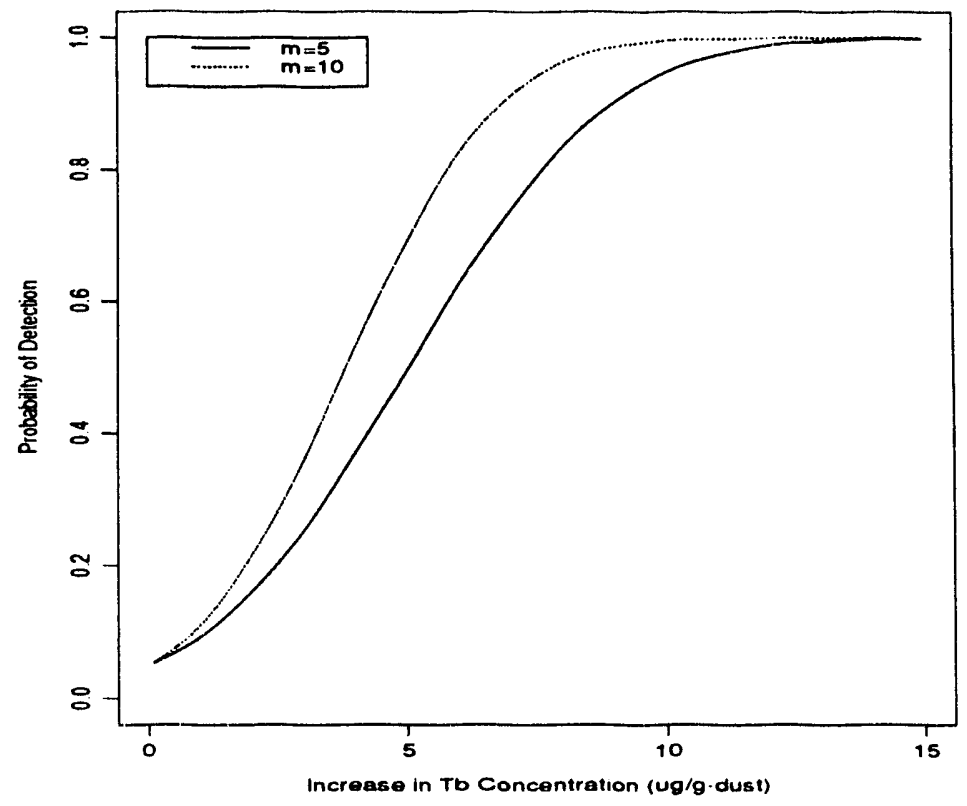

Figure 4. Plot of the power curves for testing for a difference between mean terbium concentrations for samples of size 5 and 10. 
Appendix B

Test Plan for the Cryogenic Retrieval Demonstration 


\author{
TEST PLAN \\ FOR \\ CRYOGENIC RETRIEVAL DEMONSTRATION
}

SUBCONTRACT NO. C91-133223

TAA250 - B03

\author{
SUBMITTED TO \\ EG\&G IDAHO, INC. \\ IDAHO FALLS, IDAHO
}

\author{
BY \\ SONSUB INC. \\ HOUSTON, TEXAS
}

JUNE 1992

S. E. MANSFIELD - PROJECT MANAGER 


\section{ACRONYMS \\ TEST PLAN FOR \\ CRYOGENIC RETRIEVAL DEMONSTRATION}

$\begin{array}{lll}\text { A/D } & - & \text { Analog/Digital } \\ \text { CRD } & - & \text { Cryogenic Retrieval Demonstration } \\ \text { GPM } & - & \text { Gallons Per Minute } \\ \text { INEL } & - & \text { Idaho National Engineering Laboratory } \\ \text { LN2 } & - & \text { Liquid Nitrogen } \\ \text { PC } & - & \text { Personal Computer } \\ \text { PMP } & - & \text { Project Management Plan } \\ \text { RWMC } & - & \text { Radioactive Waste Management Complex } \\ \text { TDR } & - & \text { Time Domain Reflectometry }\end{array}$

Pit \#1 Refers to the Random Dumped Barrels Pit

Pit \#2 Refers to the Random Dumped Barrels and Boxes Pit

Pit \#3 Refers to the Stacked Barrels Pit

Pit \#4 Refers to the Stacked Boxes Pit 


\begin{abstract}
This test plan defines basic test procedures for ground temperature, ground moisture, and water fill measurements during the Cryogenic Retrieval Demonstration (CRD). The method will utilize ground freezing technology for buried waste removal at the Cold Test Pit (CTP) south of the Radioactive Waste Management Complex (RWMC) located at the Idaho National Engineering Laboratory (INEL). To demonstrate the process, four (4) test pits filled with simulated waste containing drums and boxes will be cryogenically cooled utilizing liquid nitrogen $\left(\mathrm{LN}_{2}\right)$ filled freeze pipes. After freezing each pit will be fractured, excavated, and the soil and simulated waste boxed using a series of remote controlled tools.

It is expected that the ground freezing technique will provide a safe, simple, and reliable method of removing, sizing, and boxing wastes for subsequent treatment and disposal operations without dispersing contaminated dust or particles into the surrounding area. At selected points, both surface and sub-surface temperatures along with moisture levels will be monitored.

The demonstration will include instrumentation to determine rates of cryogenic cooling, absorption rates of water, if any, into the ground below the frozen block, and fracturing and excavating of the monolithic frozen block. A description of the test apparatus and test methods are provided in this plan. Quality assurance and safety requirements for this project are also identified.

Throughout this demonstration, EG\&G will be conducting air moniioring to determine if the CRD is successful in controlling dust and minimizing contamination.
\end{abstract}




\subsection{INTRODUCTION}

\subsection{Technology Description and Background}

The purpose of this test plan is to outline methods, practices, and equipment to be used to monitor ground temperature, ground moisture, and water fill volume during the Cryogenic Retrieval Demonstration (CRD). The CRD will consist of freezing and excavating eight (8) separate blocks from four (4) test pits. The technology being utilized for this demonstration is a combination of proven ground freezing techniques and specially designed excavation systems developed by Sonsub Environmental Services and the program team.

\subsection{Scope of Test}

The test area consists of four (4) test pits filled with simulated waste. The waste has been salted with rare earth elements to trace contamination spread during the waste removal process. Each pit will be divided into a front half, which will be left dry, and a rear half, which will be filled with varying quantities of water. Each pit will be monitored utilizing thermocouples for temperature measurement. Time domain reflectometry (TDR) probes will be used in the rear half of each pit to measure moisture levels below the waste. This information will be fed through an A/D converter and read into a PC file for storage. Once frozen, each pit will be fractured and excavated.

Observations will include ground freezing time and effectiveness, volume of water added, and moisture absorption into the base soil below the frozen blocks.

\subsection{Objective of Test}

The objectives of this test are:

1. Obtain temperature data at selected points in each pit to ensure that the areas between the freeze pipes are frozen and note elapsed time required for freezing.

2. Obtain ground moisture data below each pit to establish a base level for existing ground moisture and to evaluate the wetting front movement resulting from added water to the pits.

3. Determine the volume of water needed to fill the voids in the waste.

\subsection{Technology Agreement}

This Section is not applicable

\subsection{ORGANIZATION AND RESPONSIBILITIES}

\subsection{Organizational Responsibilities}

Refer to Sonsub's Project Management Plan for the Cryogenic Retrieval Demonstration, Section 3. 


\subsection{Responsibilities Of Organization Conducting Test}

SONSUB - Safety-QA/QC Manager - Responsible for all Safety and QA/QC Manuals and training on the project. He will monitor the initial setup of the demonstration.

SONSUB - Project Manager - Responsible for overall project operation, budget, schedule, and client communications.

SONSUB - Project Engineer - Responsible for the design and function of the equipment. He or one of his engineers will periodically monitor the demonstration.

SONSUB - Operations Superintendent - Responsible for system assembly, test, mobilization, on-site operations, and demobilization.

FREEZEWALL - Project Manager - Responsible for and coordinates the driving of the freeze pipes and freezing activities at the worksite. In charge of all activities involving the liquid nitrogen.

SCNSUB - Driller and Two (2) Drilling Helpers - Responsible for the activities of driving the freeze pipes in the four (4) test pits.

SONSUB - Electronic Technicians - Responsible for the electrical operation and integrity of the tools and control systems. They will also be the primary operators or he Gantry Tools. There will be two (2) Tool Stations. The third tech will monitur the sensor data in the Control Room and also record the activities inside the Gantry.

SONSUB - Mechanical/Hydraulic Technicians - Responsible for the site setup/operations, involving the excavator, forklift, and crane, and assisting the FREEZEWALL Manager with the freezing activities.

\subsection{Monitoring And Surveillance Requirements}

During the test procedure, a Sonsub Electronic Technician will be required to monitor the instrumentation in the Operations Center. The overall operation will be monitored by the Sonsub Operations Superintendent.

\subsection{Test Personnel Qualifications}

R:fer to Sonsub's Project Management Plan for the Cryogenic Retrieval Demonstration, Section 3

\subsection{DESCRIPTION OF TEST}

\subsection{Key Input And Output Parameters}

The key parameters measured by this test include:

1. Temperature as provided by the type " $E$ " thermocouples located in each test pit. 
2. Elapsed time for complete ground freezing of each pit.

3. Indication of moisture level change as provided by the "Time Domain Reflectometry" (TDR) probes located below each test pit.

4. Total water volume as provided by the totalizer monitor on the water fill lines at each pit.

\subsection{Test Location, Duration, And Schedule}

\section{Location}

South of the Solid Disposal Area (SDA), outside of the perimeter fence of the Radioactive Waste Management Complex (RWMC), located at the Idaho National Engineering Laboratory (INEL) site. Refer to Site Map (Figure 1) and Cold Test Pit Area (Figure 2).

\section{Duration and Schedule}

Refer to Figure 3 which details the schedule for the on site Demonstration Activities.

\subsection{Test Method And Uncertainties}

\section{Test Method}

Each test pit, containing simulated waste salted with rare earth tracers, will be frozen using freeze pipes injected with $\mathrm{LN}_{2}$. During the process, the rear half of the first pit will be filled with water after the perimeter and the front half have been chilled to $-20^{\circ} \mathrm{C}$. When it is determined that the rear of the pit is filled to capacity with water, that portion will also be frozen. The temperature at varinus locations will be monitored utilizing thermocouples to determine time and level of freezing. The locations of the thermocouples are illustrated in Figures 4, 5, 6, and 7. Each pit will also contain twenty four (24) other thermocouples stacked at various depths as shown in Figures 6 and 7 . These probes will be called "Stacked Temperature Probes". The change, if any, of the moisture levels below the rear half of the pit will be monitored utilizing time domain reflectometry (TDR) probes. All information from the thermocouples and the TDR probes will be fed into a data logger system and then to a personal computer for storage as shown in Figure 8. Temperature and moisture data will continue to be gathered until each individual probe is destroyed during the excavation of the pit. (Refer to Sonsub's Project Management Plan - Section 2). The method for the second pit will be the same as the first, but with half as much water added as the first pit. The actual procedure for the remaining two pits will be determined on site depending on the test results of the air monitoring system (EG\&G responsibility) obtained with the first two pits. (Refer to Section 4.0 "Sequence Of Activities" for more detail)

\section{Uncertainties}

Thermocouples $\quad \pm 1.7^{\circ} \mathrm{C}$ Accuracy 


\section{Radioactive Waste Management Complex}

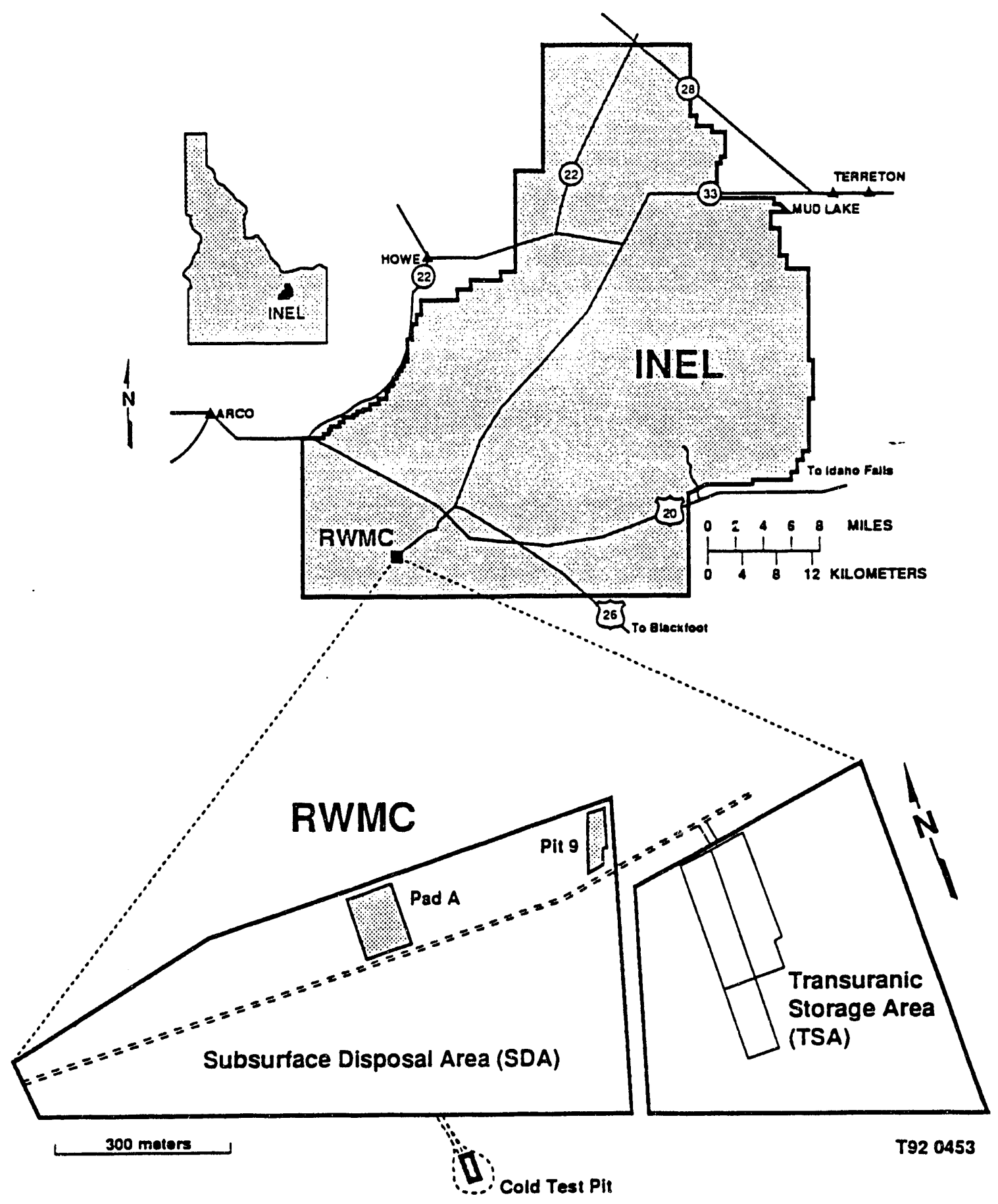

Figure 1 - INEL Site Map 


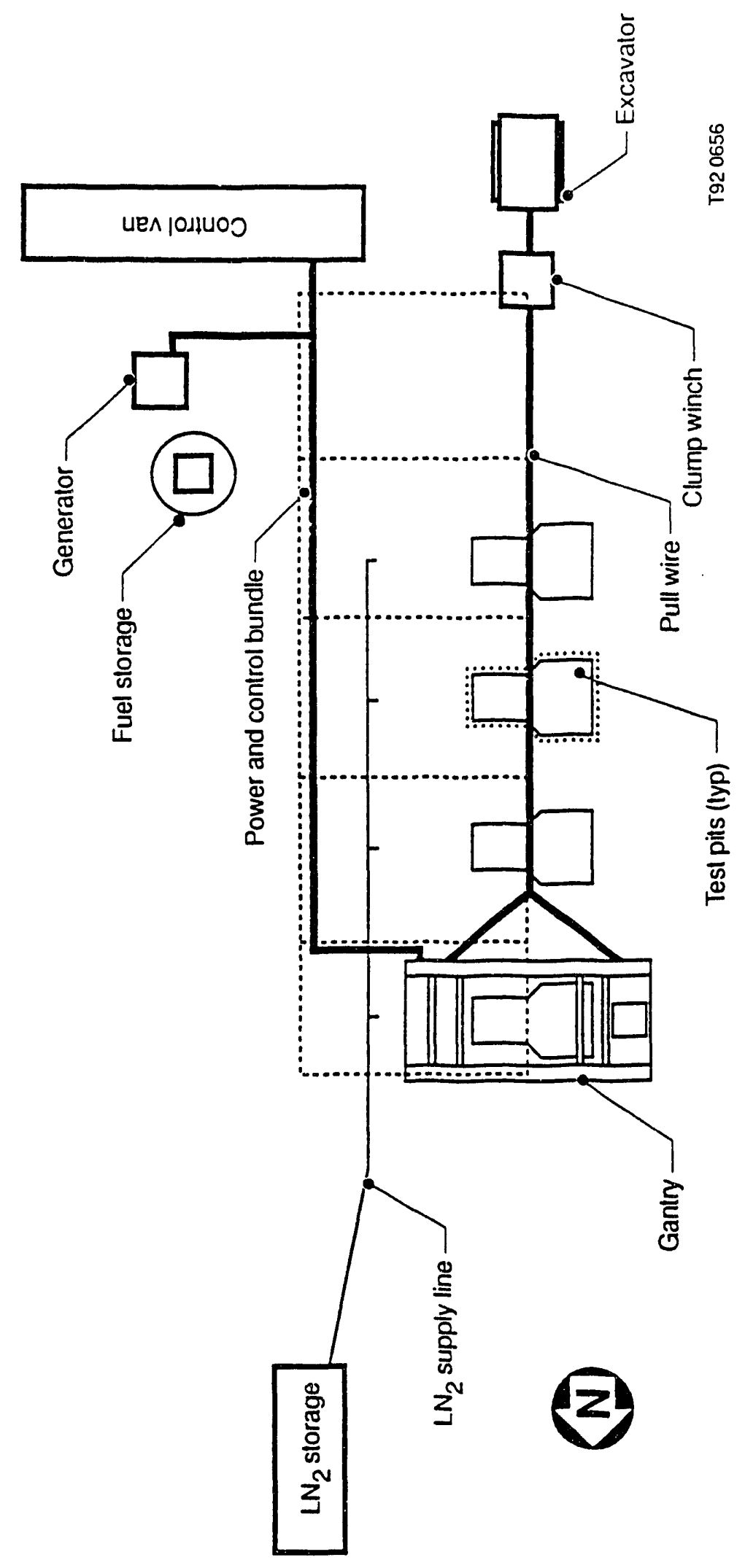

Figure 2 - Cold Test Pit Area 


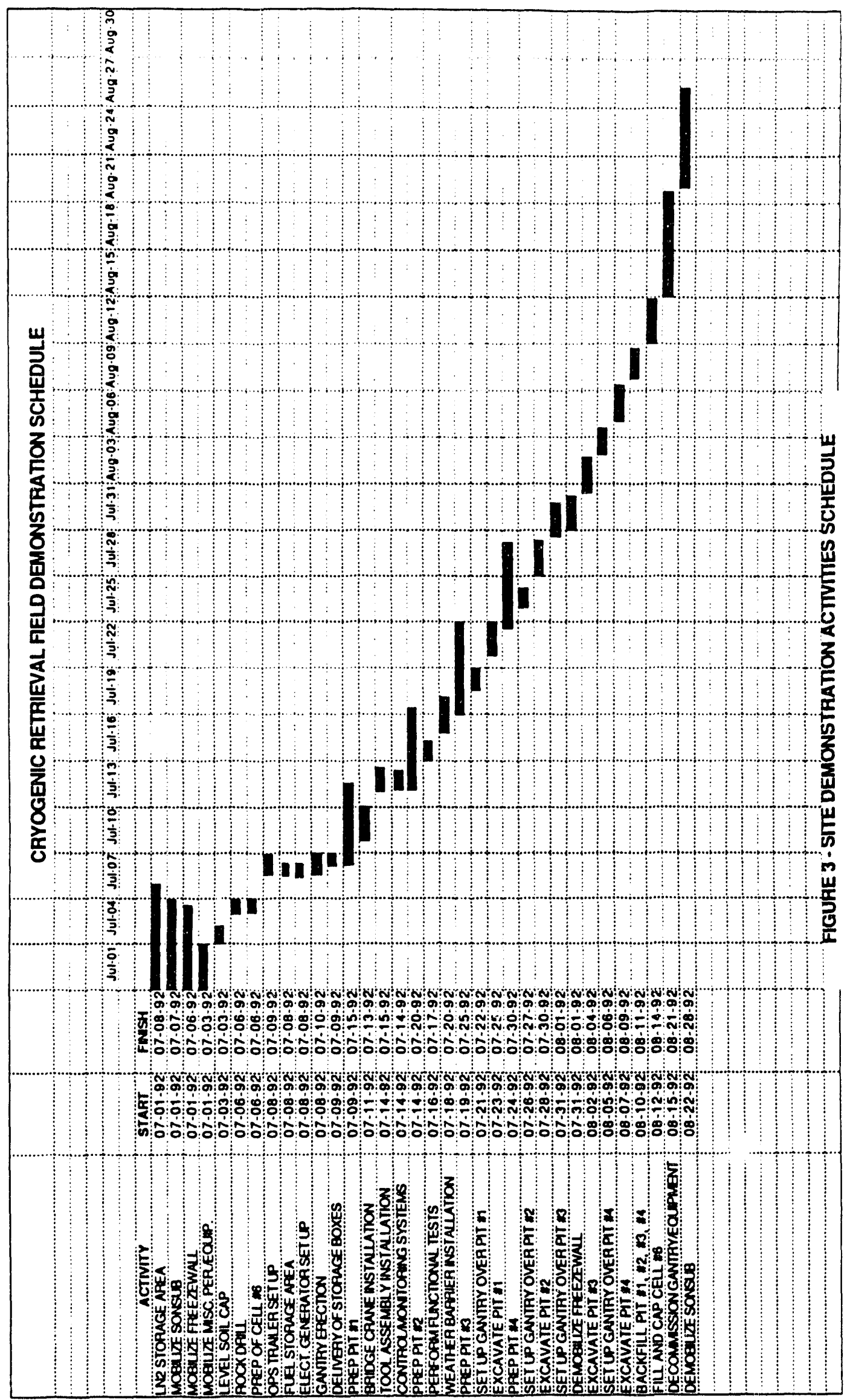




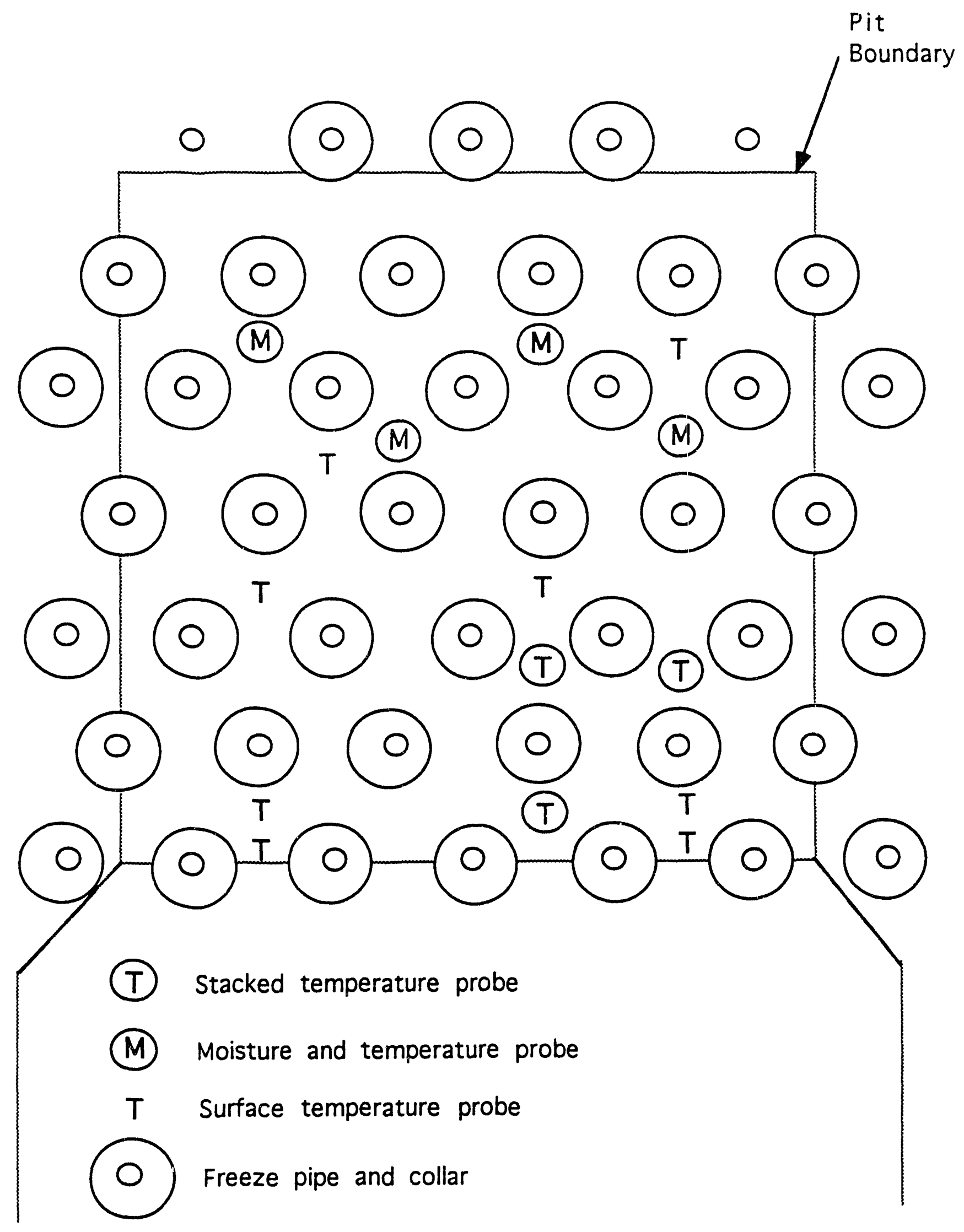

Figure 4 - Pits \#1 and \#2 Layout 


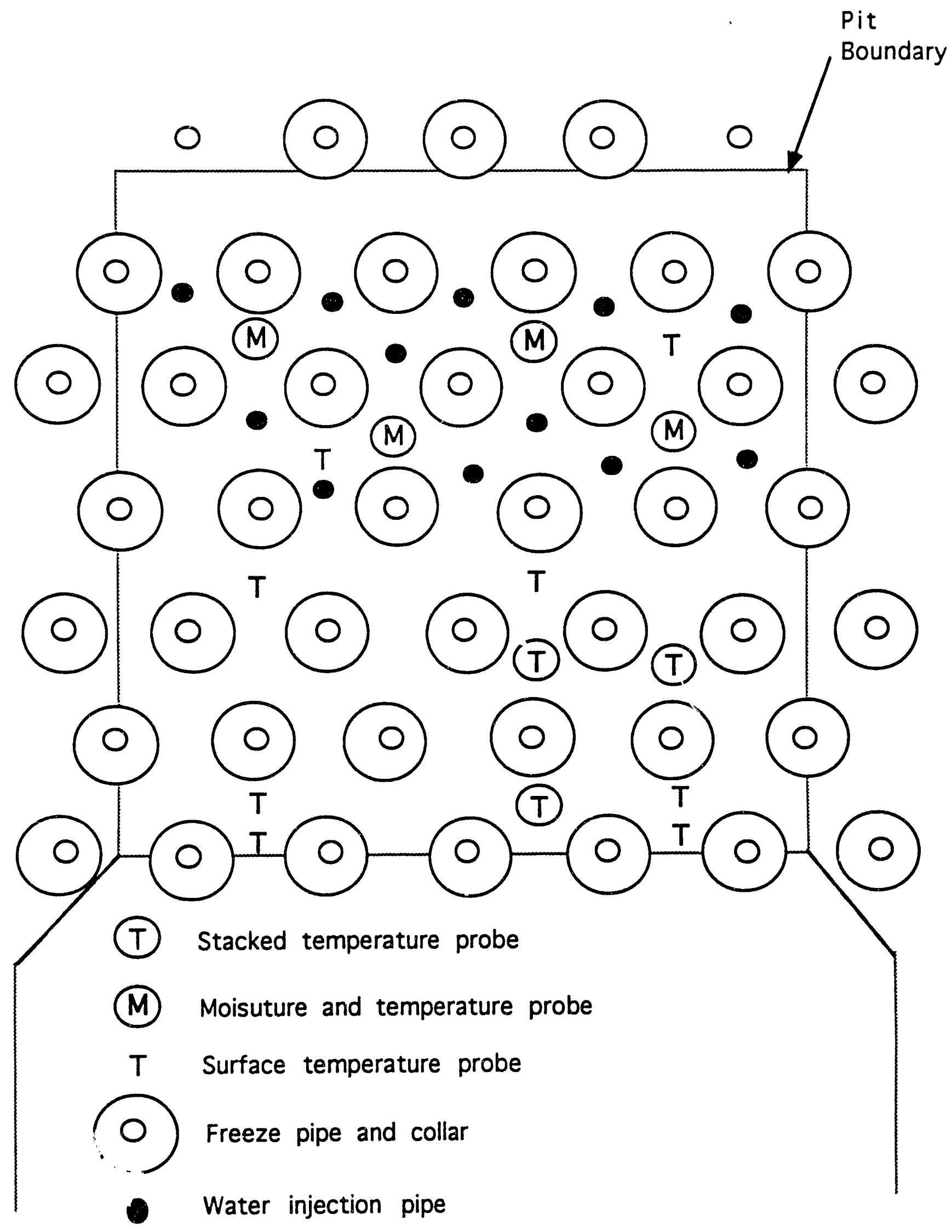

Figure 5 - Pits \#3 and \#4 Layout 


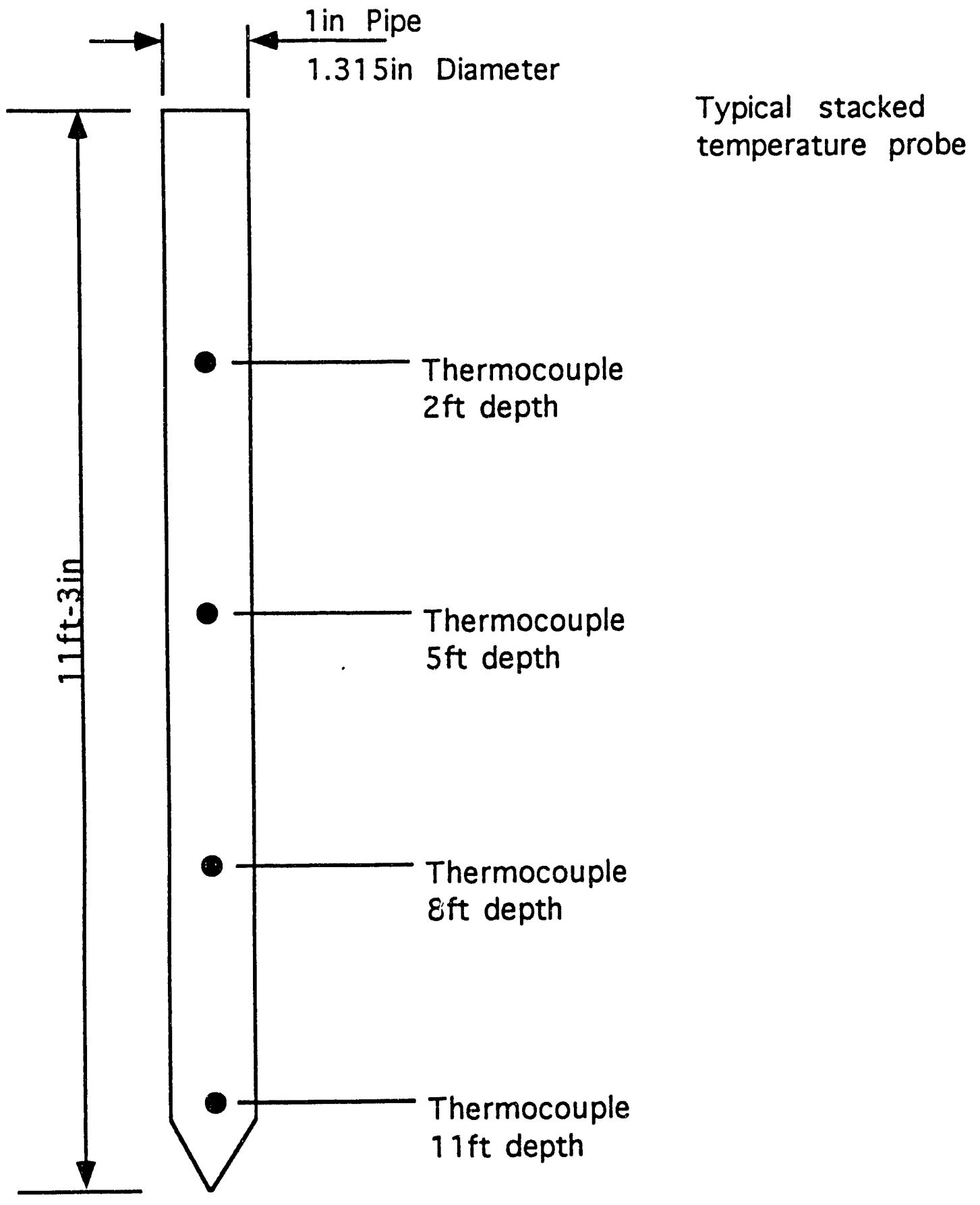

Figure 6 - Stacked Temperature Probe Configuration 


\section{Moisture/temperature probe}

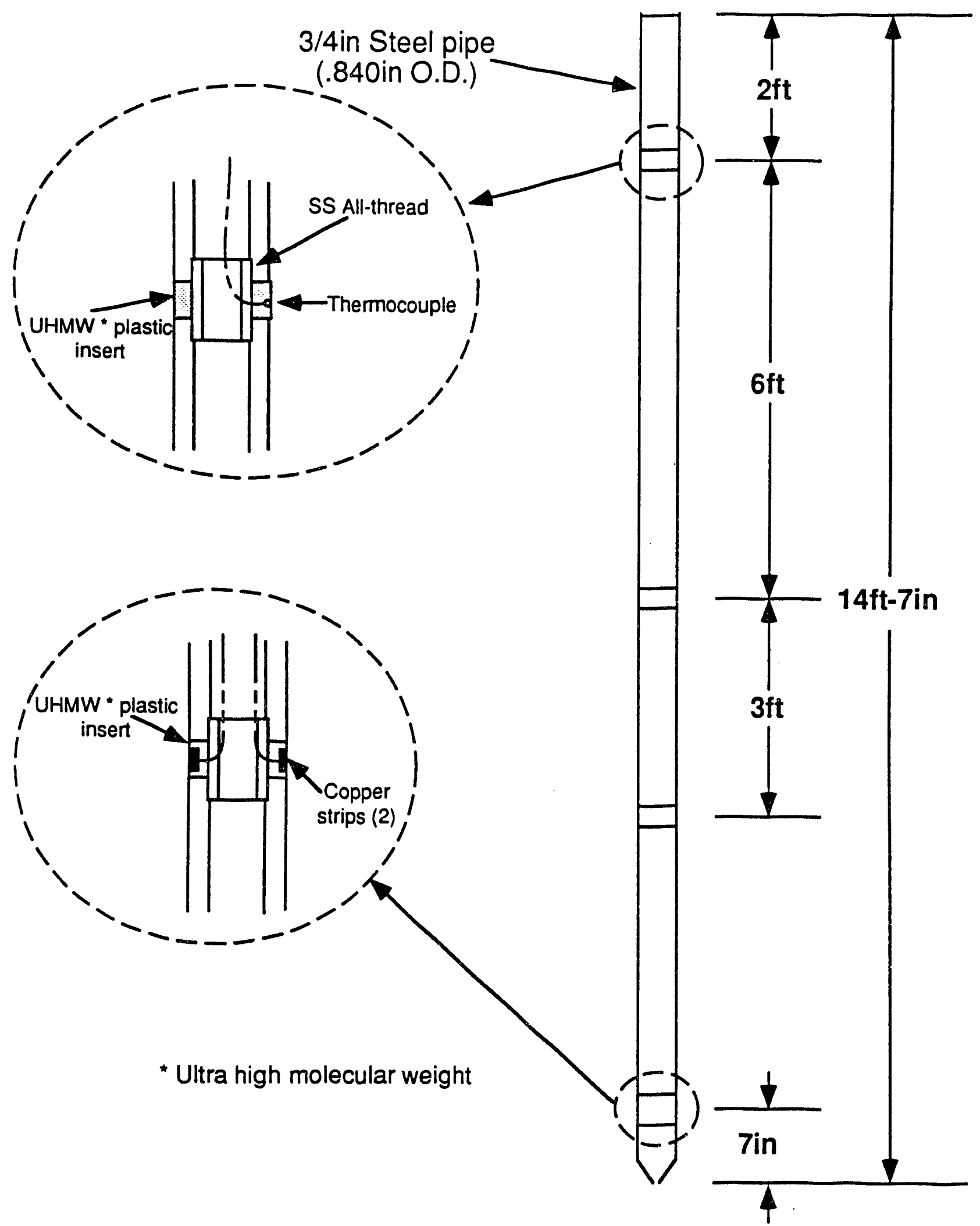

Figure 7 - Moisture/Temperature Probe Configuration 


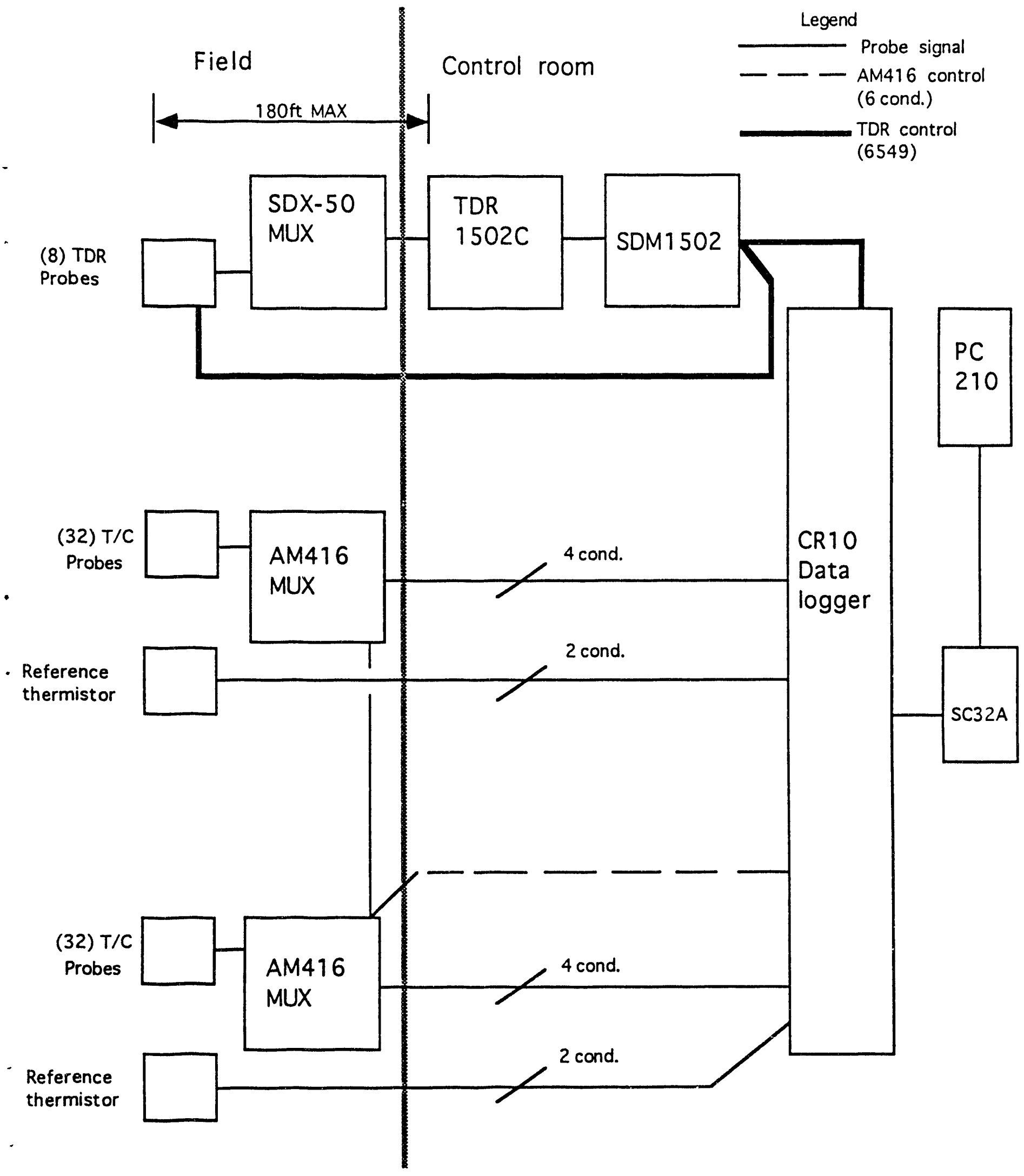

Figure 8 - Data Logger System Block Diagram 
TDR Probes - Once the ground freezes, the TDR reading will drop off to $0 \%$ moisture. Refer to Section 10.3 "Calibration" for reference to accuracy of the TDR probes.

There could be some level of uncertainty due to damage incurred while driving the pipes into the ground. This is an unpredictable event and will have to be evaluated on-site. (Refer to Section 3.6 - "Contingency Plan")

\subsection{Reference Documentation}

1. SONSUB Project Management Plan (PMP)

2. SONSUB QA/QC Assurance Manual

3. CAMPBELL SCIENTIFIC, INC. operating manuals for multiplexer, data logger, and interfaces.

4. General Logbook - Listing dates, personnel on-site, deliveries, equipment failures, maintenance, modifications, etc.

5. Test Plan Logbook - Listing actual test results, start/stop times, observations, listing of data stored on PC computer.

\subsection{Illustrations}

Refer to the following illustrations:

Figure 1 - INEL Site Map

Figure 2 - Cold Test Pit Area

Figure 3 - Site Demonstration Activities Schedule

Figure 4 - Pits \#1 \& \#2 Layout

Figure 5 - Pits \#3 \& \#4 Layout

Figure 6 - Stacked Temperature Probe Configuration

Figure 7 - Moisture/Temperature Probe Configuration

Figure 8 - Data logger System Block Diagram

\subsection{Contingency Plan}

The data from the surface temperature probes will be used to determine if the pit is ready for excavation. The stacked temperature probes will be used to obtain information that EG\&G is interested in using for modeling future cryogenic retrieval projects. The information from the stacked temperature is not imperative to the success of the projuct. One of the major objectives of the project is to determine if water added to the waste can be contained. 
A judgment of when the pit is frozen can be made from as few as two surface probes, provided that one of the probes is located along the row of freeze pipes closest to the working pit and the other probe is located in the center of the pit. If a probe begins to malfunction after the freezing begins, it cannot be replaced.

If there are major equipment malfunctions during a portion of the CRD, the Sonsub Project Manager, Sonsub Operations Superintendent, and the EG\&G Task Manager may concur that some of the data should be considered invalid.

It should be noted that there is a significant redundancy in the number of probes which will be inserted into the waste mass. Should some probes be damaged during installation, there is sufficient backup to obtain meaningful data.

\subsection{Performance Objectives}

1. Provide temperature measurement data to evaluate freezing conditions and establish a final temperature of $-20^{\circ} \mathrm{C}$ measured at the surface temperature probes.

2. Determine time required to completely freeze each pit.

3. Measure the volume of water required to fill the "wet" portion of pit \#1 so that proper volumes can be determined for subsequent pits.

4. Verify if moisture from added water seeps below pit floor as measured by TDR probes.

5. Determine if pits must have water added and at what volume, or can be frozen and excavated utilizing existing ground moisture.

6. Determine the rate at which the pit chills over time by recording the temperature data every 15 minutes.

\subsection{SEQUENCE OF EVENTS}

A general sequence of events relating to temperature, ground moisture, and water volume measurements is listed below. This sequence can be modified at any time with concurrence of the Sonsub Project Manager and the EG\&G Project Manager. Any variations from this sequence should be noted in the General and Test Plan Logbooks.

1. Drive to the depths noted, all Stacked Temperature Probes, Moisture/Temperature Probes, and Surface Temperature Probes beginning with $\mathrm{Pit} \# 1$ and continuing in sequence through Pit \#4 in a pattern as shown in illustrations in section 3.5. This work is performed in conjunction with the driving of the freeze pipes.

Probes will be driven through the waste to allow measurements at the following depths: 
Stacked Temperature Probes

Thermocouple Depths - $2 \mathrm{ft}$., $5 \mathrm{ft}$., $8 \mathrm{ft}$., $11 \mathrm{ft}$.

Moisture/Temperature Probes

Thermocouple Depths - $2 \mathrm{ft}$., $8 \mathrm{ft}$., $11 \mathrm{ft}$

TDR Probe Depth - 14ft. (or basalt rock layer, whichever is reached first), two (2) of the four (4) probes in the first pit will be placed after pilot holes are driven through the waste with one of the small diameter freeze pipes.

\section{Surface Temperature Probes}

Thermocouple Depth - 8in.

2. Connect wiring from all temperature probes on one pit to a compensated connector. Then to the AM416 Multiplexer, and then on to the CR10 Datalogger in the Control Room. A thermistor, located in the multiplexer box,is connected to the input of one thermocouple. The reading from the thermistor will be fed directly back to the CR10 Datalogger and used to compensate for any variation in the thermocouple readings caused by the multiplexer. Connect wiring from all TDR probes on the same pit to the SDMX-50 Multiplexer, the $1502 \mathrm{C}$ tester, the SDM1502 Communications Interface, and the CR10 Datalogger in the Control Room.

3. All temperature probes at each depth level in the same pit will be checked for continuity prior to any freezing or water fill. If the probes at each depth level measure $\pm 5^{\circ} \mathrm{C}$ of each other, they will be considered as undamaged and calibrated. All moisture probes (TDR) in the same pit will also be checked prior to any freezing or water fill. If the output from these probes measure within $10 \%$ of each other, they will be considered undamaged. The lead lengths on the TDRs will be adjusted before being driven into the ground so that all of the probes read within $\pm 1 \%$ of each other.

4. The Operations Superintendent will verify that all systems are operational and ready for initiation of the demonstration.

5. FreezeWALL will connect the nitrogen manifold hoses to the freeze pipes in Pit \#1. $\mathrm{LN}_{2}$ will be pumped into the perimeter freeze pipes and the front half of the pit. The temperature history will be used to verify these areas are fully chilled to $-20^{\circ} \mathrm{C}$ prior to feeding water into the rear half of the pit in a sequence as per the Work Plan (Section 2) in Sonsub's Project Management Plan. Monitoring of the TDR probes will begin when the feeding of water into the rear portion of the pit begins.

The volume of water fill will be recorded utilizing a digital meter located on the fill line. After the flow of water has slowed to less than 5 GPM, the freezing of the rear portion of the pit will begin. The temperature and moisture data for the pit will continue to be monitored until the individual probes are destroyed during the excavation.

6. When the surface temperature of the pit reaches $-20^{\circ} \mathrm{C}$ or lower, the flow 
of $\mathrm{LN}_{2}$ to the freeze pipes will be stopped to allow positioning of the Gantry over the pit. Monitoring of all temperatures in the pit will continue. Once the Gantry is in place $\mathrm{LN}_{2}$ will be flowed to the perimeter freeze pipes to maintain the integrity of the walls. If the waste temperature probes indicate an increase in temperature above $-20^{\circ} \mathrm{C}$, the flow of $\mathrm{LN}_{2}$ can be reestablished to the freeze pipes in the simulated waste.

7. Monitoring of the probes in Pit \#1 will continue until the subject probes are removed with the waste. The probes in Pit \#2 will be connected to the data logging system prior to the commencement of freezing activities. When the excavation of $\mathrm{Pit} \# 1$ is complete, then the probes to $\mathrm{Pit} \# 3$ will be connected to the data logging system.

8. Steps 2. through 6 for monitoring temperature and moisture will be repeated for Pit \#2 except that only one half of the water volume recorded for Pit \#1 will be added into the rear half of the pit.

9. Pits \#3 and \#4 will be tested the same as Pits \#1 and \#2 except that the floor of the rear half will be frozen prior to any water fill. The amount of water fill will be determined on-site based on the results of the air monitor tests conducted by EG\&G on Pits \#1 and \#2. The air monitor tests will be used to determine if dust is being contained during the wet and dry portions of the retrieval process.

\subsection{SAMPLING AND DATA COLLECTION}

\subsection{Data Collection Techniques}

\section{TEMPERATURE}

"E" thermocouples mounted in a stainless steel drive tube. The thermocouples will be calibrated and certified by the manufacturer.The collection technique used for temperature sampling will be standard ANSI Type

\section{GROUND MOISTURE}

The technique used to monitor ground moisture will be a "Time Domain Reflectometry" (TDR) probe mounted on the end of sixteen (16) of the stainless steel tubes used for the thermocouples. Four (4) TDR probes will be used for each pit. The equipment set up shown in Figure 8 and explained in Section 4.0, paragraph 2, allows a quantitative moisture measurement to be read from the TDR. This data has to be interpreted with the use of the calibration data listed in Section 10.3 .

\section{WATER FLOW RATE}

The technique used to monitor the water flow will be a standard battery operated digital liquid flowmeter and totalizer. It is factory calibrated at $\pm 1.5 \%$ accuracy and will provide an output in GPM flow and total gallons. The water will be gravity fed, not pressure injected, into the simulated waste. 


\subsection{Sampling And Data Collection Procedures}

The sampling rate for data collection will be programmed into the datalogger system. It will therefore require a minimum of operator interaction, once set up for a particular test. The thermocouple data will be read into a PC file in the following format:

TEST \# , TC ID , TIME , SD/VOLTAGE , AVG TEMPERATURE , SD

The averages and standard deviations will be taken over the eight readings for each thermocouple. The time may be arbitrarily set as the time that the first of the eight readings for the thermocouple is taken.

The sampling rate will be :

Thermocouples - Each probe will be read every two (2) minutes and averaged every eight (8) readings. The average readings will be recorded.

TDR Probes - Each of the four (4) probes will be read five (5) times, once an hour. When two (2) pits are being monitored, one (1) pit will be read at the beginning of the hour and the second pit will be read at the $1 / 2$ hour. This reading will be recorded in a sequence of:

Probe 1, Probe 1, Probe 1, Probe 1

Probe 2, Probe 2, Probe 2, Probe 2

Probe 3, Probe 3, Probe 3, Probe 3

Probe 4, Probe 4, Probe 4, Probe 4

It should take about 1 minute for the signal to be read by a probe and processed through all of the logging equipment, so the whole sample period should be about 16 minutes. The average and standard deviation of the four (4) readings for each probe shall be calculated and provided for data validation.

This data will be read into a PC in a file with a format similar to:

TEST \# , TDR ID , TIME , SDIAVG VOLTAGE , AVG MOISTURE , SD

The time can arbitrarily be chosen at the time that the first probe is sampled for that hour. Readings for the second pit will start on the $1 / 2$ hour.

Water Total Volume - This information will be manually recorded into the Test Plan Logbook for each pit.

\subsection{Sampling And Analysis Plan}

This Section Is Not Applicable

\subsection{DOCUMENT CONTROL}

\subsection{D a t a}

All of the data from the thermocouples and TDR probes will be gathered 
automatically. A voltage reading will be received from both the thermocouples and the TDR probes. This signal will be fed through an A/D converter and recorded into a PC computer file. These files will be backed up on a regular basis to maximize tape storage space. Other pertinent data, such as water volume and flow rates, will be entered into the Test Plan Logbook.

\title{
6.2 Test Plan Changes
}

During the demonstration, some minor changes may have to be made to the procedures or sequence of procedures. Such minor changes may be necessary to improve the safety for personnel or to adjust to unforeseen equipment or logistical problems. Provided the changes do not violate applicable safe work permits or Sonsub's Safety Plan, the changes may be made with verbal concurrence from the Sonsub Project Manager, and the EG\&G Project Manager. Any changes affecting safety must be approved in writing by the Sonsub Safety QA/QC Manager.

\section{$6.3 \mathrm{Logbooks}$}

Two logbooks will be issued and maintained by Sonsub throughout the test. They will be located in the Sonsub Control Room. Listed below is the minimum information to be included in each logbook. The Operations Superintendent will be responsible for the logbooks.

\section{General Logbook}

\author{
1. Dates with personnel in and out notations \\ 2. Sub-contractor information \\ 3. Deliveries \\ 4. Equipment failures \\ 5. Maintenance $\log$ \\ 6. Equipment modifications \\ 7. Excavation activities, events, etc. \\ 8. Contents log of waste storage boxes
}

Test Plan Logbook
1. Start/stop times for actual test
2. Test results
3. Observations
4. Listing of data stored on the PC computer
5. Any changes made to test procedures
6. Any other information felt necessary

Each page and entry in both logbooks shall be dated and signed with the name of the person making the entry. The logbooks will be reviewed and signed daily by the Sonsub Operations Superintendent.

\subsection{ANALYTICAL METHODS}

This Section Is Not Applicable 


\subsection{DATA REDUCTION, VALIDATION, AND VERIFICATION}

\subsection{Data Reduction}

Data reduction for both the thermocouples and the TDR moisture probes takes place in the software programming of the Campbell Scientific CR10 Datalogger located in the Sonsub Control Room (Refer to Figure 8). The thermocouple signal uses a simple algorithm to convert from voltage to temperature measurement. The method used for moisture measurement is "Time Domain Reflectometry". (Source for all equations - Campbell Scientific TDR Soil Moisture Measurement System Manual - Revision: 2/92) The software uses Topp's equation to equate volumetric water content, $W_{V}$, to dielectric constant Ka, where $\mathrm{Ka}=(1 / \mathrm{Vp})^{2}$ The propagating velocity, $\mathrm{Vp}$ is defined as the ratio of the actual velocity divided by the speed of light. The result from the datalogger (with a multiplier of 1 and an offset of 0 ) is $1 / \mathrm{Vp}$.

The equation is:

$$
\mathrm{W}_{\mathrm{v}}=-0.053+0.0292(1 / \mathrm{Vp})^{2}-0.00055(1 / \mathrm{V} \mathrm{p})^{4}+0.0000043(1 / \mathrm{Vp})^{6}
$$

\subsection{Data Validation}

The data will be validated by reviewing the functional redundancy of the individual probes. EG\&G will review the averages and standard deviations of the data to validate the data. The recording of the averages and standard deviations is explained in Section 5.2.

Each probe will be identified with a unique number during the calibration testing in Houston. This data will be entered in a logbook along with the exact location assignment for each probe in each pit. This logbook will be used during the driving of the probes in the pits.

\subsection{Acceptance Criteria}

All of the data gathered during the CRD will be recorded and furmished to EG\&G. If there are major equipment malfunctions during a portion of the $C R D$, the Sonsub Project Manager, the Sonsub Operations Superintendent, and the EG\&G Project Manager may concur that some of the data be considered unusable. Refer to Section 3.6 Contingency Plan.

\subsection{QUALITY ASSURANCE}

\subsection{Quality Level}

The document governing quality assurance on this project will be the Sonsub QA/QC Assurance Manual.

\subsection{Quality Control Methods}

The Sonsub QA/QC Manager along with the Operations Superintendent will be 
responsible for adherence to quality procedures. Following procedures described in Section 5.1 and logbook procedures described in section 6.3 will ensure quality.

\subsection{Completeness}

See Section 3.6, Contingency Plan.

\subsection{Internal Audits}

This Section Is Not Applicable

\subsection{EQUIPMENT AND INSTRUMENTS}

\subsection{List of Equipment}

The following is a list of all equipment that shall be calibrated (if necessary) and available at the start of the CRD.

Description

Quantity

PC Desktop Computer

Campbell Scientific Software

SC25PS Cable - Campbell

SC32A RS-232 Interface -Campbell

SC12 Cable - Campbell

CR10 Datalogger - Campbell

1502B TDR Cable Tester - Tektronix

SDM1502 Communications Interface - Campbell

SDMX50 Multiplexer - Campbell

Digital Flowmeter/Totalizer

Thermocouple Reference Thermister 2

Stacked Temperature Probe 12

Surface Temperature Probe 32

Moisture and Temperature Probe 16

Temperature Probe Compensated Connector 60

50 ohm Coax RG8 Coax Cable As Required

2 Conductor Cable As Required

4 Conductor Cable As Required

\subsection{Range And Accuracy}

Thermocouples-ANSI Type "E"

Temperature Range $=-200^{\circ} \mathrm{C}$ to $+900^{\circ} \mathrm{C}$

Accuracy $= \pm 1.7^{\circ} \mathrm{C}$ or $0.5 \%$ Above $0^{\circ} \mathrm{C}$ $\pm 1.7^{\circ} \mathrm{C}$ or $1.0 \%$ Below $0^{\circ} \mathrm{C}$

Water Flowmeter/Totalizer Range-0.3 to $3.0 \mathrm{GPM}$ Accuracy $= \pm 1.5 \%$ 
TDR Probes

$$
\varnothing=\frac{\text { Volume of Water }}{\text { Volume of Soil }}
$$

$\begin{array}{lcc}\text { Known Theta } & \text { Maximum } & \text { Reading } \\ 0.0 & 0.20 & 0.0 \\ 0.10 & 0.20 & 0.0 \\ 0.20 & 0.30 & 0.10 \\ 0.25 & 0.35 & 0.15 \\ 0.30 & 0.40 & 0.20 \\ 0.40 & 0.50 & 0.30\end{array}$

\subsection{Calibration}

The type "E" thermocouples are relatively common and as these devices are being purchased specifically for this demonstration, there is no need for an elaborate calibration test. All thermocouples will be received with Certificates of Quality Control from the Manufactures. When received, all temperature probes will be connected to the Data Logging System and checked to ensure all thermocouples can be read. If all readings are within 2 degrees of each other, then the thermocouples will be considered okay for field use.

The lead lengths of all TDR probes will be adjusted so that they are each within $\pm 1 \%$ moisture content of each other.

The instructions for calibration and standardization of the receiving instruments will be found in the Campbell Scientific Instruction Manuals.

\subsection{Preventive Maintenance}

Due to the short time duration of the CRD, no preventive maintenance will be required.

\subsection{SUPPLIES, CIILITIES, AND FACILITIES}

Refer to Sonsub's Project Management Plan for the Cryogenic Retrieval Demonstration.

\subsection{HEALTH AND SAFETY}

Refer to Sonsub's Safety Plan for the Cryogenic Retrieval Demonstration.

\subsection{RESIDUALS MANAGEMENT}

No hazardous or radioactive waste by-products will be generated from the work described in this plan. 


\subsection{REFERENCES}

SONSUB Project Management Plan

Demonstration Of Cryogenic Ground Freczing Technology For Waste Recovery TAA250-A03 - April 1992

SONSUB QA/QC Assurance Manual - TAA250-B02

SONSUB Safety Manual - TAA250-B01

Campbell Scientific

TDR Soil Moisture Measurement System Manual Revision: $2 / 92$ 


\section{Appendix C}

\section{Preliminary Tests Performed on In Situ TDR Probes}




\section{Preliminary Tests Performed on In-situ TDR Probes}

The following proof of principal testing was conducted at Sonsub in Houston, Texas, July 3, and July 4, 1992:

The Data Quality Objective for this test was to determine if the TDR probes that Sonsub will be using can respond to increases and decreases in soil moisture levels. The required accuracy of these probes is fairly lax. The test plan allows for the TDR to read the moisture level $10 \%$ higher or $10 \%$ lower than the actual percent soil moisture. The result of the test is that the new design should work correctly. However, the probes were not made to Sonsubs' specifications so there will be some variability in the actual readings.

$\frac{\text { CONTROL }}{\text { Oven Dried Soil }} \frac{\text { NEW TDR READING }}{-0.3 \%}$

$6.2 \%$ moisture as read by a $3 \%$ conventional Campbell Scientific probe.

Oven Dried Soil mixed with $11 \%$ approximately $15 \%$ water by volume.

$28 \%$ moisture as read by a $19 \%$ conventional Campbell Scientific probe.

These results confirm that the TDRs which Sonsub will use can meet our data quality objectives.

In addition, the soil wich the $11 \%$ TDR reading was chilled to -58 degrees centigrade to observe the effect of the cryogenic temperatures on the TDR response. Theoretically, the TDR reading should drop of to $0 \%$ moisture as the water freezes. Vie found that the TDR signal responded to the drop in temperature but the response was very slow. There are two reasons for the slow TDR response. First, the dynamics of moisture movement and freezing in the soil are very slow. Second, it takes time for the algorithm in the Campbell Scientific software to fit the curve on the signal from the TDR. This process takes longer when the signal is chariging rapidly. Such was the case with the rapid cooling. After one hour at sub freezing temperatures, the TDR read less than $1 \%$ moisture. The reading on the TDR the ntxt morning, after letting the soil thaw out uver night, was $10 \%$ moisture. Thus we have proved that in principle this new TDR probe responds to temperature and moisture changes as is expected. 
The follwing tests were done at the INEL:

A gravimetric measurement of five 100 gram soil samples from the top soil of the cold test pit was made on $7 / 16$ through $7 / 17$. The average soil moisture content was found to be $3 \%$. At the same time, Sonsub did the following test with on of the TDR probes at the cold test pit. The probe was driven 4 inches into the ground. The TDR read a 3.2\% moisture content. Two cups of water were poured in the ground around the probe, the reading rose to $4.4 \%$ moisture. An additional 1.25 quarts of water was added to the ground around the probe, 5 minutes later the TDR reading rose to $22 \%$. 


\section{Appendix D}

\section{Readiness Review Results}

D-1 
D-2 


\section{INTEROFFICE CORRESPONDENCE}

Date: $\quad J u 7 y 6,1992$

To: $\quad$ Distribution

From: $\quad$ D. J. Valentich, MS 3930

Subject: INFORMAL READINESS REVIEW - CRYOGENIC RETRIEVAL DEMONSTRATION DJV-28-92

The Project Manajer (D. Valentich) and Instrumentation Engineer (E. Yokuda) traveled to Houston, Texas during the week of June 29, to witness shop testing of the cryogenic retrieval hardware and to conduct an informal readiness review with Sonsub (the demo contractor) management and engineering personnel.

The informal readiness review was held on June 30 , and July 2 . The results of these meetings are documented in this memo. In general, Sonsub appears to have prepared very well for the up coming field demonstration. Planned and identified activities are well prepared for, and contingencies have been addressed for a host of anticipated problem areas.

It is important to note that this demonstration is experimental in nature and is intended to be an R\&D project, there are many unknown that we are set to discover during the course of the demo, so things may not always work perfectly the first time, or at all.

Two separate meetings were held. The first meeting on June 30 was to review the Buried Waste Integrated Demonstration (BWID) Preparedness and Consent Checklist. A listing of these questions and the assessment of readiness follows:

1.1 Have staffing requirements been identified?

Yes. Sonsub has carefully considered necessary personnel who will be required to help execute the field demonstration. Personnel have been selected for experience and capability, and management has chosen what appears to be an optimum crew size.

EG\&G will perform air monitoring related work and has likewise carefully selected the right number of qualified personnel.

1.2 Have training requirements been developed?

Yes. Sonsub has identified necessary training requirements.

These include Hazcom, SCBA, Firefighting, First Aid, Equipment Operation and Cryogenic Safety. 
EG\&G personnel will require SCBA training.

1.3 Have certification requirements been identified?

Yes. For both Sonsub and EG\&G the only formal training that appears to require certification is the SCBA. Certifications are in place for personnel who will be required to use SCBA gear.

2.la Has the hazards classification been determined?

Yes. A formal determination was made during the first two months of the project. The ISRC found the project to be routinely accepted by the public.

2.1b Have activities been analyzed fo: fire hazard?

Yes. As an integral part of the Safety $\mathrm{Plan}$ review for Sonsub, and the Test Plan review for EG\&G, a fire hazards, prevention, and response evaluation was performed.

2.1c Have activities been analyzed using OSHA requirement?

Yes. The basis for formulation of the Sonsub Health and Safety Plan was 1OCFR 1926--which addresses OSHA requirements.

EG\&G activities are covered by the INEL safety manual and the S\&T Safety Plan.

2.1d Have activities been analyzed to determine the need for emergency actions?

Yes. As a part of the Sonsub Health and Safety Plan, potential emergencies and responses for to the same have been evaluated. The most probable type of emergency would involve fire, medical emergency, or an accident with cryogenic liquids. There are virtually no hazardous (LN2 is classified as hazardous for burn potential, it is not toxic) and no radioactive materials or wastes associated with this demonstration.

2.2a Have project procedures been identified?

Yes. Both Sonsub and EG\&G have developed a series of procedures identified in approved work, project management, safety, quality, and test plans that will be used a basis for executing the technical and safety related aspects of the project. 
Distribution

July 6,1992

DJV-28-92

Page 3

2.3a Has an Environmental Checklist been completed?

Yes. An Environmental Checklist has been completed for the job and formal approval obtained on related NEPA documentation. A Categorical Exclusion (CX) was submitted to and approved by DOE-ID and concurrence obtained for the same from DOE-HQ.

2.3b Have activities been analyzed to determine the need for environmental permits?

Yes. As a part of the Environmental Checklist submittal and review process a determination was made concerning the need for any special permits. No environmental permits are required.

2.3c Have activities been analyzed to determine the need for spill prevention measures?

Yes. As an integral part of the Sonsub's Health and Safety Plan, the potential for spill of hazardous liquids was evaluated. The only hazardous fluids on the job site will be diesel fuel and hydraulic oil. Spill prevention and containment measures have been evaluated and implemented for working with these fluids. a) though corsidered hazardous because of the burn potential, is not toxic to the environment.

2.3d Have activities been analyzed to identify ways to minimize the generation of waste?

Yes. A thorough evaluation was made concerning the buried waste that will be retrieved during the cryogenic field demonstration, and other waste that will be generated during normal testing activities (construction debris, wrappers, bottles, etc..). The buried waste will be boxed and used to create another test cell at the cold test pit. The other waste will be recycled in accordance with INEL guidelines--metals and wood will be segregated and recycled, and other wastes will be interned at the CFA 1 andfill.

2.3e Have waste storage needs been considered?

Yes. Buried waste will be stored in standard $4^{\prime} \times 4^{\prime} \times 8^{\prime}$ plywood boxes. Other waste will be stored in metal dumpsters in accordance with INEL policy. 
Distribution

July 6, 1992

DJV-28-92

Page 4

2.3f Have waste handling needs been identified?

Yes. There are no hazardous or radioactive wastes associated with this project. Only commercial type waste will be handled and transported, so there are no special or exotic requirements. The waste that is generaced can be handled with standard equipment.

2.4a Have facility requirements been considered?

Yes. Sonsub and EG\&G will be essentially self contained while working at the cold test pit. There are no special facilities required, and no support from or use of any INEL facilities is anticipated.

2.4b Have service and utility needs been considered?

Yes. All necessary power, water, fuel, air, housing, heating, and cooling, computer and other utility needs have been considered and provided for.

2.5a Is a document control system in place?

Yes. Both Sonsub and EG\&G have quality plans in place that address the control of project documentation.

$2.5 \mathrm{~b}$ Is a self assessment system in place?

Yes. EG\&G has a formal quality/assessment plan in place at the department level. It is the project's view that assessment is a daily and on going function of all personnel associated with the work, and as such all safety, technical, and other aspects are reviewed for compliance on an ongoing basis.

2.5c Have deficiency logs been considered?

No. It is not clear what a deficiency $\log$ is or where the requirement for one stems from. If this is addressing nonconformance, it is not planned to have a non-conformance log, however, as any non-conformance are identified they will be corrected.

2.5d Will samples be taken?

Yes. Air samples will be obtained during the demonstration. How samples will be obtained is addressed in an approved test plan for the project. 
Distribution

July 6,1992

DJV-28-92

Page 5

2.5e Have process controls activities been developed?

Yes. Control of the work has been evaluated and documented in the project management $\mathrm{plan}$, work $\mathrm{plan}$, quality $\mathrm{plan}$, and test plans.

2.5f Has a Project Test Plan been developed?

Yes. Three of them. A background sampling and test $p l$ an was developed to determine natural background levels of rare earth tracers at the test site, an air monitoring test $\mathrm{plan}$, and a test plan for monitoring temperature and moisture content/migration during the test.

2.5g Has records management been considered?

Yes. At the conclusion of the project a project file will be turned over to WTDD document control for retention, and a final report documenting the overall project will be developed.

2.5h Have calibration requirements for measurement and test equipment been considered?

Yes. These are identified in the test plans.

3.1 Has required equipment been identified?

Yes. An extensive evaluation for all demonstration and testing related equipment has been performed, all equipment has been ordered and received, and is ready for field deployment.

3.2 Have equipment specifications been defined?

Yes. All equipment specifications have been addressed either in test plans, engineering drawings, or equipment specifications.

3.3 Has a contractor been identified?

Yes. Sonsub Services, Inc. is the contractor who will perform field cryogenic retrieval demonstration. They have been on formal contract since February, 1992. 
Distribution

July 6, 1992

DJV-28-92

Page 6

3.4 Has the design review been completed?

Yes. Sonsub has completed numerous internal design reviews for all work. EG\&G has likewise completed a design review for the air monitoring test plan. Additionally, EG\&G has reviewed the Sonsub designs, and the hardware will be demonstrated in the shop and again in the field.

3.5 Have contracts been completed?

Yes. All necessary contracts have been completed by both EG\&G and Sonsub.

3.6 Have vendor manuals been provided?

Vendor manuals have been obtained by Sonsub for all hardware they are responsible for. These manuals have not yet been formally turned over to EG\&G, but will be at the conclusion of the project at the same time the as built drawings are submitted.

3.7 Have as-built drawings been completed?

As built drawings are kept updated. They have not yet been completed because they will continue to be updated until the work in the field is finished. Sonsub is planning to provide a full set of as built drawings at the conclusion of the field work.

3.8 Have acceptance test been conducted on hardware?

Yes. The gantry, tools, and instrumentation systems that Sonsub is responsible for have been successfully tested in the shop and are ready for field deployment. EG\&G has conducted acceptance testing of the air monitoring system and it too is ready to be used for the actual demonstration.

3.9 Have required spare parts been identified?

Yes. Sonsub has developed a list of spare parts that will be available in the field curing the demonstration. Likewise, EG\&G has available spares for the air monitoring work.

3.10 Is equipment operational per specifications?

Yes. During the acceptance testing it was determined that all equipment was performing within operational tolerances. 
Distribution

July 6, 1992

DJV-28-92

Page 7

3.11 Is equipment calibrated or standardized per requirements?

Yes. As an integral part of the acceptance testing, calibration of equipment and instrumentation was performed in accordance with requirements set forth in the test plans.

Following the Preparedness and Consent checklist review, a review was conducted using a list of project specific questions. The results of this review are documented here (rather than list all the questions, a copy of the informal readiness review checklist that was used as a basis for discussion has been attached):

1. Yes. Sonsub has assigned one individual the responsibility of maintaining a master checklist to ensure all necessary components, tools, equipment, etc.. is accounted for and shipped to the job site.

2. Equipment and materials will be transported via common carrier. There is a detailed plan developed for the coordination of what equipment and materials will be loaded when and delivered where. All materials can be unloaded at the job site with either a forklift or crane that Sonsub will have onsite. There is a plan for the sequential delivery of materials and equipment to the job site.

3. The project manager has maintained a list of all personnel for which security forms have been submitted. This list has been checked with personnel requirements to verify all necessary personnel are accounted for. Prior to leaving for Idaho, all sonsub personnel or their subcontractors have been instructed to double check with W. C. Crownover in EG\&G subcontracts to verify that the proper clearances have been granted.

4. Sonsub has scoped out which services are needed to be subcontracted. These were reviewed, and it was verified that all subcontracted services will be provided for.

5. Arrangements have been made for the delivery of diesel fuel, which is the only type of fuel that will be used at the job site.

6. Sonsub has included special instructions with purchase orders to vendors who will be making deliveries to the job site. These instructions include a map of how to get to the site and the procedure checking in and out at the guard gate.

7. Arrangements for all rental vehicles have been made, all will be supplied with a fire extinguisher and shovel. 
Distribution

July 6,1992

DJV-28-92

Page 8

8. All personnel who are working on the site will be given a copy of the Health and Safety Plan, required to read it, sign that they have read and understand it, and will abide by the requirements stated therein. Additionally, there will be weekly tool box meetings to review safety issues and refresher talks.

9. Sonsub is going to arrange for a water truck from If to visit the site as needed.

10. The boxes have all been fabricated and are ready for delivery to the job site.

11. Freeze pipes are almost all fabricated. There are enough to do the first three pits, the rest will be ready next week. There is a plan in place to ensure the right type of freeze pipe is used in the right application.

12. Sonsub has prepared a drawing, bill of material, and plan for the connection, transfer and delivery of LN2 from the storage tank to the freeze pipes. Filling of the storage tank will be accomplished by the trucking company using standard procedures (the same company supplying the LN2 and the storage tank is providing for transport, so they are familiar with hauling and transfer).

13. Hydraulic unit will be shipped with fluid in the reservoir.

Special precautions will be taken to plug and protect all ports to prevent dirt from getting in the system. System operates at about 3000 si. The fluid is not readily available from the Idaho Falls area, however, there will be extra 55 gallon drums of fluid brought on site.

14. This is a broad question, because no one can predict exactly what is most likely to break or fail, and therefore exactly what spares should be provided for. However, an evaluation has been made of the items most likely to break and provisions have been made to repair or replace the same. Contracts have been made with a number of Idaho Falls businesses (electrical, hydraulic, electronic, welding, machining) to provide components as may be needed.

15. There are no spare freeze pipes. These are expensive items. We will "cannibalize" freeze pipes as needed in the first few pits. 
Distribution

July 6, 1992

DJV-28-92

Page 9

16. Fire safety was discussed. There is relatively little on the job site that will burn. There will be about six fire extinguishers positioned around the job site at strategic locations. No open flames will be permitted except for welding and cutting after a safe work permit has been obtained. No vehicles will be permitted off road. Smoking is permitted only is Sonsub's control trailer lo'dnge area.

17. A section has been included in the safety manual discussing working with cryogens. Additionally, Air Products, the company providing the LN2 is going to give a special on day training session for all site personnel. This training session will deal with working with cryogens.

18. The safety plan addresses working around an oxygen depleted atmosphere. All personnel when in the exclusion zone will carry 02 monitors and SCBA's. The buddy system will be employed. Prior to entering a confined space a safe work permit will be obtained.

19. A review of how the EG\&G air monitoring trailer and equipment will interface with the Sonsub provided systems will interface was conducted. A glitch was discovered when we compared the size of the filter housing with the support pipe (support pipe too smal1). This problem was corrected.

20. No smoking outside at any time. Smoking is allowed only in the Sonsub control trailer lounge.

21. If at any time anyone is feeling fatigued or overly tired they are to take a break, quit for the day, or what ever is necessary so safety is not compromised.

22. A supply of stock lumber, metal, hoses, electrical supplies, etc... will be available to the job site.

23. A11 Sonsub and subcontractor personnel will sign in at the RWMC guard gate daily and likewise sign out. Any time some one goes off site they will sign out and sign in again later in the day when they return. We reviewed what to do in case of an alarm at RWMC, and emergency phone numbers to call in case of fire, medical, or other emergencies. We reviewed how to obtain safe work permits. This will be discussed in more detail with D. gray, RWMC safety engineer. For site security, the HP's are going to provide oversite of Sonsub's work area via the roving watch. 
Distribution

July 6, 1992

DJV-28-92

Page 10

24. Kick off meeting for safety will be held as soon as S. Mansfield, B. J. Ried, and J. Lewis are on site. D. Gray will conduct the meeting. Dave will also provide weekly walk downs of the Sonsub work area.

25. Billings will continue to be made from the home office. So fare, Sonsub has done a good job of keeping billings current. In order for personnel to get paid, billings must be accrued in a timely manner.

26. Only special training required for this project is use of SCBA's. This has been accomplished and documented. Sonsub has selected personnel based on their experience and performance.

27. LN2 will be stored in a tank especially designed and built for the storage of cryogens. Deliveries will be made by tankers especially designed for the hauling and transfer of cryogens.

28. The gantry cover has about a one and a half foot overlap at the ground. Timbers will be placed around the perimeter to help secure the gantry in place.

29. It is unlikely the lenses will become fogged because the entire camera is encased in a protective housing which helps generate heat and prevent fogging. If a lens becomes dirty it will have to be manually cleaned. However, there are backup cameras so we are not dependent on just a single camera for a given tool.

30. There is a entry procedure for personnel to wear protective clothing, use a SCBA, obtain a safe work permit, and lock out/tag out for equipment prior to any one entering the work area while a breakout is in progress. This procedure is documented in the safety and work plans.

31. Similar to the testing that has been performed during the shop demonstration, the gantry will be erected, the tools mounted and exercised prior to actually starting the breakout. All control, video, instrumentation, and lighting systems will be checked prior to committing to the actual breakout.

32. More than one tool can be worked at a time. There are some limitations depending on the tool combinations. However, it would be rare that the need to operate more than one tool would occur. Also the cranes and trollies can be worked at the samr. time the tool is operating. 
Distribution

July 6, 1992

DJV $-28-92$

Page 11

33. Freezewall, Sonsub's ground freezing contractor has performed an analysis on the pit layout and been involved with the design of the overall freezing scheme, freeze pipes, and the process that will be followed during actual freezing. Freezewell has many years experience in ground freezing, with the express purpose of freezing soil to develop retaining walls.

34. The gantry will be dragged by a winch. The winch and cable has been analyzed to ensure they are the proper size. The gantry will be set on steel plates and high density, low friction, polyolophine to reduce friction while moving the gantry. The gantry is configured such that there is enough clearance over the freeze pipes, these will not present an interference.

35. Sonsub has prepared drawings and material lists showing how the freeze pipes will connect with the LN2 delivery hoses.

36. An analysis has been performed to determine the power needs for the field demonstration. The equipment that is going to be provided is adequately sized for required power.

37. Diesel fuel will be stored in an above ground 500 gal storage tank. It will be transferred both to and from the tank following standard OSHA guidelines for handling combustibles. The storage tank will be bermed and double lined for spill prevention, all other stationary equipment will be provided with catch pans.

38. Emergency response phone numbers will be posted by the phones (one in the control trailer and one in a rental vehicle).

39. Discussions and checks were held with Freezewall, Sonsub's ground freezing contractor to get input on the feasibility of driving the freeze pipes through the soil and waste. Large metal objects or basalt layers that are hit square on will probably stop the freeze pipes penetration. Otherwise, the drilling should proceed without too much trouble.

40. A review was held concerning why some pipes are carbon and other stainless. Basically, all perimeter pipes will be carbon, interior freeze pit pipes will be stainless, except for the back three rows in each pit. These pipes are carbon for experimental purposes, just to see how well this material reacts with the cryogenic temperatures and stresses imparted to the piping during breakoui. 
Distribution

July 6, 1992

DJV-28-92

Page 12

41. Drawings have been prepared for the field power distribution as well as a bill of materials. The materials have been ordered and will be delivered to the job site.

42. Topsoil will probably be stored on the east side of the cold test pit, well out of the way of any operations conducted at the pit. It will be removed and replaced with standard excavation equipment. Sonsub will have a level to check grade.

43. The pit will be frozen up until the time the gantry is moved to another pit. Immediately as the gantry is moved, the pit will be backfilled.

44. 02 monitors have been calibrated and is noted on each unit. These will be stored in the equipment trailer or the control room. All 02 monitors and SCBA units have been checked and certified. All personnel using 02 monitors or SCBA units have been shown how to use them, and in the case of the SCBA have received specific training and certification for their use. EG\&G will use 02 monitors provided by Sonsub. There are enough spares so there should not be a shortage.

45. All personnel sign in and out at guard gate each time they come on to or leave the site. The Sonsub Project Manager will check with the RWMC shift supervisor daily to advise what the planned activities are for that shift. For safe work permits we will contact D. Gray. He will have a beeper and we can contact him at home to obtain an ok to perform work requiring a safe work permit.

46. It was explained again to Sonsub that they should plan all activities such that they are totally self-supported and not rely on the RWMC for support or resources.

47. Sonsub will verify that the phone system is compatible with the INEL phone system. When Sonsub comes on site and has the phones in their possession, they will direct dial the RWMC guard gate to verify the systems are linked together.

48. Again reviewed the policy concerning foreign nationals visiting the site. One month lead time will be required for foreign nationals wanting to come on to the INEL.

49. Addressed in question number 9.

50. Yes, a complete set of drawings, specifications, vendor manuals, and project planning documentation will be available in the field. 
Distribution

July 6,1992

DJV $-28-92$

Page 13

51. Can get Federal Express to deliver to the Driftwood Hotel (where Sonsub personnel will be staying), or deliver to $D$. Valentich at the WAC.

52. Grant Inc., the jackhammer contractor is prepared to support the field demonstration.

53. Yes, an evaluation has been performed to ensure the rating of the forklift is compatible with the weight of a fully loaded storage box.

54. Yes, a check has been made to ensure that $4 p s i$ is not exceeded during any of the equipment operations performed over the cold test pit.

55. A review was held describing the type of observable data the EG\&G will want to collect during the field demonstration. These points have been documented in a separate memo, Tamera Fields (Summer Student) is responsible for obtaining this information.

56. For temperature probes, comparisons will be made between probes at the same elevations. If the readings are close and appear reasonable, then this will be a good indication that the probes are functioning properly. The moisture probe readings will likewise be compared.

57. Depending on how deep the probe bottoms out, it will be extracted and placed elsewhere. Otherwise, it will be left in place.

58. Trailer will be tied down with standard trailer ties. It is estimated it will withstand $60+\mathrm{mph}$ winds.

59. NA

60. Trash must be segregated into three types. Metal, wood, and everything else. EG\&G will provide separate dumpsters for each type of trash. Prior to interning the trash in the dumpster, the same must be surveyed and tagged by an RWMC HP. The dumpster will then be locked.

61. Radios and phones are going to be obtained from Teton Communication. There will be two phones and six radios. 
Distribution

July 6, 1992

DJV-28-92

Page 14

Instrumentation related questions were reviewed with Sonsub and Eileen Yokuda.

The results of their review are documented in Eileen's trip report.

$j 1 j$

Attachment:

As Stated

Distribution

P. G. Cannon, MS 3930

G. G. Loomis, MS 3930

S. K. Merrill, MS 3930

L. R. Watson, MS 3930

cc: Project Files, WTD-CRY092-004, MS 3930

Central Files, MS 1651

D. J. Valentich File 
JUNE, 1992

1. Is there a checklist in place to ensure all necessary equipment, materials, personnel, consumables, etc... are accounted for? Items such as nuts/bolts, fasteners, connectors, tools, and consumables are especially critical.

2. How will materials and equipment needed for the demonstration be transported to the job site? How will materials and equipment be unloaded? Is there a scheme for staging equipment and parts and timing the delivery of the same?

3. How will Sonsub ensure that security clearance forms for all personnel who will be performing work on site are submitted?

4. How has Sonsub identified which services will be subcontracted (what are they), and what type of verification has been performed to ensure that these services will be avallable in a timely manner?

5. What about fuel delivery? How many types? When?

6. Delivery drivers familiar with procedure for delivery of goods to cold test pit?

7. Rental vehicles available? Will be supplied with fire extinguisher and shovel?

8. What procedure will be employed to ensure everyone if familiar with safety requirements?

9. Water truck? Discuss where and hot to get water.

10. Boxes? Assurance they will be avallable in time?

11. Freeze pipes? Where are they being fabricated? Check to ensure right material.

12. How will $\mathrm{LN}_{2}$ be transferred into storage tank? From storage tank to freeze pipes?

13. How will hydraulic units be shipped? With/without fluid? What pressure will hydraulic system operate at? Is type of fluid readily available?

14. Spare parts, repairs, etc., contingency plans-what happens when things break, consumables run low, where will replacements, services come from?

15. How many spare freeze pipes will there be?

16. Review fire safety. Where are fire extinguishers? No open flames (except for welding and cutting allowed only after safe work permit obtained). No vehicles off road. No vehicles off of previously disturbed area around the cold test pit.

17. What precautions will be in place for working with and around cryogen's?

18. Review safety plans for working around nitrogen atmosphere/confined spaces.

19. How will Sonsub operation interface with EG\&G's instrumentation system and needs? Review.

20. Revilew smoking policy.

21. Review policy on long work hours and fatigue.

22. What kind of tools, stock lumber, metal, etc., will be available for use at the job site?

23. Review security and check in procedures. Review how to obtain safe work permit. Timeliness for obtaining permits.

24. Review EG\&G safety interface. Kick-off meeting, orientation, weekly safety walk through.

25. Timeliness of billings. How will charges from the field be accrued at and billed from the home office?

26. Any special training required? If so where is it documented? What type of exercise has Sonsub gone through to ensure that the properly qualified and trained personnel will be used for this work?

27. How will $\mathrm{LN}_{2}$ be stored at the site? How will deliveries be made?

28. How will the base of gantry fabric material be anchored to minimize fugitive dust from the outside?

29. What if camera lenses become fogged over or dirty? How will this situation be remedied?

30. What are provisions for entry into gantry if some plece of equipment breaks down during operation and needs repair

31. What will be done to ensure equipment and systems are functioning properly before enclosing the gantry--i.e. field testing?

32. Can more than one tool be worked at a time? For instance if it was necessary to pick up a section of debris with the grapple and cut it with the shears-could this be done? 
33. What type of safety precautions will be taken to ensure the edge of the plt, when frozen will no sluff or collapse?

34. How will the gantry be moved from pit to pit? What about potential interferences from protruding freeze pipes?

35. How will $\mathrm{LN}_{2}$ piping or hose be connected to the freeze pipes?

36. What type of analysis has been performed to ensure there will be adequate power available?

37. How will fuel be stored and transferred? Where will it be stored? Stored at a distance in accordance with OSHA safety requirements? Spill prevention?

38. Emergency response--phone numbers known and where will they be posted?

39. What type of investigation performed to ensure freeze pipes can be driven? Any contingency plans for problems driving the freeze pipes?

40. Review logic for why some pipes will be stainless steel and others will be carbon steel. What type of material will the collars be?

41. What kind of sketch and bill of materials will be prepared for the field power distribution system? How will Sonsub ensure all the necessary cables, fittings, etc., are accounted for and available to support start up?

42. Where will topsoil be stored when it is removed from the cold test pit? How will it be removed and replaced? Will Sonsub have a level to measure how much soll is to be removed?

43. How will Sonsub ensure that rare earth tracers do not spread from an excavated pit between the time the gantry is moved and the pit is backfilled? Also Sonsub is planning on filling the pit ASAP after the excavation to prevent collapse.

44. Where will $\mathrm{O}_{2}$ monitors be located and what is the policy governing their use? What is calibration, tagging and training policy regarding $\mathrm{O}_{2}$ monitors and SCBA units? Review EG\&G interface and usage of $\mathrm{O}_{2}$ monitors.

45. Review sign in and check out procedures at the guard gate. Review policy for checking with $t$ he shift supervisor-contact for obtaining safe work permits or water.

46. Review policy that Sonsub will essentially be self-supported (except for water) and that RWMC or other facilities should generally not be depended on for equipment or other resources to support the testing.

47. Verify that modular phones are compatible with INEL phone system. Need to double check to see that the shift supervisor and RWMC guard gate can be direct dialed.

48. Foreign Nationals visiting the site--will need to start processing paperwork a month in advance of when they want to visit.

49. How will water get from the water truck to the excavation pits?

50. Will Sonsub have the necessary drawings, specifications, literature, etc. to erect systems in the fleld?

51. Check with hotel to see if they will accept mail (federal express)? Know where federal express, airborne express are located in IF?

52. Jackhammer contractor lined up? Any special accommodations for same?

53. Has a check been made to ensure forklift can adequately handle filled boxes?

54. Equipment evaluated to ensure 4psi not exceeded when operating on top of cold test pit?

55. Review what elements of the test EGikg will want to collect data points on.

56. How will it be determined that temperature and moisture probes are functional (within tolerance) after placement?

57. What if one of the moisture/temperature probes encounters an immovable object during the driving and placement of the probe?

58. How will the traller be blocked and supported?

59. Review trash disposal policy.

60. Review status of radios and phones.

\section{NSTRUMENTATION RELATED QUESTIONS}

1. Demonstrate how data from temperature and TDR will be downloaded to an ASCII file. How will the flles be named and documented so that there is no question as to which test each flle pertains to?

2. How will the volume of waier added to a pit be controlled/measured?

3. How will dacron tubing for air monitoring be draped over the top of the gantry?

4. Exactly where and how will hi vol monitors be mounted on the skids?

5. Is the PVC tubing for the $47 \mathrm{~mm}$ air monitors in place? How easily do the monitors slide in and out? Does it cause any kinks in the dacron tubing?

D-18 
6. Exactly where and how will the tool shed be placed relative to the south side of the gantry?

7. Demonstrate that the data acquisition system is working properly.

8. Are weatherproof enclosures provided for all multiplexers and data loggers?

9. Are there two openings in the weather shield for the electrical cords from the hi volume monitors to run through? 10. Are the wires routed in such a way that there will be no safety hazards?

11. How will the shed be moved?

12. Are the PVC pipe stubs and flaps installed in the gantry cover to allow access for the air monitoring filters?

13. How will instrumentation calibrations be verified?

14. Review calibration procedure for TDR's and curve data generated during actual calibration. 


\section{INTEROFFICE CORRESPONDENCE}

Date: $\quad$ July 8, 1992

To: $\quad$ S. K. Merrill, MS 3930

From: $\quad$ E. L. Yokuda, MS 3416

Subject: TRIP REPORT AND READINESS REVIEW REPORT ELY-30-92

From June 30 through July 4, Dave Valentich and I visited Sonsub Services, Inc. in Houston Texas to participate in an informal readiness review for the Cryogenic Retrieval Demonstration and to witness shop testing of the hardware. I was mainly concerned with the instrumentation for the moisture and temperature monitoring. The method that will be used for monitoring the moisture is Time Domain Reflectonetry (TDR). Thermocouples will be used for all of the temperature monitoring. I was al so concerned that the final gantry design accommocated space for our air monitoring system.

The purpose for embedding the thermocouples into the pits is to collect data on the rate at which the waste will be chilled. The thermocouple readings will also be used by Sonsub to determine when the pit is ready to be excavated. The main objective of having the TDR as a moisture probe is to determine if there is or is not perceptible water migration below the pit during the demonstration.

I was pleased to find that Sonsub had received all of the equipment, including the software for the data acquisition from Campbell Scientific. The use of such standardized data acquisition equipment will help ensure that the data is valid. One TDR and one thermocouple system was hooked up to a PC that was running the Campbell data acquisition software.

One of the challenges that Sonsub had on this project was to design a TDR probe that could be driven into the ground. Richard Smith, one of Sonsub's technicians, came up with a very ingenious design. Some proof of principle testing on the new probe was done during my visit and is described in detail in item 14 of the Readiness Review.

On the down side, Sonsub has provided little engineering support for the soil temperature an moisture monitoring. Richard, the one technician assigned to this task, is only working part time on the instrumentation and has to dedicate much of his time to the video system in the gantry. As a result, the complete data acquisition system was not working as smoothly as I had anticipated. The following details still need to be completed before the system is ready for use in the demonstration. 
S. K. Merrill

July 8, 1992

ELY $-30-92$

Page 2

1.Program the system to read the probes and download the data automatically to ASCII files.

2.Program the system to automatically average the data for each probe over several readings.

3. Program the system to download data from different pits into separate files. Thermocouple and TDR data also need to be sent to separate files.

All of these tasks are relatively straight forward. Knowing the caliper of the equipment that Sonsub is using, and the abilities of Richard Smith, I do not foresee any problem in finishing these tasks before the demonstration is ready to begin.

Calibration and test data on all of the TDR probes and three of the stacked thermocouple probes must be compiled before the probes can be driven into the ground.

All of the TDR probes arrived during my visit. All of the probes were out of tolerance on the most critical dimension, the gap between the metal on the TDR probe. Richard will correct these as best he can, however, there is likely to be variability between the probes aue to this problem. Nevertheless, each probe will be calibrated against a standard Campbell Scientific probe so that adjustments caln be made for the errors.

\section{INSTRUMENTATION READINESS REVIEW QUESTIONS}

1. Demonstrate how daci from temperature and TDR will be downloaded to an ASCII file. How will the files be named and documented so that there will be no question as to which file pertains to each pit.

The data acquisition software is standard Campbell Scientific softwere. Although the downloading was not specifically demonstrated, it ia a function in the main menu of the program. For the purpose of segregating the data from the different pits, a numbering system for each thermocouple was devised. Pits 1-4 are renamed Pits $A-D$ and the thermocouples in each pit are numbered 1-32. I gave a sketch of the numbering system for the pits to Richard Smith of Sonsub.

2. How will the volume of water added to the pit be controlled/measured.

The flow of water will be controlled by a valve and hose system attached to a water truck. A totalizing water meter is in this system. All of this equipment was at Sonsub at the time of our visit. 
S. K. Merrill

JuTy 8, 1992

ELY-30-92

Page 3

3. How will dacron tubing for the air monitoring be draped over the top of the gantry?

The tubing will not be draped over the top of the gantry, but run along the sides of the gantry. On the west side of the gantry it will have to be run up and over the opening for removing the boxes.

After seeing the size of the gantry for myself, I realized that it would be impractical to drape the tubing over the top. Also, a crane will only be available at the beginning and end of the project so it would be impossible to access the tubing during the demonstration if it was draped over the top.

4. Exactly where and how will the $\mathrm{Hi}$ vol monitors be mounted on the skids?

The monitors will be welded to plates and the plates will be welded to the gantry skids. One will be placed in the southwest corner of the gantry and the other monitor will be placed in the northeast corner of the gantry. The monitors will be set between the framework of the gantry and the weather shield.

5. Is the PVC tubing for the $47 \mathrm{~mm}$ air monitors in place? How easily do the monitors slide in and out? Does it cause any kinks in the dacron tubing?

On Tuesday the brackets for the air monitors were laying by the gantry. I noticed that those were too small for the air monitors. I showed Sonsub the air monitor which I brought with me and they had new brackets fabricated. Sonsub has not attached the tubing or the brackets. They are waiting to mount the weather shield to make sure that the sleeves in the weather shield line up with the brackets.

6. Exactly where and how will the tool shed be placed relative to the south side of the gantry?

The tool shed will be centered along the south side of the gantry. It will be placed with one of Sonsub's forkl ifts. Steve Mansfield, Sonsub's project manager, has agreed to be responsible for moving the shed during the demonstration.

7. Demonstrate that the data acquisition system is working properly. Can it record the data required for the test plan?

As noted earlier, details for downloading the data are still be worked by Sonsub.

8. Are weather proof enclosures provided for all of the multiplexers and data loggers?

I saw one. Steve Mansfield said that enclosures are on hand for all multiplexers and data loggers. 
S. K. Merrill

July 8, 1992

ELY $-30-92$

Page 4

9. Are there two openings in the weather shield for the electric cords from the $\mathrm{Hi}$ volume monitors to run through?

No. According to Steve Mansfield, the cords will run under the weather shield.

10. Are the wires routed in such a way so that they will not be a safety hazard?

The exact routing will be determined in the field. The wires will be routed so that they are not a safety hazard. The wire from the multiplexer to the trailer will run with all other wires along the east end of the site.

11. How will the shed be moved.

The shed will be moved by a fork lift provided by Sonsub.

12. Are the PVC pipe stubs and flaps installed in the gantry cover to allow access for the air monitoring filters?

The PVC tubing was not installed at the time oi ciur visit. The flaps, or "socks", are an integral part of the gantry cover.

13. How will the instrumentation calibrations be verified?

According to the calibration plan that I wrote while I was at Sonsub, Sonsub is supposed to mark each TDR with a unique identifying number and the calibration data is to be recorded in a log book.

14. Review calibration procedure for the TDR, and the calibration curves for the TDRs. Demonstrate the use of the TDR.

Sonsub had no standard calibration procedures established for these TDRs. I wrote some calibration procedures for them. There were also no calibration curves available because they had not started any calibration.

We did get to do some short proof of principle tests on the TDR. These tests were very important because Sonsub developed a new type of TDR probe for this application and there has been speculation at the INEL as to whether the probe would work correctly or not.

The Data Quality Objective for this test was to determine if the TDR probes that Sonsub will be using can respond to increases and decreases in soil moisture levels. The required accuracy of these probes is fairly lax. The test plan allows for the TDR to read the moisture level 10\% higher or 10\% 1ower than the actual percent soil moisture.

The result of the test is that the new design should work correctly. However, the probes were not made to Sonsubs' specifications so there will be some variability in the actual readings. Some of the readings taken during the proof of principle testing are listed on the next page. 
S. K. Merrill

July 8, 1992

ELY - 30-92

Page 5

CONTROL

Oven Dried Soil

$\frac{\text { NEW TDR READING }}{-0.3 \%}$

$6.2 \%$ moisture as read by a

$3 \%$

conventional Campbell Scientific

probe.

Oven Dried Soil mixed with

$11 \%$

approximately $15 \%$ water by

volume.

$28 \%$ moisture as read by a

$19 \%$

conventional Campbell Scientific

probe.

These results confirm that the TDRs which Sonsub will use can meet our data quality objectives.

In addition, the soil with the $11 \%$ TDR reading was chilled to -58 degrees cen ${ }^{+}$ade to observe the effect of the cryogenic temperatures on the TDR respicis. Theoretically, the TDR reading should drop of to $0 \%$ moisture as the water rreezes. We found that the TDR signal responded to the drop in temperature but the response was very slow. There are two reasons for the slow TDR response. First, the dynamics of moisture movement and freezing in the soil are very slow. Second, it takes time for the algorithm in the Campbell Scientific software to fit the curve on the signal from the TDR. This process takes longer when the signal is changing rapidly. Such was the case with the rapid cooling.

After one hour at sub freezing temperatures, the TDR read less than $1 \%$ moisture. The reading on the TDR the next morning, after letting the soil thaw out over night, was $10 \%$ moisture. Thus we have proved that in principle this new TDR probe responds to temperature and moisture changes as is expected.

15. Where will the Self Contained Breathing Apparatus (SCBA) equipment be stored?

According to Steve Mansfield, the SCBAs can be stored in the trailer which Sonsub will use as a "tool shed".

16. When will Sonsub be ready to accept the shed with the air monitoring instrumentation?

Steve estimates that Sonsub can accept the shed during the second week that Sonsub is on site at the cold test pit. That is, around July 15. 
S. K. Merrill

July 8, 1992

ELY $-30-92$

Page 6

17. Is the generator capable of delivering the 80 AMPS to power the air monitoring system? Where will the generator be located?

According to Steve, the generator will be able to provide that power. The generator will be located in the southeast corner of the cold test pit site, about $145^{\prime}$ away from the farthest gantry setup.

18. How long does the data acquisition system take to read a signal from a TDR probe.

Normally this takes about a minute. It may take longer to get an accurate reading if there was a sudden increase or decrease in the moisture content of the soil.

19. Can someone from Sonsub walk around the area with one of the air monitoris personnel to act as a "buddy".

Yes, there should be 2 to 3 people from Sonsub available for tasks such as this at all times.

20. Where will the enclosures for the data loggers and multiplexers be placed.

The enclosures will sit on pallets.

21. When will the first group of air samples be taken?

On July 26 at the earliest.

22. Where is the generator now.

Sonsub will be renting the generator from a contractor in Salt Lake City.

ely

Distribution

P. G. Cannon, MS 3930

S. B. Grover, MS 3415

M. E. Leavitt, MS 3906

G. G. Loomis, MS 3930

L. R. Watson, MS 3930

cc: Central Files, MS 1651

E. L. Yokuda Ltr File 
Appendix E

Results of Smears Taken During Freeze Pipe Placement 
Cate: $\quad$ September 10, 1992

To: $\quad$ D. J. Valentich MS 3930

From: $\quad$ M. R. Winberg, MS 7113

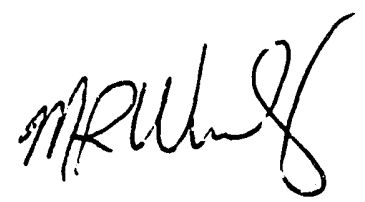

Subject: RESULTS OF SMEAR SAMPLES TAKEN FROM FREEZE PIPES FROM

PITS 3 AND 4 OF THE CRD - MRW-15-92

At your request additional smear samples were taken on the freeze pipes on Pits 3 and 4 after their placement at the Cold Test Pit. The purpose of these samples was to attempt to determine if any tracers were released during the driving of the freeze pipes into the waste zone. Each sample represents a composite of 4 smears taken at random around the freeze pipes and collars on each pit. Each of the 4 smears were used on an approximately $10 \mathrm{~cm}^{2}$ area on 4 separate pipes. Therefore, each composite sample represents areas of 16 freeze pipes from each pit. An additional sample was collected from a set of freeze pipes before they were drilled in place. This sample represents the natural background tracer levels on the freeze pipes. The results of all samples are presented below (note that all tracer concentrations have been corrected for blank tracer coricentrations on the smears):

\section{TRACER CONCENTRATIONS ON FREEZE PIPES (micrograms tracer/sample)}

$\begin{array}{llcc}\text { TRACER } & \text { PIT 3 } & \text { PIT 4 } & \text { BACKGROUND } \\ \text { Dy } & 0.175^{(b)} & 0.262 & 0.400 \\ \text { Nd } & 0.977 & 1.463 & 2.652 \\ \text { Tb } & 0.035^{(b)} & 0.058^{(b)} & 0.086^{(b)} \\ \text { Yb } & 0.086^{(b)} & 0.120^{(b)} & 0.188^{(b)} \\ \text { b } & \text { Tracer concentration is less than } 10 \text { times the instrument LLD. }\end{array}$

Samples were analyzed by the EG\&G ECU using ICP-MS. The background tracer levels are a factor of 2 or more higher than the samples collected from the pipes after they were driven. One possible explanation is that the freeze pipes from which the background samples were collected were laying horizontal on the open ground where the natural dust could collect on the pipe. During the driving process the pipes were placed in a vertical position and driven into the ground causing the 
D. J. Valentich

September 10, 1992

MRW-15-92

Page 2

loose dust to vibrate off. Results from the driven pipe show that the tracer concentrations on the smear samples were below the background samples. These results indicate that for the areas smeared that there was no significant tracer release during the placement of the freeze pipes into the waste zone.

If there any questions regarding these results, please feel free to contact me.

CC: A. L. Freeman, MS 7113

G. G. Loomis, MS 3930

K. L. Martin, MS 7113

P. D. Randolph, MS 7113

D. N. Thompson, MS 7113

E. L. Yokuda, MS 3416

V. E. Wixom, MS 7113

Central Files, MS 1651

M. R. Winberg 1 tr file 


\section{Appendix F}

\section{Cost Estimate}




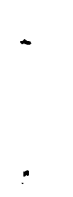

F-2 


\title{
COST PROJECTIONS TO USE CRYOGENICS ON A WASTE PIT CONTAINING TRU RADIOACTIVE WASTE MATERIAL
}

\author{
PREPARED BY SONSUB SERVICES, INC.
}

The following spreadsheets represent a estimate of what the costs would be to use the same general technique for waste retrieval on a "hot" pit as was demonstrated by Sonsub during the summer of 1992 on the Cold Demonstration Pit. Per specifications supplied by EG\&G for this estimate, the site would be four (4) square acres by a depth of 15 feet.

The demonstration was used as the basis for these estimates, but we need to realize that there were some areas where design and/or operational changes would be warranted. As such, the following assumptions were made in the development of this estimate.

a) The concept of breaking out a "popsicle" was abandoned in favor of a more conventional mining type of operation.

b) The liquid nitrogen manifolding system would be automated to a degree.

c) Liquid nitrogen wculd still be supplied from Salt Lake City. It may be prudent to investigate the construction of a Cryogenic Plant locally as the cost for the $\mathrm{LN}_{2}$ is over $\$ 34,000,000$.

d) $\mathrm{LN}_{2}$ usage represents a $30 \%$ increase in efficiencies over that experienced during the demonstration.

e) The numbers for the freeze pipes reflect smaller diameter pipes using carbon steel as these will not be used for "breakout" purposes.

f) A new tool would be introduced into the gantry to assist with the handling of the debris excavated by the Jackhammer. This tool would be similar in construction to the jackhammer, yet would have a "spade/shovel" end effector.

g) The total time frame covered by this estimate represents an approximate 5 year project duration.

h) The issue/problem of moisture has not been addressed in this estimate.

i) The size of the gantry is an important element in this estimate. For this reason we have assumed that the pit would not be any wider than 150'. The length has no real bearing on the size of the gantry.

It should be noted that this estimate is only an order of magnitude based on limited information. The technology employed in the demonstration is far from "Proven" as much of the data is still being analyzed. Certainly some aspects of the demonstration showed good potential, yet more development work is still warranted. 


\section{PROJECTED COSTS FOR CRYOGENIC RETRIEVAL ON A FOUR ACRE WASTE SITE INCLUDING TRU RADIOACTIVE WASTE MATERIALS}

\section{TASK DESCRIPTION}

PROJECT MANAGEMENT ENV. SAFETY \& HEALTH QANC ENGINEERING DRAFTING HARDWARE FAB. \& PROC. INTEGRATION \& TESTING OPERATIONS PROCUREMENT OPS. MANUALS \& TRAINING MOBILIZATION CRYOGENIC OPERATIONS SITE SETUP EXCAVATION OPERATIONS DECONTAMINATION DECOMMISSION \& DEMOB

\section{LABOR COSTS}

$$
\begin{array}{r}
\$ 2,359,210 \\
\$ 1,064,780 \\
\$ 825,620 \\
\$ 1,387,990 \\
\$ 979,170 \\
\$ 557,540 \\
\$ 20,340 \\
\$ 501,830 \\
\$ 1,043,840 \\
\$ 86,940 \\
\$ 958,740 \\
\$ 7,533,160 \\
\$ 661,180 \\
\$ 305,650
\end{array}
$$

\section{3rd PARTY COSTS}

$\$ 1,033,960$ $\$ 135,980$ $\$ 160,180$ $\$ 240,270$

$\$ 22,376,240$

$\$ 273,180$

$\$ 2,588,450$ $\$ 714,560$

$\$ 1,040,410$

$\$ 41,631,210$

$\$ 3,167,840$

$\$ 3,293,480$

$\$ 115,760$ $\$ 393,610$
G \& A

$\$ 678,634$

$\$ 240,152$

$\$ 197,160$

$\$ 325,652$

$\$ 4,671,082$

$\$ 166,144$

$\$ 521,758$

$\$ 243,278$

$\$ 416,850$

$\$ 8,343,630$

$\$ 825,316$

$\$ 2,165,328$

$\$ 155,388$

$\$ 139,852$
FEE

$\$ 244,308$ $\$ 86,455$ $\$ 70,978$

$\$ 117,235$

$\$ 1,681,590$

$\$ 59,812$

$\$ 187,833$

$\$ 87,580$

$\$ 150,066$

$\$ 3,003,707$

$\$ 297,114$

$\$ 779,518$

$\$ 55,940$

$\$ 50,347$
TOTAL

$\$ 4,316,112$

$\$ 1,527,367$

$\$ 1,253,938$

$\$ 2,071,147$

$\$ 29,708,082$

$\$ 1,056,676$

$\$ 3,318,381$

$\$ 1,547,248$

$\$ 2,651,166$

$\$ 53,065,487$

$\$ 5,249,010$

$\$ 13,771,486$

$\$ 988,268$

$\$ 889,459$

TOTALS

$\$ 18,285,990$

$\$ 77,165,130 \$ 19,090,2246$

$\$ 6,872,481$

$\$ 121,413,825$

NOTES: $\quad$ LABOR COSTS INCLUDE OVERHEAD FACTOR OF $30 \%$

G \& A WAS FIGURED USING A FACTOR OF $6 \%$

FEE REPRESENTS A FACTOR OF $6 \%$

COST PER CUBIC YARD FOR RETRIEVAL ONLY (DOES NOT INCLUDE ANY CHARACTERIZATION, TREATMENT, OR RECLAMATION) IS BASED ON A FOUR ACRE SITE, 15 FEET DEEP $(97,000$ CUBIC YARDS OF SOIL AND WASTE). INCLUDES ALL COSTS IDENTIFIED ABOVE--- $\$ 121,413,825 / 97,000=\$ 1252 / C U B I C$ YARD 


\section{PROJECT MANAGEMENT}

\section{TASK DESCRIPTION}

PROGRAM MANAGER

OPERATIONS MANAGER

PROJECT ADMINISTRATOR

PROJ. PLANNER \& SECRETARY

PROJECT ENGINEER

OFFICE FURN \& EQUIP.

OFFICE SPACE \& UTIL.

SUPP./COURIER FEES

RECR. \& RPTG. EXPENSES

PERSONNEL TRANS. EXPENSES

PROJECT SPECIFIC INSURANCE
LABOR

COSTS

$\$ 719,260$

$\$ 492,1 ? 0$

$\$ 435,340$

$\$ 50,920$

$\$ 643,550$

$\$ 18,020$

TOTALS

$\$ 2,359,210$ 3rd PARTY

COSTS

$\$ 124,080$

$\$ 68,640$

$\$ 68,640$

$\$ 18,240$

$\$ 105,320$

$\$ 35,470$

$\$ 136,960$

$\$ 74,460$

$\$ 71,250$

$\$ 180,900$

$\$ 150,000$

$\$ 1,033,960$

\section{ENVIRONMENTAL, SAFETY \& HEALTH}

\section{TASK DESCRIPTION}

PROJECT ES\&H MANAGER

SITE SAFETY OFFICERS

EQUIP. DECON STATION
LABOR COSTS

$\$ 397,490$

$\$ 624,620$

$\$ 42,670$

TOTALS $\$ \mathbf{\$ 1 , 0 6 4 , 7 8 0}$

3rd PARTY

COSTS

$\$ 135,980$

$\$ 135,980$

\section{QUALITY CONTROL}

TASK DESCRIPTION

QUALITY MANAGER QUALITY INSPECTORS
LABOR COSTS

$\$ 546,070$ $\$ 279,550$

TOTALS $\$ \$ 825,620$ 3rd PARTY COSTS

$\$ 95,880$

$\$ 64,300$

$\$ 160,180$ 


\section{ENGINEERING/DRAFTING}

TASK DESCRIPTION

GANTRY \& TOOL ASSEMBLIES

FREEZE PIPES

HYDRAULIC POWER SYSTEM

FOUNDATION DESIGN

DESIGN REVIEWS
LABOR

COSTS

$\$ 1,231,130$

$\$ 25,050$

$\$ 33,580$

$\$ 31,370$

$\$ 66,860$ 3rd PARTY

COSTS

$\$ 211,970$

$\$ 14,500$

$\$ 0$

$\$ 12,000$

$\$ 1,800$

\section{TOTALS $\$ \mathbf{\$ 1 , 3 8 7 , 9 9 0} \quad \$ 240,270$}

\section{HARDWARE FABRICATION \& PROCUREMENT}

TASK DESCRIPTION

GANTRY \& MISC STRUCTURE

FREEZE PIPES

HYDRAULIC POWER SYSTEM

FOUNDATION MATERIALS

FREEZE MANIFOLD SYSTEM
LABOR COSTS

$\$ 783,990$

$\$ 61,110$

$\$ 52,580$

$\$ 34,090$

$\$ 47,400$

TOTALS $\$ \$ 979,170$ 3rd PARTY COSTS

$\$ 11,110,590$

$\$ 9,210,400$

$\$ 316,840$

$\$ 613,670$

$\$ 1,124,740$

$\$ 22,376,240$

\section{HARDWARE INTEGRATION \& TESTING}

TASK DESCRIPTION

SITE PREPARATION

GANTRY \& TOOL ASSEMBLIES

TESTING \& REWORK

DISMANTLING
LABOR COSTS

$\$ 29,900$

$\$ 68,250$

$\$ 53,110$

$\$ 43,780$

TOTALS $\$ 557,540$ 3rd PARTY

COSTS

$\$ 16,300$

$\$ 144,780$

$\$ 39,650$

$\$ 72,450$

$\$ 273,180$

\section{OPERATIONS PROCUREMENT}

TASK DESCRIPTION

HAND TOOLS \& EQUIPMENT

SPARE PARTS

CONSUMABLES
LABOR

COSTS

$\$ 3,850$

$\$ 11,650$

$\$ 4,840$ 3rd PARTY

COSTS

$\$ 167,400$

$\$ 1,635,750$

$\$ 785,300$

\section{TOTALS}

$\$ 20,340$

$\$ 2,588,450$ 
OPERATIONS MANUALS \& TRAINING

TASK DESCRIPTION

LABOR

COSTS

OPERATION MANUALS

PERSONNEL TRAINING

$\$ 168,640$

$\$ 333,190$

TOTALS $\$ 501,830$

3rd PARTY

COSTS

$\$ 25,210$

$\$ 689,350$

$\$ 714,560$

MOBILIZATION

TASK DESCRIPTION

LABOR

COSTS

3rd PARTY

COSTS

PACKAGING \& TRUCKING

$\$ 1,043,840$

$\$ 1,040,410$

TOTALS $\$ \mathbf{\$ 1 , 0 4 3 , 8 4 0}$

$\$ 1,040,410$

\section{CRYOGENIC OPERATIONS}

TASK DESCRIPTION

FREEZE PIPE INSTALLATION

MANIFOLD SETUP

LIQUID NITROGEN SUPPLY
LABOR COSTS

$\$ 40,430$

$\$ 20,860$

$\$ 25,650$

$\$ 86,940$ 3rd PARTY

COSTS

$\$ 6,328,300$

$\$ 439,5 i 0$

$\$ 34,863,400$

TOTALS

$\$ 86,940$

$\$ 41,631,210$ 
SITE SETUP

TASK DESCRIPTION

GANTRY \& TOOL ASSEMBLIES

SETUP CONTROL VAN

MISC. EQUIPMENT SETUP
LABOR

COSTS

$\$ 825,260$

$\$ 52,670$

$\$ 80,810$

TOTALS $\$ \$ \$ 58,740$

EXCAVATION OPERATIONS

TASK DESCRIPTION

LABOR

COSTS

EXCAVATE \& BOX WASTE

$\$ 7,533,160$

TOTALS $\$ \mathbf{\$ 7}, 533,160$

DECONTAMINATION

TASK DESCRIPTION

DECONT. OF EQUIPMENT

TOTALS $\$ \$ 661,180$

LABOR

COSTS

$\$ 661,180$ 3rd PARTY COSTS

$\$ 3,091,850$

$\$ 1,560$

$\$ 74,430$

$\$ 3,167,840$ 3rd PARTY COSTS

$\$ 3,293,480$
$\$ 115,760$

3rd PARTY

COSTS

$\$ 115,760$

\section{DECOMMISSION \& DEMOBILIZATION}

TASK DESCRIPTION

DISMANTLING

DEMOBILIZATION
LABOR COSTS

$\$ 43,780$

$\$ 261,870$

TOTALS $\$ 305,650$ 3rd PARTY

cosTs

$\$ 84,330$

$\$ 309,280$ 

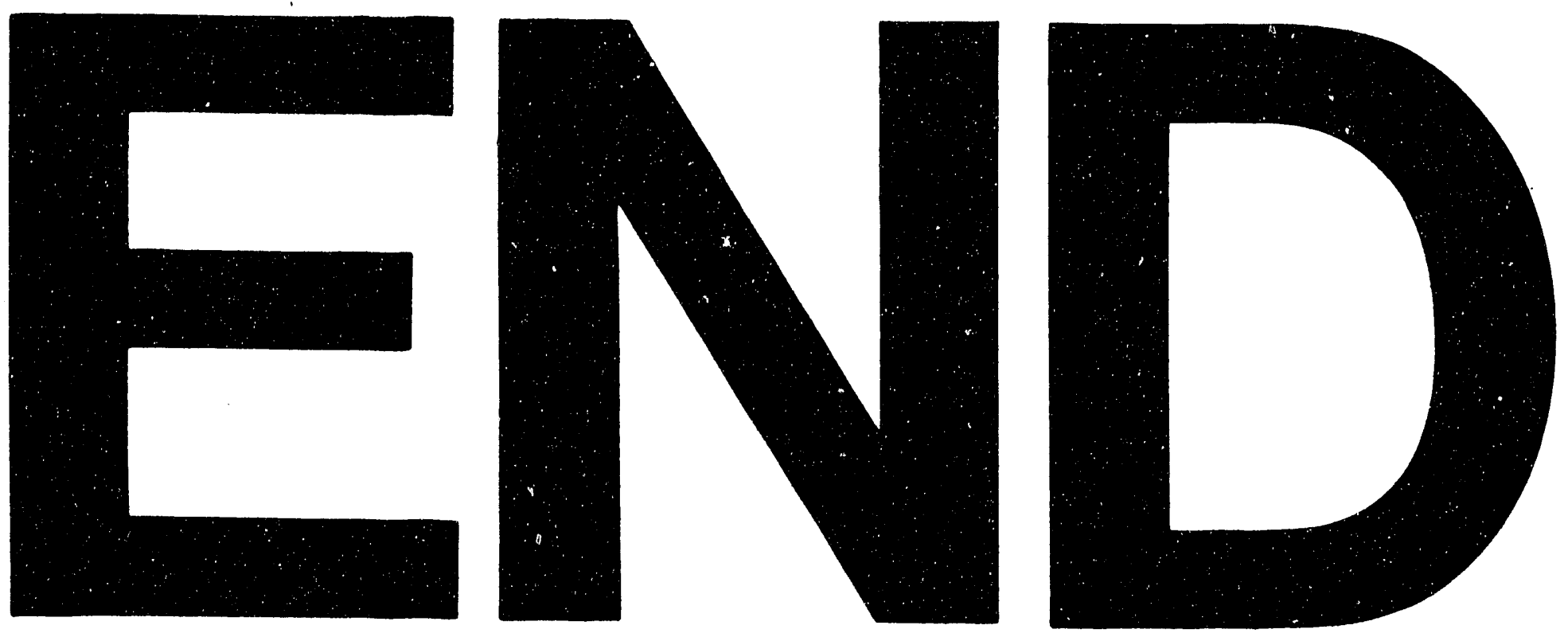

1
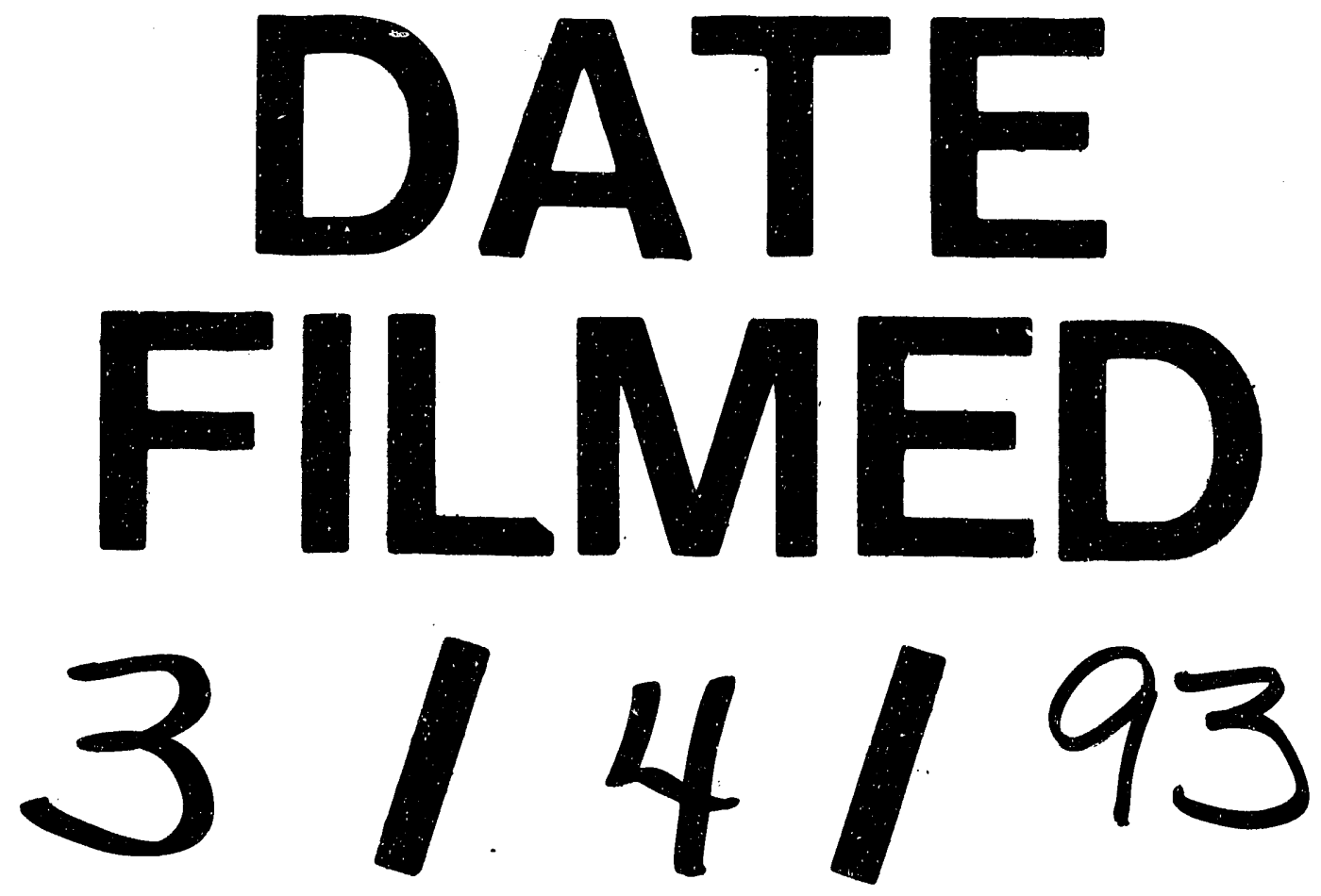